$1 \times 43-40$

\title{
AN AUDIBLE AUTOMOBILE BACK-UP PEDESTRIAN WARNING DEVICE - DEVELOPMENT AND EVALUATION
}

\section{Contract No. DOT-HS-5-01185 November 1976}

Final Report

PREPARED FOR:

\section{U.S. DEPARTMENT OF TRANSPORTATION}

National Highway Traffic Safety Administration

Washington, D.C. 20590 
Prepared for the Department of Transportation, National Highway Traffic Safety Administration under Contract No. DOT-HS-5-01185. The opinions, findings, and conclusions expressed in this publication are those of the authors, and not necessarily those of the National Highway Traffic Safety Administration. 


\begin{tabular}{|c|c|c|c|}
\hline $\begin{array}{l}\text { 1. Ropor. No. } \\
\text { DOT HS-802 } 083\end{array}$ & \multicolumn{2}{|c|}{ 2. Government decession No. } & 3. Recipient' Coralog No. \\
\hline \multicolumn{3}{|c|}{$\begin{array}{l}\text { An Audible Automobile Back-Up Pedestrian Warning } \\
\text { Device - Development and Evaluation. }\end{array}$} & $\begin{array}{l}\text { 5. Report Da'e } \\
\text { November } 1976 \\
\text { 6. Periorming Drgani zation Code }\end{array}$ \\
\hline \multicolumn{3}{|c|}{$\begin{array}{l}\text { 7. Autor(s) } \\
\text { Ron Brown, Louis C. Sutherl and }\end{array}$} & $\begin{array}{l}\text { 6. Performing Orponi sotion Report No. } \\
\text { WR 76-12 }\end{array}$ \\
\hline \multicolumn{3}{|c|}{$\begin{array}{l}\text { 9. Pariorming Orgenizotion Nome and Adoress } \\
\text { Wyle Laboratories } \\
\text { Wyle Research } \\
\text { 128 Maryland Street } \\
\text { El Segundo, California } 90245 \\
\end{array}$} & $\begin{array}{l}\text { 10. Work Unit No. } \\
\text { 11. Contract or Gront No. } \\
\text { DOT-HS-5-01 } 185 \\
\text { 13. Type of Repert and Period Corered }\end{array}$ \\
\hline \multicolumn{3}{|c|}{$\begin{array}{l}\text { 12. Sponsoring Asoncr Nome ond Addios" } \\
\text { Traffic Safety Administration, Office of Management Sys. } \\
400 \text { Seventh Street, S.W. } \\
\text { Washington, D.C. } 20590\end{array}$} & $\begin{array}{l}\text { Final Report } \\
6 / 75-7 / 76 \\
14 \text { Sponsoring synsy Coda }\end{array}$ \\
\hline \multicolumn{4}{|l|}{ 15. Suspiementory Nates } \\
\hline \multirow{2}{*}{\multicolumn{4}{|c|}{$\begin{array}{l}\text { 16. Abstrect } \\
\text { The purpose of this study was to develop and field-test an audible back-up warning } \\
\text { device for use on automobiles. Detailed criteria of pedestrian age and hearing ability } \\
\text { combined with noise characteristics of typical accident sites provide the basis for selec- } \\
\text { tion of a warning signal format. The warning signal (a tone at } 1250 \mathrm{~Hz} \text { pulsed on for } \\
0.1 \text { sec and off for } 0.2 \mathrm{sec} \text { ) is generated by a small loudspeaker mounted at the rear of } \\
\text { the vehicle. An essential element of the design, that the system sense the ambient level } \\
\text { and adjust its output accordingly, results in a warning signal level approximately equal } \\
\text { to the A-weighted noise level throughout the danger zone. This is comparable to a level } \\
\text { at least } 10 \mathrm{~dB} \text { above the pedestrian's detection threshold. } \\
\text { Evaluation of a prototype system was conducted in typical parking sites using pedestrian } \\
\text { subjects of opportunity. Results comparing the normal situation with a test sequence } \\
\text { using the warning signal indicated a tenfold improvement in the number of pedestrians } \\
\text { warned of the presence of a backing vehicle. }\end{array}$}} \\
\hline & & & \\
\hline \multicolumn{2}{|c|}{$\begin{array}{l}\text { 17. Kay mords } \\
\text { Auditory Signals, Warning Systems, } \\
\text { Pedestrian Safety, Automotive Safety }\end{array}$} & \multicolumn{2}{|c|}{$\begin{array}{l}\text { 18. Distribjtion Statemont } \\
\text { Document is available to the public } \\
\text { through the National Technical Inform- } \\
\text { ation Service, Springfield, Virginia } \\
22161\end{array}$} \\
\hline $\begin{array}{l}\text { 15. Secur.". Eiossil. lot this repor } \\
\text { Unclassified }\end{array}$ & Ou. Security & $\begin{array}{l}\text { this page) } \\
\text { ified }\end{array}$ & $\begin{array}{c}\text { 21. No. of Pojes } \\
165\end{array}$ \\
\hline
\end{tabular}

Form DOT F $1700.7 \quad\{9-69\}$ 
METAIC CONVERSION FACTORS

Approximate Conversions to Metric Measures

Symbol When You know Muttiply ty To find Symbal

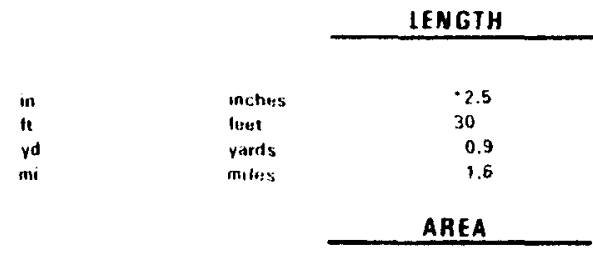

$\mathrm{in}^{2}$
$\mathrm{ti}^{2}$
$\mathrm{vd}$
$\mathrm{min}$

square tochess
square teet

square liet

square vards

6.5

0.09
0.8
2.6
0.4

MASS (weight)

ox
Ib

tsp
Tbsp
$t 10 x$
$c$
$p t$
$q t$
$9 a 1$
$t^{3}$
$y d^{3}$

\begin{tabular}{|c|c|}
\hline ounces & 28 \\
\hline & 0.45 \\
\hline \multirow{2}{*}{$\begin{array}{l}\text { shout tonis } \\
12000 \text { (b) }\end{array}$} & 0.9 \\
\hline & VOLUME \\
\hline
\end{tabular}

\begin{tabular}{|c|c|c|}
\hline $10>>>$ & 5 & intinters \\
\hline tablespouns & 15 & milliliters \\
\hline Huid ounces & 30 & Imolliltters \\
\hline cups & 0.24 & fillers \\
\hline pints & 0.47 & liters \\
\hline quarts & 0.95 & loters \\
\hline gatlons & 3.8 & Isters \\
\hline cubic teet & 0.03 & cubic un:ter: \\
\hline cotuc yids & 076 & cubic neter \\
\hline
\end{tabular}

IEMPERATURE (eXaCt)

Fubrenthent 59 latter Celsws

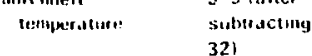

tempersture

Millogis

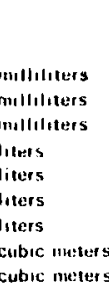

\section{Approximate Conversions from Metric Measures}

Symbol

When You know Multioly by

To find

Symbel

LEMGTH

millimeters

centimeters
meters

meters

kilometers

0.04
0.4
3.3
1.1
0.6

inches

$c m$
$m$
$m$
$k m$

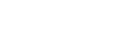

AREA

$\mathrm{cm}^{2}$
$\mathrm{~m}^{2}$
$\mathrm{~km}^{2}$
$\mathrm{ha}$

square centimeters

square meters

squart kilomieters
hectares $\left(10,000 \mathrm{~m}^{2}\right.$

0.1
1.2
0.4
2.5

0.16
0.4
2.5

square vards

MASs (weight)

$\stackrel{9}{\mathrm{~kg}}$

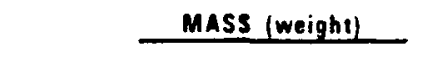

grams $\quad 0.035 \quad$ ounces

$\begin{array}{lll}\text { hilograms } & 2.2 & \text { pounds } \\ \text { tonnes }(1000 \mathrm{~kg}) & 1.1 & \text { short tons }\end{array}$

$0 i$
16

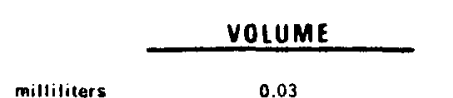

millititers
liters
liters
liters
cubic meters
cubic meters

0.03
2.1

2.1
1.06
0.26

0.26
35

fluid ounces

pints

quarts

gallons
cubic teet
cubic yards

11 o
$p t$
$q t$
$g a l$
$11^{3}$
$y d^{3}$

\section{TEMPERATURE (EXECt)}

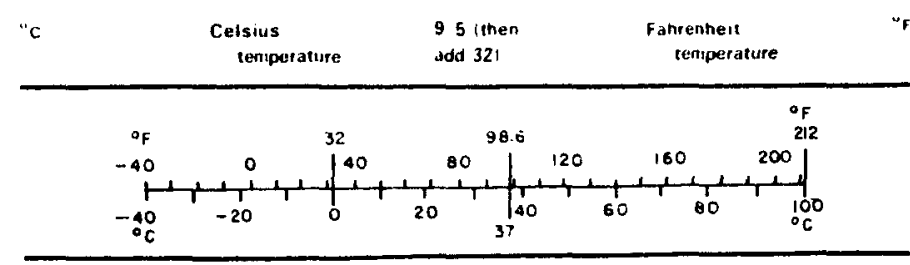


TECHNICAL SUMMARY

\begin{tabular}{|c|c|c|}
\hline CONTRACTOR & $\begin{array}{l}\text { Wyle Laboratories, Wyle Research } \\
128 \text { Maryland Street, El Segundo CA } 90245\end{array}$ & $\begin{array}{l}\text { CONTRACT NUMBER } \\
\text { DOT-HS-5-01185 }\end{array}$ \\
\hline REPORT TITLE & $\begin{array}{l}\text { An Audible Automobile Back-Up Pedestrian Warning } \\
\text { Device-Development and Evaluation. }\end{array}$ & $\begin{array}{l}\text { REPORT DATE } \\
\text { July } 1976\end{array}$ \\
\hline
\end{tabular}

Each year an estimated 260 pedestrians are killed and over 5,000 are injured by backing vehicles. This type of accident is classified as preventable, as an effective warning signal could eliminate a large majority from the accident rolls. To verify this thesis, the National Highway Traffic Safety Administration authorized a program to

- Estimate the potential effectiveness of an audible warning signal.

- Study the factors related to the ability of a pedestrian to detect a warning signal.

- Analyze the noise environment of potential back-up accident sites.

- Select an optimum warning signal format.

- Design a prototype warning device.

- Evaluate the effectiveness of the device.

This program has now been completed and all goals have been successfully reached. This report details the results of the program and, as outlined below, summarizes the essential conclusions from the study. A noteworthy result of the study predicts a change from a potential 50 percent accident rate, if unawareness is the main cause of accidents, to only 6 percent when the audible warning signal is used.

Pedestrian Back-Up Accident Data Analysis - An examination of existing back-up accident data was made to determine whether the pedestrian would have successfully detected the vehicle in time to avoid the accident if the vehicle had been equipped with an audible back-up warning device. An estimated 73 percent of these accidents would have been prevented if the pedestrian could have heard a warning signal. Data from these accident cases were also used in later sections to identify factors related to potential accident victims and the type of sites where these accidents may occur.

The Target Population - This section identifies the distribution of accident victims by age and sex, and defines their critical characteristics - hearing ability and reaction time being the primary factors. Over 37 percent of the back-up accident victims are 45 or older and over 18 percent are over 65. Thus, older segments of the population comprise the primary "population at risk" and, therefore, the main benefactors of a warning signal system. (Continue on additional pages)

"PREPARED FOR THE DEPARTMENT OF TRANSPORTATION, NATIONAL HIGHWAY TRAFFIC SAFETY ADMINISTRATION UNDER CONTRACT NO.: DOT-HS-5-01185. THE OPINIONS, FINDINGS, AND CONCLUSIONS EXPRESSED IN THIS PUBLICATION ARE THOSE OF THE AUTHORS AND NOT NECESSARILY THOSE OF THE NATIONAL HIGHWAY TRAFFIC SAFETY ADMINISTRATION." 
page 2

The Accident Site - The distribution of back-up accidents at different types of sites and the time of occurrence were derived from the accident data. Background information is presented which defines the ambient noise variations and typical sprectra to be expected at various potential accident sites, and noise data is presented from eight specific site locations. Analyses of the vehicle self-noise, the limiting ambient level, and the elapsed time of driver actions preparatory to backing are also discussed. A. design ambient noise level exceeded less than 5 percent of the time $\left(L_{5}\right)$ between $63 \mathrm{dBA}$ and $87 \mathrm{dBA}$ is projected.

Selection of the Warning Signal - An integration of the preceding factors results in development of the optimum warning signal format. An analysis of possible accident scenarios illustrates the geometry of backing accidents. A brief discussion of the signal detection process and correlation of the levels and spectra of all pertinent factors result in the selection of $1250 \mathrm{~Hz}$ as an optimum warning signal. Subjective tests of various warning signal formats identify a timing sequence of $100 \mathrm{msec}$ on and $200 \mathrm{msec}$ off at a level approximately $17 \mathrm{~dB}$ above the detection threshold as an optimum signal.

The Warning Signal System - The peak warning signal level, as heard by the pedestrian, will be approximately equal to the A-weighted ambient noise level throughout the danger zone. Propagation of the warning signal, including potential annoyance which is projected as minimal due to the ambient sensing feature of the system, is also discussed. Detailed descriptions of the warning signal system, including a complete schematic of the prototype system, are presented. System installation and operation instructions, and a specification for the warning signal are also included.

Evaluation of the Warning Signal System - Finally, the most important objective of the program measuring the effectiveness of an actual system - is described. It has been found that approximately 95 percent of the subjects "noticed" the warning device. "This was based on subject response as observed by the investigator and/or a verbal response from the subject elicited during an interview. Analyses of the evaluation test data by walking speed and by type of site, along with ambient noise level data, are also presented. Noise levels measured compare favorably with earlier projections.

The final results of the warning system evaluation predict that a vast improvement in the pedestrian's ability to avoid injury would ensue if an audible warning signal were present. Specifically, the percentage of those who did not notice a vehicle backing was decreased from 55 percent to 5.6 percent - a factor of 10 improvement in potential accident rate.

It is obvious from these results that an audible warning would substantially reduce the accident risk for pedestrians walking near vehicles about to back up. At least two unknown factors should be examined and resolved prior to considering adopting the system for use on all passenger cars: 


\section{TECHNICAL SUMMARY - Continued}

page 3

- The cost of producing the device, including installation and servicing, may affect public acceptance of its adoption. Cost estimates of this type must, of necessity, be provided by the potential manufacturer to be realistic. However, based on current technology in electronics, the initial cost is expected to be low compared to the potential benefits.

- Based upon measurements, subjective tests, and theoretical predictions, annoyance to the general public should be minimal. However, an accurate assessment of this aspect will require a greater effort than could be expended on this program.

A recommendation for future adoption of the device should thus be tempered by the results of an analysis of these two issues. Nevertheless, a simple device such as tested, which can save perhaps 200 lives a year and reduce the number of people injured from 5,000 per year to a much lower number, is considered worthy of consideration. 


\section{ACKNOWLEDGEMENTS}

This program has benefited from the experience and expertise of many individuals. The authors wish to acknowledge the support of NHTSA personnel, sspecially Dr. Robert L. Henderson, Contract Technical Managyer, who has provided technical guidance during the conduct of the program.

Sincere appreciation is given to members of the Wyle Laboratories Staff who have made significant contributions to the program. In particular, Dr. Norman J. Meyer, Director of the Research Staff, who took particular interest in solving several challenging problems which developed during the one year program. Mr. C. Christian Stiehl contributed to the system evaluation and analysis of the experimental data; Mr. Bob R. Beavers consulted on the system circuit design; and Mr. Gary E. Mange and Mr. Richard E. Stambaugh served ably during the experimental evaluation phase of the program. The support of these and many other Wyle personnel, helped to achieve the goals succeśsfully reached. 


\section{TABLE OF CONTENTS}

Page

1.0 INTRODUCTORY SUMMARY . . . . . . . . .

2.0 PEDESTRIAN BACK-UP ACCIDENT DATA ANAALYSIS . . . 2-1

2.1 Study by Operations Research, Inc. - 1971 . . . . 2-1

2.2 Accident Data from Bio-Technology Study, 1973 and 1974 (Urban) . . . . . . . . . 2-3

2.3 Study by Bio-Technology - Rural Accidents . . . . 2-4

2.4 Summary of the Accident Data Analysis . . . . 2-5

2.5 Estimated Benefit of a Warning Device . . . . 2-6

3.0 The target population . . . . . . . . . . . .

3.1 Reaction Time of the Population . . . . . . 3-1

3.2 Acoustic Perception by the Population . . . . 3-2

3.3 Age Distribution of Accident Victims . . . . 3-7

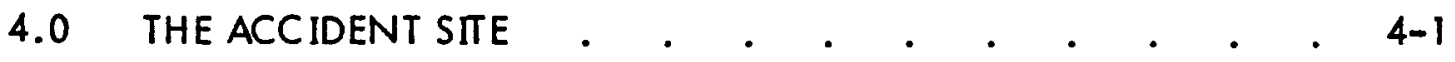

4.1 Location of the Accident Site . . . . . . . 4-1

4.2 Parking Site Background Noise Levels . . . . 4-5

4.2.1 Typical Statistical Levels at Back-Up Accident

Sites . . . . . . . . . . 4-5

4.2.2 Typical Noise Spectra in Back-Up Hazard Areas . 4-16

4.3 Self Noise of the Automobile . . . . . . . 4-22

4.3 The Automobile Driver . . . . . . . . 4-31

5.0 SELECTION OF THE WARNING SIGNAL . . . . . . 5-1

5.1 Possible Accident Scenarios . . . . . . . 5-1

5.1.1 The "Critical Distance" Model . . . . . 5-4

5.2 General Acoustical Requirements . . . . . . 5-11

5.2.1 Detection of a Signal in the Presence of Noise . 5-12

5.2.2 Warning Signal Parameters . . . . . 5-18

5.3 Subjective Evaluation . . . . . . . . . 5-21 
TABLE OF CONTENTS (Continued)

Page

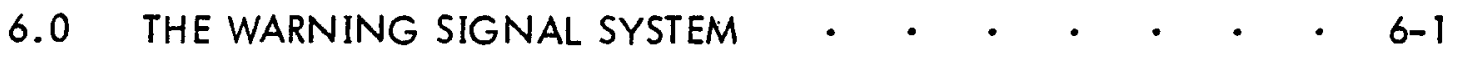

6.1 Circuit Description . . . . . . . . . 6-3

6.2 Warning System Characteristics . . . . . . . 6-7

6.3 System Installation and Operation . . . . . . 6-10

6.4 System Design Comments . . . . . . . . 6-11

6.5 Propagation of the Warning Signal . . . . . . 6-12

6.5.1 Signal Propagation Near the Vehicle . . . 6-13

6.5.2 Propagation Within the Community . . . . 6-14

6.6 Specification of the Warning Signal . . . . . 6-16

6.6.1 Mounting . . . . . . . . . 6-16

6.6.2 Power . . . . . . . . . . 6-16

6.6.3 Device Characteristics . . . . . . 6-16

6.6.4 Acoustic Measurement Procedures . . . . 6-18

7.0 EVALUATION OF THE WARNING SIGNAL SYSTEM . . .

7.1 Evaluation Method . . . • . . . . . 7-2

7.2 Subject Selection . . . . . . . . . $7-3$

7.3 Site Selection . . . . . . . . . . $7-4$

7.4 Evaluation Test Data . . . . . . . . 7-7

7.5 Noise Data Analysis . . . . . . . . $7-12$

REFERENCES

APPENDIX A - SUMMARY OF BACK-UP ACCIDENT DATA A-1

APPENDIX B - FIELD EVALUATION - SUBJECT DATA ANALYSIS B-I

APPENDIX C - EVALUATION TEST SITE DIAGRAM AND DESC FIPTIONS C- 


\section{LIST OF TABLES}

Table

Poge

2-1 Summary of Back-Up Accident Causation (Accident Cases from Table $A-1$ )

2-2 Summary of Back-Up Accident Causation (Accident Cases from Bio-Technology Study, 1973 and 1974, Urban)

2-3 Summary of Back-Up Accident Causation (Accident Cases from Bio-Technology Study, Rural)

2-4 Summary of Back-Up Accident Data Analysis $\quad 2-5$

2-5 Back-Up Accident Economic Lass - Worksheet 2-7

3-1 Age and Sex of the Population and Accident Victims 3-9

4-1 Summary of the Locations of 160 Pedestrian Back-Up Accidents 4-2

4-2 Parking Sites for Acoustic Noise Measurements 4-9

4-3 Summary of the Statistical Levels Measured at the Parking Sites 4-10 Listed in Table 4-2

4-4 Estimated Distribution of Median $\left(L_{50}\right)$ Levels in Parking Areos in Typical Medium Density Cities and in Large High Density Cities . 4-13

4-5 Estimated $\left(\mathrm{L}_{5}\right)$ A-Weighted Noise Levels Not Exceeded More Than 5 Percent of the Time in Back-Up Accident Sites 4-16

4-6 Relative One-Third Octave Band Spectra to be Applied to $L_{5}$ Levels in Table 4-5 to Define Ambient Spectrum

4-7 Summary of Starting and Running Noise Measured at the Rear of Typical Automobiles

5-1 Correction Factors to Determine Approximate Critical Band Levels By Adding to One-Third Octave Band Levels

5-2 Computation of Threshold Levels of Pure Tone Warning Signals for Specified Sites and for 95 Percent Percentile of 48 to 65 Year Age Group 


\section{LIST OF TABLES (Continued)}

Table $\quad$ Page

5-3 Warning Signal Formats Tested 5-23

6-1 Warning Signal Tone - On and Off Time for Each Switch Position 6-11

6-2 Warning Signal System Parameters 6-18

7-1 Accident Victims' Age and Sex 7-3

7-2 Evaluation Test Subjects' Age and Sex 7-4

7-3 Accident Locations $\quad$ 7-4

7-4 Distribution of Test Subjects by Age and Site Locations 7-5

7-5 Test Sites and Number of Subjects Observed During Evaluation Tests 7-6

$\begin{array}{lll}\text { 7-6 Overall Effectiveness } & \text { 7-8 }\end{array}$

7-7 Noticing the Test Vehicle Versus Walking Speed 7-9

7-8 Test Data Versus Test Location $\quad 7-10$

7-9 Subject Reactions to Back-Up Warning Device 7-11

7-:0 Summary of Ambient Levels Measured at the Evaluation Test Sites 7-14 


\section{LIST OF FIGURES}

Figure

Page

1-1 Relationship Between the Factors Governing Selection of the

Warning Signal Level

1-2 Percentage of Effectiveness of the Back-Up Worning Device (74 subjects)

3-1 Approximate Mean Reaction Time of the Male and Female Population for Audible and Visual Stimuli

3-2 Standard Reference Threshold Sound Pressure Levels

3-3 Hearing Level of 90 Percent of the Population Within Each Indicated Age Group

3-4 Comparison of Hearing Thresholds for Two Age Groups 3-6

3-5 Comparison of the Hearing Ability of the Male and Female Population 3-8

3-6 Age Distribution of the Population and Accident Victims 3-10

4-1 Distribution of Accidents by Time of Doy 4-3

4-2a Percentage of Adults Traveling on Each Hour $\quad$ 4-4

4-2b Average Outdoor Hourly Noise Level Relat ive to Day-Night Average Noise Level $\left(L_{d n}\right)$ for Three Residential Sites in Los Angeles

4-3 Daytime Outdoor Noise Levels Found in 18 Locations Ranging Between the Wilderness and the Downtown City, with Significant Intruding Sources Noted

4-4 Comparison of Data on Probability Distribution of Median Outdoor $\left(L_{50}\right)$ Noise Levels Mecsured in Residential Areos in Daytime

4-5 Daytime Sample of the Outdoor Noise Level at Eight Parking Locations

4-6 Comparison of Median ( $\left.\mathrm{L}_{50}\right)$ Noise Levels at Back-Up Accident Sites to Urban Areas 


\section{LIST OF FIGURES (Continued)}

Figure

Page

4-7 Average Normalized Statistical Levels Over 15 Hour Daytime Period (0700-2200) at 16 Residential Sites

4-8 Typical Spectra of the Ambient Noise Level at Site 1

4-9 Typical Spectra of the Ambient Noise Level at Site 2 4-19

4- 10 Typical Spectrums of the Ambient Noise Level at Site 3 4-20

4-11 Relative One-Third Octave Band Spectra at Outdoor Sites 4-21

4-12 Time History of the Noise Level at Location 3 - Downtown

Los Angeles

4-13a Comparison of Starting and Running Noise Measured at the Rear of Typical Automobiles

4-13b Comparison of Starting and Running Noise Measured of the Rear of Typical Automobiles

4-14 Starting Noise Spectra Measured at the Rear of a 1975 Chevrolet Monte Carlo Compared to Estimates of Ambient Noise Exceeded 5 Percent of Time $\left(L_{5}\right)$ at 50 Percent of Back-Up Sites ir Average (Low-Medium Density) Cities

4-15 Estimated Distribution Profile of Ambient Noise in Parking Areas over Sites in Average (Low-Medium Density) Cities and Over Time Compared to the Estimated Distribution of Idling Self-Noise of Automobiles

4-16 Observed Sequence of Events Preparatory to Backing Up

5-1 Possible Back-Up Accident Scenarios

5-2 Approximate Envelope of Potential Back-Up Accident Zone for Most 1975 U.S. Automobiles for Cose A in Figure 5-1

5-3 Geometry of General Back-Up Accident Case

5-4 Variation in Critical Warning Distance with Total Pedestrian Response Time for Different Values of Average Backing Speed and Backing Delay Time 


\section{LIST OF FIGURES (Continued)}

Figure

Page

5-5 Locus of Critical Warning Distances for Several Variations of Back-Up Accident Scenarios - Case A

5-6 Comparison of Various Critical Bandwidth Measurements

5-7 Growth of a Partially Masked Tone for Normal and Abnormal Ears to Illustrate the Phenomenon of Recruitment

5-8 Hearing Level of Eight Subjects at $1 \mathrm{kHz}$ and $2 \mathrm{kHz}$

5-9 Detection Level and Warning Quality of the Warning Signal in the Presence of Noise

6-1 Functional Block Diagram of the Warning Signal System 6-2

6-2 Illustration of the Waming Signal Level Parameters 6-4

6-3 Circuit Diagram of the Warning System 6-5

6-4 Frequency Response of the Acoustic Sensor 6-8

6-5 Directivity of the Warning Signal System 6-9

6-6 Illustration of the Signal Level Variations in the Vertical Plane Behind the Vehicle

7-1 Time History Examples of the Warning Signal Test Sequence 7-13

7-2 Recorded Ambient Level for the Field Evaluation Tests 7-13 


\subsection{INTRODUCTORY SUMMARY}

Each year an estimated 260 pedestrians are killed and over 5000 are injurod by backing vehicles. This type of accident is clessified as preventable, as on effective warning signal could eliminate o large majority from the accident rolls. To verify this thesis, the National Highway Traffic Safety Administration (NHTSA) authorized a program to:

- Estimate the potential effectiveness of an audible warning signal.

- Study the factors related to the ability of a pedestrian to detect a warning signal.

- Analyze the noise environment of potential back-up accident sites.

- Select an optimum warning signal format.

- Design a prototype warning device.

- Evaluate the effectiveness of the device.

This program has now been completed and all goals have been successfully reached. This report details the results of the program and, as outlined below, summarizes the essential conclusions from the study. A noteworthy result of the study predicts a change from a potential 50 percent accident rate to only 6 percent when the audible warning signal is used.

Pedestrian Back-Up Accident Data Analysis - An examinotion of existing backup accident data was made to determine whether the pedestrian would have successfully detected the vehicle in time to avoid the accident if the vohicle had been equipped with an audible back-up warning device. An estimated 73 percent of these accidents would have been prevented if the pedestrian could have hoard a warning signal. Data from these accident cases were also used in later sections to identify factors related to potential accident victims and the type of sites where these accidents may occur.

The Target Population - This section identifies the distribution of accident victims by age and sex, and defines their critical characteristics; hearing ability and reaction time being the primary factors. Over 37 percent of the back-up accident 
victims are 45 or older and over 18 percent are over 65. Thus, older segments of the population comprise the primary "population at risk" and, therefore, the main benefactors of a warning signal system.

The Accident Site - The distribution of back-up accidents at different types of sites and the time of occurrence were derived from the accident data. Background information is presented which defines the ambient noise variations and typical spectra to be expected at various potential accident sites, and noise data is presented from eight specific site locations. Analyses of the vehicle self-noise, the limiting ambient level, and the elapsed time of driver actions preparatory to backing are also discussed. A design ambient noise level exceeded less than $5 \%$ of the time $\left(L_{5}\right)$ between $63 \mathrm{~d} 3 \mathrm{~A}$ and $87 \mathrm{dBA}$ is projected.

Selection of the Warning Signal - An integration of the preceding factors results in development of the optimum warning signal format. Art anolysis of possible accident scenarios illustrates the geometry of backing accidents. A brief discussion of the signal detection process and correlation of the levels and spectra of all pertinent factors result in the selection of $1250 \mathrm{~Hz}$ as an optimum warning signal. Subjective tests of various warning signal formats identify a timing sequence of $100 \mathrm{msec}$ on and $200 \mathrm{msec}$ off at a level approximately $17 \mathrm{~dB}$ above the detection threshold as an optimum signal.

The Warning Signal System - The peak warning signal level, as heard by the pedestrian, will be approximately equal to the A-weighted ambient noise level throughout the danger zone. Propagation of the warning signal, including potential annoyance, which is projected as minimal due to the ambient sensing feature of the system, is also discussed. Detailed descriptions of the warning signal system, including a complete schematic of the prototype system are presented. System installation and operation instructions, and a specification for the warning signal is also included.

Evaluation of the Warning Signal System - Finally, the nost important objective of the program, measuring the effectiveness of an actual system, is described. 
It has been found that approximately 95 percent of the subjects "noticed" the warning device. This was based on subject response as observed by the investigator and/or a verbal response from the subject, elicited during an interview. Analyses of the evaluation test data by walking speed and by type of site along with ambient noise level data are also presented. Noise levels measured compare favorably with earlier projections.

In summary, the primary program results may be reviewed as follows: Figure 1-1 presents the relationship between the no ise levels affecting detection of the warning signal and the warning signal itself. The hearing threshold of the target population, which is seldom a limiting factor, is shown. Spectrum levels $(1 / 3$ octave) of the vehicle engine noise, often the controlling ambient for the warning system, are approaching the community ambient levels heard by the pedestrian. The range of community noise levels exceeded 5 percent of the time $\left(L_{5}\right)$ to be expected at potential accident sites is shown and in relation to this, the warning signal level at the extent of the danger zone.

The final results of the warning system evaluation are shown in Figure 1-2. These data, extracted from Table 7-6, predict that a vast improvement in the pedestrian's ability to avoid injury would ensue if an audible waming signal were p'esent.

\begin{tabular}{|l|c|c|}
\hline Test & Noticed & $\begin{array}{c}\text { Did Not } \\
\text { Notice }\end{array}$ \\
\hline $\begin{array}{l}\text { With } \\
\text { Device }\end{array}$ & $94.4 \%$ & $5.6 \%$ \\
\hline $\begin{array}{l}\text { Without } \\
\text { Device }\end{array}$ & $45 \%$ & $55 \%$ \\
\hline
\end{tabular}

Figure 1-2. Percentage of Effectiveness of the Back-up Warning Device (74 subjects) 


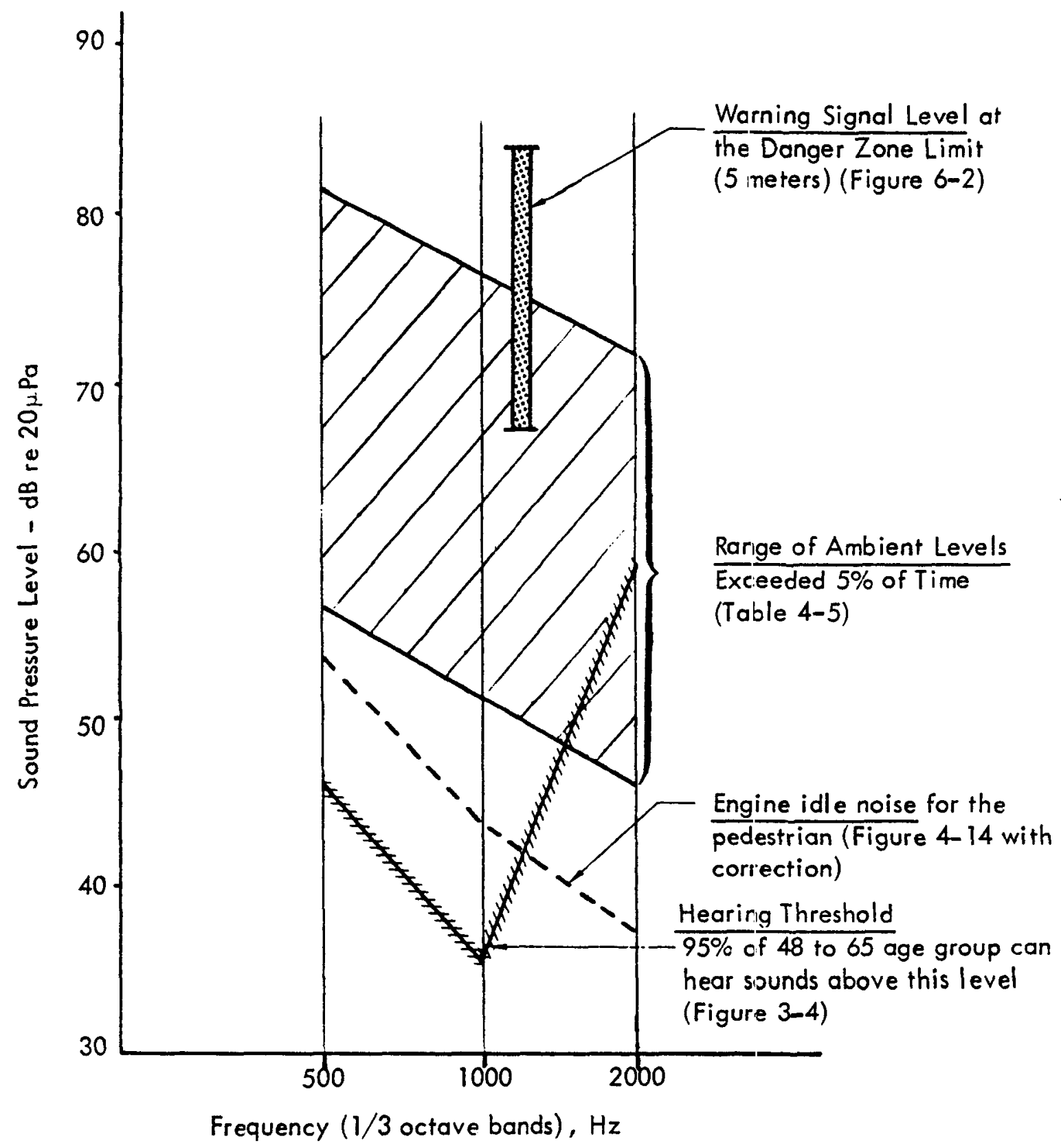

Figure 1-1. Relationship Between the Factors Governing Selection of the Warning Signal Level. 
Specifically, the percentage of those who did not notice a vehicle backing was decreased from 55 percent to 5.6 percent - a factor of 10 improvement in potential accident rate.

It is obvious from these results than an audible warning would substantially reduce the accident risk for pedestrians walking near vehicles about to back-up. At least two unknown factors should be examined and resolved prior to considering adopting the system for use on all passenger cars.

- The cost of producing the device, including installation and servicing may affect public acceptance of its adoption. Cost estimates of this type must, of necessity, be provided by the potential manufacturer to be realistic. However, based on current technology in electronics, the initial cost is expected to be low compared to the potential benefits.

- Based upon measurements, subjective tests, and theoretical predictions, annoyance to the general public should be minimal. However, an accurate assessment of this aspect will require a greater effort than could be expended on this program.

A recommendation for future adoption of the device should thus be tempered by the results of an analysis of these two issues. Nevertheless, a simple device such as tested, which can save, perhaps, 200 lives a year and reduce the number of people injured from 5000 per year to a much lower number, is considered worthy of consideration. 
Prior to the selection of a warning signal and designing the device, a study was made of 160 back-up accidents involving pedestrians in order to determine whether an audible warning device would have been effective in preventing these accidents. This section presents the results of the accident data review and related statistics are shown to provide a basis for evaluating the study results. Also, although the research necessary to prepare meaningful cost estimates is beyond the scope of this program, some relevant economic costs are presented to provide insight into the viability of the program.

\subsection{Study by Operations Research, Inc. - 1971}

An examination was made of 34 vehicle back-up accident cases involving 37 pedestrians.* This examination was made to determine the effectiveness that an audible warning device would have in preventing these back-up accidents. In some instances, the data was inadequate to determine whether the pedestrian saw the vehicle prior to being struck, but many pedestrians obviously had inadequate time to avoid being hit.

The study, of which the reviewed accident data-was a part, identified the accident precipitating factors - the details of which were listed in Table 4.1

of Reference 9. For all pedestrian accidents, 71 percent of the precipitating factors were assigned to pedestrian failures with the remaining 29 percent assigned to the driver. A similar tabulation of back-up accident precipitating factors, derived from the reviewed accident data, indicated 40 percent of the factors were assigned to the pedestrian and 60 percent were assigned to the vehicle driver.

The accident data was analyzed to determine if the pedestrian would have successfully detected the vehicle in time to avoid the accident if each vehicle had been equipped with an audible back-up warning device. A summary of the detailed pertinent facts from the original data is shown in Table A-1 of Appendix A. These data were

"The original accident data from Reference 9. 
analyzed and pedestrians were classified according to (1) those who would not have been helped by an audible warning, and (2) those who would likely have responded to an audible warning. Table 2-1 summarizes the results of this analysis and identifies a few of the specific classes of identified accident causations. Examination of this data indicates that 79 percent of all the pedestrians involved in these back-up accidents would have benefited from an audible warning device.

\section{Table 2-1}

\section{Summary of Back-up Accident Causation (Accident Cases from Table A-1)}

Pedestrians who would not benefit from an audible warning

Code Accident Cause
a. Pedestrian saw vehicle, unable to avoid
b. Pedestrian saw vehicle, did not avoid
c. Young child (less than 5 years of age)

Total 7

Pedestrians who would likely benefit from an audible warning

Code

Accident Cause

Number of Cases

d. Pedestrian was not aware the vehicle was backing

e. Pedestrian saw vehicle too late to avoid

Total 27 


\subsection{Accident Data from Bio-Technology Study, 1973 and 1974 (Urban)}

A similar examination was made of 99 vehicle back-up accident cases involving 102 pedestrians. Table A-2 in Appendix A contains the detailed pertinent data derived from these accident coses. An analysis of these accident coses revealed that 73 percent of the accidents probably would not have occurred if a back-up waming device had been operational. The factors relating to the pedestrians' possible help from a warning device are enumerated in Table 2-2 with the number of cases falling within each category.

\section{Table 2-2}

Summary of Back-up Accident Causation (Accident Cases from Bio-Technology Study, 1973 \& 1974, Urban, Reference 17)

Pedestrians who would not benefit from an audible warning

Code

a. Pedestrian saw vehicle, unable to avoid

b. Pedestrian saw vehicle, did not avoid

c. Young child (less than 5 years of age)

f. Unoccupied vehicle
Number of Cases

Total $\frac{2}{28}$

Pedestrians who would likely benefit from an audible warning

Code Accident Cause Number of Cases

d. Pedestrian was not aware the vehicle was backing 50

e. Pedestrian saw vehicle too late to avoid 21

Total 71 


\subsection{Study by Bio-Technology - Rural Accidents}

Accident data from a study currently being performed by' Bio-Technology, Inc. produced 27 cases of vehicle back-up accidents involving 28 pedestrians. Summary data extracted from the reports are shown in Table A-3 of Appendix A. A determination of the effectiveness an audible device would have had was made and the results are shown in Table 2-3. This analysis indicates 67 percent of the pedestrian accidents could have been prevented if an audible warning signal had been operational.

\section{Table 2-3}

Summary of Back-up Accident Causation

(Accident Cases from Bio-Technology Study, Rural, Reference 17)

Pedestrians who would not benefit from an audible warning

\begin{tabular}{llc} 
Code & Accident Cause & Number of Cases \\
\cline { 3 - 3 } & Pedestrian saw vehicle, unable to avoid & 2 \\
b. Pedestrian saw vehicle, did not avoid & \\
c. Young child (less than 5 years of age) & Total $\frac{7}{9}$
\end{tabular}

Pedestrians who would likely benefit from an audible warning

$\begin{array}{llc}\text { Code } & \text { Accident Cause } & \text { Number of Cases } \\ & \text { Pedestrian was not aware the vehicle was backing } & 9 \\ \text { e. Pedestrian saw vehicle too late to avoid } & 9\end{array}$

Total 18 


\subsection{Summary of the Accident Dato Analysis}

Table 2-4 is a tabulation of the total pedestrian accident cases in each of the studies and the number of back-up accident cases reviewed. Analysis of the accident causation related to the pedestrian indicates that 73 percent of the vehicle back-up pedestrian accidents would have been prevented if all pedestrians could have heard a waming device. Of course, some pedestrians - particularly those in their later years may have inadequate hearing ability and may fail to respond to an audible warning signal.

\section{Table $2-4$}

Summary of Back-up Accident Data Andysis

\begin{tabular}{|l|r|r|r|r|}
\hline Accident Cases & $\begin{array}{r}\text { ORI } \\
\text { Study } \\
\text { (Urban) }\end{array}$ & $\begin{array}{r}\text { 8TI } \\
\text { Study } \\
\text { (Urban) }\end{array}$ & $\begin{array}{r}\text { BTI } \\
\text { Study } \\
\text { (Rural) }\end{array}$ & $\begin{array}{r}\text { Total } \\
\text { Number }\end{array}$ \\
\hline Pedestrian Accident Coses & 2,157 & 3,827 & 1,632 & 7,616 \\
\hline Back-up Accident Cases & 34 & 99 & 27 & 160 \\
\hline Pedestrian Fatalities & 2 & 4 & 1 & 7 \\
\hline Pedestrian Injuries & 26 & 94 & 24 & 144 \\
\hline $\begin{array}{c}\text { Accident Cases Preventable by } \\
\text { an Audible Warning Device }\end{array}$ & 27 & 71 & 18 & 116 \\
\hline
\end{tabular}

Back-up accident data statistics derived -

Back-up Accidents $=2.1$ percent of Pedestrian Accidents

Back-up Fatalities $=4.4$ percent of Back-up Accidents

Back-up Injuries $\quad=90$ percent of Back-up Accidents

Urban Pedestrian Accidents (BTI Study) -

1973 Back-up Accidents $=2.5$ percent of Urban Pedestrian Accidents

1974 Back-up Accidents $=2.7$ percent of Urban Pedestrian Accidents 


\subsection{Estimated Benefit of a Warning Device}

The determination of costs to produce and install a warning device on all new automobiles on a high-volume production basis is complex and was deemed not feasible within the scope of the program. As an alternative, a brief analysis was performed to evaluate the benefits to be derived by implementing the prograin, and thereby determine the maximum amount to be committed to the program, using normal cost-benefit criteria. Table 2-5 lists information used to perform this calculation. These data - in conjunction with approximate dollar loss-per-accident values supplied by NHTSA - yield an economic loss of $\$ 106$ million due to back-up accident fatalities and injuries.

The review of the 160 back-up accidents in this study indicates approximately 70 percent could have been prevented if the vehicles had been equipped with warning devices. Using an economic loss value of $\$ 240,000$ per fatality and $\$ 8,000$ per injury, the annual value (benefit) of prevented accidents - once the national automobile fleet is fully equipped - is approximately $\$ 74$ million. Assuming that no more than $\$ 74$ million would be committed annually and assuming a yearly production rate of 10 million automobiles, a maximum unit cost of $\$ 7.40$ is derived.

It should also be pointed out that the benefits will lag the costs until the national fleet is fully equipped. A previous Wyle study of vehicle registrations for the year 1973 indicated that 50 percent of the automobile fleet were over 5 years old and 12 percent were over 10 years old. ${ }^{16}$ Therefore, assuming a similar retirement rate in the future, it is expected to take approximately 5 years to equip one-half the fleet (assuming no used-car retrofit) and over 10 years to reach full implementation. 
Table 2-5

Back-up Accident Economic Loss - Worksheet

Relevant Accident Statistics

Ref.

Total Accidents Per Year

25.6 million

(1973) 15

Total Traffic Fatalities

55,800

(1973) $\quad 15$

Total Traffic Injuries

5.2 million

(1973) $\quad 15$

Pedestrian Accidents

286,500

(1973) $\quad 14$

Pedestrian Fatalities

10,500

(1973) 14

Pedestrian Injuries

277,000

(1972) $\quad 15$

Back-up Accidents (2.1\% of Ped. Accidents*)

6,017

17

Back-up Fatalities (4.4\% of Back-up Accidents*)

263

17

Back-up Injuries (90\% of Back-up Accidents*)

5,417

17

Total Loss Due to Accidents

$\$ 19$ billion

(1972)

15

Total Economic Loss Computation:

Back-up Accident Fatalities - 263 at $\$ 240,000$ each $\$ 63$ million

Back-up Accident Injuries - 5,417 at \$8,000 each \$43 million

Total - \$106 million

Potential Benefit Computation:

Estimated prevention rate of $70 \% \times \$ 106$ million $=\$ 74$ million

References - 14: Accident Facts, 1974

15: Statistical Abstracts, 1974

17: Data from Bio-Technology Study

* Table 2-4 derived from BTl and ORI Studies 


\subsection{THE TARGET POPULATION}

There are several factors bearing on the success of an audible automobile back-up warning device. Of course, the primary concern is to alert pedestrians in the danger zone behind the automobile soon enough for them to take evasive action. However, a number of pedestrian back-up accidents occur which would not be prevented by an audible warning; among these are:

- Pedestrians who see the vehicle but are unable to avoid it;

- Pedestrians who see the vehicle but do hot feel evasive action is necessary; and

- Young children who may not recognize the danger.

These categories of pedestrians are beyond the ability of any warning device to help, although the audible signal may enhance the importance of a dangerous situation and thus prevent additional accidents. The present program was directed toward those pedestrians - the target population - who would not normally see the backing automobile soon enough to avoid injury, but would be alerted in time by an audible warning device.

Our primary goal is to evoke an appropriate response from members of the target population when they hear the warning signal. Their complete response is relatively complex, but primarily includes the following:

- Audibly detecting a warning signal;

- Visually confirming the direction of the impending danger; and

- Taking physical action to minimize the danger.

\subsection{Reaction Time of the Population}

The reaction time of people depends on many variables ${ }^{4}$, some of which will be considered here. The mean reaction time of both the male and female 
population as a function of age (shown in Figure 3-1) indicates a range of approximately 2 to $I$ between young and old pedestrians. There are also minor differences in reaction time depending on the initial cue, whether it is visual or audible, an audible cue yielding approximately 20 percent faster reaction times.

\subsection{Acoustic Perception by the Population}

The pedestrian's ability to be alerted by an audible alarm is, of course, dependent on his ability to perceive the warning signal. The acoustic characteristics of the warning signal - its frequency content arid interisity - are paramount, but we must also consider the pedestrian's hearing ability.

The standard (reference) threshold of hearing represents the level of sound in a free progressive sound field just audible to a hypothetical young adult with no history of medical problems of the ear. This reference hearing threshold, in Figure 3-2 shows that the normal ear can hear sounds with the lowest sound pressure level at frequencies in the vicinity of $1000 \mathrm{~Hz}$. The actual hearing ability of people is specified in terms of their "hearing level" - the difference in the level of a just audible sound relative to the standard reference threshold in Figure 3-2. The "hearing level" of the average person decreases (rather the difference between his threshold and the standard threshold increases) as one grows older - a process appcrently due to normal aging (presbycusis) and possibly to progressive hearing loss suffered by normal exposure to high level noise in our society (sociocusis). ${ }^{6}$ Figure $3-3$ shows this trend in decreased hearing ability with age; each curve represents the hearing level exceeded by no more than 10 percent of the population.

If these hearing levels are added to the standard threshold given in Figure 3-2. the hearing threshold for two age groups are obtained as illustrated in Figure 3-4 . These data. considered representative of the most reliable infornation on hearing levels available, show the sound level as a function of frequency which can be heard by the specified percent of the population for the age groups indicated. 


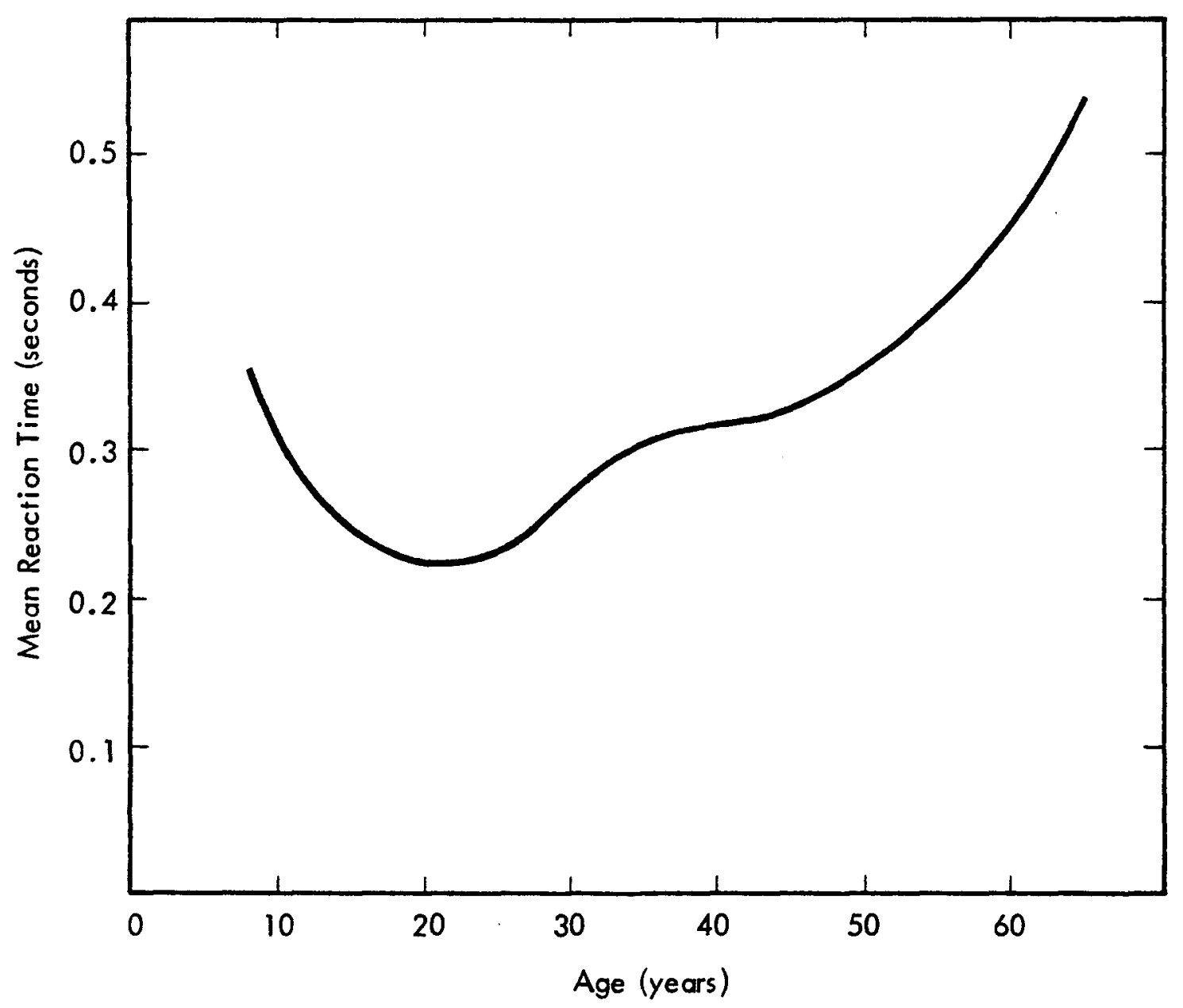

Figure 3-1. Approximate Mean Reaction Time of the Male and Female Population for Audible and Visual Stimuli (Reference 13) 


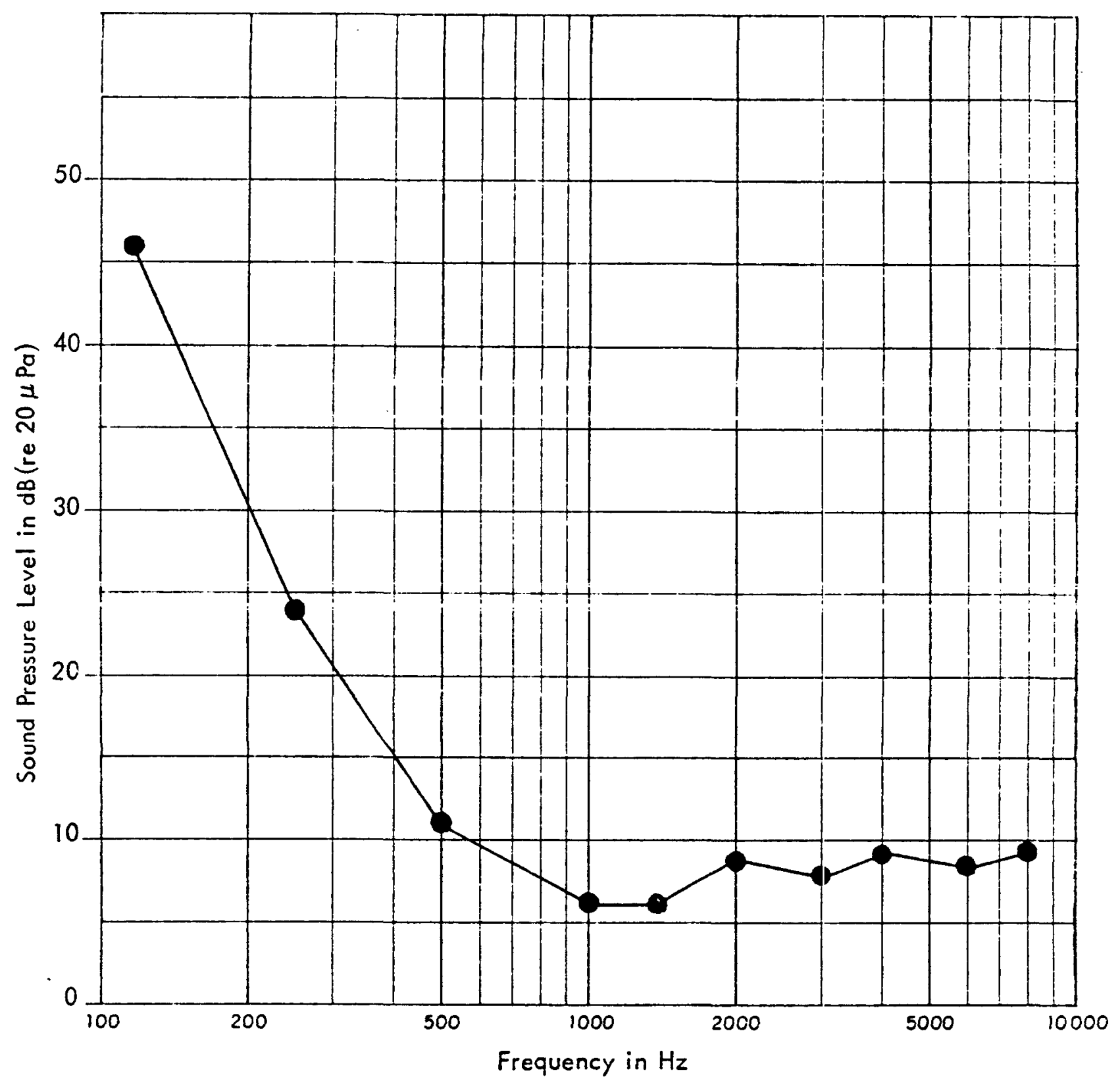

Figure 3-2. Standard Reference Threshold Sound Pressure Levels ISO (1963) (Reference 12) 


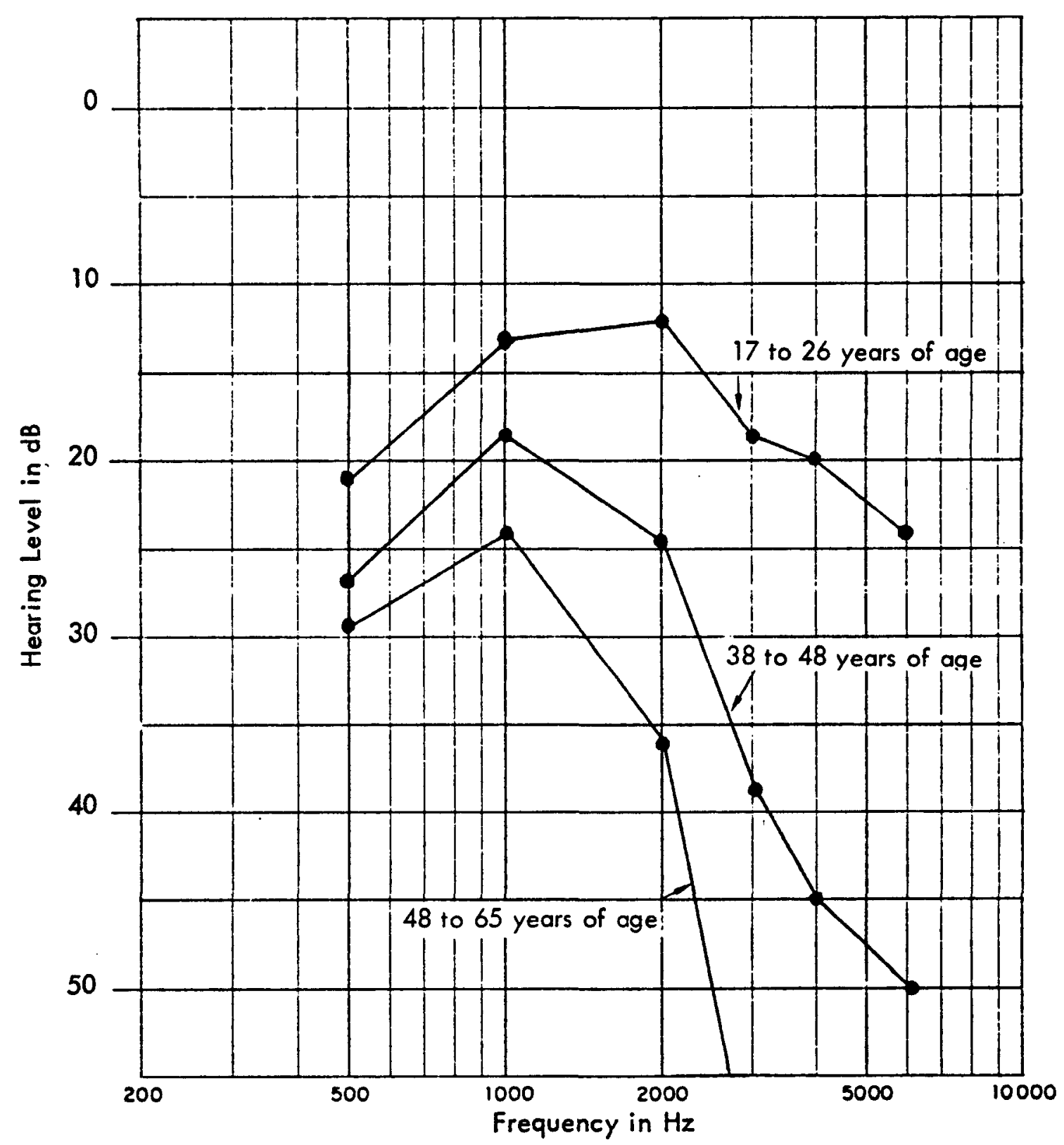

Figure 3-3. Hearing Level of 90 Percent of the Population Within Each Indicated Age Group (Reference 1) 


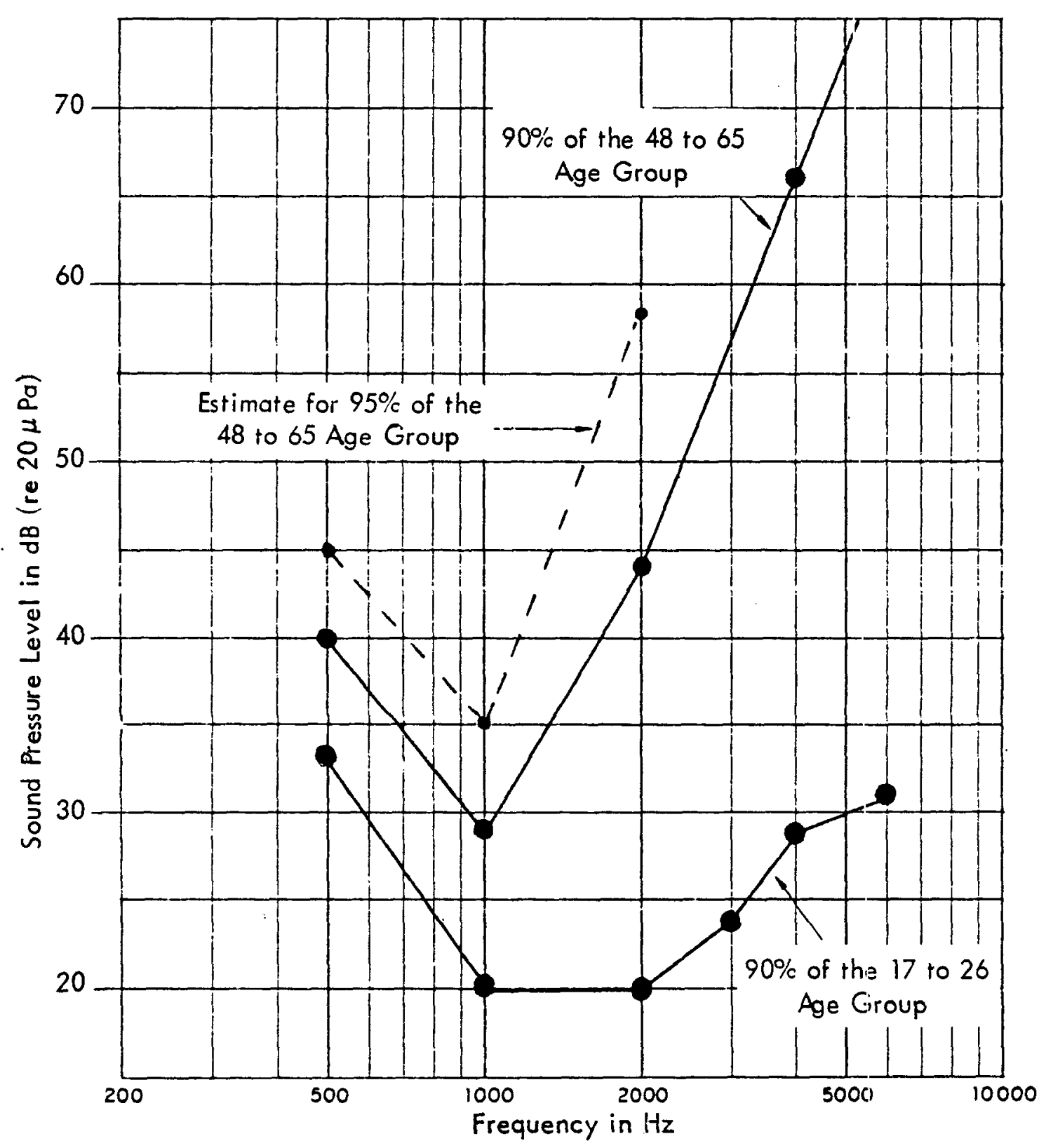

Figure 3-4. Comparison of Hearing Thresholds for Two A.ge Groups 
The differences in the hearing ability of the male and female population are also of interest. Figure 3-5 illustrates the differences at two frequencies as a function of age. It is interesting to note the reversed hearing capability of men and women at the two frequencies shown.

\subsection{Age Distribution of Accident Victims}

To establish on approximate profile of the target population, comparisons were made between the distribution of ages and sex for: 1) pedestrian back-up accident victims, 2) all pedestrian accident victims, and (3) the total U.S. population. Table 3-1 lists the details derived from three different sources showing the age distribution and percentages of each sex. These data show that approximately 10 percent of the total population is 65 years of age or older and a similar percentage of the pedestrian accident victims are in this age group. However, over 18 percent of the back-up accident victims are 65 or older. Based on the limited sample of the latter, age appears to be a unique added risk factor for the target population. This may be due to such factors as reduced reaction time, and lowered hearing and visual acuity.

Figure 3-6 shows graphs of the three categories - total population, pedestrian victims, and back-up victims. These graphs illustrate the dissimilarity among these three categories and the fact that back-up accident victims moy not be identified with a particular age group. 


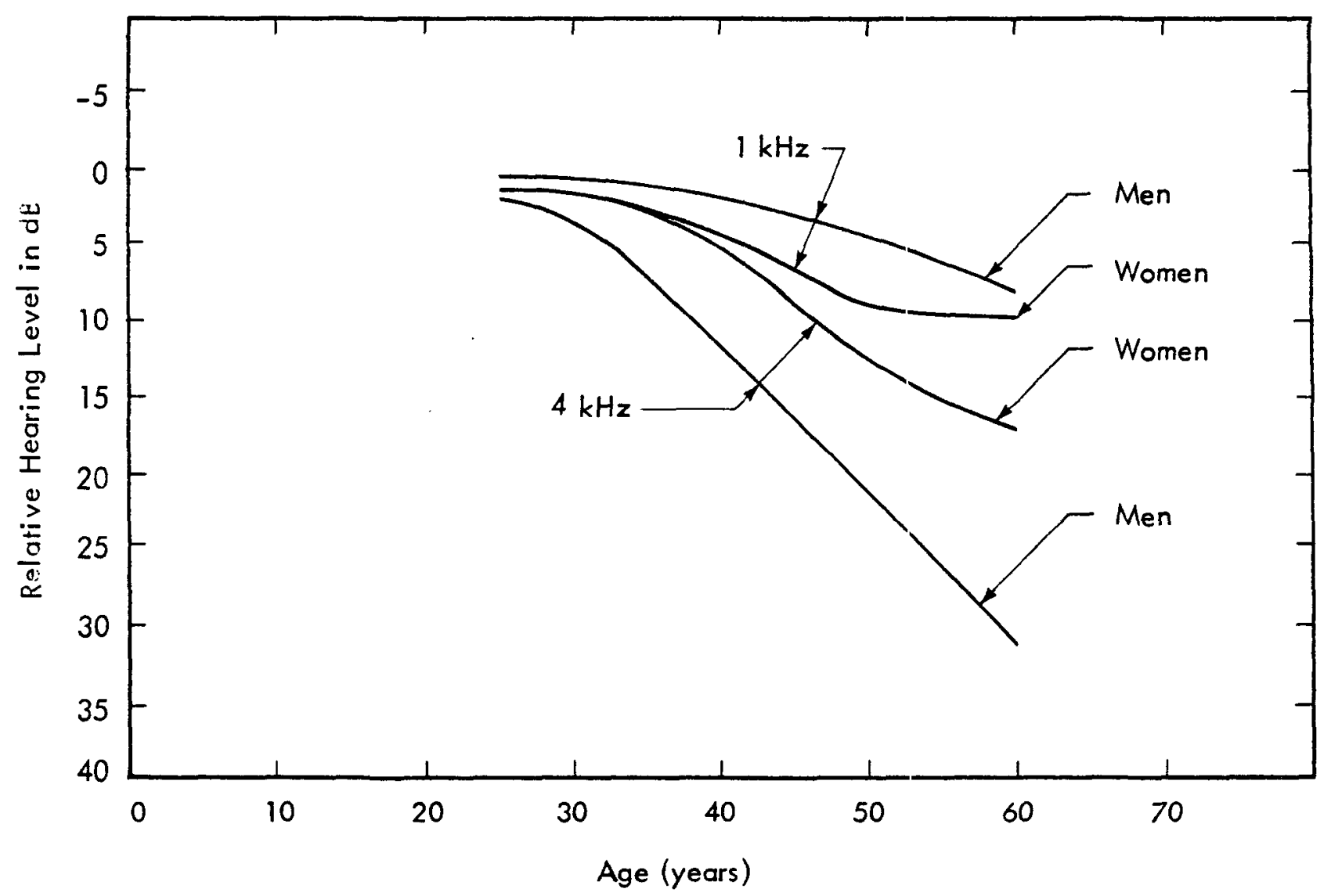

Figure 3-5. Comparison of the Hearing Ability of the Male and Female Population (Reference 18) 
Table 3-1

Age and Sex of the Population and Accident Victims

(See Figure 3-6 for Graphical Presentation)

\begin{tabular}{|c|c|c|c|c|c|c|c|}
\hline & & & & & ictims & & ictims \\
\hline & & $1972 \mathrm{U}$ & Jlation & Fato & Injuries & Fato & Injuries \\
\hline & Age Group & $\begin{array}{c}\text { Totol } \\
\text { Population } \\
(\%)\end{array}$ & $\begin{array}{c}\text { Moles } \\
\text { in each } \\
\text { Category } \\
(\%)\end{array}$ & $\begin{array}{l}\text { Total } \\
(\%)\end{array}$ & $\begin{array}{c}\text { Nales } \\
\text { in each } \\
\text { Cotegory } \\
(\%) \\
\end{array}$ & $\begin{array}{l}\text { Tolal } \\
(\%)\end{array}$ & $\begin{array}{c}\text { Males } \\
\text { in each } \\
\text { Category } \\
(\%) \\
\end{array}$ \\
\hline & $0-4$ & 8.3 & 51.1 & 10.0 & 71.2 & 12.7 & 66.7 \\
\hline & $5-9$ & 9.0 & 50.9 & 29.5 & 65.5 & 9.7 & 56.3 \\
\hline & $10-14$ & 10.0 & 51.0 & 10.7 & 65.6 & 2.4 & 50.0 \\
\hline & $15-19$ & 9.6 & 50.9 & 6.5 & 61.2 & 4.2 & 85.7 \\
\hline & $20-24$ & 8.7 & 50.4 & 5.7 & 64.1 & 7.9 & 38.5 \\
\hline c & $25-29$ & 7.2 & 49.7 & 4.9 & 61.4 & 8.5 & 85.7 \\
\hline & $30-34$ & 5.9 & 49.4 & 2.9 & 69.4 & 7.9 & 46.2 \\
\hline & $35-39$ & 5.3 & 49.0 & 2.9 & 53.3 & 6.1 & 50.0 \\
\hline & $40-44$ & 5.6 & 48.8 & 3.6 & 67.1 & 1.2 & 100.0 \\
\hline & $45-49$ & 11.3 & 48.1 & 2.8 & 70.7 & 3.6 & 33.3 \\
\hline & $50-54$ & & & 2.8 & 61.4 & 9.1 & 40.0 \\
\hline & $55-59$ & 9.1 & 47.1 & 2.9 & 54.2 & 4.2 & 57.1 \\
\hline & $60-64$ & & & 3.0 & 48.2 & 3.6 & 83.3 \\
\hline & $65-69$ & 6.2 & 43.5 & 3.5 & 54.2 & 3.6 & 50.0 \\
\hline & $70-74$ & & & 3.6 & 51.4 & 4.2 & 71.4 \\
\hline & $75-79$ & & & 2.6 & 51.9 & 2.4 & 25.0 \\
\hline & $80-84$ & 3.9 & 38.1 & 1.2 & 62.5 & 4.8 & 62.5 \\
\hline & $85-89$ & & & 0.6 & 53.8 & 1.8 & 33.3 \\
\hline & $90-i 00$ & & & & & & \\
\hline & Unknown & & & & & 1.8 & 66.7 \\
\hline & Total Number & 208 Mill & Jation & & ims & & ims \\
\hline & Source & $\operatorname{Ref}$ & & & & & 2.0 \\
\hline
\end{tabular}



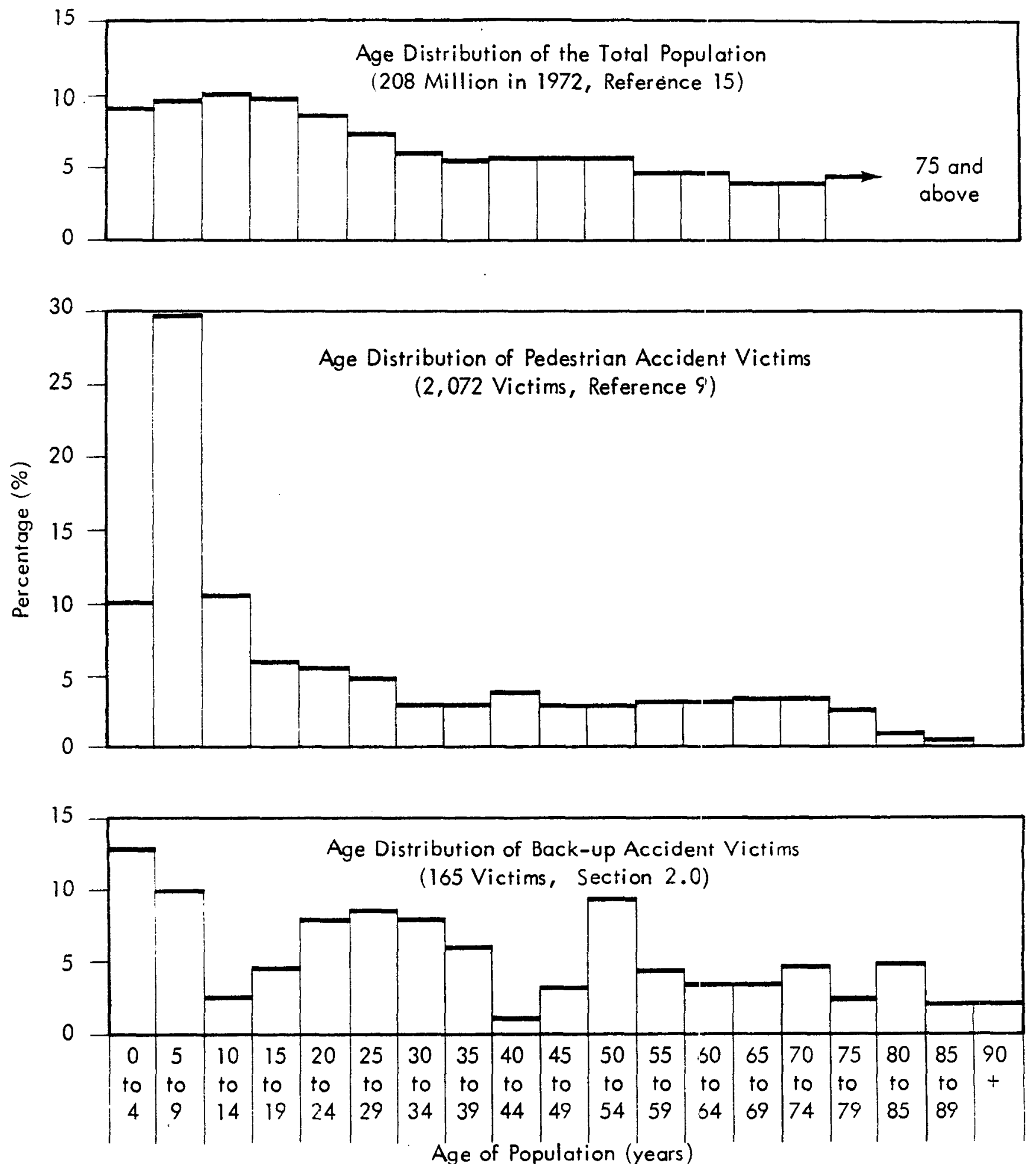

Figure 3-6. Age Distribution of the Population and Accident Victims 


\subsection{THE ACCIDENT SITE}

An analysis of vehicle back-up accidents in which pedestrians were involved was performed early in the program to determine the potential effectiveness of andible warning signal. A total of 160 occident cases were studied and details pertinent to the task of designing a warning system were identified. This study (described in Section 2.0) of accident data provided information regarding the location and time of occurrence of back-up accidents. The most important facts describing a potential accident site related to the present study are:

- The site location

- The time of accident occurrence

- The ambient noise level in the vicinity

These aspects of the site description have been analyzed in detail and results are presented to substantiate the warning signal design goals, based upon the environment it must operate within.

\subsection{Location of the Accident Site}

A review of available pedestrian back-up accident data revealed that a bare majority (58 percent) of the back-up aceidents occurred in residential areas as opposed to commercial areas as illustrated in Table 4-1.9, 17 However, this fact may be misleading since the residential classification includes multifamily dwelling areas and areas which are mixed but predominantly residential. Also, the residential areas mainly comprise a quiet type of location, where an audible warning would be most effective, but also most annoying. This aspect of the problem may lack adequate data to resolve completely, but a brief discussion is contained in Section 6.5.

Figure 4-1 illustrates the distribution of different types of motor vehicle accidents throughout the day. If the back-up accidents reviewed in the referenced studies are a representative somple, this type of accident seems to be somewhat more 
Table 4-1

Summary of the Locations of 160 Pedestrian Back-Up Accidents

(Section 2.0),

\begin{tabular}{|c|c|c|}
\hline Accident Site & \multicolumn{2}{|c|}{ Number of Back-Up Accidents } \\
\hline $\begin{array}{l}\text { Commercial/Industrial } \\
\qquad \begin{array}{l}\text { Intersection } \\
\text { Mid-Block } \\
\text { Driveway or Alley } \\
\text { Off Street Area }\end{array}\end{array}$ & - Total & $\begin{array}{l}17 \\
17 \\
13 \\
16\end{array}$ \\
\hline $\begin{array}{l}\text { Residential/Rural } \\
\text { Intersection } \\
\text { Mid-Block } \\
\text { Driveway or Alley } \\
\text { Off Street Area }\end{array}$ & - Total & $\begin{array}{r}14 \\
40 \\
33 \\
6\end{array}$ \\
\hline Other & - Total & 4 \\
\hline Total Accident Cases & & 160 \\
\hline
\end{tabular}

evenly spread through the day than other types of pedestrian acisidents (compare Figures $4-\mathrm{lb}$ and $4-\mathrm{lc}$ ). Based on the limited data, late mornirig and late afternoon periods seem to be the most critical for back-up pedestrian accidents. As shown in Figure 4-2a and Figure 4-2b, the early morning time corresponds to a period of reduced travel activity for people and fairly high outdoor noise levels, while for the late afternoon period, both travel and outdoor noise levels are relatively high. The late afternoon or early evening period, therefore, is clearly the most hazardous for pedestrians.

The remainder of this section discusses the acoustic noise aspects of the back-up accident or parking sites. Detailed descriptions of various types of sites and related acoustic measurements and data are presented. 

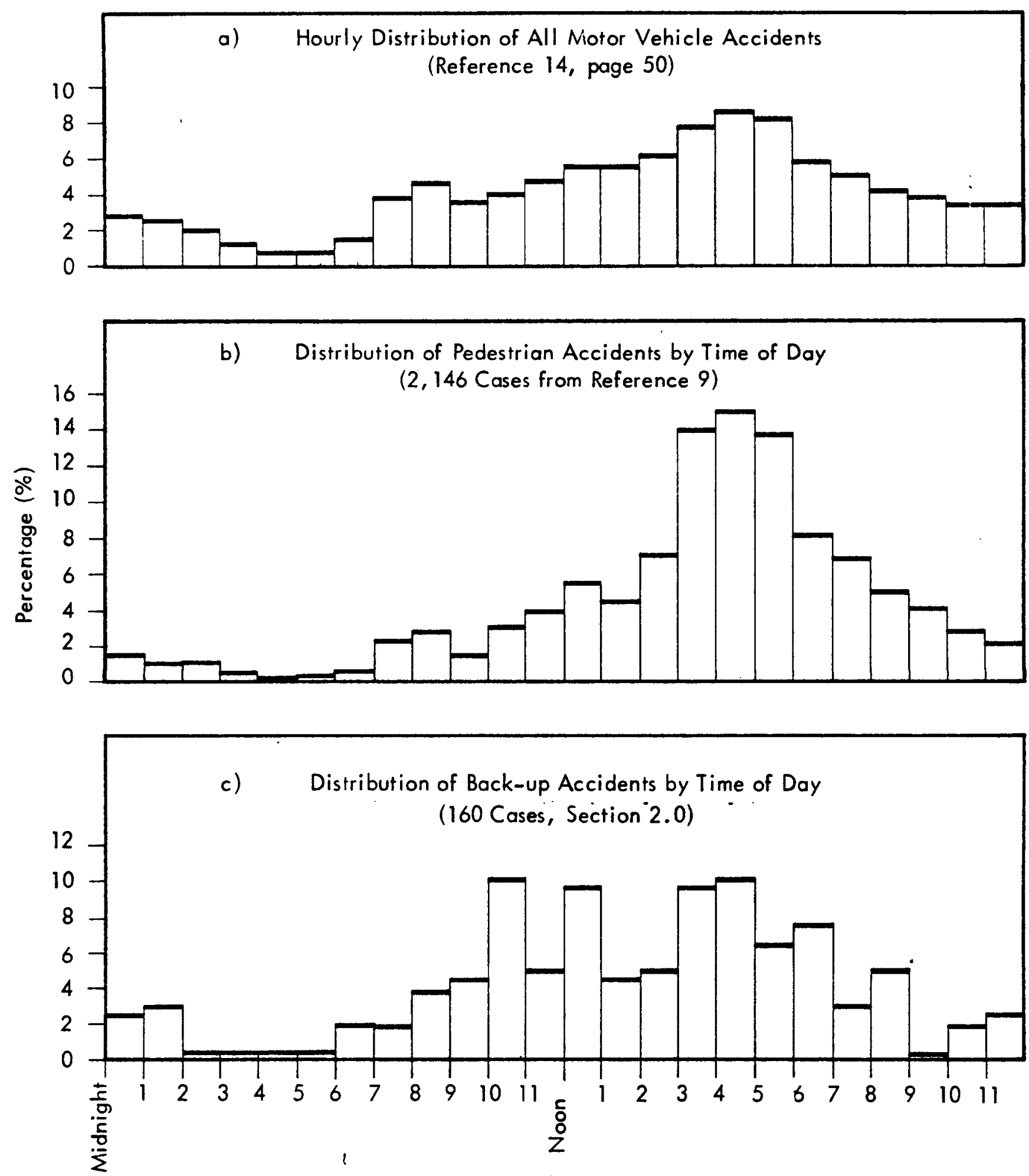

Hour of Day

Figure 4-1 Distribution of Accidents by Time of Day 


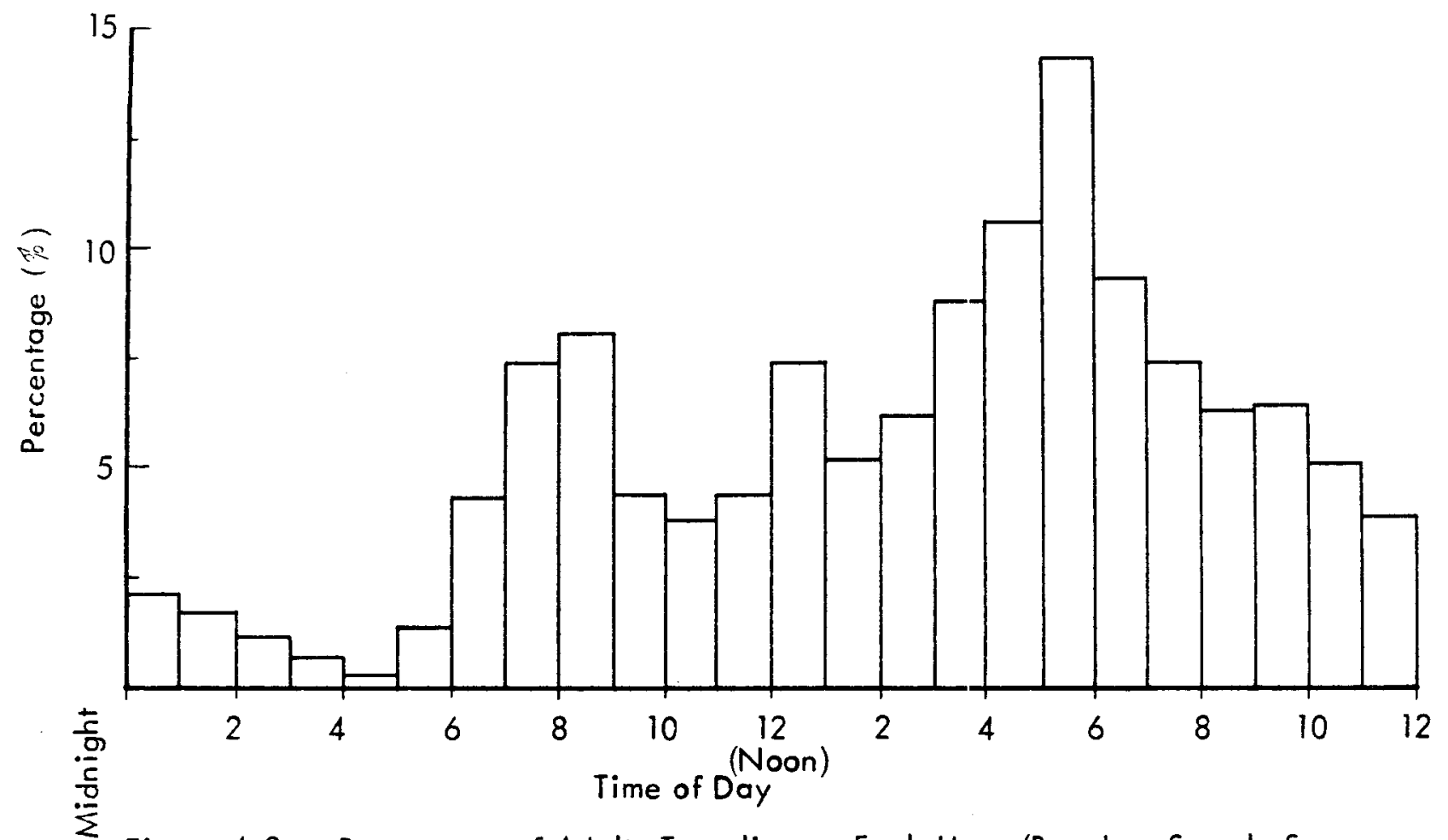

Figure 4-2a. Percentage of Adults Traveling on Each Hour (Based on Sample Survey of 1197 Adults in 44 U.S. Cities.) Pertains to All Forms of Traveling, i.e., Public Transport, Private Automobile, and Walking 21

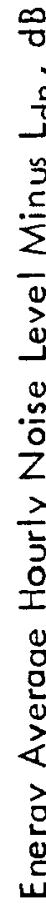

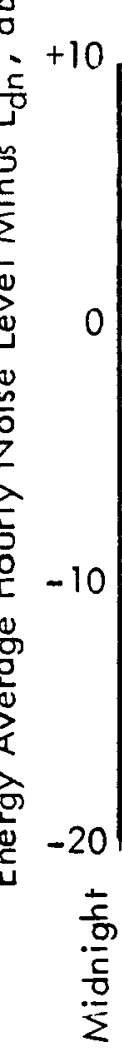

Figure 4-2b. Average Outdoor Hourly Noise Level Relative to Day-Night

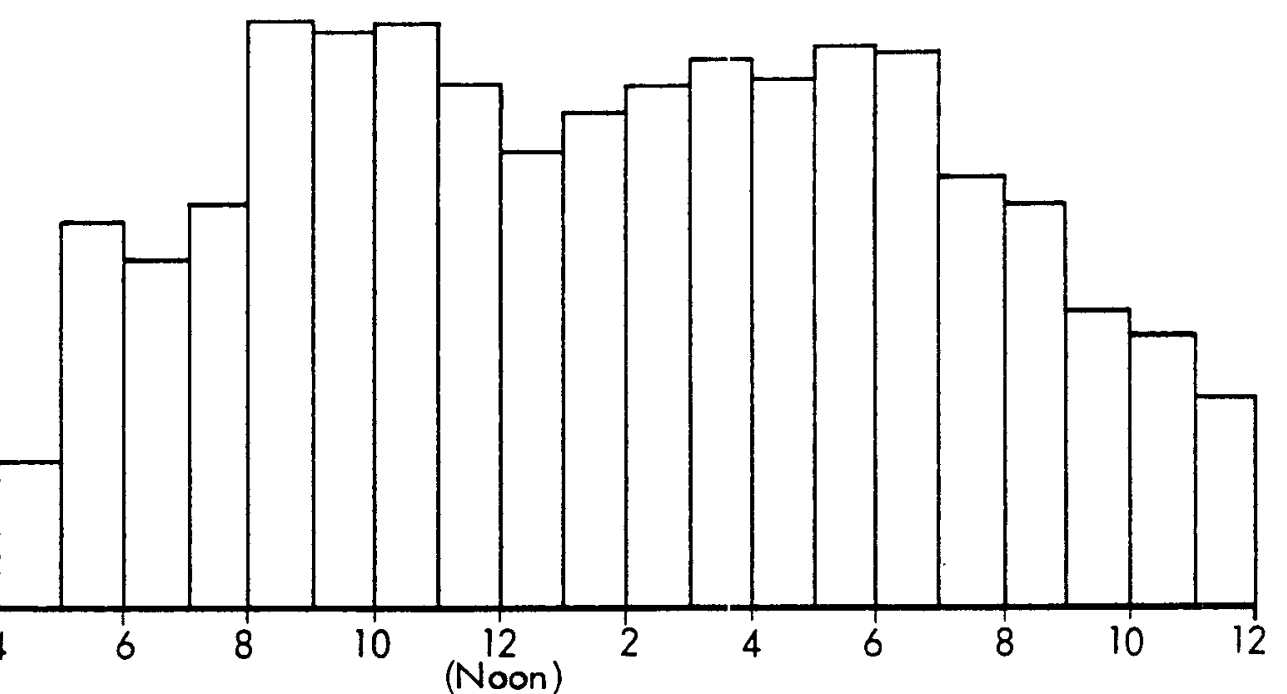

Time of Day Average Noise Level $\left(L_{d n}\right)$ for Three Residential Sites in Los Angeles 3 


\subsection{Parking Site Background Noise Levels}

Potential back-up accident sites exist wherever vehicles are present, where the background noise levels range from the quietest residential neighborhood to the noisiest downtown business district. Figure 4-3 illustrates the extreme range of noise levels experienced in various outdoor locations during the daytime period. 20 The levels shown are statistical levels which are exceeded the stated percentage of time. For most practical purposes $L_{90}$ is considered as the residual noise level, $L_{50}$ the median level, with $L_{10}$ and $L_{1}$ describing the approximate level of primary intrusive noises. The maximum noise levels will often exceed the $L_{1}$ value by 10 to $15 \mathrm{~dB}$.

\subsubsection{Typical Statistical Levels at Back-Up Accident Sites}

To provide a more definitive picture of the potential noise levels at accident sites, it is desirable to examine in detail, the extensive statistical data available on outdoor noise levels avoilable from previous community noise studies. These dato may be used to estimate the detailed statistical variation over space and time of outdoor noise levels. From this broad data base, and the limited sample of noise levels actually measured in parking areas for this program, it is possible to estimate a design ambient noise level for the back-up warning device - a level exceeded not more than 5 percent of the time in parking areas.

The cumulative probability distribution, over space (or sites) of the median (in time) $L_{50}$ levels observed in a wide range of outdoor locations in typical urban areas is shown in Figure 4-4. 3,22 These distributions based on studies covering about 2000 sites in the U.S. and over 11,200 sites outside the U.S., tend to fall into two groups. One group is for all of the sites studied except those in the largest cities New York City and London. The other group consists of the approximate distribution in these two very large cities. There ore, of course, exceptions, but the trend is quite evident and verifies that the design ambient noise level for back-up warning devices may be significantly higher for large, densely populated cities than for the 


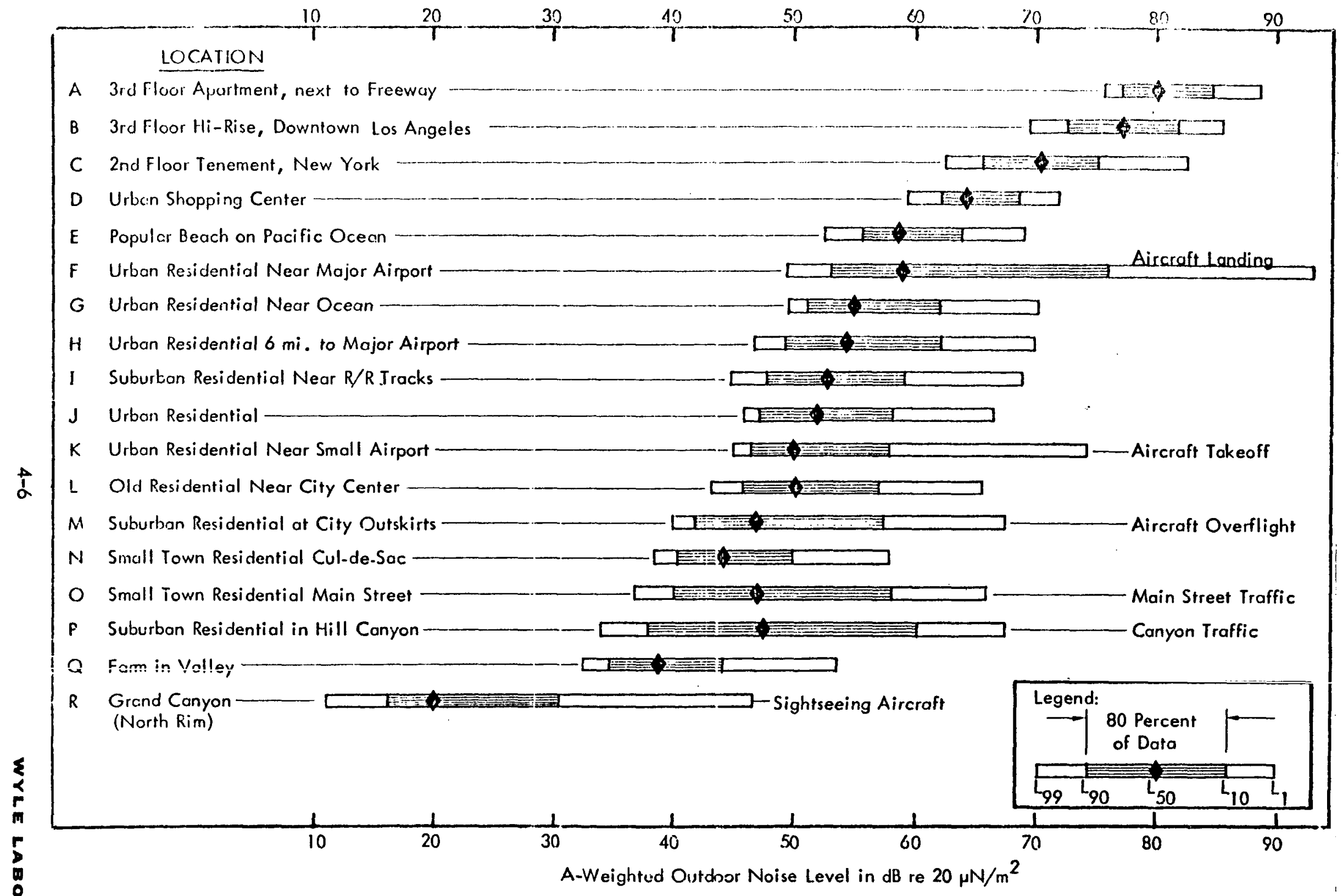

Figure 4-3. Daytime Outdoor Noise Levels Found in 18 Locations Ranging Between the Wilderness and the Downtown City, with Significant Intruding Sources Noted. Data are Aritlimetic Averages of the 12 Hourly Values in the Daytime Period (7:00 o.m. - 7:00 p.m.) of the Levels Which are Exceeded

S9, 90, 50, 10 and 1 Percent of the Time

(Reproduced from Ref. 20) 


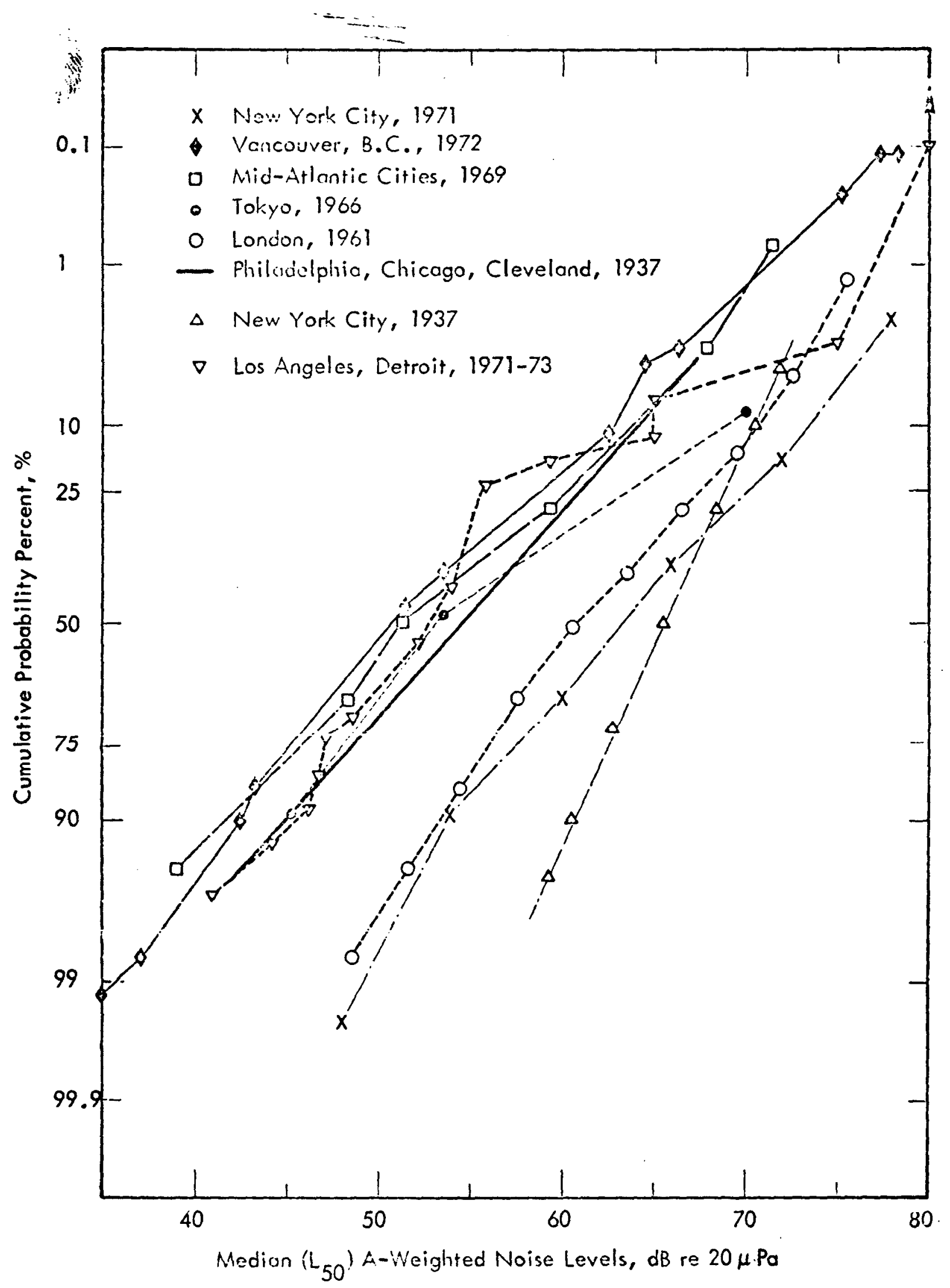

Figure 4-4. Comparison of Data on Probability Distribution of Median Outdoor (L50) Noise Levels Measured in Residential Areas in Daytime (Reproduced from Ref. 3) 
average medium density city. This range in design ambient level is, as, of course, anticipated by the automatic ambient-sensing feature required for the back-up warning device.

In order to estimate the range of noise characteristics of actual back-up accident sites, a group of eight sites (listed in Table 4-2) wert selected and noise data samples recorded. (Noise characteristics at sites where field tests of the warning system were conducted are contained in Section 7.0.) A microphone was mounted at a height of 6 feet, close to the rear of an automobile. Ten to 15 minute samples of noise were recorded and subsequently analyzed in the laboratory to compute noise descriptors and desaribe the intrusive noise events. Table 4-3 lists the results of this analysis and for comparison purposes a graph of the data in the same format as the community noise data shown in Figure 4-3 is shown in Figure 4-5. The sites examined obviously represent examples of noisier community locations. While the data is strictly only valid for a 10 to 15 minute measurement period during the noisy part of the day, the hour-to-hour variation at any one back-up accident site is expected to be substantially less than the variation between sites.

The cumulative distribution median $\left(L_{50}\right)$ noise levels for this sample of back-up accident sites is compared, in Figure $4-6$ to the distribution in $L_{50}$ levels in comparable urban areas shown earlier in Figure 4-4. A straight line for a cumulative distribution on this probability graph implies a normally distributed sample where the slope of the line is proportional to the standard deviation. This comparison indicates that the noise levels over all back-up accident sites (or at least parking lot sites) will tend to have a higher mean value than that for all types of outdoor locations in the typical low to medium density city ( $64 \mathrm{dBA}$ versus $52 \mathrm{dBA}$ respectively) The estimated distribution for the parking area noise levels has a somewhat steeper slope corresponding to a standard deviation of $7.2 \mathrm{~dB}$ as compared to a standard deviation of about $8 \mathrm{~dB}$ for noise levels in oll sutdoor sites in low to medium density cities. 
Table 4-2

Parking Sites for Acoustic Noise Measurements (Greater Los Angeles Area)

\begin{tabular}{|c|c|c|c|}
\hline $\begin{array}{c}\text { Site } \\
\text { Number }\end{array}$ & Type of Site & $\begin{array}{l}\text { Time } \\
\text { of Doy }\end{array}$ & Location \\
\hline 1 & $\begin{array}{l}\text { Residential } \\
\text { Off Street Area }\end{array}$ & 1230 & $\begin{array}{l}\text { Carl's Jr. Parking Lot, Brookhurst \& } \\
\text { Warner, Fountain Valley (Restaurant) }\end{array}$ \\
\hline 2 & $\begin{array}{l}\text { Commercial } \\
\text { Off Street Area }\end{array}$ & 1315 & $\begin{array}{l}\text { Sears Parking Lot, Westminster Mall, } \\
\text { San Diego Freeway \& Golden West, } \\
\text { Westminster }\end{array}$ \\
\hline 3 & $\begin{array}{l}\text { Commercial } \\
\text { Mid-Block }\end{array}$ & 1545 & $\begin{array}{l}\text { Downtown Los Angeles, Broadwoy } \\
\text { between 4th and 5th Streets }\end{array}$ \\
\hline 4 & $\begin{array}{l}\text { Commercial } \\
\text { Mid-Block }\end{array}$ & 1640 & $\begin{array}{l}\text { Downtown Hollywood, Hollywood } \\
\text { Boulevard, West of Ivar }\end{array}$ \\
\hline 5 & $\begin{array}{l}\text { Commercial } \\
\text { Off Street Area }\end{array}$ & 1710 & $\begin{array}{l}\text { Universal Studios Tour Parking Lot, } \\
\text { Universal City }\end{array}$ \\
\hline 6 & $\begin{array}{l}\text { Commercial } \\
\text { Mid-Block }\end{array}$ & 1025 & $\begin{array}{l}\text { Los Angeles International Airport, } \\
\text { Baggage Check-in Area, Los Angeles }\end{array}$ \\
\hline 7 & $\begin{array}{l}\text { Commercial } \\
\text { Off Street Area }\end{array}$ & 1045 & $\begin{array}{l}\text { Los Angeles International Airport Tower } \\
\text { Parking Lot }\end{array}$ \\
\hline 8 & $\begin{array}{l}\text { Commercial } \\
\text { Off Street Area }\end{array}$ & 1130 & $\begin{array}{l}\text { May Company Parking Lot, South Bay } \\
\text { Center, Artesia \& Hawthorne Blvds., } \\
\text { Redondo Beach }\end{array}$ \\
\hline
\end{tabular}


Table 4-3

Summary of the Statistical Levels Measured at the Parking Sites Listed in Table 4-2

\begin{tabular}{|c|c|c|c|c|c|c|c|}
\hline Site & $L_{\text {eq }}(1)$ & $L_{90}$ & $L_{50}$ & $L_{10}$ & $L_{1}$ & $L_{.1}$ & $\sigma(2)$ \\
\hline 1 & 62.5 & 56.5 & 59.0 & 63.9 & 72.1 & 78.1 & 4.42 \\
2 & 61.2 & 57.7 & 59.6 & 62.9 & 67.4 & 72.0 & 4.72 \\
3 & 74.7 & 67.7 & 71.2 & 77.1 & 82.5 & 88.3 & 4.82 \\
4 & 76.0 & 65.3 & 70.6 & 76.4 & 86.9 & 96.2 & 3.87 \\
5 & 58.1 & 55.3 & 56.5 & 59.7 & 64.6 & 67.6 & 4.72 \\
6 & 72.8 & 65.7 & 70.2 & 75.3 & 80.8 & 84.3 & 3.83 \\
7 & 66.4 & 62.4 & 64.5 & 68.7 & 72.9 & 75.4 & 4.49 \\
8 & 58.8 & 55.1 & 56.7 & 60.6 & 65.7 & 70.7 & 4.62 \\
\hline Average & 66.3 & 60.7 & 63.5 & 68.1 & 74.1 & 79.1 & 4.44 \\
\hline
\end{tabular}

(1) Energy-average noise level during 10 to 15 minute sample period.

${ }^{(2)}$ Standard deviation of noise level during sample period. 


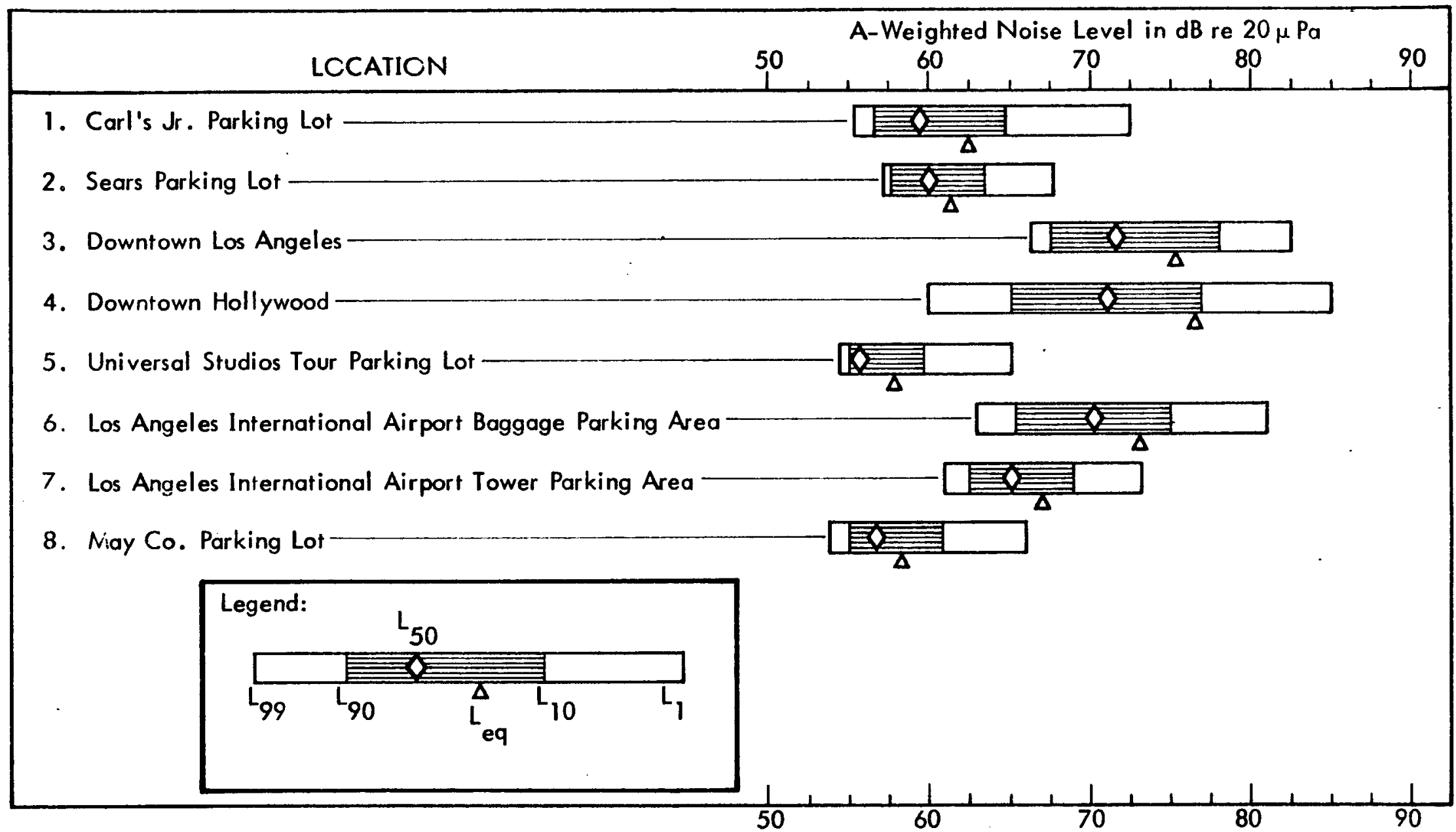

Figure 4-5. Daytime Sample of the Cutdoor Noise Level at Eight Parking Locations (for comparative data, see Figure 4-3) 


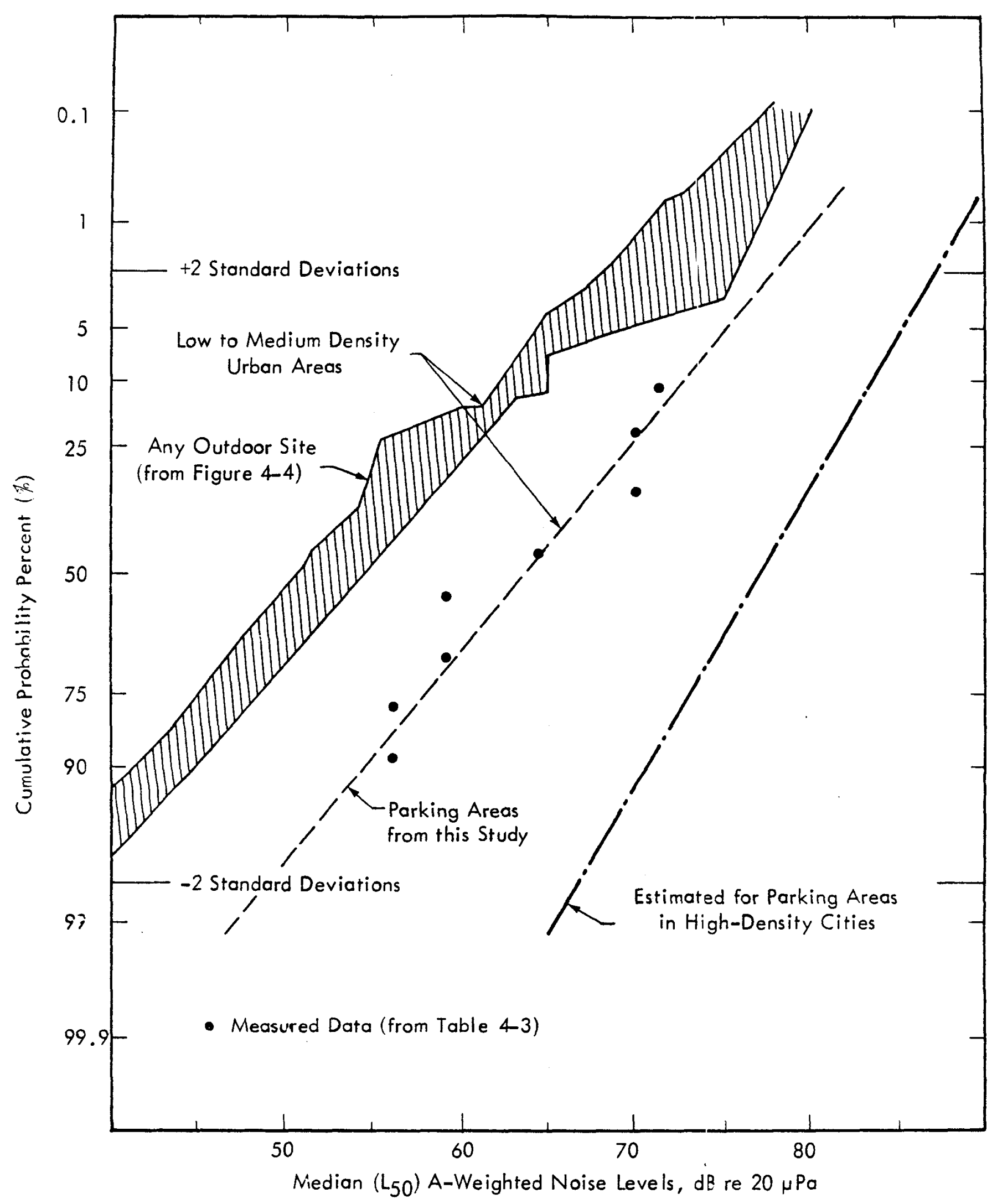

Figure 4-6. Comparison of Median (L50) Noise Levels at Back-up Accident Sites to Urban Areas 
Figure 4-6 also shows an estimate of the distribution of $L_{50}$ noise levels in parking areas in large, densely populated cities, such as New York. For this latter estimate, it was assumed that the mean (over sites) $L_{50}$ (median in time) level for parking areas was also $12 \mathrm{~dB}$ higher (i.e., 64 to $52 \mathrm{dBA}$ ) than the mean noise level for all outdoor sites in large, densely populated areas. Based on the data in Figure 4-4, this indicated that the mean $L_{50}$ level for parking areas in such cities would be about $65+12=77 \mathrm{dBA}$. The standard deviation for this estimated distribution was also assumed to be slightly less by the ratio $(7.2 / 8.0)$ than for all sites in densely populated areas. The resulting estimate of the standard deviation was $5 \mathrm{~dB}$ for the parking areas as compared to an estimated standard deviation of $5.6 \mathrm{~dB}$ for all sites.

Table 4-4

Estimated Distribution of Median $\left(L_{50}\right)$ Levels in Parking Areas in Typical Medium Density Cities and in Large High Density Cities

\begin{tabular}{|c|c|c|c|c|c|}
\hline \multirow{2}{*}{ City Type } & \multicolumn{5}{|c|}{ L50 Level in Parking Areas, dBA Exceeded at: } \\
\cline { 2 - 6 } & $\begin{array}{c}95 \text { Percent } \\
\text { of Sites }\end{array}$ & $\begin{array}{c}80 \text { Percent } \\
\text { of Sites }\end{array}$ & $\begin{array}{c}50 \text { Percent } \\
\text { of Sites }\end{array}$ & $\begin{array}{c}20 \text { Percent } \\
\text { of Sites }\end{array}$ & $\begin{array}{c}5 \text { Percent } \\
\text { of Sites }\end{array}$ \\
\hline $\begin{array}{l}\text { Low-Medium } \\
\text { Density (1) }\end{array}$ & 52 & 58 & 64 & 70 & 76 \\
\hline High Density (2) & 68.5 & 72.5 & 77 & 81 & 85 \\
\hline $\begin{array}{l}\text { (1) Like Denver, Los Angeles. } \\
\text { (2) Like New York City. }\end{array}$
\end{tabular}

Table 4-4 summarizes these estimates of the distribution of the median $L_{50}$ daytime levels in parking areas in typical medium-density and large, very dense cities. It will be assumed, for conservatism, that back-up accident sites in purely residential areas have a distribution of noise levels comparable to those estimated for commercial parking areas. 
Now having established estimates of the distribution of $L_{50}$ noise levels over accident sites, it remains to establish the estimated variation over time at these sites in order to determine the "5 percent of the time" design level.

From previous analyses of the statistics of time variation in outdoor noise levels, the following empirical model has been established. 3,23

In contrast to the usual assumption of a normal distribution for time variation in outdoor noise levels, it was found, as illustrated in Figure 4.-7 that a Rayleigh distribution provides a better, albeit empirical, fit to the distribution over time of outdoor noise levels. The solid data points shown in Figure 4-7 are from three separate studies of outdoor noise involving continuous noise measurement, over 24 hours and encompassing 116 sites in urban areas. The open symbols represent the average of the data measured at the eight parking sites (see Table 4-3). The latter generally fall reasonably close, and on the conservative side of the "empirical" Rayleigh distribution curve so that the latter is used for design. Note that in Figure 4-7, these cumulative distributions are piotted in normalized form; i.e., the statistical level at $X$ percent $\left(L_{x}\right)-\left(L_{50}\right)$ is normalized by the standard deviation $(\sigma)$ of the time distribution. The theoretical form for this distribution is given by: 3

$$
\frac{L_{x}-L_{50}}{\sigma}=\left\{\left[\operatorname{Ln} e^{(100 / x)}\right]^{\frac{1}{2}}-\left[\operatorname{Ln}_{e}(2)\right]^{\frac{1}{2}}\right\} /[1-\pi / 4]^{\frac{1}{\varepsilon}}
$$

From additional analysis of the data cited in Figure 4-4, it has been found possible to roughly estimate the standard deviation (over time) $(\sigma)$ of the daytime outdoor levels by the empirical expression:

$$
\sigma=\left\{\begin{array}{rrr}
12.9-0.141 L_{50} d B & L_{50}>49 \mathrm{dBA} \\
6 & , d B & L_{50} \leq 49 \mathrm{dBA}
\end{array}\right.
$$




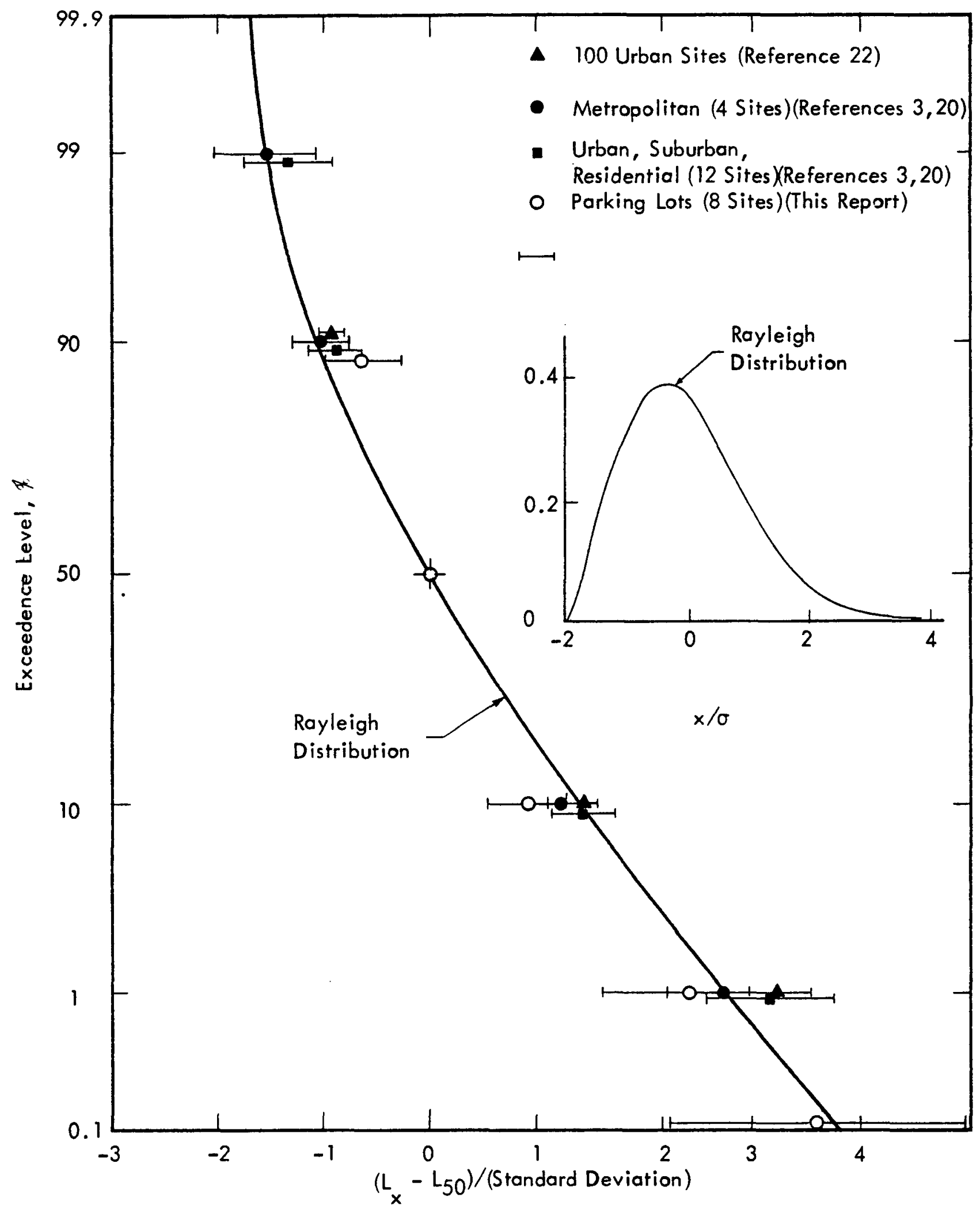

Figure 4-7. Average Normalized Statistical Levels Over 15 Hour Daytime Period (0700-2200) at 16 Residential Sites (Airport Sites Excluded) 
With these expressions, and the values of median levels $\left(L_{50}\right)$ specified earlier in Table 4-3, it is now possible to provide estimates of the $L_{5}$ design level - the noise level not exceeded more than 5 percent of the time - at any of the sites. The results of this evaluation are presented in the following table:

Table 4-5

Estimated $\left(L_{5}\right)$ A-Weighted Noise Levels Not Exceeded More Than 5 Percent of the Time in Back-Up Accident Sites

\begin{tabular}{|c|c|c|c|c|c|}
\hline \multirow{2}{*}{ City Type } & \multicolumn{5}{|c|}{ L5 Level, dBA Exceeded at } \\
\cline { 2 - 6 } & $\begin{array}{c}\text { 95 Percent } \\
\text { of Sites }\end{array}$ & $\begin{array}{c}80 \text { Percent } \\
\text { of Sites }\end{array}$ & $\begin{array}{c}50 \text { Percent } \\
\text { of Sites }\end{array}$ & $\begin{array}{c}\text { 20 Percent } \\
\text { of Sites }\end{array}$ & $\begin{array}{c}5 \text { Percent } \\
\text { of Sites }\end{array}$ \\
\hline $\begin{array}{l}\text { Low-Medium } \\
\text { Density }\end{array}$ & 63 & 67 & 72 & 76 & 80 \\
\hline High Density & 75 & 78 & 81 & 84 & 87 \\
\hline
\end{tabular}

According to the values in Table 4-5, the $L_{5}$ design ambient level for the back-up warning device will vary from the quietest conditions of $63 \mathrm{dBA}$ (arbitrarily taken as the level exceeded 5 percent of the time at 95 percent of the sites in low to medium density cities) to the noisiest conditions of $87 \mathrm{dBA}$ (taken as the level exceeded 5 percent of the time at only 5 percent of the sites in high-density cities). This range in the design ambient level of 63 to $87 \mathrm{dBA}$ should be accommodated by the variable output feature to be built into the back-up warning device. Later, it will be shown that when the self-noise of the bocking automobile is taken into account, this dynamic operating range is not really altered.

\subsubsection{Typical Noise Spectra in Back-up Hazard Areas}

Characterization of the noise at each location must also include spectrum analyses of the noise to define its frequency content. In terms of the parameters most important for the warning signal system, the spectrum should be averaged over a relatively short period of time. This is consistent with the way the ear perceives a warning 
signal which must effectively penetrate the background ambient. The data recorded at three parking locations were analyzed with a B\&K 3347 Real Time Analyzer (RTA) to obtain plots of the one-third octave band spectrum levels. Figures 4-8, 4-9, and 4-10 illustrate the variations in these one-third octave band noise levels at the three locations. Spectrum analysis samples are shown for periods close to the minimum level and also for typical periods when intrusive events occur producing the moximum levels. These samples were obtained using the "fast random " time constant of the RTA, an averaging time which very roughly corresponds to the averaging time of the ear (see Section 5.0).

Just as was done for the A-weighted noise levels, it is desirable to augment this limited sample of spectral content of outdoor noise levels from previous community noise studies. By normalizing all of the spectral plots in the three previous figures to their respective A-weighted noise levels, the average relative one-third octove band level spectra shown in Figure $4-11$ is obtained. This average is indicated by the solid line drawn through the mean of the normalized measured data. Note that the relative spectra are very nearly the same for both residual and intrusive events for the frequency range of interest for the back-up warning device.

The dashed line represents the average (over surveys), median (in time) $1 / 3$ octave band levels during daytime hours from several extensive outdoor noise surveys conducted in the past. These data, taken from the summary in Reference 3, are also normalized in the same way to the A-weighted level and show very nearly the same average spectra. Since they are conservative for frequencies below $000 \mathrm{~Hz}$, are realistic above $1000 \mathrm{~Hz}$, and are based on a much broader data base than was attempted in this study, the dashed line in Figure 4-11 will be used to define the spectral content for the design ambient levels. Note, however, that without the benefit of the limited sample of spectral data recorded at actual parking areas in this study, it would not have been possible to be certain of the utility of the earlier data. By simply adding the relative one-third octave band levels from the 


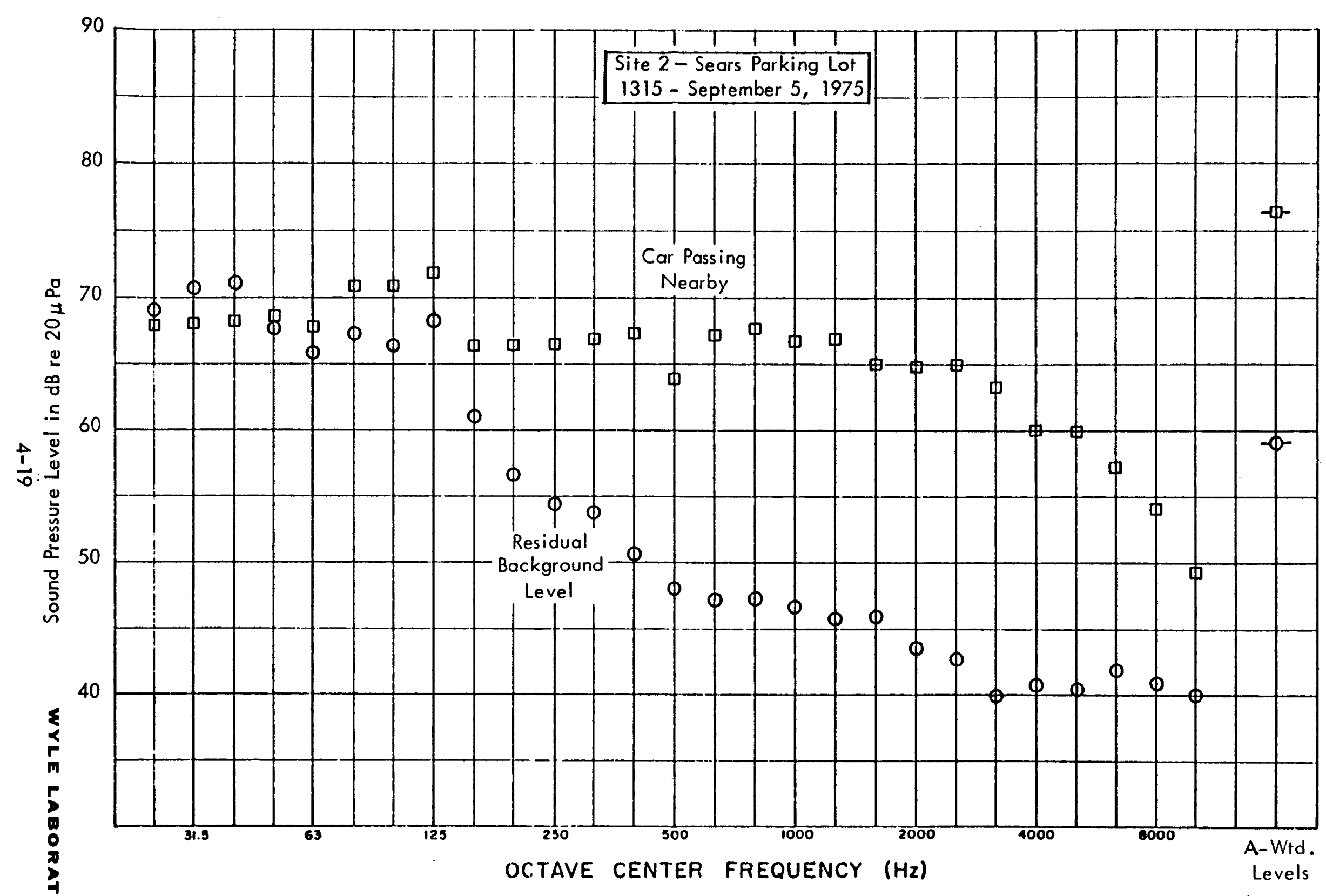

Figure 4-9. Typical Spectra of the Ambient Noise Level at Site 2 


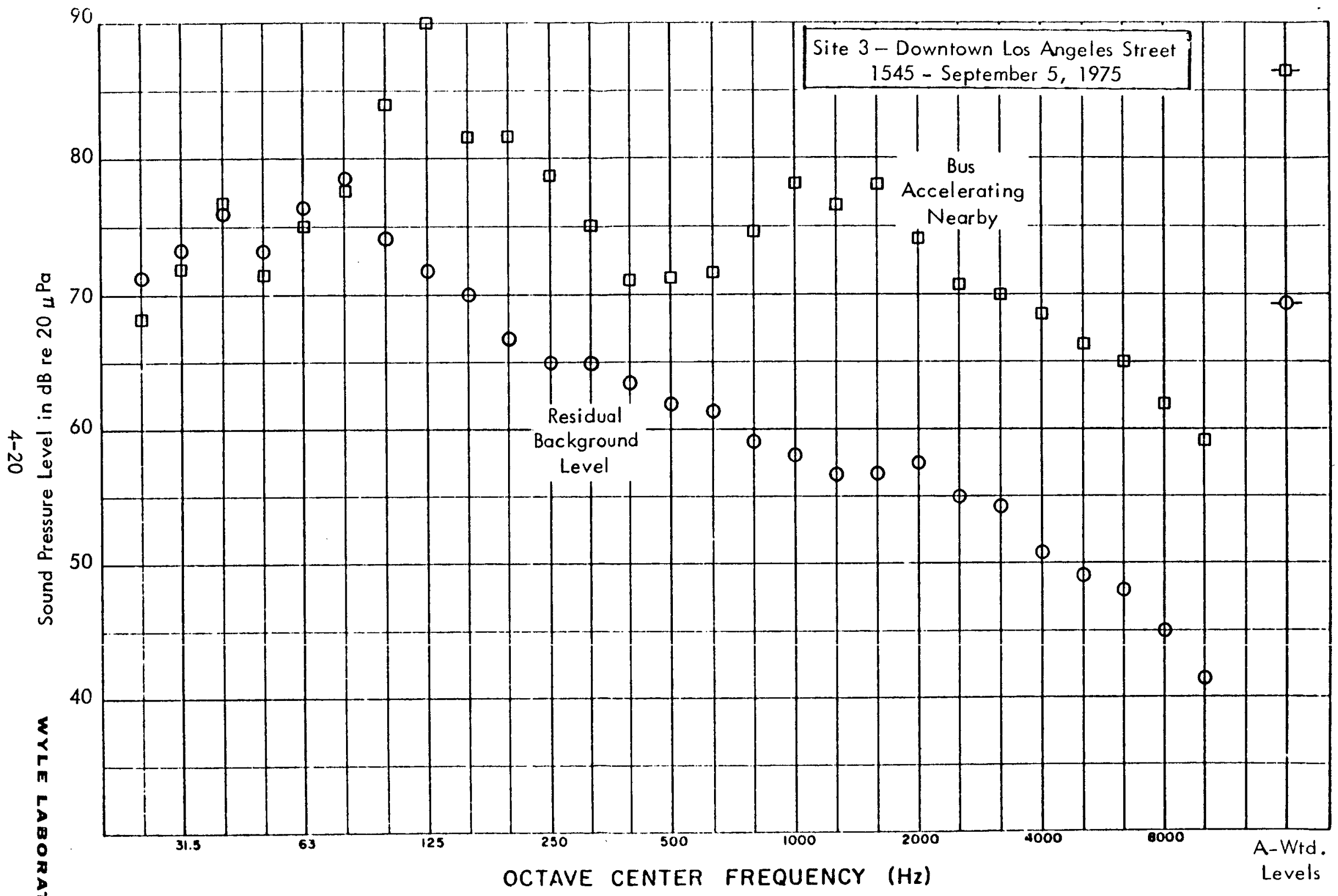

Figure 4-10. Typical Spectra of the Ambient Noise Level at Site 3 


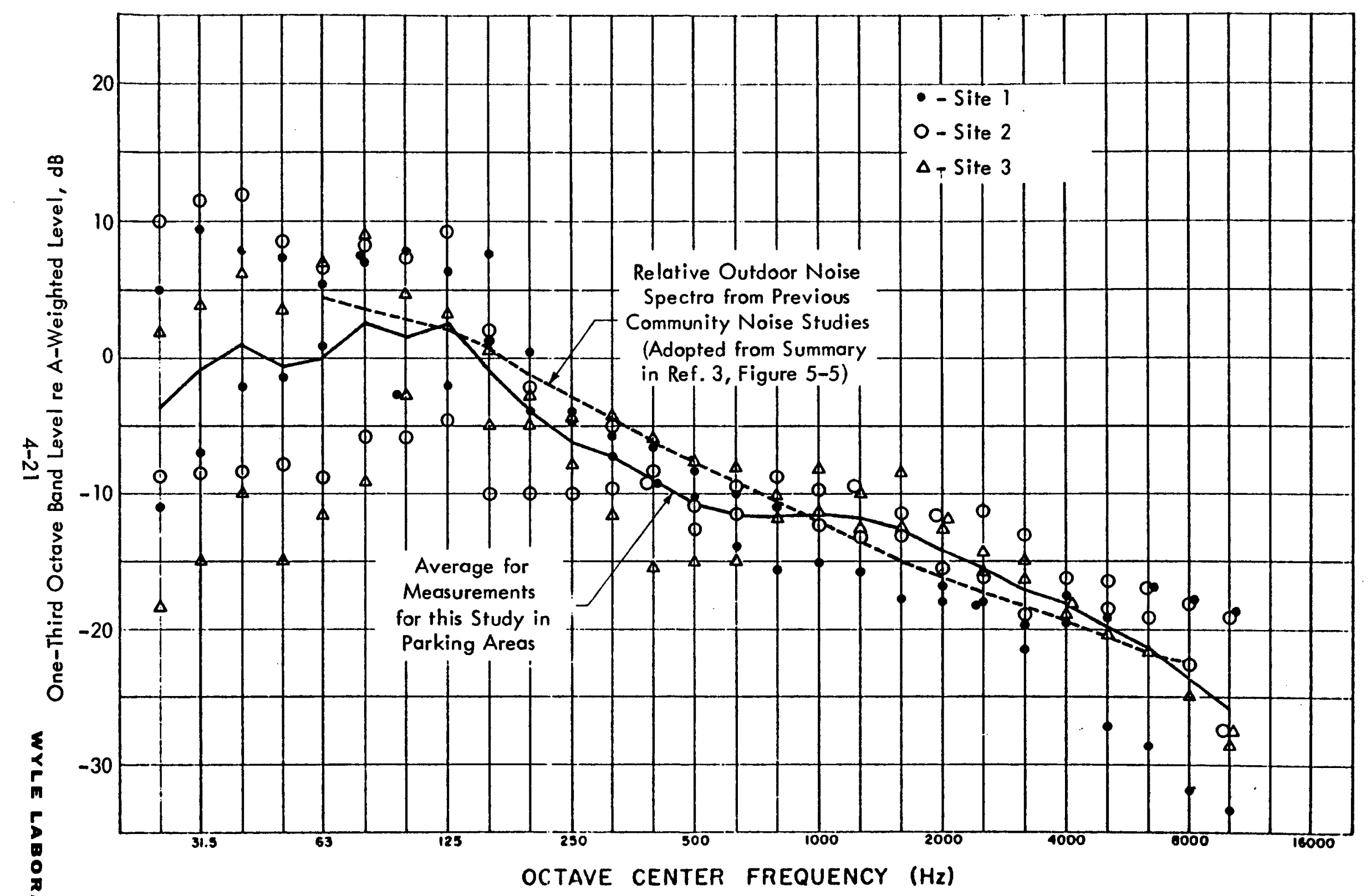

Figure 4-11. Relative One-Third Octave Band Spectra at Outdoor Sites 
dashed line in this figure to the design values for $L_{5}$ specified earlier in Table 4-5, one can obtain the desired one-third octave band spectra for any of the sites defined by this table.

Table 4-6 lists the relative one-third octave band correction factors which will be utilized to help define audible signal characteristics of the warning device.

\section{Table 4,-6}

Relative One-Third Octove Band Spectra to be Applied to $L_{5}$ Levels in Table 4-5 to Define Ambient Spectrum

\begin{tabular}{|l|r|r|r|r|r|r|r|r|}
\hline Frequency, $\mathrm{Hz}$ & 63 & 80 & 100 & 125 & 160 & 200 & 250 & 315 \\
\hline $\begin{array}{l}\text { Relative One- } \\
\text { Third Octave } \\
\text { Band Level, dB }\end{array}$ & 4.5 & 3.5 & 3 & 2 & 1 & -1 & -2.5 & -4.5 \\
\hline Frequency, Hz & 400 & 500 & 630 & 800 & 1000 & 1250 & 1,600 & 2000 \\
\hline $\begin{array}{l}\text { Relative One- } \\
\text { Third Octave } \\
\text { Band Level, dB }\end{array}$ & -6.5 & -7.5 & -9 & -10.5 & -12 & -13.5 & -15 & -16 \\
\hline Frequency, $\mathrm{Hz}$ & 2500 & 3150 & 4000 & 5000 & 6300 & 8000 & 10,000 & \\
\hline $\begin{array}{l}\text { Relative One- } \\
\text { Third Octave } \\
\text { Band Level, dB }\end{array}$ & -17 & -18.5 & -19.5 & -20.5 & -22 & -23.5 & -25 & \\
\hline
\end{tabular}

To illustrate the variable nature of the noise level at a potential accident site, Figure 4-12 shows a time history of the noise level in a noisy business district. In this figure all major intrusive events are identified and listed. This recording was obtained with the car parked at the curb and the microphone biehind it at a 6 foot height.

\subsection{Self Noise of the Automobile}

So far we have considered only the ambient noise exclusive of the backing vehicle. Consider now the noise source which will control the minimum ambient level in the area of the automobile, the automobile itself. This will negate the need 


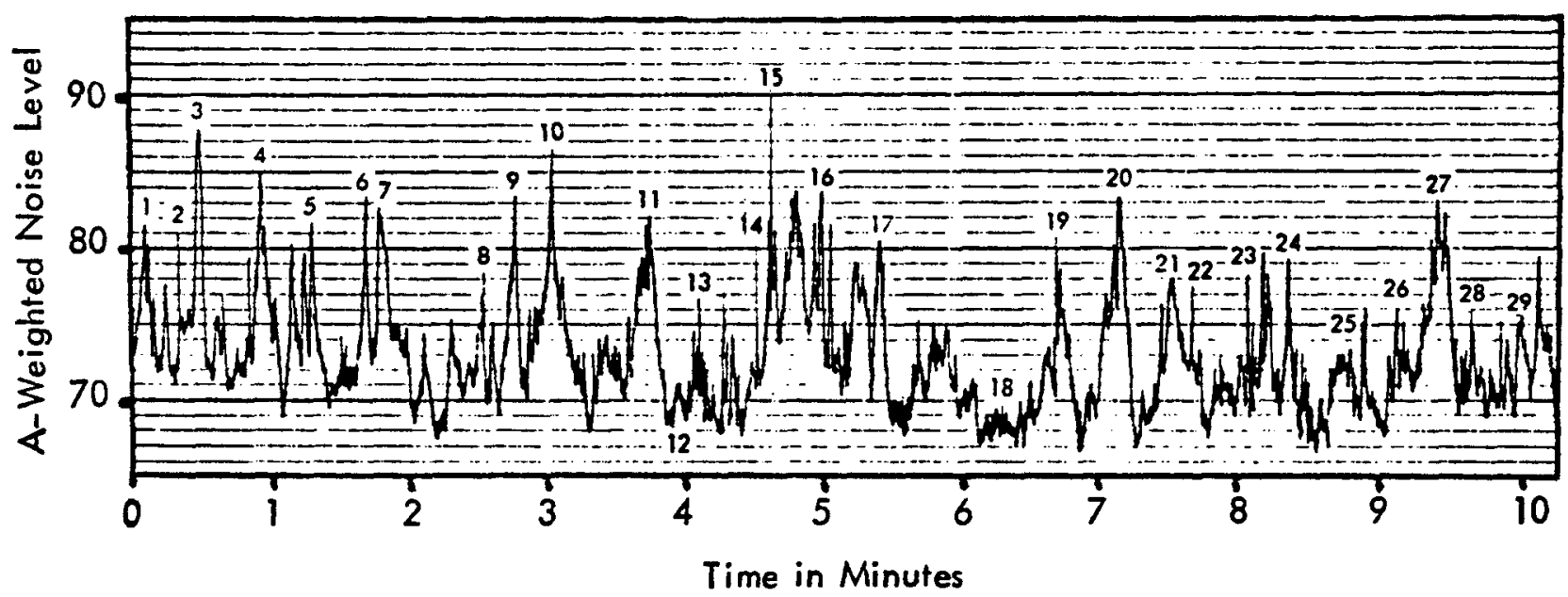

$\begin{array}{rlll}1 & \text { Bus Passing } & 16 & \text { Vehicles Passing-Several } \\ 2 & \text { Horn } & 17 & \text { Motorcycle Passing - Slowly } \\ 3 & \text { Bus Pulling Away } & 18 & \text { Ambient - No Vehicles Passirg } \\ 4 & \text { Truck Possing } & 19 & \text { Cor Passing } \\ 5 & \text { Bus Passing } & 20 & \text { Bus Passing } \\ 6 & \text { Cor Possing } & 21 & \text { Car Passing } \\ 7 & \text { Bus Pulling Away } & 22 & \text { Children Yelling } \\ 8 & \text { Voice-Yelling } & 23 & \text { Children Yelling } \\ 9 & \text { Bus Passing } & 24 & \text { Truck Possing } \\ 10 & \text { Truck Passing } & 25 & \text { Car Starting-up Nearby } \\ 11 & \text { Truck Possing } & 26 & \text { Car (VW) Passing } \\ 12 & \text { Voices on Sidewalk } & 27 & \text { Bus Pessing } \\ 13 & \text { Cor Passing } & 28 & \text { Children's Voices } \\ 14 & \text { Horn } & 29 & \text { Bus Pulling Away in Distance } \\ 15 & \text { Tire Screech-Braking } & & \end{array}$

Figure 4-12. Time History of the Noise Level at Location 3-Downtown Los Angeles. Intrusive events are identified by numbers 
for a detailed examination of the quietest potential accident sites since the warning signal may be held constant at some minimum ambient noise level.

The noise originates from the engine and the exhaust pipe and in very quiet areas, it is the dominant noise source. In extremely quiet areas the automobile's noise will likely provide an adequate audible warning for nearby pedestrians, but as the ambient level increases, the automobile noise ceases to be a distinct identifiable noise source. At this point an audible warning signal is necessary.

Measurements were made at the rear of seven different automobiles which would be representative of later model cars and the noise they produce. The microphone was placed above the bumper near the car at a point where the final warning system might be mounted. Recordings were made while each car was started and the engine was run-up and idled. Figure 4-13 shows time histories of the A-weighted noise level during each of these starting sequences and Table 4-7 lists the average noise level for the different conditions. The minimum noise level measured during the time any of the cars were running was $62 \mathrm{dBA}$. The average level for both the starting noise and engine idling noise is $67 \mathrm{dBA}$, indicating a possible limiting noise threshold for the system microphone to be around $65 \mathrm{dBA}$.

As an illustration of the acoustic noise spectrum present at the rear of an automobile while it is running, Figure 4,-14 shows data typical of the automobiles investigated. The one-third octave band spectra shown here represent samples taken before the automobile was started (ambient), while the starter was turning, and while the engine was idling. Level fluctuations below $100 \mathrm{~Hz}$ are primarily due to ambient variations but at higher frequencies the one-third octave band levels and consequently the A-weighted levels, are controlled by the automobile noise. For comparison, the statistical ambient noise levels and relative spectra of Tables 45 and 4-6, respectively 


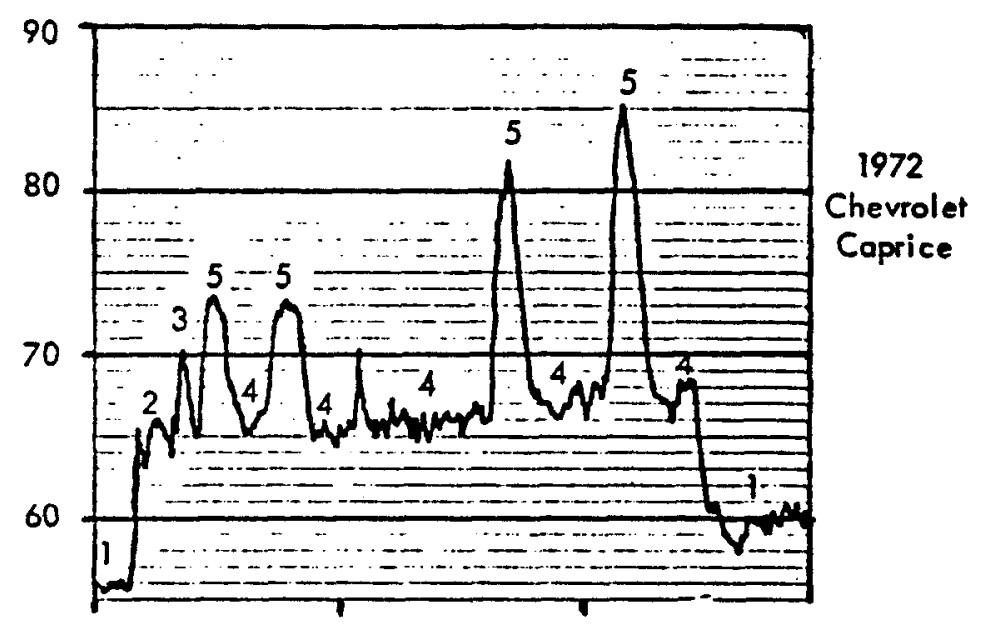

\begin{tabular}{|ll|}
\hline (1) & Ambient Background Level \\
(2) & Starter Noise \\
(3) & Engine Starting \\
(4) & Engine Idling \\
(5) & Engine Run-Up \\
\hline
\end{tabular}
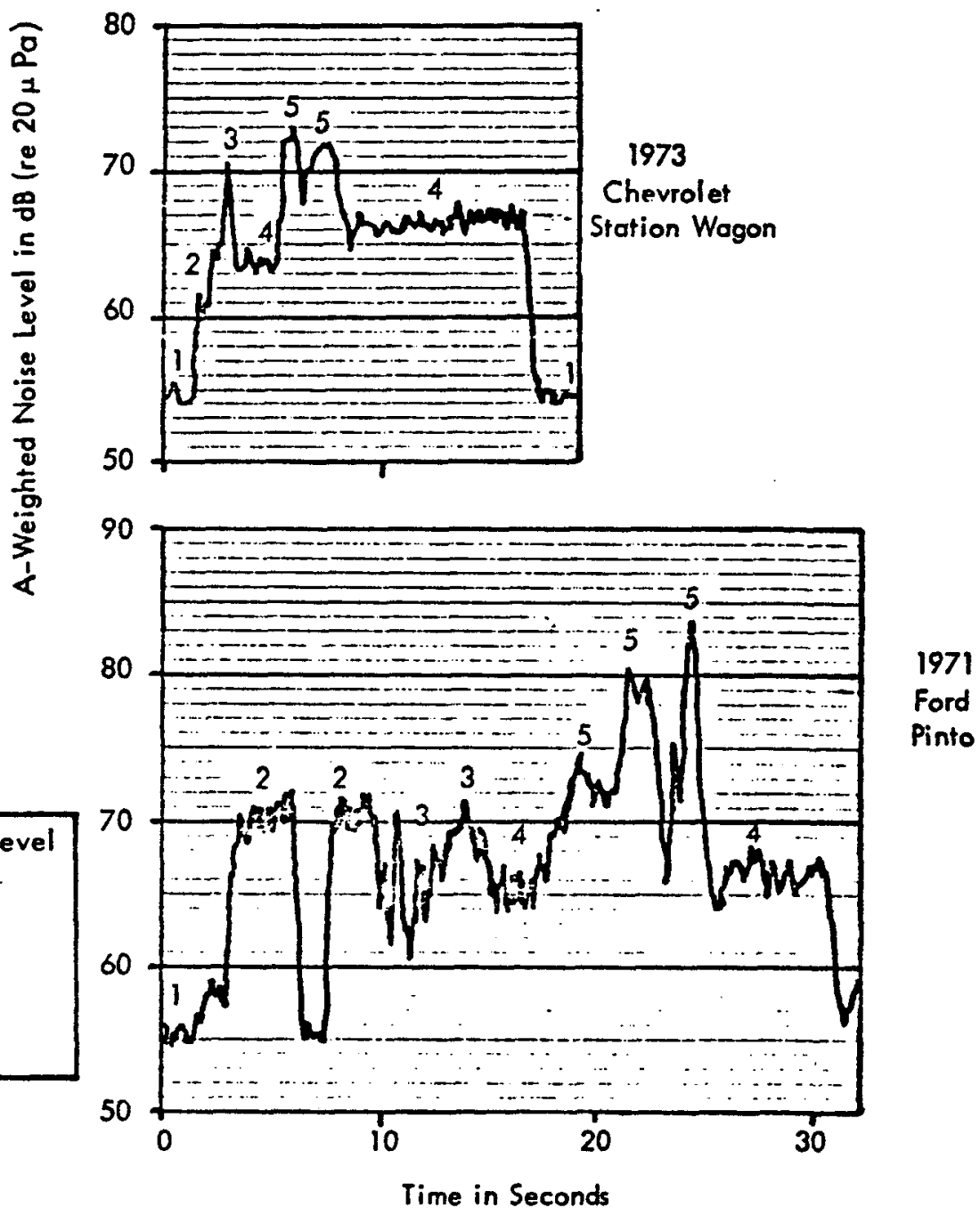

Figure 4-13a. Comparison of Starting and Running Noise Measured at the Rear of Typical Automobiles 


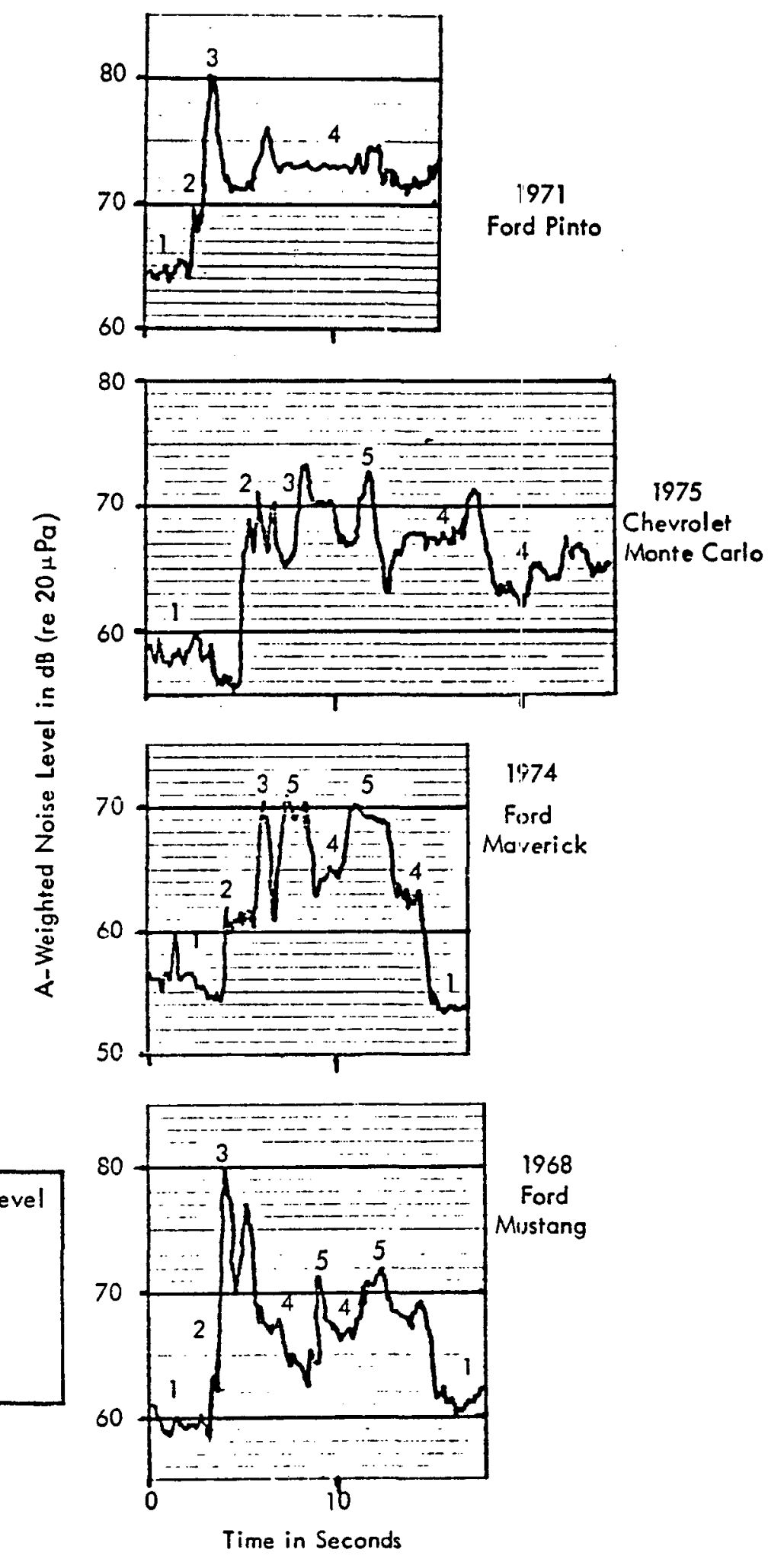

Figure 4-13b. Comparison of Starting and Running Noise Measured at the Rear of Typical Automobiles 


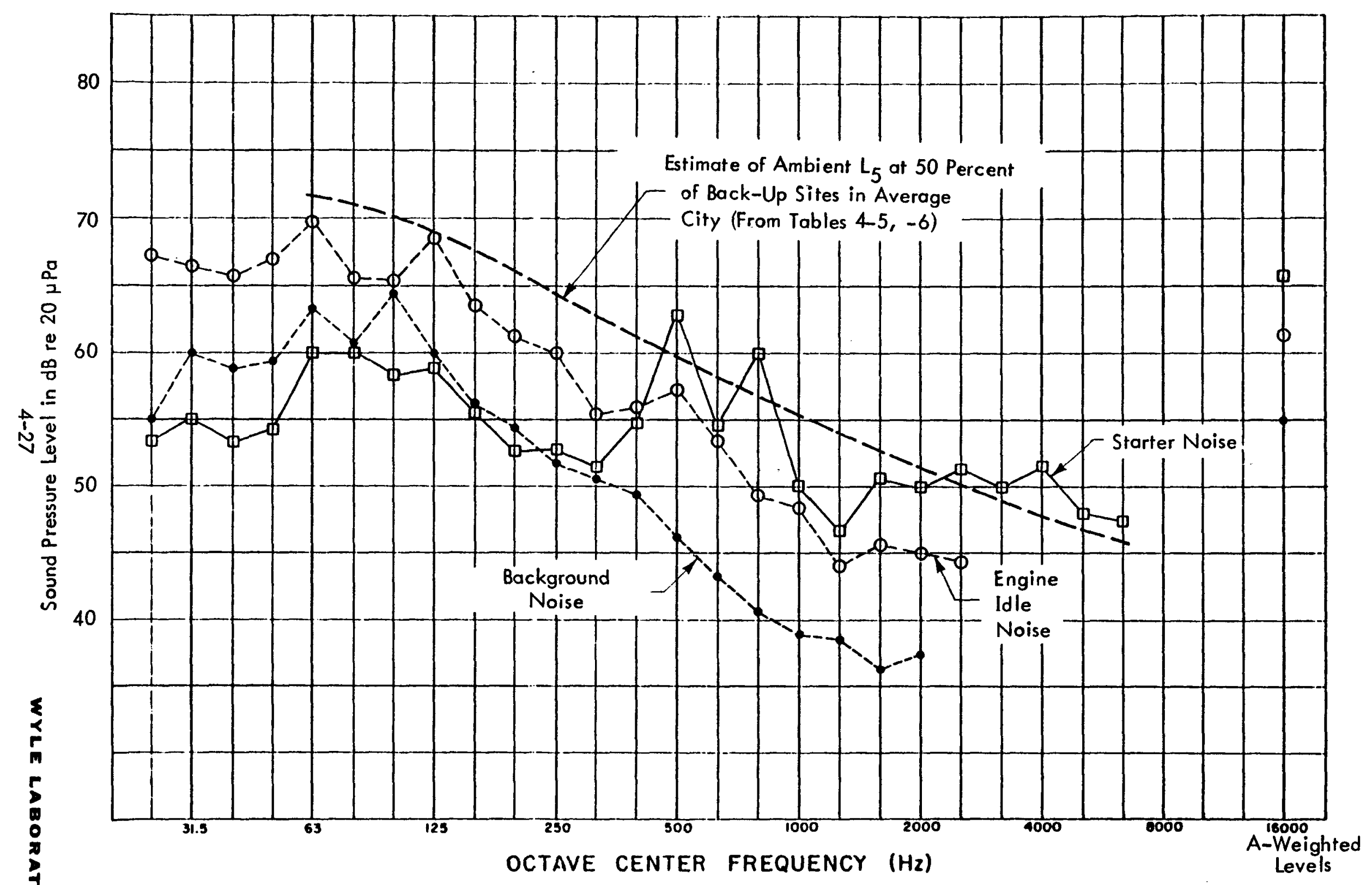

Figure 4-14. Starting Noise Spectro Measured at the Rear of a 1975 Chevrolet Monte Carlo Compared to Estimates of Ambient Noise Exceeded 5 Percent of Time $\left(L_{5}\right)$ at 50 Percent of Back-Up Sites in Average (Low-Medium Density) Cities 
Table 4- 7

Summary of Starting and Running Noise Measured at the Rear of Typical Automobiles." Values shown are average maximum levels from Figure $4-13$

\begin{tabular}{|c|c|c|c|c|}
\hline \multirow[b]{2}{*}{ Automobile } & \multicolumn{4}{|c|}{ A-Weighted Noise Level (dBA) } \\
\hline & Ambient & Starting Noise & $\begin{array}{c}\text { Engine Idle } \\
\text { Noise }\end{array}$ & $\begin{array}{l}\text { Engine } \\
\text { Run-Up }\end{array}$ \\
\hline 72 Chevrolet & 56 & 71 & 66 & 83 \\
\hline 73 Chev. Wagon & 55 & 62 & 64 & 73 \\
\hline 71 Pinto & 56 & 72 & 6.6 & 82 \\
\hline 71 Pinto & 65 & 70 & 73 & 80 \\
\hline $\begin{array}{l}75 \text { Chevrolet } \\
\text { Monte Carlo }\end{array}$ & 58 & 70 & 6,7 & 75 \\
\hline 74 Maverick & 57 & 62 & 6,8 & 71 \\
\hline 68 Mustang & 60 & 63 & 68 & 80 \\
\hline Average & 58 & 67 & 67 & 78 \\
\hline
\end{tabular}

* Measured above rear bumper near anticipated location of audible warning device.

have been used to construct the estimated ambient $L_{5}$ level (exceeded 5 percent of the time) at 50 percent of the backing sites in the average (low to medium density) city. This estimate shown in Figure 4-14 by the upper dashed line, indicates that only the starter noise would tend to exceed this $L_{5}$ ambient noise level. More significant, however, is that with the rare exception of the manual transmission outomobile started with the car in reverse (and the clutch in), the starting action will usually have stopped before the average driver engages the car in reverse - usually while the car is idling.

According to the limited self-noise data in Table 4-7 and Figure 4-13, engine idle noise levels will have an average value of about $67 \mathrm{dBA}$ and an estimated standard 
deviation over all cars of about $4 \mathrm{~dB}$. From this estimated distribution of engine starting noise and the data on statistical variation of ambient noise levels given earlier, it was possible to construct the three-way distribution profile shown in Figure 4-15 of the ambient noise distributed over sites and over time and the idling self-noise distributed over automobiles.

Based on these data, the dynamic range for the bockground noise (site ambient noise or automobile idling noise) which the warning system will monitor and adjust the signal level to, can now be confirried.

The minimum A-weighted bockground noise level is again selected as $63 \mathrm{~dB}$ based on the estimated idling self-noise level of $63.5 \mathrm{~dB}$ exceeded by 80 percent of the automobiles. This level is consistent with the earlier choice based on the fact that only 5 percent of the sites are expected to have an $L_{5}$ level lower than this. The maximum background noise level for the average low-medium density city can be taken as $80 \mathrm{~dB}-$ it is exceeded only 5 percent of the time at 5 percent of the sites. However, as indicated earlier in Table 4-5, this maximum level increases to 87 when ambient levels in high density cities are included. Thus, the previously estimated dynamic range for the bockground noise of 63 to $87 \mathrm{~dB}$ is confirmed even when the self-noise levels of the automobile are considered.

However, it is clear from these data that the limiting background noise level will tend to actually be the self-noise of the automobile for quieter sites and the site ambient noise for less quiet sites. The ambient-sensing characteristic of the back-up warning device must therefore be capable of responding to either type of time-varying environment. The former tends to have a fairly uniform noise level with time for the few seconds between engine start-up and reversing operation while the normal outdoor ambient may vary drastically with time. 


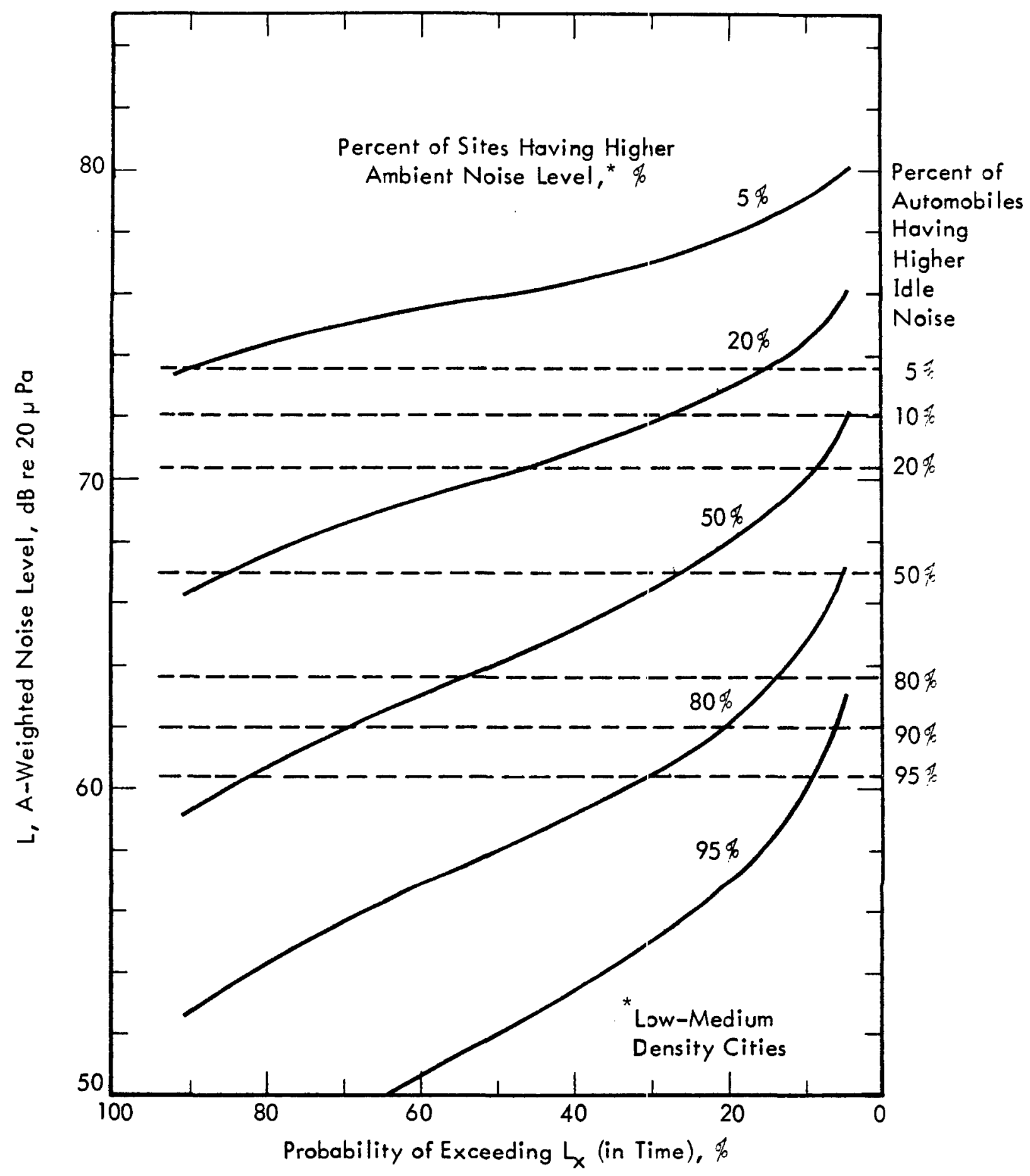

Figure 4-15. Estimated Distribution Profile of Ambient Noise in Parking Areas over Sites in Average (Low-Medium Density) Cities and Over Time Compared to the Estimated Distribution of ldling Self-Noise of Automobiles 
4.4 The Automobile Driver

Although it was not intended to study the detailed vehicle operations related to back-up accidents, a few observations were made on a sample of eight drivers (selected at random) to determine the typical sequence of events and elapsed time between particular actions of these drivers. Figure 4-16 illustrates the results of these observations made in a typical commercial parking lot. A narrative recording was made describing the four events with indications of their time of occurrence and this recording was later analyzed to determine the elapsed time between eoch event. Subject Number 9 appeared to exhibit atypical behavior well removed from the majority of the events, and was discounted. If the time intervals between events for the other seven subjects are examined, the following values are obtained:

\begin{tabular}{|l|c|c|c|}
\hline \multirow{2}{*}{ Interval Events } & \multicolumn{3}{|c|}{ Time Interval, seconds 1 } \\
\cline { 2 - 4 } & Minimum & Average & Maximum \\
\hline Car door closed to starting engine & 4.0 & 7.5 & 11.0 \\
Starting engine to car in reverse & 2.0 & 6.1 & 13.0 \\
Car in reverse to car moving back & 1.0 & 2.8 & 6.5 \\
\hline I Excluding Subject No. 9. & & \\
\hline
\end{tabular}

Although the values shown ore not derived from a large number of observations, they are probably a good representation of the time variations to be expected. It should be mentioned, the data shown was obtained in a shopping center parking lot where the engines were probably still warm, so longer time intervals would likely be observed where cars are started cold.

The time interval between the engine turning over and the car being placed in reverse will be utilized by the warning system to determine the acoustic background level. The minimum time observed for this interval was 2 seconds, suggesting an upper limit for the averaging time of the microphone circuit of approximately I second. This 


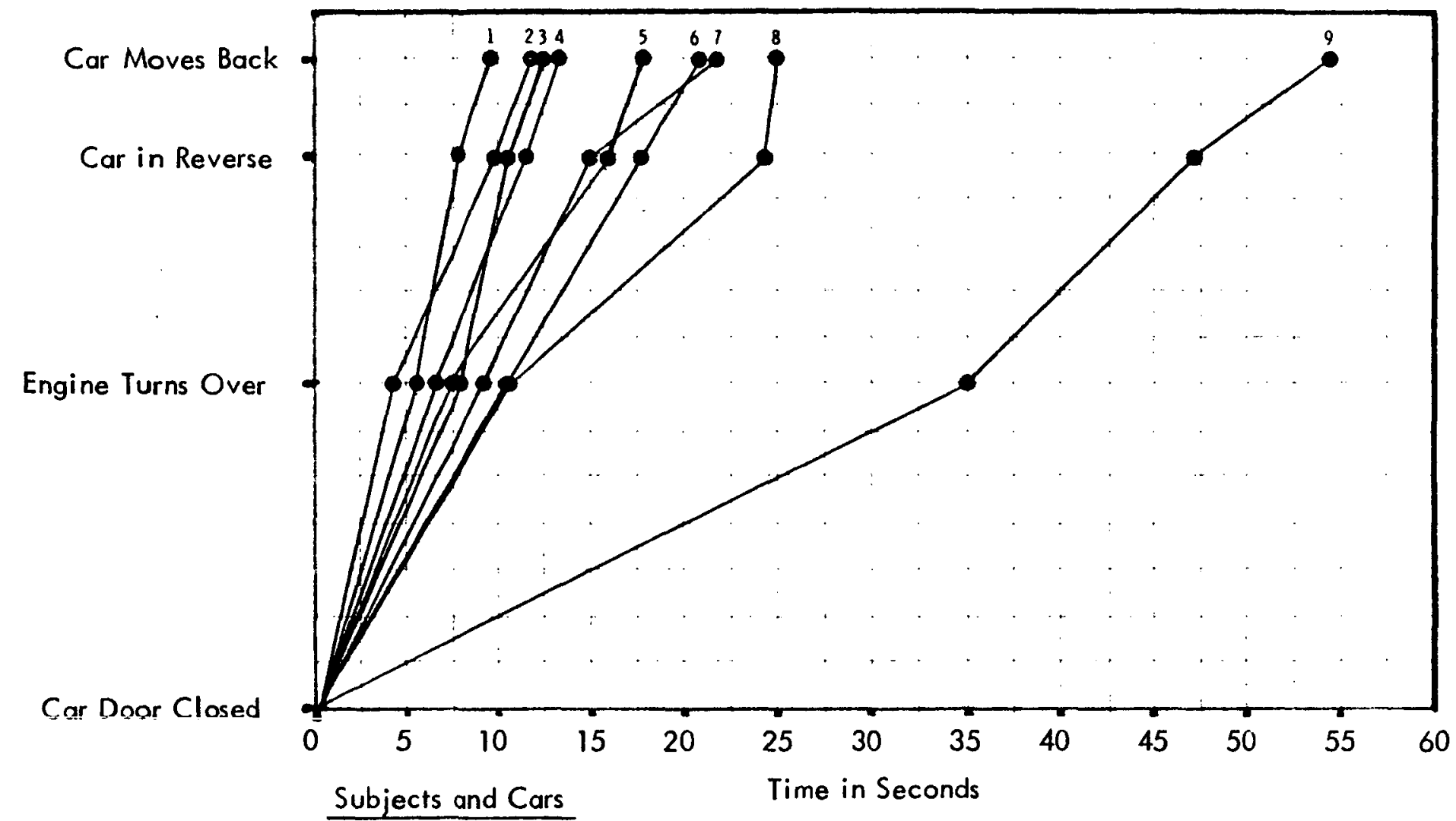

1 - Woman in Chevrolet El Camino

2 - Man In Van

3 - Man in Cadillac

4 - VW Minibus

5 - Woman in Mercury Station Wagon
6 - Average of All Events (Straight Line)

7 - Man in Chevrolet El Camino

8 - Woman in Ford Pinto

9 - Old Pick-up Truck

Figure 4-16. Observed Sequence of Events Preparaiory to Backing Up 
would allow sufficient time for determination of the background level before the microphone circuit is de-energized and the warning signal activated when the car is placed in reverse.

The interval between placing the car in reverse and the cars motion to the rear is a crucial time for the pedestrian. The endangered pedestrian must evaluate the situation and take action to avoid being struck within a very short period of time. Motion of the automobile to the rear occurs within 1 second after being placed in reverse, in some cases. The waming signal should thus be activated and audible immediately upon the automobile being placed in reverse to provide the pedestrian with the maximum time to respond. 


\subsection{SELECTION CF THE WARNING SIGNAL}

The characteristics of the potential target population and accident site have been defined in the preceding sections. It remains now to integrate these features into a model for the design requirements of the warning signal. The objective is to provide a waming device which has a 95 percent probability of alerting a target population which is within a danger zone near a backing automobile with ambient noise that would not be exceeded more than 5 percent of the time. The "danger zone" is nominally identified as extending 5 meters from the rear of the automobile. However, it is desirable to define this danger zone more carefully in order to clearly establish the range requirements for the warning signal.

\subsection{Possible Accident Scenarios}

Figure 5-1 illustrates four general scenarios for possible back-up accidents. Cases $A$ and $B$ involve o pedestrian walking directly toward an automobile backing out of a perpendicular parking slot or at 90 degrees to its path, respectively. Case $C$ corresponds to a pedestrian who is walking parallel and in the same direction as an automobile backing away from a parallel parking slot next to a curb. He then suddenly turns into its path. Case $D$ involves a pedestrian standing directly in the path of an automobile backing out of a long driveway or alley. While this is by no means an exhaustive sample of possible back-up accident scenarios, it serves to illustrate the basic types from which one can construct a reasonable model for the "danger zone." First of all, it should be noted that the accident zone - the actual location where an impact could occur - is indicated in Figure 5-1 by the cross-hatched area. This is intended to identify an envelope of the area that could be actually occupied by the backing automobile. The size of the fan-shape accident zone shown in Figure 5-1 for Cases A and B can be estimated as having a radius to the end of the "fan" as much as two car lengths (8.7 to 11.9 meters) for most 1975 U.S. cars and 

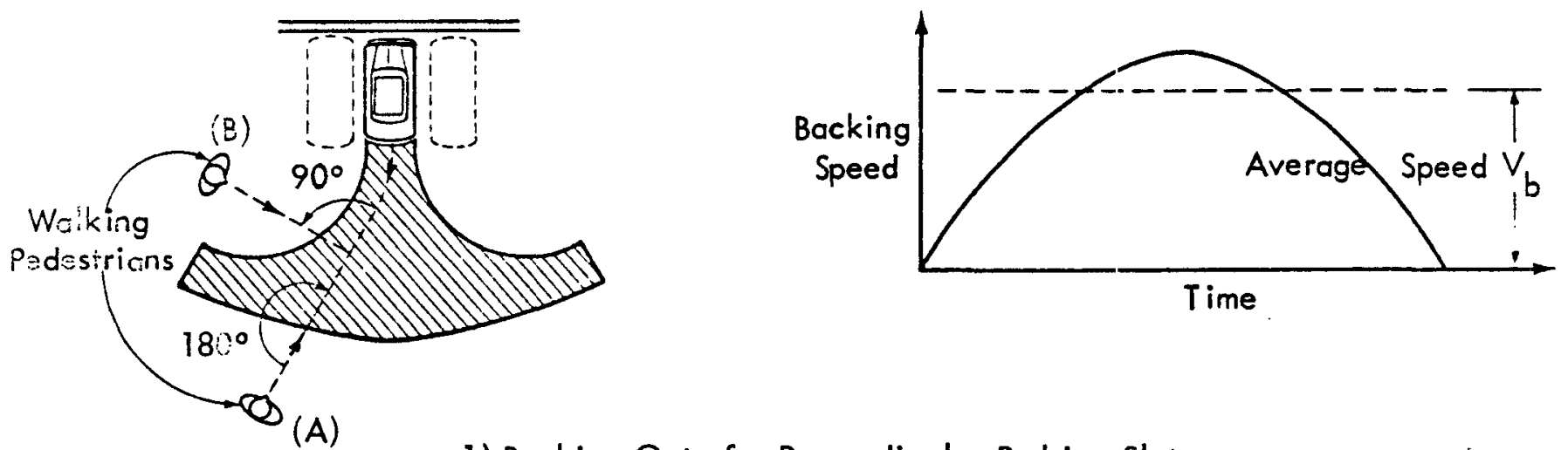

1) Backing Out of a Perpendicular Parking Slot
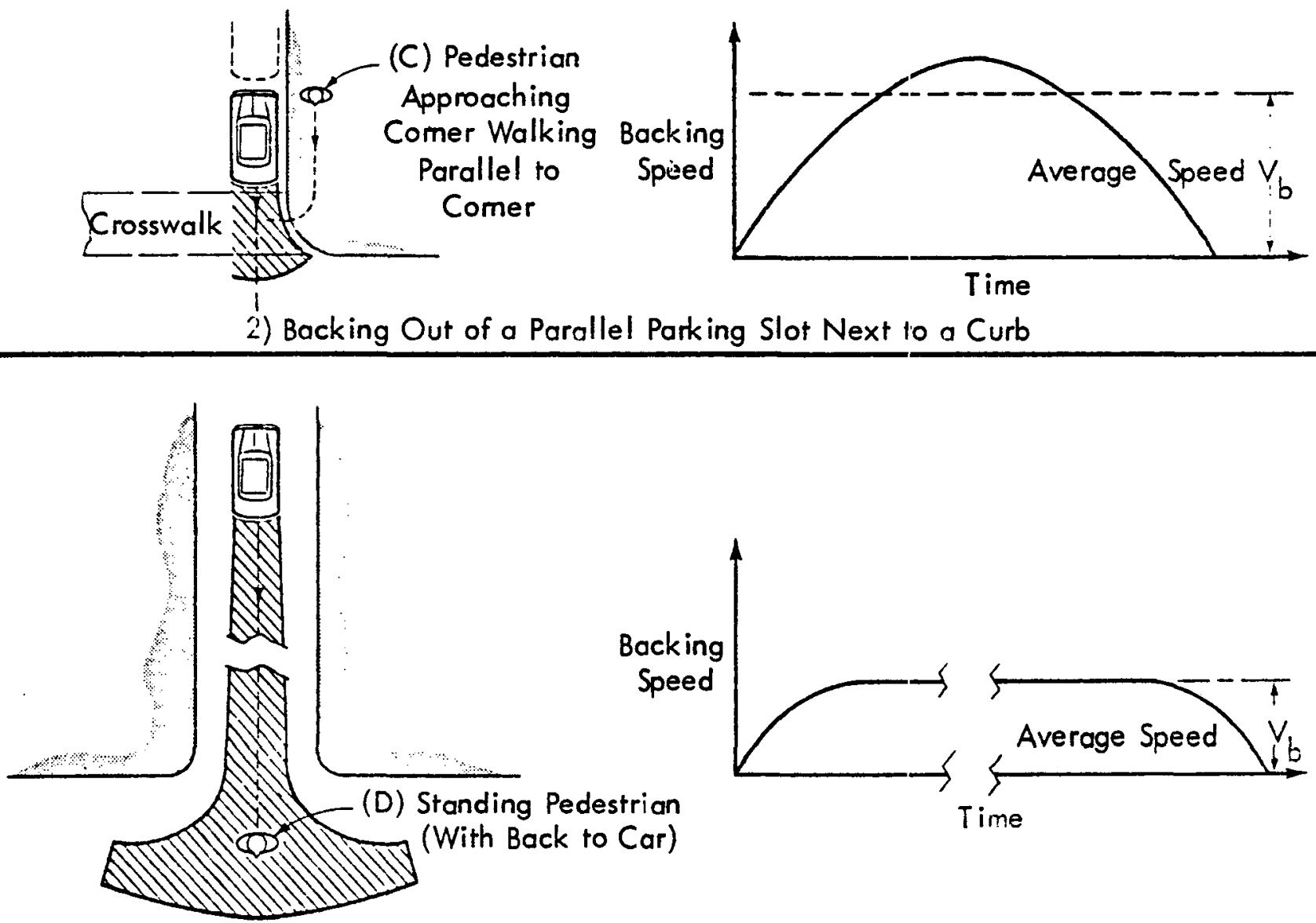

Figure 5-1. Possible Back-Up Accident Scenarios 
having a minimum radius on the side of the fan equal to the minimum tuming radius of an automobile ( 4.7 to 6.7 meters) for most 1975 U.S. cars. This envelope of the accident zone for Case $A$ or $B$ is illustrated in more detail in Figure 5-2.

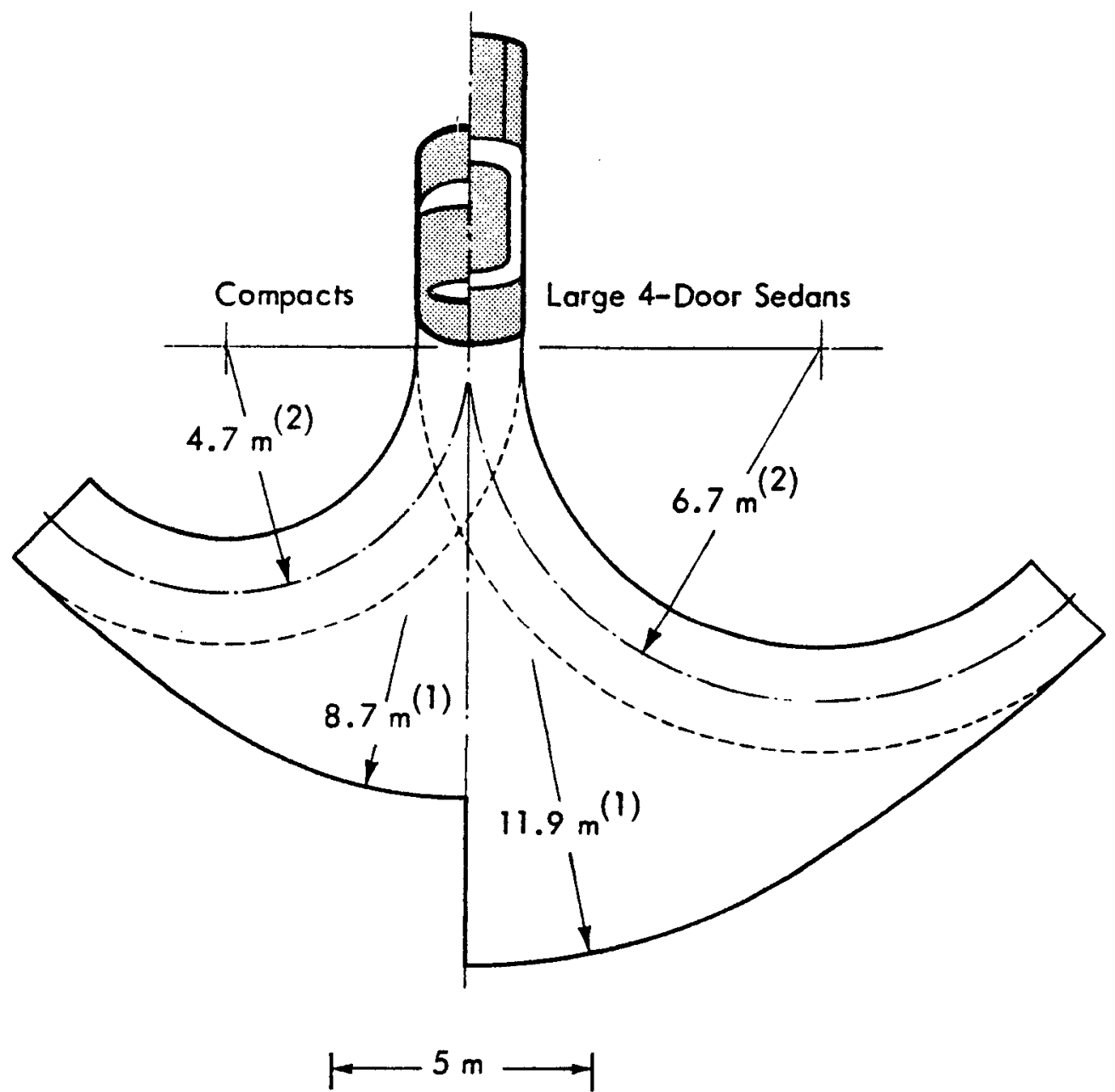

(1) T wo car lengths.

(2) Minimum turning radius

Figure 5-2. Approximate Envelope of Potential Back-Up Accident Zone for Most 1975 U.S. Automobiles for Case A in Figure 5-1 
The actual danger zone for the pedestrian can extend beyond the boundaries of this accident zone since the pedestrian must be wirned in time to tak'e evasive action before entering the accident zone. Thus, a critical warning distance $\left(D_{c}\right)$ can be defined as the separation between the automobile and the pedestrian at the moment he hears the warning signal, at a time just sufficient to allow him to take the necessary avoidance action. The following simple model provides a means of estimating this critical distance $D_{c}$.

\subsubsection{The "Critical Distance" Model}

Examination of the various scenarios in Figure 5-1 indicates that they can all be represented, analytically, by the general case illustrated in Figure 5-3. The curved backing paths indicated in Figure 5-1 are reduced here to equivalent linear paths.

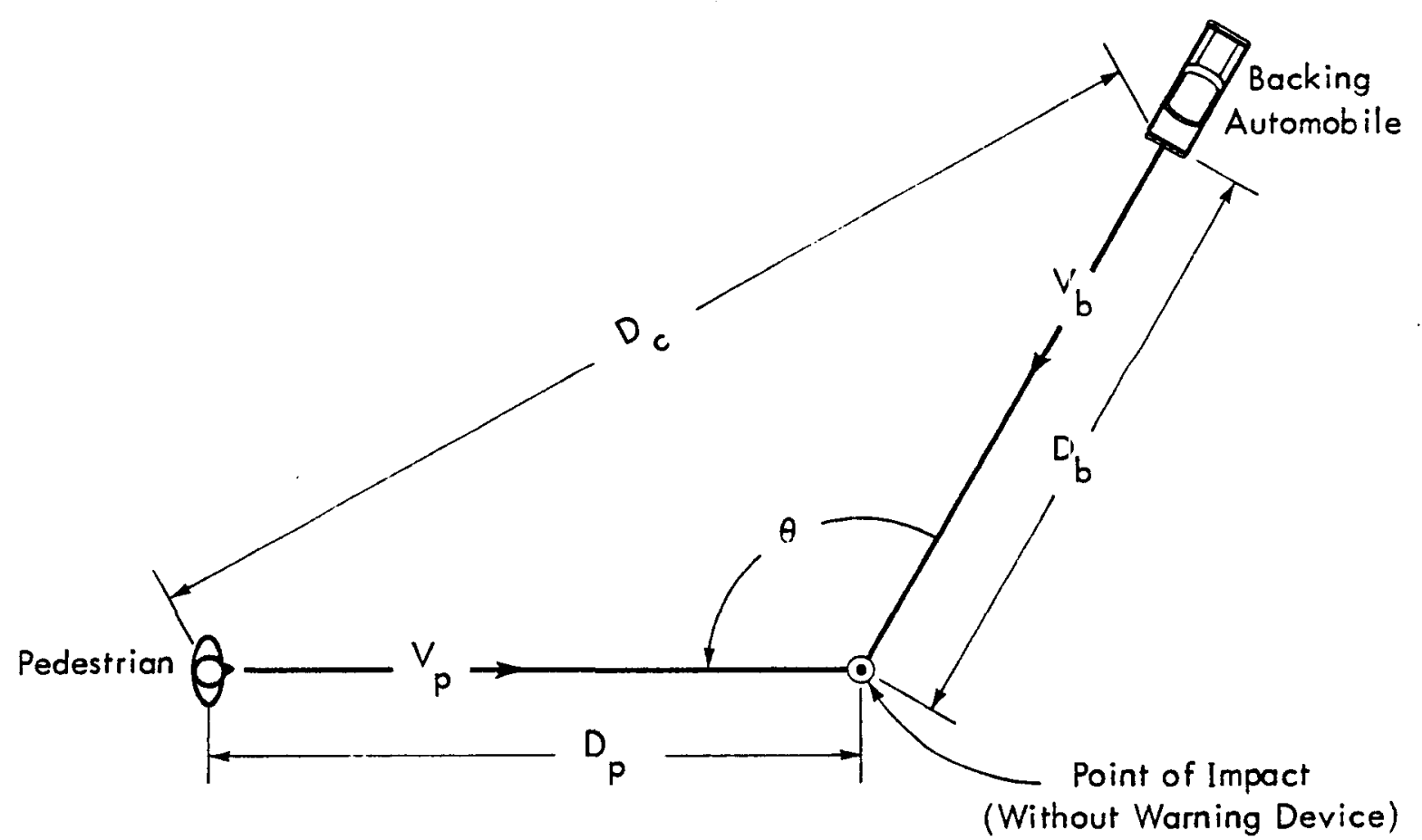

Figure 5-3. Geometry of General Back-Up Accident Case 
This sketch shows the backing automobile at an initial distance $D_{b}$ from the potential impact point. It is assumed that it travels along this line with a constant (average) velocity $V_{b}$. Lying at an angle $\theta$ from the automobile path is the path of motion of the unwamed pedestrian traveling at a velocity $V_{p}^{\prime}$. Had he been wamed when he was a distance $D_{p}$ from the point of impact, or the critical distance $D_{c}$ from the automobile, he would just have had sufficient time to avoid the impact.

The independent time sequences involved in this model for the automobile and pedestrian motion can be defined as follows:

\begin{tabular}{|c|c|c|c|c|c|}
\hline \multicolumn{3}{|c|}{ Automobile } & \multicolumn{3}{|c|}{ Pedestrian } \\
\hline Time & $\begin{array}{l}\text { Duration } \\
\text { of Interval }\end{array}$ & Event & Time & $\begin{array}{l}\text { Duration } \\
\text { of Interval }\end{array}$ & \\
\hline 0 & $t_{b}^{t}$ & $\begin{array}{l}\text { Auto in Reverse } \\
\text { (Waming Signal On) }\end{array}$ & 0 & $i$ & $\begin{array}{l}\text { Pedestrian Position } \\
\text { When Auto in } \\
\text { Reverse } \\
\text { (Waming Signal } \\
\text { Received) }\end{array}$ \\
\hline 2 & $t_{i}^{t}$ & $\begin{array}{l}\text { Auto Starts to Back } \\
\text { Up }\end{array}$ & 1 & $t_{a}^{t}$ & $\begin{array}{l}\text { (Pedestrian Starts } \\
\text { to React if } \\
\text { Warned) }\end{array}$ \\
\hline 3 & 1 & $\begin{array}{l}\text { Impact } \\
\text { (If Warning Signal } \\
\text { is Not Used) }\end{array}$ & 3 & 1 & $\begin{array}{l}\text { Impact (If Warned, } \\
\text { Pedestrian Just } \\
\text { Completes } \\
\text { Avoidance Action) }\end{array}$ \\
\hline
\end{tabular}

where: $\quad t_{i}+t_{b}=t_{r}+t_{a}$

At time 0 , the automobile is engaged in reverse and if a warning signal is present, the signal is turned on and (neglecting the finite sound propagation time) received by the pedestrian.

At time 1 ( $t_{r}$ seconds after time 0$)$, if a waming signal is on, the pedestrian starts to act. According to the reaction time data shown previously in Figure 3-1, 
this reaction time $t_{r}$ can be as short as 0.25 to 0.5 seconds, depending on the pedestrian's age.

At time $2\left(t_{b}\right.$ seconds after time 0$)$, the automobile starts to move in reverse. According to the typical backing time sequences defined in Section 4.4, this backing delay time $t_{b}$ can vary from typically 1 to 6.5 seconds.

At time $3\left(t_{i}\right.$ seconds after time 2 or $t_{a}$ seconds after time 1$)$, the auto and pedestrian impact, or, if a successful warning has occurred, the pedestrian has enough time $\left(t_{a}\right)$ to complete a safe avoidance action. It is estimated that this action time $\left(t_{a}\right)$ would not be less than 1 to 2 seconds.

Based on these time periods and the motion diagram in Figure 5-3, the distances traveled by the auto $\left(D_{b}\right)$ and pedestrian $\left(D_{p}\right)$ along their respective paths will be:

For the auto,

$$
D_{b}=V_{b} t_{i}=V_{b}\left(t_{r}+t_{a}-t_{b}\right)
$$

since

$$
t_{i}=t_{r}+t_{a}-t_{b} \geq 0
$$

For the pedestrian,

$$
D_{p}= \begin{cases}V_{p}\left(t_{r}+t_{a}\right)-\text { Pedestrian initially in motion } \\ V_{p} t_{a} & - \text { Pedestrian initially standing still }\end{cases}
$$

From Figure 5-3, applying the law of cosines, the critical warning distance $D_{c}$ can be given as:

$$
D_{c}=\left[D_{b}^{2}+D_{p}^{2}-2 D_{b} D_{p} \cos \theta\right]^{\frac{1}{2}}
$$

Applying this expression to each of the four cases illustrated in Figure 5-1 gives the following expressions for the critical distances subject to the constraint that the total pedestrian response time $\left(t_{r}+t_{a}\right)$ cannot be less than the backing delay time $t_{b}$, to yield a sensible value of the critical distance. 
Cose A, $\theta=180^{\circ}$,

$$
D_{c}=\left(V_{b}+V_{p}\right)\left(t_{r}+t_{a}\right)-V_{b} t_{b}
$$

Case $B, A=90^{\circ}, \quad D_{c}=\left\{V_{b}^{2}\left[t_{r}+t_{a}-t_{b}^{2}+V_{p}^{2} t_{r}+t_{a}\right]^{2}\right\}^{\frac{1}{2}}$

and

$$
D_{p}=V_{p}\left(t+t_{q}\right)
$$

Case $C, \theta=0^{\circ}$,

$$
D_{c}=\left(V_{b}-V_{p}\right)\left(t_{r}+t_{a}\right)-V_{b} t_{b}
$$

Case $D, \theta=180^{\circ}$,

$$
\begin{aligned}
& V_{p}=0 \text { from time } 0 \text { to time } 1 \\
& D_{c}=\left(V_{b}+V_{p}\right)+t_{a}+V_{b}\left(t_{r}-t_{b}\right)
\end{aligned}
$$

Examination of these equations reveals that the critical distance will be greatest for $A=180^{\circ}$, minimum values of the backing delay time $t_{b}$ and maximum values of the velocities and the Dedestrian reaction and action times $t_{r}$ and $t_{a}$ respectively. Figure 5-4 illustrates the variation in the critical waming distance $D_{c}$ with the total pedestrian response time $\left(t_{r}+t_{a}\right)$ for idealized versions of Case $A$ $\left(\theta=180^{\circ}\right)$ and Case $B\left(\theta=90^{\circ}\right)$ and for two different values of the backing speed and backing delay time.

A design range for audibility of 5 meters will cover a large percentage of back-up accident scenarios. However, it is suggested that under "maximum hazard" conditions, with a maximum backup speed of $5 \mathrm{~m} / \mathrm{s}(11.2 \mathrm{mph}$ ) a minimum back-up delay time of 1 second and total pedestrian response time of 2.5 seconds (say, $t_{r}=0.5$ seconds and $t_{a}=2$ seconds - reasonable values for an elderly pedestrian). The critical warning distance $D_{c}$ for a Case $A$ or Case $D$ scenario would be about 10 meters. Therefore, consideration should be given in the design of the audible warning signal to extending its range of effectiveness to as much as 10 meters. It is not unreasonable to postulate, however, that this type of extreme case might occur when (1) the automobile is backing out of a blind driveway bounded by buildings on each side so that the normal oropagation loss of the waming signal from source to receiver would tend to be reduced, or (2) when the automobile is backing out of a long 

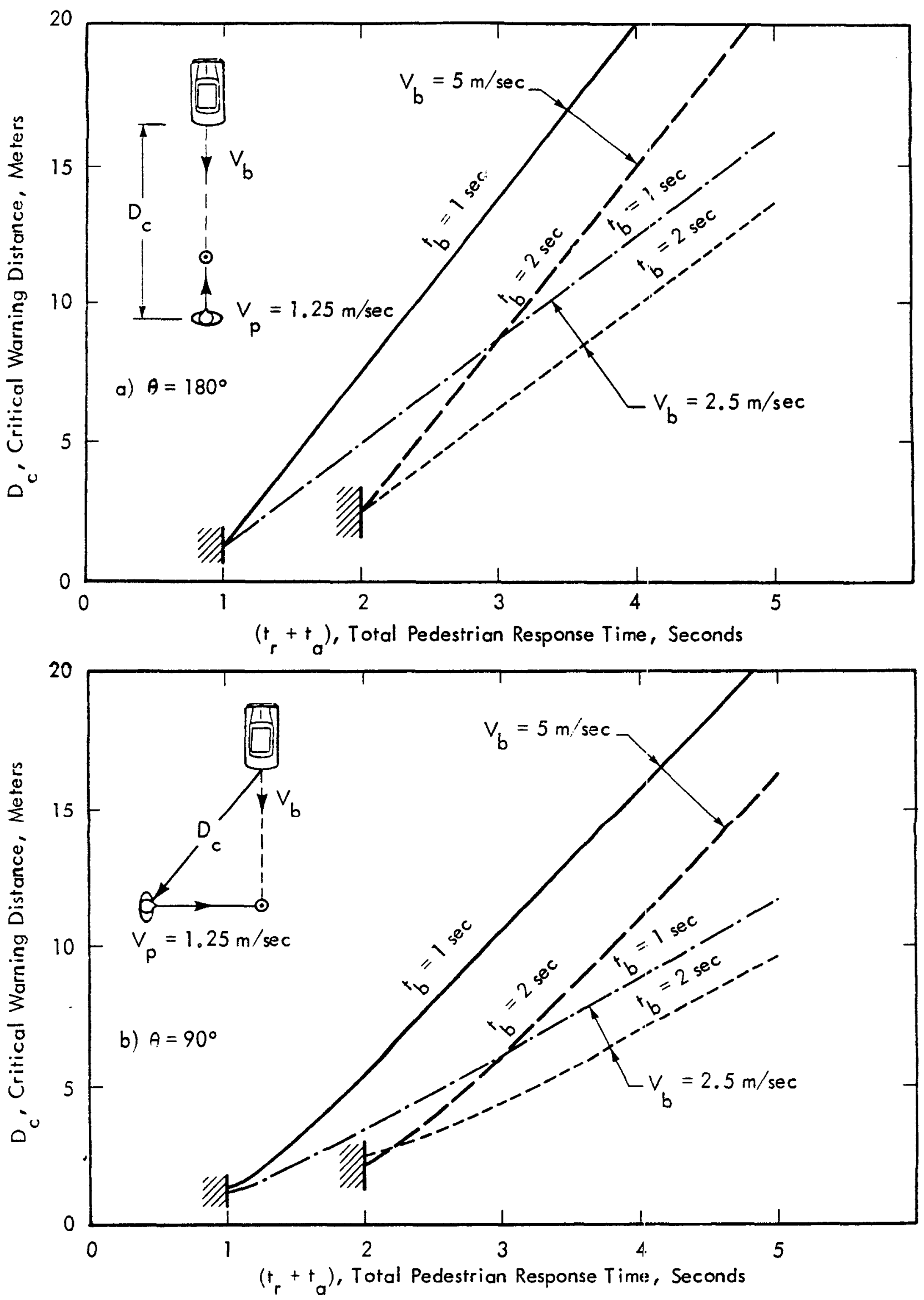

Figure 5-4. Variation in Critical Waming Distance $D_{c}$ with Total Pedestrian Response Time for Different Values of Average Backing Speed $\left(V_{b}\right.$ ) and Backing Delay Time $\left(t_{b}\right)$ 
driveway in a residential area where lower ambient noise levels would tend to make the warning signal effective at a greater distance. Nevertheless, the tentative design range of 5 meters is considered a minimum with potential extension to as much as 10 meters desirable. All other things being equal, this extension of the range would require an increase in the source level of approximately $6 \mathrm{~dB}-0$ 4-to-1 increase in acoustic power. Clearly, seemingly small changes in the effectiveness design range can have a substantial influence on the system performance requirements.

To provide some guidance relative to the desired directivity of the back-up warning device, the locus of the critical distances for all approach angles of the pedestrian and for two different values of the backing speed and backing delay time is shown in Figure 5-5. For any one case, the circular locus of the critical distance is centered at a distance $D_{b}=V_{b}\left(t_{r}+t_{a}-t_{b}\right)$ from the rear of the automobile and has a radius $D_{p}=V_{p}\left(t_{r}+t_{a}\right)$. It defines the boundary of the danger zone within which the pedestrian would not receive a warning signal in time to take evasive action. The envelope of these loci for these various cases is roughly defined, for the worst case, by a rectangle with a maximum length $\left[V_{b}+V_{p}\right]_{\max } \cdot\left[t_{r}+t_{a}\right]_{\max }-V_{b} t_{b} \min$ and $a$ width equal to $2 \cdot V_{p \max }\left[t_{r}+t_{a}\right]_{\max }$. In any event, an elongated directivity pattern is clearly desirable with the greatest range in the direction of backing.

Finally, it should be pointed out that a strict interpretation of one of the design goals of this audible warning system - performance with a 95 percent probability of alerting - would require a detailed statistical evaluation of the dynamics of backing automobiles and pedestrians potentially subject to impact. Such an effort was beyond the scope of this study. The preceding analysis has served, however, to clearly define the desired range of the warning device. Now it remains to utilize all of the preceding design constraints to establish its required acoustical characteristics. 


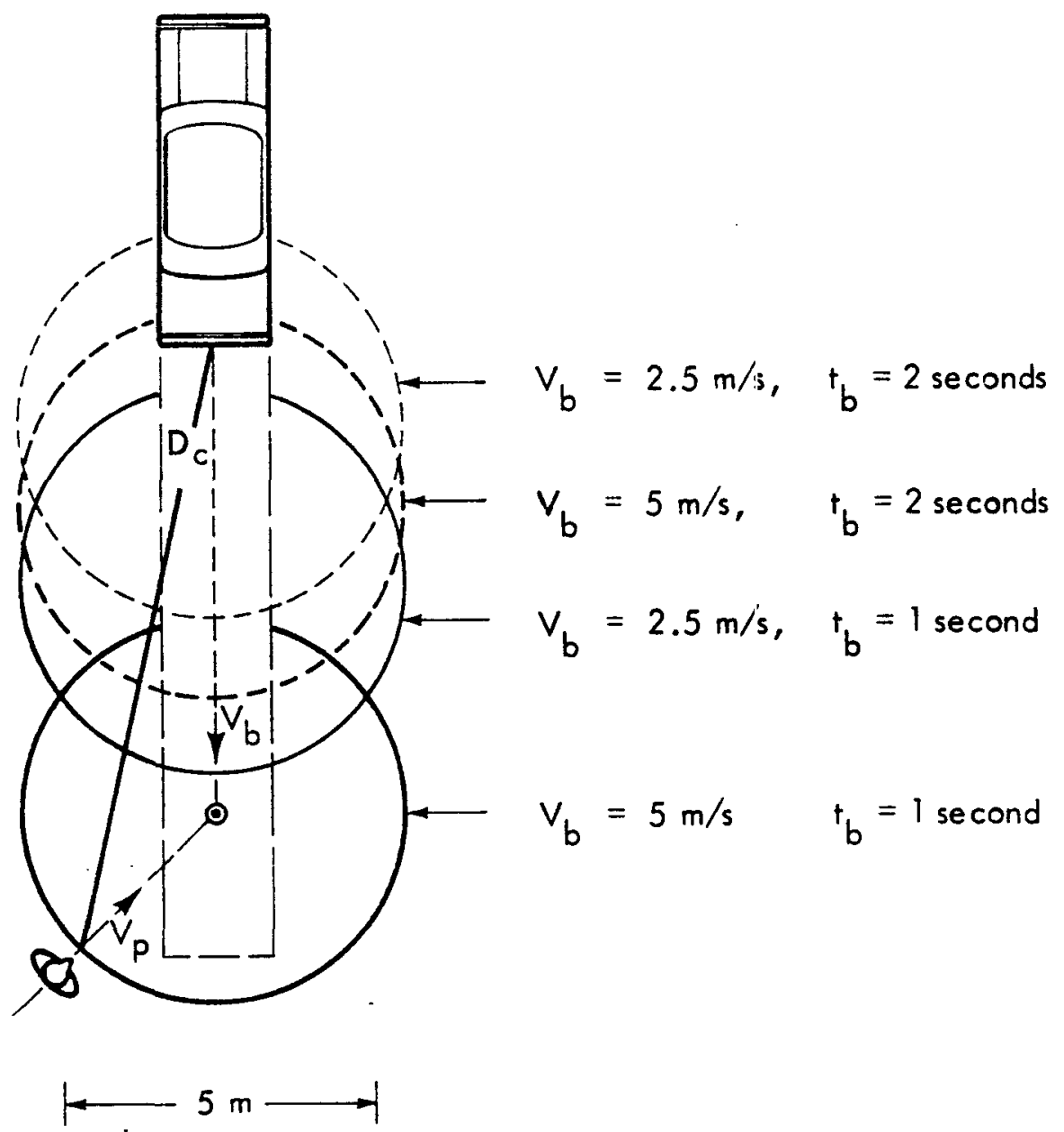

Figure 5-5. Locus of Critical Warning Distances for Several Variations of Back-Up Accident Scenarios Case A. Pedestrian Speed and Total Response . Time $=1.25 \mathrm{~m} / \mathrm{s}(2.8 \mathrm{mph})$ and 2.5 seconds Respectively 


\subsection{General Acoustical Requirements}

The general acoustic features of an effective acoustic waming signal suitable for this program should include the following: ${ }^{18}$

- Concentrate its frequency spectrum in the vicinity of $1000 \mathrm{~Hz}$ where the ear of any pedestrian is most sensitive.

- Provide some degree of complexity to the signal through the use of periodic interruption, level modulation, and or addition of multiple tones. (This requirement must be carefully balanced against the economic constraint for simplicity and low mass-production cost.)

- If possible, project a directional beam.

- Select a level to ensure effective alerting of the pedestrian, but limited to minimize community annoyance.

Each of these general features will be considered in this section by analyzing the acoustic characteristics required of an effective acoustic waming signal.

To be effective, the audible signal must be presented at a level significantly above the masking background noise. Just how much above is a function, essentially, of the following two basic factors.

1. The detection threshold of the signal in the presence of the masking background noise.

2. The relative increase in intensity above this detection threshold to elicit a subjective "alarm" response just sufficient to motivate positive avoidance action by a pedestrian. 


\subsubsection{Detection of a Signal in the Presence of Noise}

The threshold of audibility (or hearing threshold) of a sound is defined as its sound pressure level which is just audible (detectable 50 percent of the time) to the human ear in silence. Actually, the silence can really be considered as consisting of the intemal masking noise inside the ear which limits our own threshold of audibility in the absence of any other sound. The hearing thresholds applicable to 90 or 95 percent of the population within different age groups in the target population were presented earlier in Section 3 (see Figure 3-4).

In the presence of background noise, the normal threshold of audibility will rise due to the masking effect. The amount of masking (i.e., the increase in the signal level above the normal threshold in quiet) can be determined by the spectral analysis characteristics of the human ear in terms of "critical bands." In the simplest possible sense, "critical bands" represent the ear's intemal spectral analysis filters whose bandwidths correspond to the minimum frequency separation of two tones whose excitation regions on the basilar membrane in the inner ear do not overlap to any significant degree. This model explains masking the following way. 6

When a pure tone is masked by a very narrow band of noise, i.e., one whose bandwidth is only a few $\mathrm{Hz}$ wide and whose center frequency coincides with the pure tone frequency, the amount of masking increases, up to a specific limit, as the bandwidth of the masking noise increases. The critical bandwidth is reached when any further increase in the width of the band of masking noise has little or no influence on the amount of masking produced on the pure tone at the centel of the band. The addition of noise energy outside the critical band may be unpleasant, but it does not increase the masking of the pure tone.

This critical bandwidth model, first proposed by Fletcher in 1946, has since provided a basic foundation for most of the observed characteristics of the sensation of sounds. 25-35 The only major source of disagreement between researchers is in the exact dimensions of the critical bands themselves. 
Plotted in Figure 5-6 are critical bandwidths from various researchers as a function of the frequency of the pure tone being masked. The apporent discrepancies between the curves begin to disappear, however, when differences in the measurement method of the critical bands are taken into account. Fletcher, 25 and Hawkins and Stevens 26 used an indirect method based on assuming that a pure tone was just masked by a critical band of noise centered on the same frequency and having the same intensity. The more direct measurements of the critical bands by noting changes in masking for changes in the masking noise bandwidth, outlined earlier, produced the larger values of the width of the critical bands observed by Zwicker ${ }^{29}$ and Greenwood. 31 Note that the results from these two experimenters agree quite well at frequencies of interest for this study.

Based on the concepts outlined in the preceding discussion, it is possible to construct a model for aural detectability of warning signals. This model was first derived by Ollerhead ${ }^{7}$ and has been extensively tested in laboratory and field experiments on oural detectability of helicopter sounds. 7, 8

The first step in applying the model is to define the "critical band levels" of the masking noise. Ideally, this is best accomplished by first obtaining a narrow band spectrum of the background masking signals and then mathematically converting this into critical band spectra as described in Reference 8. For the present purposes, however, it is simpler to use the available spectrum levels of the masking noise. These may be converted into approximate critical band levels (according to Greenwood's experimental values) by adding the following constants contained in Table 5-1.31

In the above discussion it has been assumed that the masking noise level was significantly above the threshold of audibility. Since this is not always the case, it is necessary to add the critical band levels of the masking noise to the equivalent internal noise levels of the threshold of audibility to establish a true masked threshold. This summation must be performed on an energy basis. 


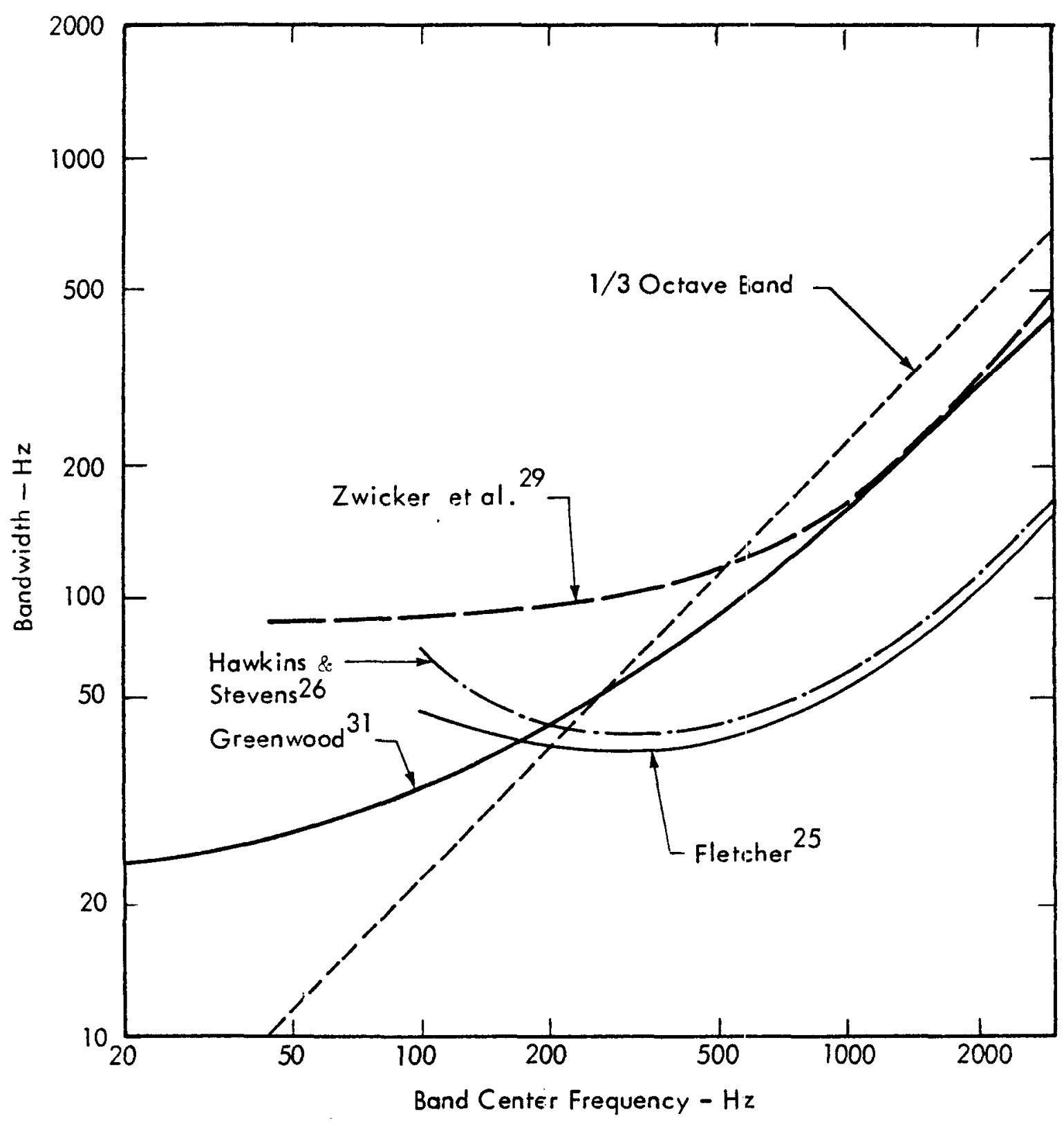

Figure 5-6. Comparison of Various Critical Bandwidth Measurements 
Table 5-1

Correction Factors to Determine Approximate Critical Band Levels By Adding to One-Third Octave Band Levels (According to Greenwood's Experimental Volues) ${ }^{31}$

\begin{tabular}{|l|r|r|r|r|r|r|c|c|}
\hline & \multicolumn{8}{|c|}{$\begin{array}{c}\text { Add to One-Third Octave Band Levels } \\
\text { To Obtain Critical Band Levels }\end{array}$} \\
\hline Frequency, $\mathrm{Hz}$ & 50 & 63 & 80 & 100 & 125 & 160 & 200 & 250 \\
\hline Correction, dB & 4 & 3.5 & 3 & 2 & 1.5 & 1 & 0.5 & 0 \\
\hline Frequency, $\mathrm{Hz}$ & 315 & 400 & 500 & 630 & 800 & 1000 & 1250 & $1600-10,000$ \\
\hline Correction, dB & -5 & -.5 & -1 & -.1 & -1.5 & -1.5 & -1.5 & -2.0 \\
\hline
\end{tabular}

Based on the preceding discussion, the equation for predicting the sound level $\left(L_{k}\right)$ in the $k^{\text {th }}$ critical band of a signal detectable 90 percent of the time in a background noise can be given as: 8

$$
L_{k}=10 \log \left[10^{T_{k} / 10}+10^{\left(M_{k}+X\right) / 10}\right]+1.0, \mathrm{~dB}
$$

where

$$
\begin{aligned}
L_{k}= & \text { warning signal level in } k^{\text {th }} \text { critical band }(\mathrm{dB}) \\
T_{k}= & \text { sound pressure level at the threshold of audibility corresponding } \\
& \text { to center frequency of } k^{\text {th }} \text { critical band }(\mathrm{dB}) \\
M_{k}= & \text { level of masking signal in } k^{\text {th }} \text { critical band }(\mathrm{dB}) \\
X= & \text { "fine tuning parameter" }(\approx-5 \mathrm{~dB} \text { for detection by } 50 \text { percent of } \\
& \text { individuals, } \approx 0 \mathrm{~dB} \text { for detection by } 90 \text { percent of individuals })
\end{aligned}
$$

A $1 \mathrm{~dB}$ constant has been added to the above equation to ensure correct results for low levels of masking noise near the threshold of audibility. 8 For the "fine tuning parameter," however, a value of $-5 \mathrm{~dB}$ is used to provide a threshold level corresponding to the usual 50 percent response level which will be the starting point for the increase in level required to achieve a "warning" quality. 
One minor simplification has been made in proposing this model for this study; namely, that the effective bandwidth of the critical band is independent of the level of the masked threshold. Zwicker ${ }^{36}$ shows significant broadening of the critical band characteristics at high noise levels (above $85 \mathrm{~dB}$ ). However, for this program, this is expected to be a second order effect and the linear equation specified above is used for computing the signal threshold for all levels of masking noise.

Based on the preceding expression, the range of masking noise levels and spectra defined in Section 4.0 and the threshold of audibility not exceeded by 95 percent of the target population in the 48 to 65 year age group from Figure $3-4$ in Section 3.0, the threshold levels for the warning signal have been computed. The results are summarized in Table 5-2, assuming the warning signal would consist of only a single pure tone within any one-third octave band in the frequency range 500 to $2500 \mathrm{~Hz}$.

The three frequencies giving the lowest threshold levels for the quietest ambient design level of $63 \mathrm{dBA}$ (taken from Table 4-5) are 800,1000 , and $1250 \mathrm{~Hz}$ for which the threshold levels of the pure tone warning signals would be $47.7,46$, and $46.8 \mathrm{~dB}$ respectively. For the highest ambient design level of $87 \mathrm{dBA}$, the selected frequencies with the lowest threshold levels are $12.50,1600$, and $2000 \mathrm{~Hz}$, providing threshold levels of $68,66.2$, and $66.1 \mathrm{~dB}$ respectively. The $1250 \mathrm{~Hz}$ frequency band is the only one common to these two extreme ranges, so in order to provide one optimum design for all sites, this frequency should be selected as the basic waming signal frequency.

A tentative selection for the threshold level of the warning signal at the ear of the pedestrian is thus defined as ranging from 47 to $68 \mathrm{~dB}$ a a frequency of $1250 \mathrm{~Hz}$. It remains to define the additional characteristics of this tone required to establish it as an effective warning signal. 
Table 5-2

Computation of Threshold Levels of Pure Tone Warning Signals for Specified Sites and for 95 Percent Percentile of 48 to 65 Year Age Group

\begin{tabular}{|c|c|c|c|c|c|c|c|c|c|c|}
\hline \multirow[b]{2}{*}{ Site } & \multirow[b]{2}{*}{ Porameter } & \multicolumn{9}{|c|}{$k^{\text {th }}$ Frequency, $\mathrm{Hz}$} \\
\hline & & 500 & 630 & 800 & 1000 & 1250 & 1600 & 2000 & 2500 & $L_{A}$ \\
\hline \multirow{7}{*}{$\begin{array}{l}\text { Lew- } \\
\text { Medium } \\
\text { Density } \\
\text { City }\end{array}$} & $T_{k}^{(1)}, d B$ & 45 & (42) & $(38.5)$ & 35 & $(42.5)$ & (51) & $(58.5)$ & $(65)$ & - \\
\hline & $\Delta L^{(2)}, d B$ & -7.5 & -9 & -10.5 & -12 & -13.5 & -15 & -16 & -17 & - \\
\hline & $L_{M}{ }^{(3)}, d B$ & 55.5 & 54 & 52.5 & 51 & 49.5 & 48 & 47 & 46 & 63 \\
\hline & $J C B L^{(4)}, d B$ & -1 & -1 & -1.5 & -1.5 & -1.5 & -2 & -2 & -2 & - \\
\hline & $M_{k}^{(5)}, d B$ & 54.5 & 53 & 51 & 49.5 & 48 & 46 & 45 & 44 & - \\
\hline & $M_{k}-(4), d B$ & 49.5 & 48 & 46 & 44.5 & 43 & 41 & 40 & 39 & - \\
\hline & $L_{k}^{(6)}, d B$ & 51.8 & 50 & 47.7 & 46.0 & 46.8 & 52.4 & 59.6 & 66 & - \\
\hline \multirow{6}{*}{$\begin{array}{l}\text { High- } \\
\text { Density } \\
\text { City }\end{array}$} & $\Delta L_{A}{ }^{(2)}, d B$ & -7.5 & -9 & -10.5 & -12 & -13.5 & -15 & -16 & -17 & - \\
\hline & $L_{M}^{(3)}, d B$ & 79.5 & 78 & 76.5 & 75 & 73.5 & 72 & 71 & 70 & 87 \\
\hline & $\triangle C B L^{(4)}, d B$ & -1 & -1 & -1.5 & -1.5 & -1.5 & -2 & -2 & -2 & - \\
\hline & $M_{k}^{(5)}, d B$ & 78.5 & 77 & 75 & 73.5 & 72 & 70 & 69 & 68 & - \\
\hline & $M_{k}-(4), d B$ & 73.5 & 72 & 70 & 68.5 & 67 & 65 & 64 & 63 & - \\
\hline & $L_{k}^{(6)}$ & 74.5 & 73 & 71 & 69.5 & 68 & 66.2 & 66.1 & 68.1 & - \\
\hline
\end{tabular}

(1) $T_{k}=$ Hearing threshold for 95 percent percentile age 48 to 65 group, $($ ) interpolated.

(2) $\triangle L_{A}=$ Relative one-third octove band level for ambient levels from Table $4-6$.

(3) $L_{M}=$ One-third actove band ambient level = A-weighted design level plus (2).

(4) $\triangle C B L=$ Correction foctor for critical band levels from Table 5-1:

(5) $M_{k}=L_{M}+1 C B L$.

(6) $L_{k}=$ Threshold level of pure tone in $k^{\text {th }}$ band, $d B$ re $20 \mu P a$, computed from Equation 5-9 in iext - lewest three zones sere eneicsec. 


\subsubsection{Warning Signal Parameters}

Since the signal defined above would be only detected about 50 percent of the time in the environmental conditions specified, it must be modified to achieve an effective warning capability. The simplest modification is to increase the level until the signal is clearly noticeable and then to change its presentation by either adding additional components or by interrupting the signal to increase its alerting qualities. The "critical band" model again plays a useful role in establishing a minimum rate of interruption to avoid degrading the loudness of the tone.

Whenever a broadband noise spectrum is analyzed by a filter (such as one may consider the "critical bands" with in the ear), the output of the filtered band of noise should be examined for a minimum period of time (T) of the order of $40 / 2 \Delta f$, where $\Delta f$ is the bandwidth of the filter in $\mathrm{Hz}$. This relationship provides at least 40 degrees of freedom for the analysis and ensures that the filtered output will not fluctuate excessively. ${ }^{37}$ Thus, if the signal frequency is $1250 \mathrm{~Hz}$. the critical bandwidth $(\Delta f)$. From Greenwood's data in Figure $5-6$, is $200 \mathrm{~Hz}$, then the ear should have $40 /(2 \cdot 200)=0.1$ second to look at each burst of the tone. Thus. an interruption rate less than 10 per second is desired. A rate of 3 per second has been selected.

The anticipated increase in level of about $15 \mathrm{~dB}$ required beyond the threshold values was verified in a brief experiment conducted during this program. The results, to be discussed in the next section, indicated that a pure tone signal of $1000 \mathrm{~Hz}$ or $2000 \mathrm{~Hz}$ presented at three bursts per second at an average level of $17 \mathrm{~dB}$ above the threshold level in a noise background of 65 to $70 \mathrm{dBA}$ achieved a satisfactory "warning signal" quality according to the subjective judgment of the subjects. Therefore, a tentative design range for the warning signal level at the ear of the pedestrian is:

\section{Minimum Level for Low-Niedium Density Cities}

$$
47+17=64 \mathrm{~dB}
$$


Maximum Level for High Density Cities

$$
68+17=85 \mathrm{~dB}
$$

Finally, assume a 1 meter reference point for rating the source output and allow for simple inverse square law propagation loss from that point to the minimum desired critical distance of 5 meters $(\Delta L=20 \log 5 / 1=14 \mathrm{~dB})$ or the desired range capability of 10 meters $(\Delta L=20 \mathrm{~dB})$. * Thus, the reference source level at a 1 meter distance would range from $64+14=78 \mathrm{~dB}$ for the quietest conditions and minimum critical distance of 5 meters to $85+20=105 \mathrm{~dB}$ for the noisiest conditions and the maximum (10 meters) range. In both cases, a pure tone of $1250 \mathrm{~Hz}$ interrupted at three times per second is assumed.

Literature on the desirable acoustic characteristics of warning devices has been reviewed and the following criteria have been identified: 38

- The warning signal frequency should be greater than $700 \mathrm{~Hz}$ - Maximum audibility of a signal in a noise field is attained if the frequency is greater than $1000 \mathrm{~Hz}$

- Pulsing a signal does not detract from its alerting potential and it does not appear to enhance it. It does however, make the signal more distinctive.

In conclusion, an optimum alerting signal (one which attracts attention) must:

1. be audible

2. have attention getting characteristics

3. be distinctive

There is one additional aspect regarding subjective judgments of a signal in the presence of a masking noise that has not been discussed. This is the phenomenon of loudness recruitment which is illustrated in Figure 5-7. With loudness recruitment, the apparent loudness of a tone, masked by noise, grows more rapidly than it would in the absence of the masking noise. This effect is illustrated in Figure 5-7 by the solid line which shows the increased rate of growth of loudness observed for normal ears

*There is no need to consider any other loss effects over such a short range. 


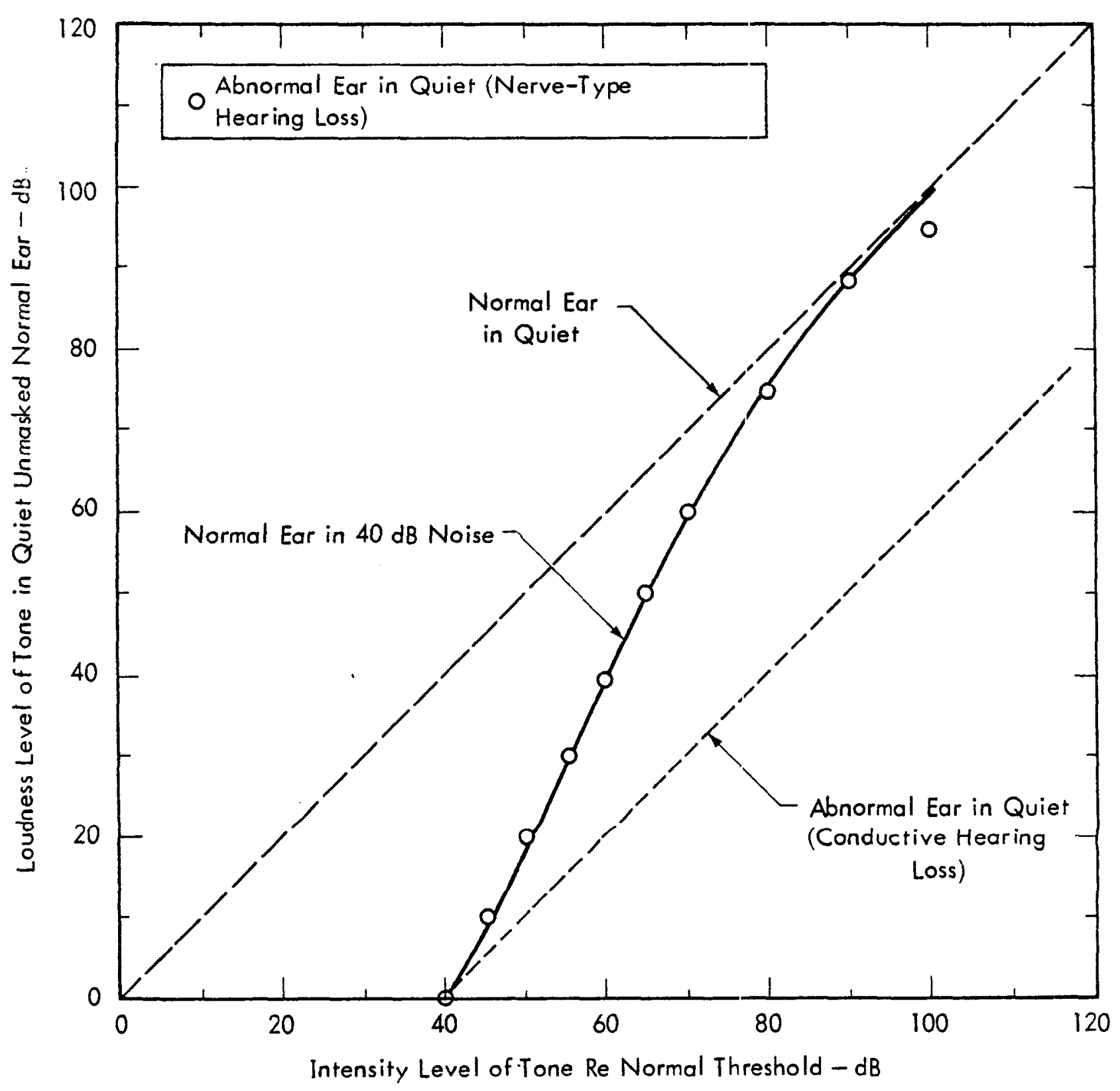

Figure 5-7. Growth of a Partially Masked Tone for Normal and Abnormal Ears to Illustrate the Phenomenon of Recruitment 
listening to a tone masked by $40 \mathrm{~dB}$ noise. The data points show that people with nerve-deafness (inner ear loss similar to the type of hearing loss observed for older people) exhibit exactly the same type of behavior when listening to a tone in the

quiet. In other words, their nerve-type hearing loss acts like an external masking noise does to the normal ear as far as loudness growth is concerned.

Also illustrated in Figure 5-7 is the loudness growth curve that would be observed for a person with conductive-type hearing loss due to disfunction of the middle ear. The point is that for people with normal ears and those with nerve-type hearing loss, the way the ear perceives the growth of loudness of a tone in the presence of noise is very nonlinear compared to the normal ear in quiet. Although this effect could possibly be utilized to improve the effectiveness of a waming signal, the added complexity of a nonlinear amplitude control was not deemed a cost effective design criteria.

\subsection{Subjective Evaluation}

Based upon an early brief examination of the important waming signal parameters, a subjective evaluation of waming signal characteristics was conducted. A group of eight subjects was first tested to determine their hearing thresholds and then asked to judge the level of detection and the level at which a signal attained a waming quality, both with the signal masked by noise.

Audiometric pure tone threshold hearing tests were performed using a Beltone Model 90 portable audiometer. The audiometric testing was performed using earphones with a circumaural cushion, used in lieu of the standard earphone cushion. The audiometer had been calibrated approximately to ANSI S3.6-1969, considered adequate for our purposes since the results were intended for comparison purposes only. Results of these tests are illustrated in Figure 5-8 where the best hearing level of either ear is shown. 


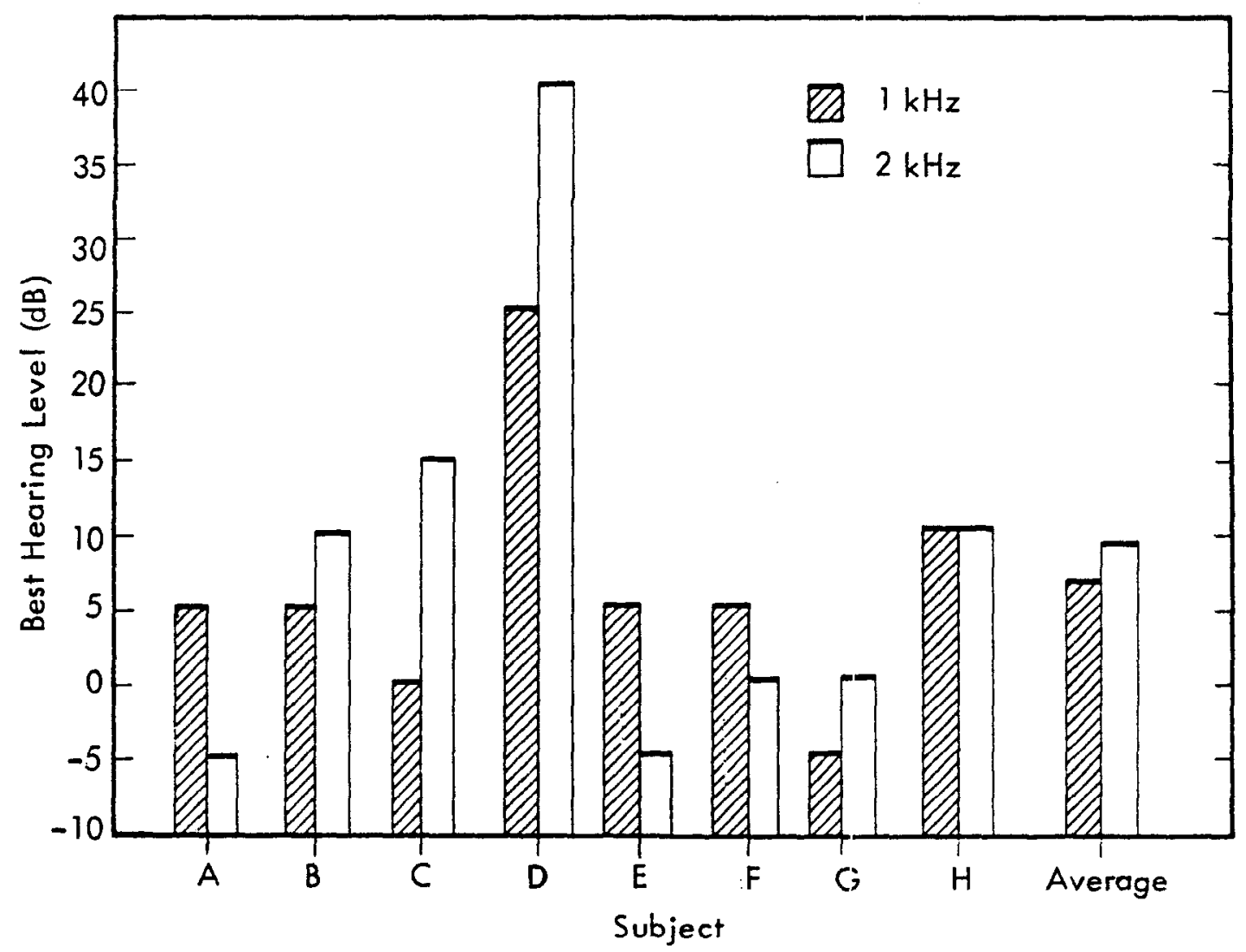

Figure 5-8. Hearing Level of Eight Subjects at $1 \mathrm{kHz}$ and $2 \mathrm{kHz}$. Beltone Model 9D Portable Audiometer Used

Directly following the audiometric testing, the subjects were asked to perform a second task. A simulated warning signal was mixed with brcoadband pink noise and played through a loudspeaker in the test room. The broadband level of the pink noise alone for the subject in the room was 65 to $70 \mathrm{dBA}$. While this noise level was held constant, the signal level was increased until the subject indicated its audibility. This sequence was repeated for each of the signal formats listed in Table 5-3 at both $1 \mathrm{kHz}$ and $2 \mathrm{kHz}$. Regarding the relative detectability of any one format over onother, there were no consistent results to portray. The detectability of both $\mathrm{I} \mathrm{kHz}$ and $2 \mathrm{kHz}$ were almost identical based on the data shown in Figure 5-9a. If the corrections shown 
earlier in Table 5-1 are applied to the data in Figure 5-9a, the audibility thresholds obtained are in excellent agreement with expected levels.

Table 5-3

Warning Signal Formats Tested

\begin{tabular}{|c|c|c|c|}
\hline Signal Duration & Signal Off Time & \multicolumn{2}{|c|}{$\begin{array}{l}\text { Relative Level } \\
\text { Slow RMS Meter }\end{array}$} \\
\hline Continuous & 0 & \multicolumn{2}{|c|}{$0 \mathrm{~dB}$} \\
\hline $50 \mathrm{~m} \mathrm{sec}$ & $0.3 \mathrm{sec}$ & -8 & $\pm 0.2 \mathrm{~dB}$ \\
\hline $100 \mathrm{~m} \mathrm{sec}$ & $0.3 \mathrm{sec}$ & -5.5 & $\pm 0.2 \mathrm{~dB}$ \\
\hline $100 \mathrm{~m} \mathrm{sec}$ & $0.5 \mathrm{sec}$ & -8 & $\pm 0.7 \mathrm{~dB}$ \\
\hline $100 \mathrm{~m} \mathrm{sec}$ & $0.2 \mathrm{sec}$ & -5 & $\pm 0.2 \mathrm{~dB}$ \\
\hline
\end{tabular}

The subjects were also asked to select a level at which the signal attained a waming or alarm quality. Results of this test are portrayed in Figure 5-96. There appears to be a slight advantage in using $2 \mathrm{kHz}$ since a lower level is required, but the majority of the subjects selected $\mathrm{l} . \mathrm{kHz}$ as a preferred waming signal.

It is significant to note the almost complete lack of correlation between the subjects' hearing level and their ability to detect the warning signal in the presence. of a moderate intensity level of noise. These results are not unexpected, as discussed in earlier sections; once the noise and signal exceed the subjects' threshold of hearing, they will detect the waming signal with equal ease. 


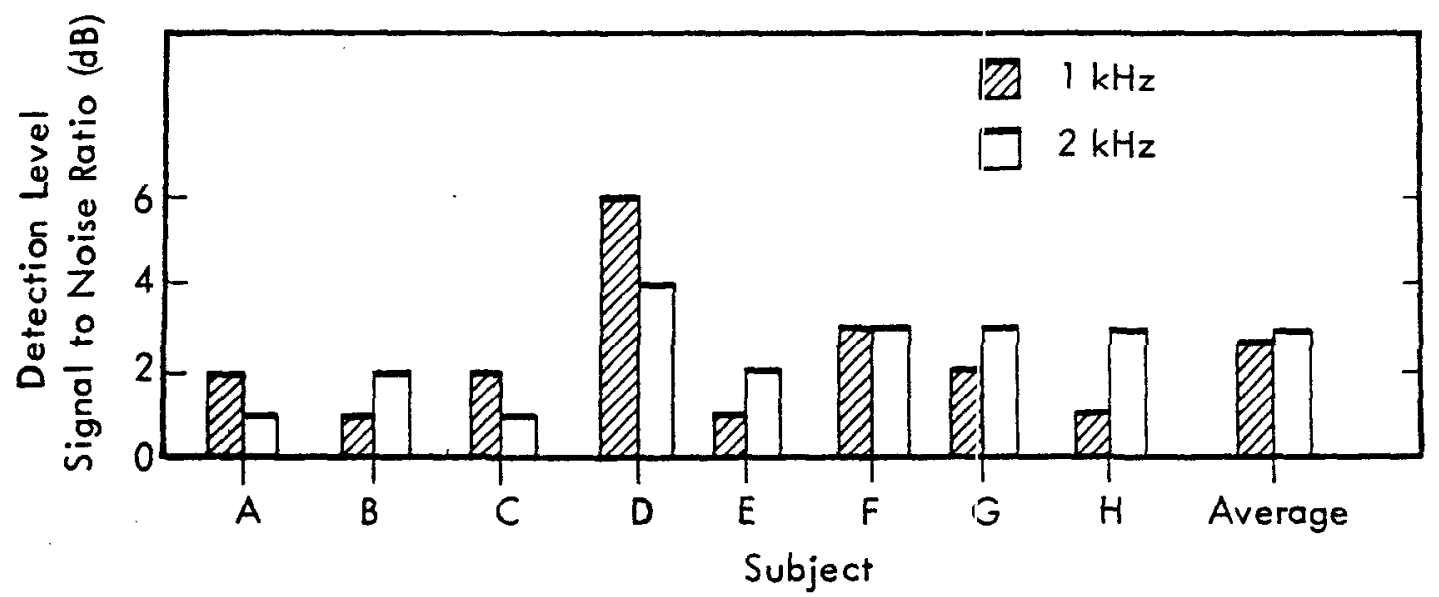

(a) Detection Level (Signal to Noise Ratio) of a $1 \mathrm{kHz}$ and $2 \mathrm{kHz}$ Warning Signal of $100 \mathrm{msec}$ Duration and $200 \mathrm{msec}$ Off Time

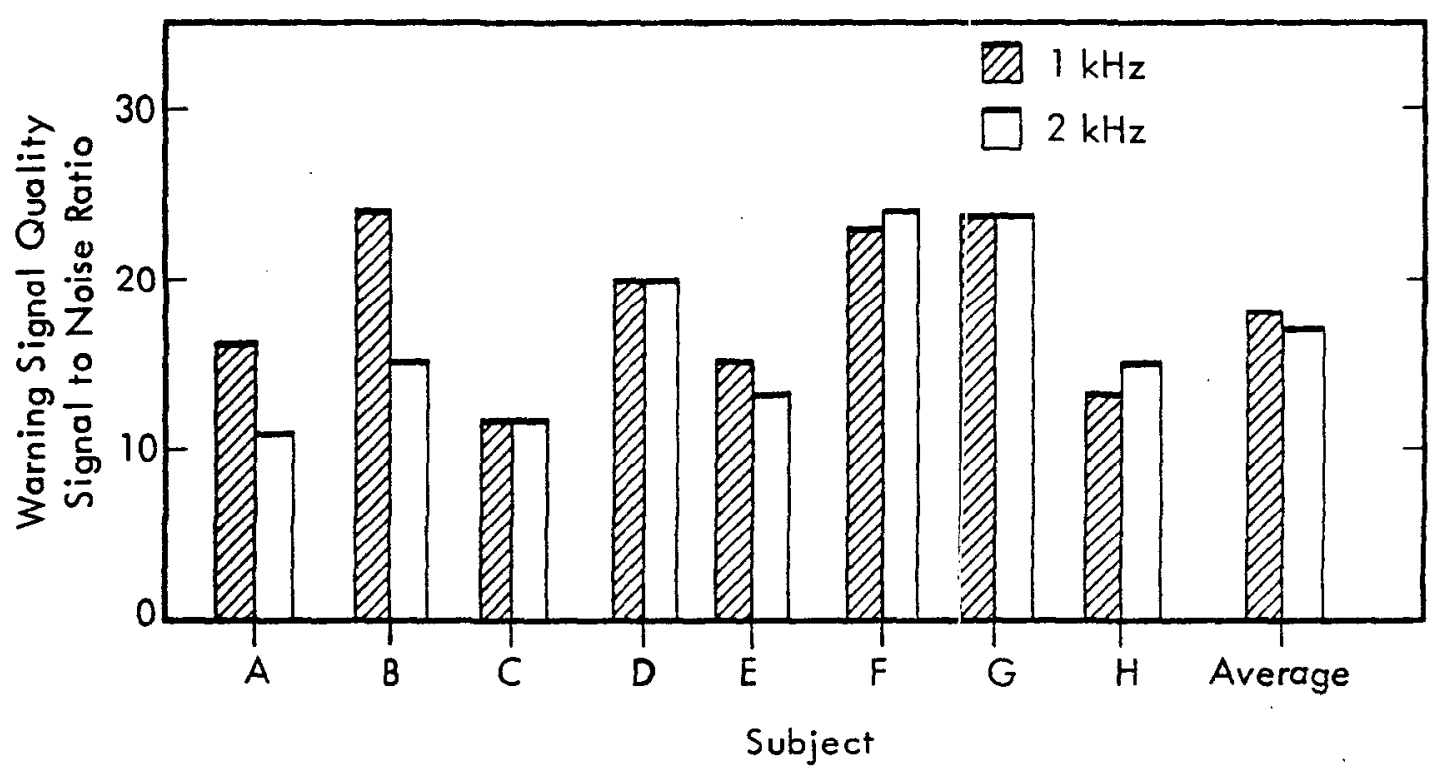

(b) Warning Signal Quality Level (Signal to Noise Ratio) of a $1 \mathrm{kHz}$ and $2 \mathrm{kHz}$ Warning Signal of $100 \mathrm{msec}$ Duration and 200 msec Off Time

Figure 5-9. Detection Level and Warning Quality of the Warning Signal in the Presence of Noise. Pink Noise Level in the Room was 65 to $70 \mathrm{dBA}$. Signal Levels are Shown Relative to the OneThird Octave Band Level of the Noise at Each Frequency 
The preceding sections of this report define the desirable characteristics of the warning signal. A system has been designed which fulfills all the program objectives. It has been constructed with controls to allow signal timing and level variations to be made if further evaluation studies or demonstrations are desired. If, in the future, the system is adopted for use in passenger cars, minor circuit design changes will be required to incorporate the major circuit elements into a single chip.

It was recognized that the system could be designed in several ways and still perform the same identical functions. Basically, the system was developed from the following requirements:

- The device must sense the ambient acoustic level (such as A-weighted) in the near vicinity of the vehicle.

- The device must generate an acoustic warning signal proportional to the measured ambient level when the gearshift is placed in reverse.

These fundamental requirements were satisfied by a circuit with functions as illustrated in Figure 6-1.

The final system design utilized a single inexpensive loudspeaker to perform both receiver and audio output functions. In the block diagram of Figure 6-1, both the acoustic sensor and loudspeaker are common.

When ignition power is applied, the system monitors the ambient level, producing a control voltage which continues to track the ambient until the gearshift is placed in reverse. At this time the control voltage is held and a signal proportional to the ambient is generated. The signal, a pulsed tone at $1250 \mathrm{~Hz}$, is generated at a level approximately $15 \mathrm{~dB}$ above the $\mathrm{A}$-weighted noise level at the source speaker. 


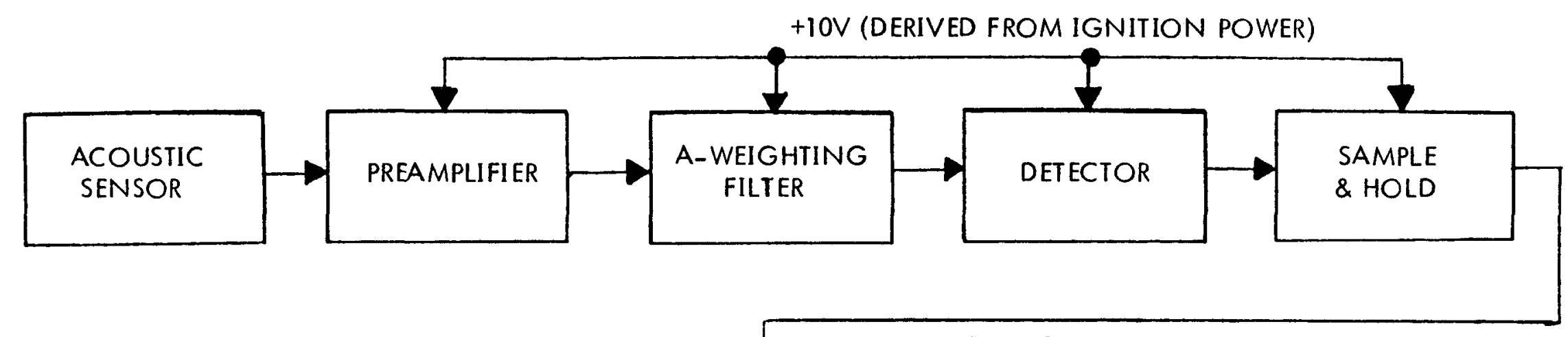

$\stackrel{a}{i}$

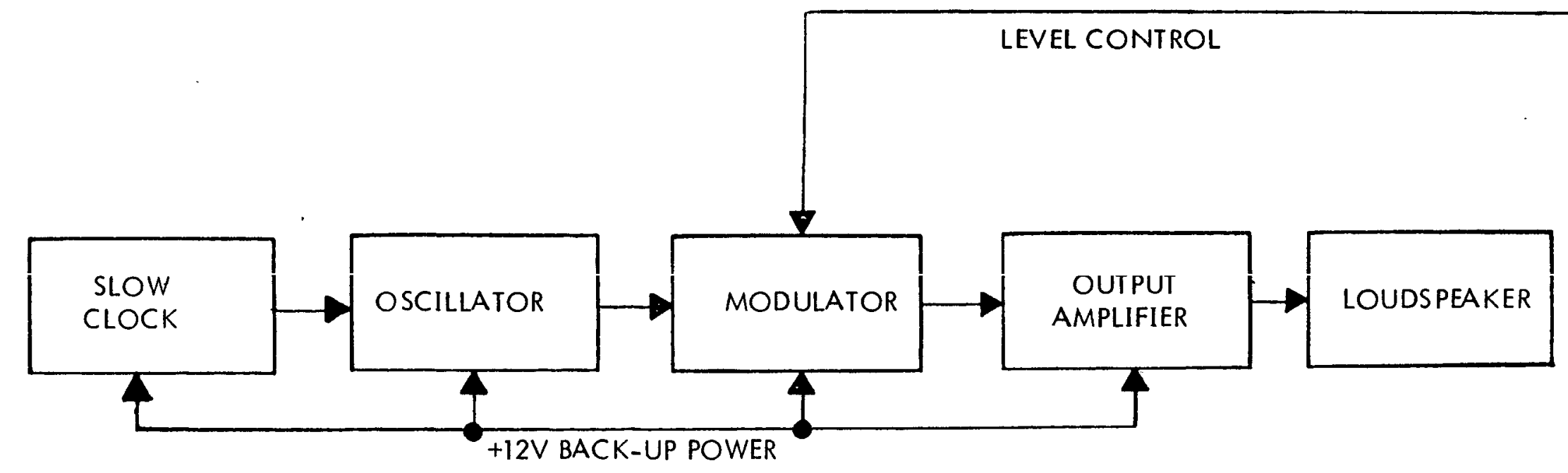

FIGURE 6-1. FUNCTIONAL BLOCK DIAGRAM OF THE WARNING SIGNAL SYSTEM 
Figure 6-2 illustrates the peak warning signal levels behind the vehicle relative to the detected ambient level and the threshold of audibility. The levels shown appear to represent an increase over earlier design levels; this is primarily due to the change to a linear relationship between the ambient and signal, but also due to signal reinforcement from pavement reflections. Other characteristics of the system will be discussed following the circuit description, a diagram of which is shown in Figure 6-3.

\subsection{Circuit Description}

The input stage is a differential amplifier biased about the $+6 \mathrm{~V}$ point. The two $0.047 \mu \mathrm{F}$ capacitors are needed to isolate the bias from the output transistors when they are off, and are the first stage of the input signal filter. The lOK input resistors are necessary to limit the input current to a safe level when the output stage is on. The cutoff frequency of this first stage is approximately $300 \mathrm{HZ}$ to limit the low-frequency response. The gain of this stage is set to $20 \mathrm{~dB}$.

The second stage is a single-ended gain stage producing approximately $28 \mathrm{~dB}$ gain, with a cutoff frequency of $200 \mathrm{HZ}$ controlled by the $0.03 \mu \mathrm{F}$ capacitor and the $33 \mathrm{~K}$ input resistor of the second stage.

The third stage has a variable gain which ranges from 21 to $37 \mathrm{~dB}$ which controls the ambient to signal ratio of the system. The $0.1 \mu \mathrm{F}$ capacitor with the 10K resistor is the final stage of the input signal filter. Detection is accomplished in this stage by biasing the output to zero volts. This eliminates the $0.6 \mathrm{~V}$ offset that would occur if a diode had been used, and increases the dynamic range of the DC signal.

The fourth stage is a DC amplifier stage used to optimize the DC signal for the sample and hold circuit. An integrating filter is included in this stage to provide a smoothing time constant. The $0.1 \mu \mathrm{F}$ used gives a value of 0.03 second which, being quite short, keeps the decay time short enough that signals will not build up if the device is rapidly switched on and off. The output of this stage is also biased to zero volts to give the maximum dynamic range of DC values. The diode in the feedback loop serves to allow the output to reach exactly zero volts. 


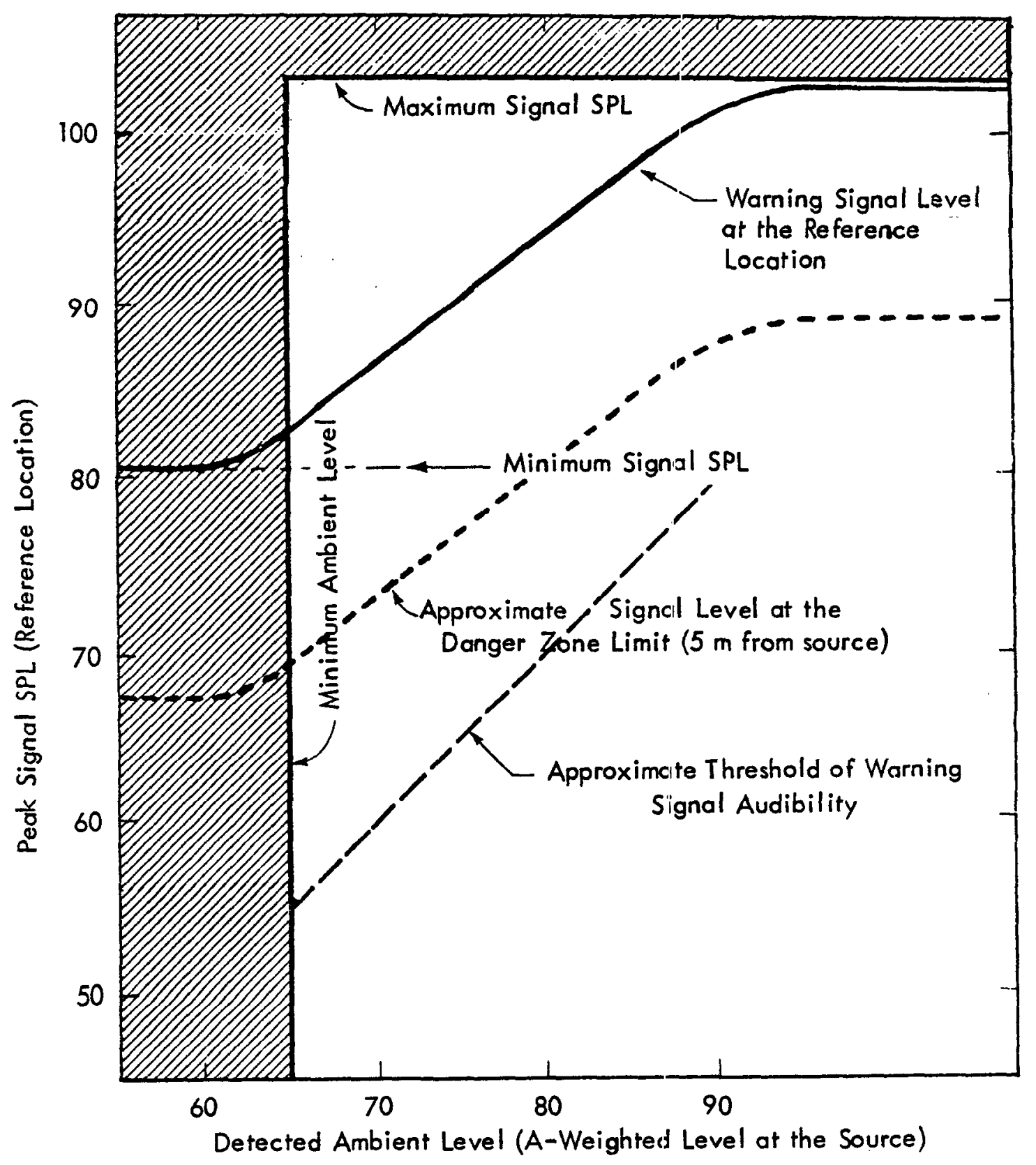

Figure 6-2. Illustration of the Warning Signal Level Parameters 


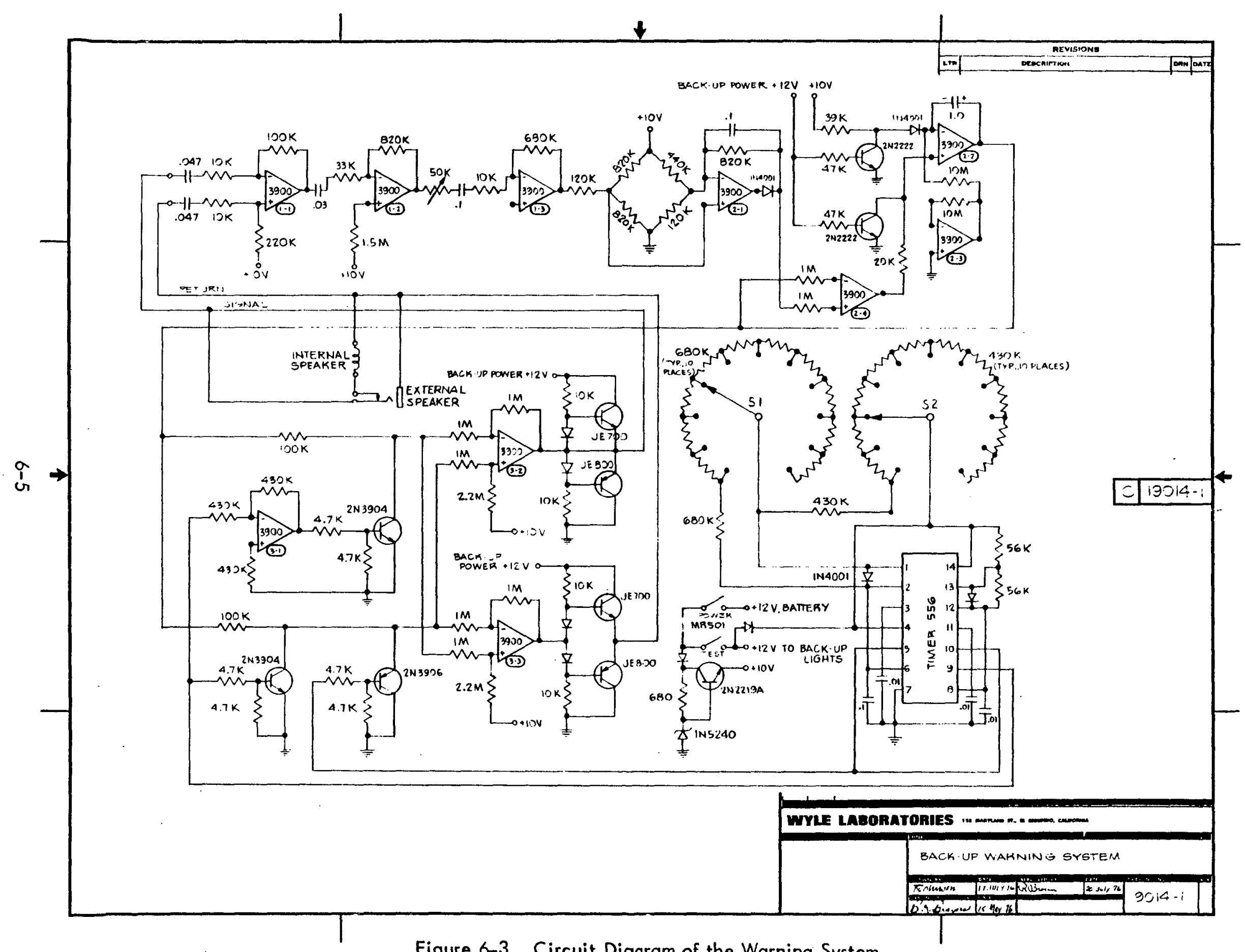

Figure 6-3. Circuit Diagram of the Warning System 
The sample-and-hold circuit is composed of three operational amplifiers designated Q2-2, Q2-3, and Q2-4. Amplifier Q2-3 is used to balance the current flowing into $Q 2-2$. Since they are on the same monolithic chip, their input current will closely match. This technique reduces the external inpust current into Q2-2 to a very low level and can be trimmed if necessary by adjusting the midpoint of the two $10 \mathrm{M} \Omega$ resistors. The input is switched by the two $2 \mathrm{~N} 2222$ transistors. Q2-4 buffers the input and compores the output of Q2-2 with the input and causes it to track. The sampling capacitor is a $1.0 \mu \mathrm{F}$ tantalum which ollows hold times of several minutes.

The $1250 \mathrm{~Hz}$ oscillator and the timing circuit are constructed utilizing a 556 timer IC. This chip contains two separate timer circuits which are used to produce the square wave and control the on-off times.

The first half of the 556 timer (pins 1 thru 6) is used to control the on-time and off-time of the square wave tone. Two rotary switches have been utilized to provide varying resistances $R_{a l}$ and $R_{b l}$. The diode across $R_{b l}$ allows duty cycles of less than 50\%. The on time and off time for the circuit are given by:

$$
\begin{aligned}
& T_{\text {on }}=(0.69)\left(R_{a l}\right)\left(C_{l}\right) \\
& T_{\text {off }}=(0.69)\left(R_{b l}\right)\left(C_{l}\right)
\end{aligned}
$$

The output of this "slow clock" is fed to the reset (pin 10) of the other half of the 556 timer to turn the $1250 \mathrm{~Hz}$ oscillator on and off. This oscillator is constructed with two $56 \mathrm{~K}$ resistors producing a $50 \%$ duty cycle. The output of this "fast clock" is a $1250 \mathrm{~Hz}$ square wave.

The actual square wave output tone is generated by modulating the $D C$ output of the sample-and-hold circuit with the two 2 N3904 switching transistors. The operational amplifier Q3-1 is used to invert the output of the fast clock with unity gain so as to produce equal but out-of-phase inputs to the nfxt amplifier stage. The 2 N3906 transistor turns off the second output when the oscillator is turned off by the slow clock. 
The modulator is followed by a pair of differential drivers Q3-2 and Q3-3. These are biased at $1 / 2$ the supply voltage and drive the bridge connected Darlington outputs. The bridge connection quadruples the output power available at $12 \mathrm{~V}$ into $8 \Omega$ and eliminates the need for a large $D C$ blocking capacitor in series with the speaker. This amplifier is capable of delivering over 6 WATTS at $12 \mathrm{~V}$ supply levels.

A simple IOV regulator is used to supply IC- 1 and $\mathrm{IC}-2$ and el iminate electrical noise on the battery line. IC-3 and the 556 timer are operated directly off the $12 \mathrm{~V}$ back-up supply to maximize output: because of this, the supply must be a low impedance as the current pulses drawn by the output circuit are quite large.

\subsection{Warning System Characteristics}

Important characteristics of the warning signal system will be described. The parameters shown are derived from measurements of the system used for the evaluation tests.

The frequency response of the loudspeaker operating as a microphone is shown in Figure 6-4. The response is not smooth, an expected result for an inexpensive loudspeaker, but is more than adequate for the application.

Directivity of the worning signal in the region behind the vehicle is a relatively complex parameter. The signal is essentially a pure tone, thus it is subject to severe reinforcement and cancellation due to reflections, especially from the hard povement. The horizontal directivity was measured with the device mounted on the test vehicle at a height of 15 "from the pavement. The directivity pattern is illustrated in Figure 6-5, with variations caused by ground reflections illustrated in Figure 6-6. The combined effects of attenuation, signal reflections, and directivity variations will be discussed further in Section 6.5. 


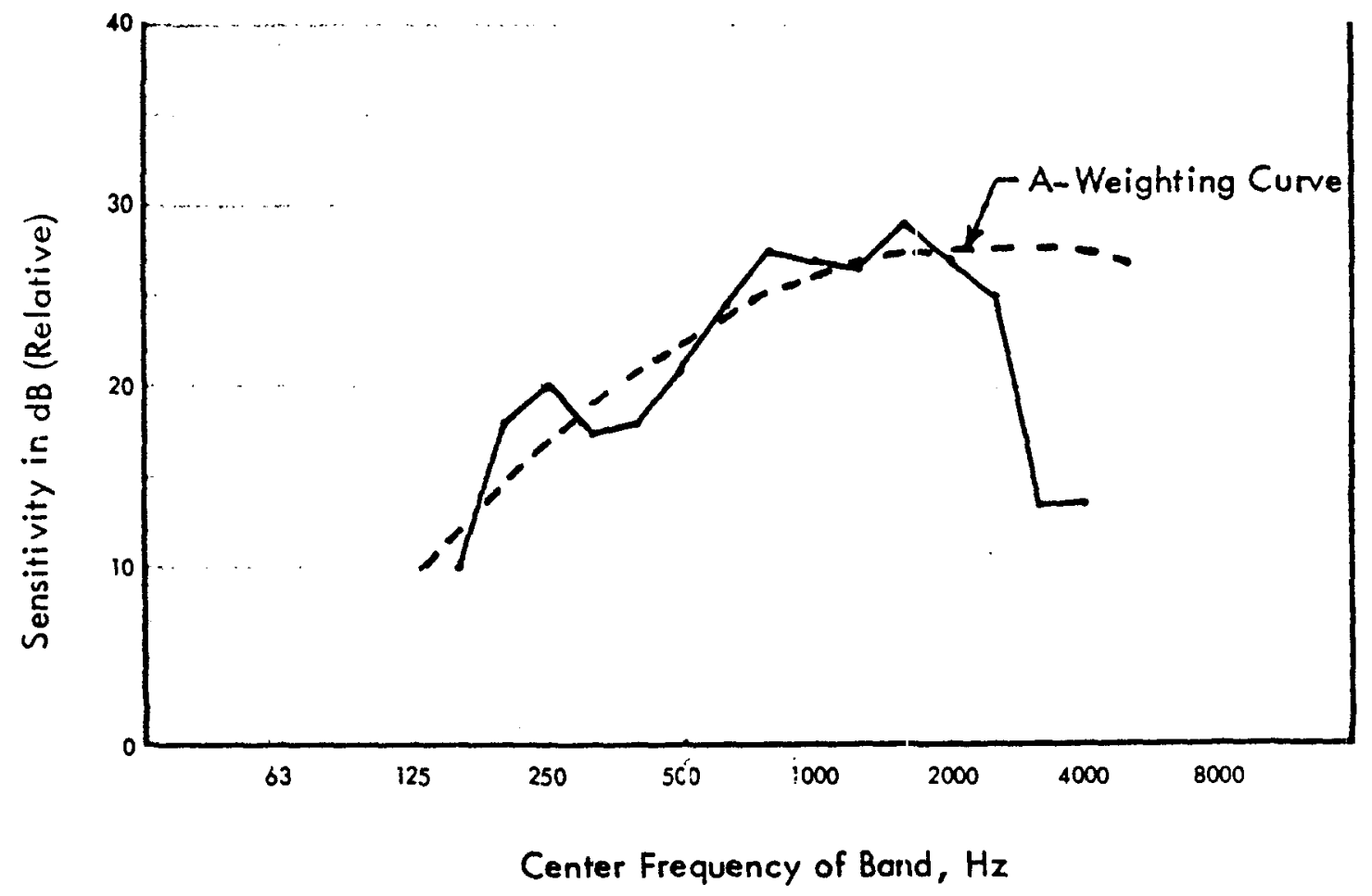

Figure 6-4. Frequency Response of the Acoustic Sensor. Measured with $1 / 3$ octave bands of pink noise. 


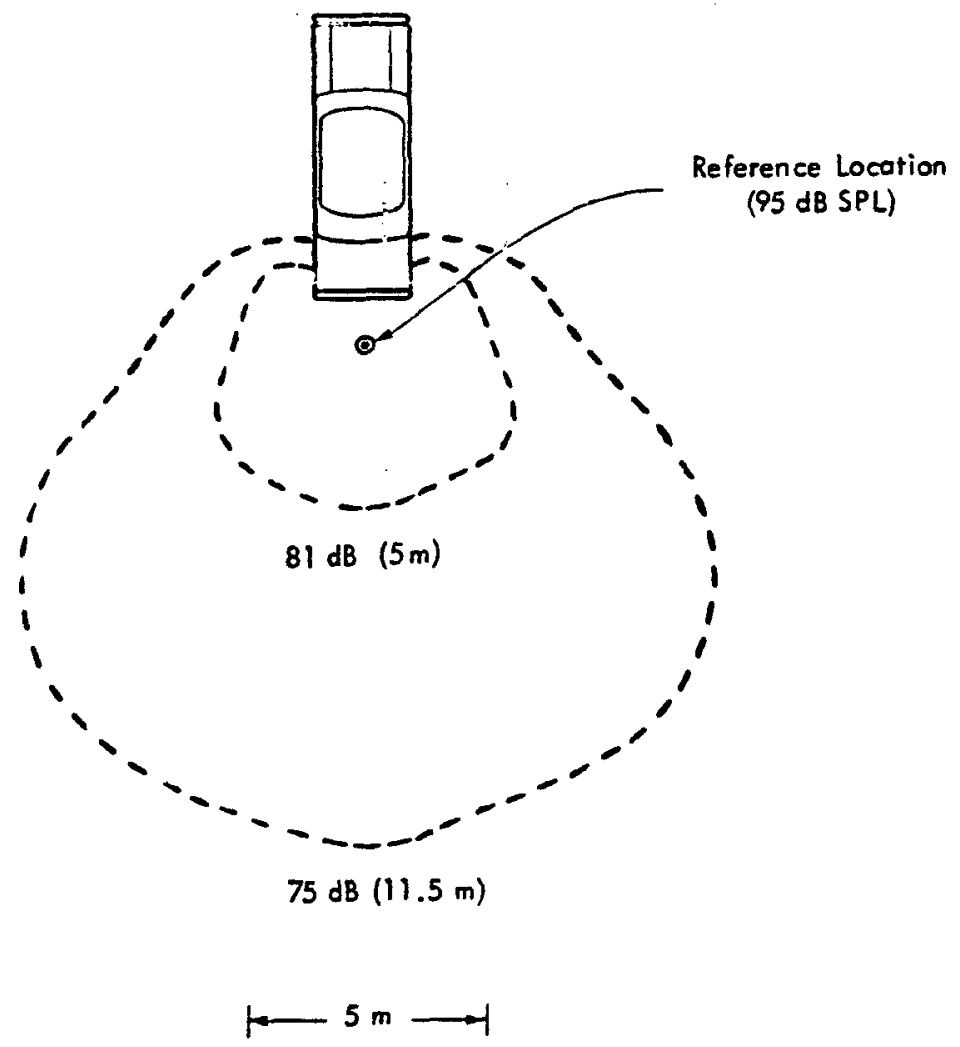

Figure 6-5. Directivity of the Warning Signal System. Dashed Lines are Contours of Equal Sound Pressure Level.

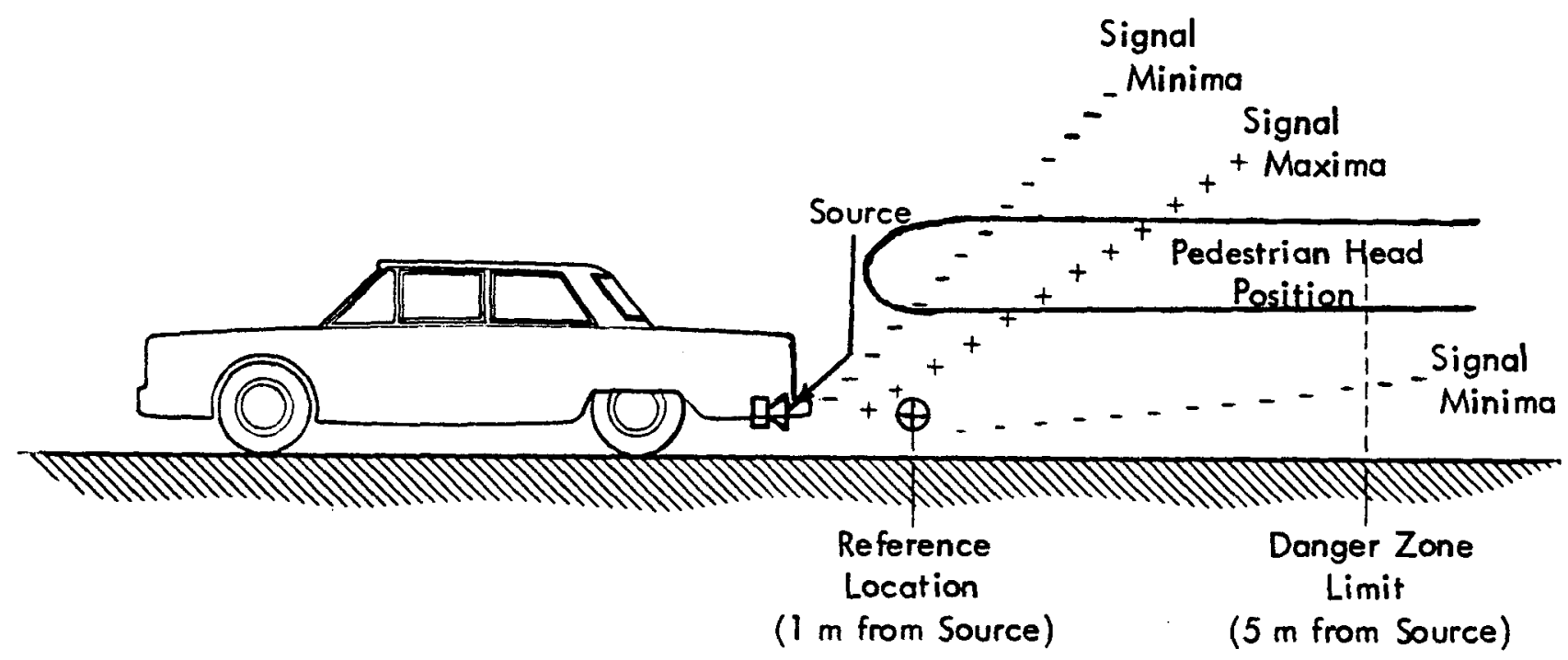

Figure 6-6. Illustration of the Signal Level Variations in the Vertical Plane Behind the Vehicle. 
Input power requirements for the system are nominal: during receiving only 23 ma at 12 volts are required. When driving the loudspeaker at maximum output levels, input current pulses are approximately 2 amps peak to peak.

\subsection{System Installation and Operation}

The warning signal system is completely self-contained requiring only a $12 \mathrm{~V}$ DC supply which is normally available in most vehicles. It contains an internal loudspeaker which may be used for demonstration purposes and a phone jack allows connection of an external speaker, which disconnects the internal unit. Two rotary switches control the on and off time of the pulsed tone over a range of 10 to 1 .

Installation of the system in a vehicle is accomplished by connecting the +12 Volt battery lead to the barrier strip, connecting ground to the vehicle body, and connecting a lead to the back-up light circuit. The external loudspeaker should be mounted at the rear of the vehicle facing backward. On some vehicles it may be mounted just below the bumper to make it least conspicuous. If a permanent installation is being made, the +12 Volt power should be tapped following the ignition switch. When the system is connected as described here, it will operate using the three toggle switches or by leaving the main power switch and the warning signal switch on and operating the vehicle normally.

On and off times of the warning signal are controlled by setting the positions of the two rotary switches. Table 6-1 lists the duration times for each switch position. Any combination of on and off times are available by selecting the appropriate positions. Evaluation of the system was performed with SI set to position 3 and S2 set to position 2 .

Once the system is installed, it should be calibrated. The best method is to choose a quiet location where the idling vehicle will control the ambient at the speaker. With a sound level meter measure the A-weighted noise level at the speaker location. Activate the warning signal and measure the signal level at 1 
Table o- 1

Warning Signal Tone - On and Off Time for Each Switch Position

\begin{tabular}{|c|l|l|}
\hline $\begin{array}{c}\text { Switch S1 or S2 } \\
\text { Position }\end{array}$ & $\begin{array}{l}\text { Tone Off } \\
\text { Period (S1) }\end{array}$ & $\begin{array}{l}\text { Tone On } \\
\text { Period (S2) }\end{array}$ \\
\hline 1 & $0.035 \mathrm{sec}$ & $0.042 \mathrm{sec}$ \\
2 & 0.131 & 0.095 \\
3 & 0.200 & 0.142 \\
4 & 0.267 & 0.190 \\
5 & 0.336 & 0.236 \\
6 & 0.402 & 0.283 \\
7 & 0.468 & 0.327 \\
8 & 0.526 & 0.368 \\
9 & 0.595 & 0.420 \\
10 & 0.662 & 0.463 \\
\hline
\end{tabular}

meter directly in line with the speaker. The sound level meter will indicate a level approximately $5 \mathrm{~dB}$ below the desired peak signal level which can be read off the curve of Figure 6-2. For example; if the ambient level is $65 \mathrm{dBA}$, the measured signal level at the reference location should be approximately $76 \mathrm{dBA}$. Sensitivity changes may be made by adjusting the 50K, 10 turn potentiometer on the system circuit board, accessible through a hole in the cose.

\subsection{System Design Comments}

The first breadboard of the system utilized an electret microphone as the acoustic sensor. Electret microphones, of the type used, have become quite common, being used extensively in hearing aids and inexpensive tape recorders. If a microphone of this type were used, good environmental protection would be required. It was felt this would severely limit the acceptability of the design.

Using a microphone in the circuit did allow a valuable design concept to be used. An electronic switch was used to deactivate the microphone circuit during bursts of the loudspeaker, a period of 100 milliseconds. The microphone would thus "listen" between each burst of the warning signal and continuously readjust the signal 
level to track the ambient. This design feature would be extremely berieficial; the signal would obviously be less annoying because it would not exceed the preset ambient-to-signal level, and it would also be less likely to result in the signal being unheard in a suddenly increased ambient behind the vehicle.

The second generation breadboard eliminated the nicrophone but maintained the continuous level adjustment. A single loudspeaker, func"ioning as a microphone between output signal bursts, was used. Again, an electronic switch was required to deactivate the microphone circuit during output signal bursts. The circuit was never completely operational, as the timing control of the preamplifier was critical due to the loudspeaker ringing after being driven with each tone burst. After each burst, the loudspeaker would continue to oscillate or ring for up to 50 milliseconds, depending on the drive amplitude. If the microphone circuit was activated immediately after the output burst, it would receive a large signal not due to the acoustic ambient. Eliminating this transient required additional complexity in the timing circuitry.

This circuit also utilized a variable transconductance amplifier, a relatively new development in integrated circuits. It was used for amplifier switching and gain control functions but it was not easily adaptable to this single supply amplifier design.

Because of its complexity, the continuously adjustable output level feature was finally abandoned. A system design of this type would be ideal, as it could be powered from the back-up light circuit alone and would continuously adjust itself to the ambient level.

The final system design described earlier was the best choice, considering the many options available at this time. Trade offs between system complexity, circuit element costs and potential environmental protection problems, were the guiding criteria of the design.

\subsection{Propagation of the Warning Signal}

There are two conflicting aspects to the use of an audible back-up warning signal on automobiles. First, we wish to produce a signal level which will adequately warn a pedestrian who is in danger from the backing vehicle. 
And in conflict with this requirement, we'must minimize the annoyance to the remainder of the population.

Of course, there is some educational benefit to be derived in having a signal which is audible to much of the populace; they would then become familiar with the device and its intent. The educational process may be brief, evidence the publics' rapid familiarity with seat belt warning signals. For this reason, the signal should be optimized to warn the target population and simultaneously not annoy the general population.

The peak warning signal output level has been selected to be: approximately equal to or slightly above the ambient level in the region 5 meters from the rear of the vehicle. Exact values for this difference are impossible to assign due to the following:

- In quiet ambient-areas, the automobile self-noise controls the signal level. This would result in an elevated signal level relative to the pedestrians ambient.

- A loud, short term noise, possibly from a passing vehicle could result in an artifically high signal level.

- If the ambient level was minimum when the signal was activated, the signal could be unheard when the ambient increases.

\subsubsection{Signal Propagation Near the Vehicle}

A warning signal frequency of $1250 \mathrm{~Hz}$ has been selected with the intensity controlled by a microphone monitoring the ambient level up to the instant the car is placed in reverse. Propagation of the warning signal in the near vicinity of an automobile (out to the danger zone limit of 5 meters) will be highly variable due to reflections and shadow effects from close-by structures and vehicles. Based upon the relationship between the ambient level and the warning signal level (illustrated earlier in Figure 6-2) there will be a condition where the signal will be only about $12 \mathrm{~dB}$ above the threshold of audibility. Of course these conditions exist straight back from the vehicle at the extent of the warning zone. The source directivity (shown in Figure 6-5) cause signal levels at right angles from the vehicle rear to be approximately $6 \mathrm{~dB}$ lower than straight back. 
If it is assumed the ambient level in the vicinity of the vehicle is constant, the warning signal level will seldom exceed this ambient noise level out to the limit of the danger zone. Thus the signal from one vehicle would seldom affect the level control of a system on a second vehicle. This influence of other vehicles upon the level control mechanism was studied in a large parking lot. This observation to be described in the next section indicated that seldom does more than one car back at a time, and when they do they are separated by several rows of parked cars.

\subsubsection{Propagation Within the Community}

We have reported the noise level extant at various types of community locations and the level variations to be expected were portrayed in Figure $4-3 .^{20}$ To exactly determine the signal level in the near region of the test vehicle during the system evaluation was not a feasible task.

Audibility tests were performed at different parking locations to determine the distance of signal perception. The results were highly variable, dependent on the fluctuations of the ambient at both the vehicle and the receiving location. Generally the signal was only barely audible at distances of 150 feet. Variability of this distance was also due to obstacles in the near vicinity of the vehicle.

The factor of multiple vehicles backing simultaneously was also examined. A large parking lot in a commercial shopping area was carefully watched for a period of about 10 minutes. The lot could hold almost 600 cars and during the observations, approximately 300 cars were present.

During each minute of this period a maximum of 2 vehicles at a time were backing, with several rows of parked cars separating them. In the 10 minute period a total of 9 vehicles backed. This data sample, taken at midday should represent the average activity. Store closing times, and sale days would likely result in more backing activity but the observations indicated the annoyance factor in this area would be minimal. 
To estimate the impact of the warning signal on the community A-weighted energy average noise level ( $\left.L_{e q}\right)$ we must consider, in addition to its amplitude, the duty cycle of the signal and the activation period of the warning.

The warning signal duty cycle has been defined: a burst of 0.1 second duration followed by 0.2 second of silence. This implies that only one-third of the acoustic energy is emitted as compared to the case when the signal is on 100 percent of the time. A reduction of one-third in acoustic energy corresponds to a level reduction of about $5 \mathrm{~dB}$ below the signal peak level. Thus, this correction must be applied to the energy average estimation.

Based upon observations made of drivers preparing to back, described in Section 4.4, it is estimated that an average duration for backing a vehicle would be approximately 7 seconds. An estimate of the number of vehicles backed within any given hour would be difficult to assess. At some locations, such as following a sporting event, several hundred could be backed within a short period. However, at an average parking site, during a busy period of the day, a conservative estimate may be that between 20 to 50 vehicles per hour would be backed. This would then result in 140 to 350 seconds of warning signals being generated within the parking area, corresponding to 3.9 percent to 9.7 percent of exposure time, respectively. Thus, in order to affect the $L_{e q}$ during this average hour, the noise level produced by the warning signals must approach within:

For 3.9 percent exposure time -

$$
14-6=8 d B
$$

and for 9.7 percent exposure time -

$$
10-6=4 \underline{d B}
$$

above the existing $L_{e q}$ in the parking area. The $6 \mathrm{~dB}$ correction in the above calculation allows for the difference in levels required to produce an increase of $1 \mathrm{~dB}$ in the existing level. When the signal duty cycle correction is applied, the final values are between $13 \mathrm{~dB}$ and $9 \mathrm{~dB}$ as the range of differences required for the peak warning signal level to exceed the $L_{e q}$ and thus af fect it. 
It was shown in Figure 6-2 that the warning signal does not exceed the ambient A-weighted noise levei except for a small distance from the vehicle. 20 It would therefore appear to be a minimal problem of the warning signal annoying an appreciable segment of the population except under rare special conditions.

\subsection{Specification of the Warning Signal}

This specification establishes the characteristics of an audible automobile back-up warning device. The device will incorporate a transducer to measure the ambient background noise level and establish the signal output at a predetermined level above the ambient. It is intended for use on privare automobiles and other vehicles which normally operare on public streets and thoroughfares.

\subsubsection{Mounting}

The device shall be mounted at the rear of the vehicle and be protected to withstand normal wear and tear, and adverse environmental conditions. It shall be mounted with the sound source projecting the signal rearward and unless the source also acts as the microphone, this sensor will be incorporated as an integral part of the assembly.

\subsubsection{Power}

When ignition power is availabie, the microphone section of the system shall be activated and monitor the acoustic noise level. When the gearshift is placed in reverse, the warning signal shall be activated and remaln on until the gearshift is disengaged from reverse or until Ignition power is removed.

\subsubsection{Device Characteristics}

\subsubsection{Microphone Circuit}

The frequency response of the microphone section of the device shall approximate the characteristics of a Type 3 sound level meter as described in 
ANSI S1.4 - 1971. The A-weighted relative response from $100 \mathrm{~Hz}$ to $2 \mathrm{kHz}$ shall be met for sound arriving at perpendicular incidence. The tolerance for the response shall be $\pm 5 \mathrm{~dB}$.

The electronic noise level of the microphone circuit, when measured in a quiet environment, shall be equivalent to less than $55 \mathrm{~dB}$ SPL.

\subsubsection{Control Voltage}

The microphone section shall produce a control voltage proportional to the measured input SPL. The input SPL will range from $65 \mathrm{~dB}$ SPL (10 dB above the internal noise floor) to a maximum level of $85 \mathrm{~dB}$. As an example, control voltages for these two SPLs would be $100 \mathrm{mv}$ and 1 volt respectively.

\subsubsection{Warning Signal Format}

The warning signal shall be a pulsed sinusoid (or square wave) at a frequency of $1250 \mathrm{~Hz}( \pm 200 \mathrm{~Hz})$. The signal on-time shall be $100 \mathrm{~m} \mathrm{sec}( \pm 20 \mathrm{~m} \mathrm{sec})$ and the signal off-time shall be $200 \mathrm{~m} \mathrm{sec}( \pm 40 \mathrm{~m} \mathrm{sec})$. Rise and fall times of the signal shall be less than $5 \mathrm{~m} \mathrm{sec}$. The first pulse of the warning signal shall occur within $100 \mathrm{~m} \mathrm{sec}$ of the time the auto is placed in reverse and the system shall continue pulsing until the gearshift is disengaged from reverse or until ignition power is removed.

\subsubsection{Warning Signal Output}

Output of the warning device shall be measured at a horizontal distance of 1 meter behind the rearmost point of the vehicle at the same height as the device. At this reference location the peak SPL shall be as indicated in Table 6-2 when measured according to paragraph 6.4. The values of the control voltage shown in this table are not required; it is only necessary to maintain the relationship between the input SPL and warning signal SPL. 
Table 6-2

Warning Signal System Parameters

\begin{tabular}{|l|c|c|}
\hline Input SPL, dB & $\begin{array}{c}\text { Control Voltage* } \\
\text { Volts }\end{array}$ & $\begin{array}{c}\text { Peak Varning Signal SPL } \\
\text { at Reference Location } \\
\text { dB re 20 } \mu \text { Pa }\end{array}$ \\
\hline 65 and less & 0.1 & 80 \\
70 & 0.18 & 85 \\
75 & 0.32 & 90 \\
80 & 0.56 & 95 \\
85 and greater & 1.0 & 100 \\
\hline
\end{tabular}

*These values are shown for illustration purposes only.

\subsubsection{Acoustic Measurement Procedures}

Sound pressure level output of the device shall be measured according to the procedures described in paragraph 2 of ANS1 51.2-1971, "Method for the Physical Measurement of Sound." Measurements shall be made with a microphone system or sound level meter conforming to the specification: of a Type 2 General Purpose Sound Level Meter set forth in ANSI S1.4-1971, "5pecification for Sound Level Meters." If necessary, appropriate corrections will be applied to account for the warning signal duty cycle. 


\section{$7.0 \quad$ EVALUATION OF THE WARNING SIGNAL SYSTEM}

The effectiveness of the waming signal was measured by performing a series of evaluation tests at locations where pedestrians are typically in danger from backing vehicles. Four levels of effectiveness were measured. Two of these levels are defined in terms of the subject's verbal report, and two in terms of the subject's non-verbal behavior. The criterion of effectiveness becomes more stringent from the lowest level (1) to the highest level (4). The four levels of effectiveness were:

Verbal Reports

(1) Subject reports having heard the signal (signal detectability).

(2) Subject attributes the signal to the appropriate source (signal discrimination).

Non-Verbal Behavior

(3) Subject emits an observational response, e.g., glances at the appropriate automobile.

(4) Subject executes an ovoidance response, i.e., stops walking. changes course, speeds up, etc.

The criteria for success of the system was that the subject either reports having heard the signal or that the subject was observed to notice the signal. This process of alerting was judged successful if 95 percent of the target population responded favorably.

One problem in interpreting the evaluation of the back-up warning device is that pedestrians do not presently know the meaning of its signal; i.e.. they would not attribute the sound of the device to a backing automobile without additional information or other cues. The effectiveness of the device would therefore be significantly underestimated if one considered only the percentage of cases in which the subject executes an avoidance response.

In addition to determining whether the device was successful according to the criteria discussed above, the field experiment determined its effectiveness relative to a control condition. The percentage of cases in which the device satisfies each of the four criteria mentioned above were compared for an experimental and a control treatment. In the experimental treatment, the subject was exposed to the waming 
device plus all the customary cues of a backing automobile (except movement of the automobile). The control condition exposed the subject to the same conditions as the experimental treatment, except that the warning signal was omitted.

\subsection{Evaluation Method}

During each test sequence of the evaluation tests the driver of the test vehicle would sit, apparently unaware of the pedestrian activity. In some cases the rear view or side mirror was used to determine when the subjest was entering the test area. In others, the interviewer or observer signalled the driver to start the sequence. The driver used care to avoid looking at or making eye contact with the subject. Even with these precautions, some subjects reported in the interview that the driver was aware of their presence and thus they felt no threat from the vehicle.

Tests were performed both with the device and without it:

- With the device -- The test vehicle engine was started and allowed to idle. When the subject reached the danger zone boundary, usually 5 to 10 feet before the accident zone, the warning signal and back-up lights were activated and left on until the subject passed the vehicle.

- Without the device -- The sequence timing was identical, engine started, and then back-up lights only were activated.

For both sequences, brake lights were also activated with the back-up lights, but the gearshift was never placed in reverse. A microphone was mounted above the rear bumper and recordings of the acoustic levels, ambient and signal, were made during each test sequence.

The observer and interviewer took positions on oppcisite sides of the test zone to allow them to best observe each subjects reaction to the tests. They intentionally tried to be inconspicuous to minimize the subjects being distracted. They also avoided obviously watching the subject before each test. When the subject passed the vehicle, at the end of the test sequence, the interviewer would approach the subject and conduct the interview. Reactions to the interview were varied. 


\subsection{Subject Selection}

At the request of the National Highway Traffic Safety Administration, Wyle studied 160 back-up accidents and extracted data relevant to the potential effectiveness of a back-up warning device. These data, presented in Section 2.0 of this report, provide a logical basis for the design of experiments to evaluate the effectiveness of such o device. Many factors bear on the accident cause and its prevention. A large percentage of the pertinent factors were incorporated into the experimental design but some were difficult to guarantee as controlling elements of the experiment. The previous research has shown that both age and sex are determiners of risk in the back-up situation and can influence one's capability to respond to a warning device. Table 7-1 shows a breakdown of the actual accident victims by age and sex; percentages shown were used as a guideline for subject selection.

Table 7-1

Accident Victims' Age and Sex (percent of total)

\begin{tabular}{|c|c|c|c|}
\cline { 2 - 4 } \multicolumn{1}{c|}{} & Young (0-24) & Middle (25-44) & Older (45+) \\
\hline Male (58\%) & 22 & 14 & 23 \\
Female (42\%) & 15 & 10 & 16 \\
\hline TOTAL & $37 \%$ & $24 \%$ & $39 \%$ \\
\hline
\end{tabular}

During the evaluation tests subjects were selected from available pedestrians at each site. Although some percentages varied from those desired, the values obtained, illustrated in Table 7-2, were not unreasonably distributed. 
Table 7-2

Evaluation Test Subjects' Age and Sex

(percent of total)

\begin{tabular}{|c|c|c|c|}
\cline { 2 - 4 } \multicolumn{1}{c|}{} & Young (0-24) & Middle (25-44) & Older (45+) \\
\hline Male $(38 \%)$ & 4 & 19 & 11 \\
Female $(62 \%)$ & 15 & 17 & 31 \\
\hline TOTAL & $19 \%$ & $36 \%$ & $45 \%$ \\
\hline
\end{tabular}

Details of the data shown in Table 7-2 are derived from the data in Appendix B. Ages shown are estimates based on observations of the testing personnel.

\subsection{Site Selection}

A major factor in the cause of a back-up accident is the type of location. Table 7-3 shows the back-up accident distribution by type of location derived from Section 2.0. These data show that nearly two-thirds of all accidents occur in parallel parking situations or when backing out of an alley or driveway.

Table 7-3

Accident Locations

\begin{tabular}{|c|c|}
\hline Location & Percent of Accidents Accounted For \\
\hline Mid-block, near curb & 36 \\
Alley or driveway & 29 \\
Off-street parking areas & 13 \\
Crosswalk & 19 \\
Other & 3 \\
TOTAL & $100 \%$ \\
\hline
\end{tabular}

During the evaluation tests observations were made at locations as illustrated by the distribution shown in Table 7-4. 
Table 7-4

Distribution of Test Subjects by Age and Site Locations ( 74 Subjects)

Percent of Subjects Observed

\begin{tabular}{|l|c|r|r|c|}
\hline \multirow{2}{*}{ Type of Site } & \multicolumn{4}{|c|}{ Age } \\
\cline { 2 - 5 } & $0-24$ & $25-44$ & $45+$ & Total \\
\hline Mid-Block & $7 \%$ & $8 \%$ & $5 \%$ & $20 \%$ \\
Alley or Driveway & 0 & $11 \%$ & $11 \%$ & $22 \%$ \\
Parking Lot & 0 & $4 \%$ & $3 \%$ & $7 \%$ \\
Crosswalk & $12 \%$ & $13 \%$ & $26 \%$ & $51 \%$ \\
\hline TOTAL & $19 \%$ & $36 \%$ & $45 \%$ & $100 \%$ \\
\hline
\end{tabular}

The distribution shown in Table 7-4 does not exactly match the desired balance between types of sites but time did not allow sufficient observations at some of the more sparsely active sites.

The accident data, from Section 2.0, wire also analyzed to determine the time of day most back-up accidents occur. The results indicated the peak incidence rates occur near lunchtime and in the late afternoon, but with some accidents occurring during all hours. The evaluation tests were mostly performed during the late morning to mid afternoon period, when pedestrian subjects were most plentiful at the sites.

Table 7-5 lists the test sites, their classification, and the number of subjects observed at each. Complete descriptions of each site are contained in Appendix $C$. 
Table 7-5

Test Sites and Number of Subjects Observed During Evaluation Tests

\begin{tabular}{|c|l|l|c|}
\hline $\begin{array}{c}\text { Site } \\
\text { Number }\end{array}$ & Site Location & $\begin{array}{c}\text { Type of } \\
\text { Site }\end{array}$ & $\begin{array}{c}\text { Number of } \\
\text { Subjects Observed }\end{array}$ \\
\hline 1 & Sepulveda (North), Westchester & Crosswall: & 25 \\
2 & Sepulveda (South), Westchester & Crosswalk & 13 \\
3 & Karls Stationers, Westchester & Mid-Block & 4 \\
4 & F. W. Woolworth, Westchester & Mid-Block & 11 \\
5 & Boys Market, Hawthorne & Parking L.ot & 3 \\
6 & 9th Street, Los Angeles & Alley & 0 \\
7 & 6th Street, Los Angeles & Alley & 16 \\
8 & Sav-On, Westchester & Parking l.ot & 2 \\
\hline
\end{tabular}




\subsection{Evaluation Test Data}

This section presents data and data analyses from the field evaluation tests of the back-up warning device for automabiles. The effectiveness of the device was evaluated in terms of data gathered from behovioral observations and subject interviews in the field. The device would be considered successful if it were shown to have elicited a noticeable response and/or the subject indicated that he noticed the device in 95 percent of the tests.

The dato were gathered on log sheets and later coded as shown in Appendix B. In the analyses that follow, the data for 74 subjects were tabulated to indicate the comparison of interest and the appropriate statistical test(s) follow. A total of 94 subjects were observed. The signal level was inadequate for the first six subjects tested with the device. For subsequent subjects, the signal level was higher in amplitude than for these first six. For 14 other subjects, the observational and interview data were inadequate.

Several types of data were gathered, but critical among these for testing the effectiveness of the device were the behavioral observations and interview data. Two observers carefully watched each subject as he passed behind the test vehicle. The observers were positioned so that they had different viewing angles. Thus, one observer may have seen an avoidance behavior while the other did not. After the test and interview, the observers discussed what each saw and agreed upon a pooled rating. The pooled ratings were used for the analysis that follows. The interview obtained data directly from the subjects as to whether they noticed the test vehicle or not. A subject was considered to have "noticed" if he exhibited a visual or physical response to the test vehicle, or stated during the interview that he noticed. Thus, if the subject was aware of the vehicle, but no response was observed, this subject was effectively warned and it was discovered during the interview. Not all subjects consented to an interview, and some subjects were not adequately observed because of traffic patterns (both pedestrian and automobile). Thus, there were 14 unknowns on both pooled rating and interview data in the 88 subjects. These subjects were excluded from the data analyses. 
In Table 7-6 below, "Subject Noticed" were all of those who were given a pooled rating of 2 (visual response only) or higher (physical response) and/or gave a positive response on the interview when asked if they noticed the test vehicle or the warning device (when used). The data in Table 7-6 indicate: 1) that approximately $95 \%$ of the observed subjects noticed the test vehicle when the cevice was used, and 2) the tests with the device resulted in significantly more subjects noticing than the tests without the device $\left(x^{2}=20.15, d f=1, p<0.001\right)$. The $x^{2}$ value was calculated using the Yates correction for continuity as shown in equation $(7-1)$, where $a=51, b=3, c=9, d=11$, and $N=74$ from the table.

$$
x^{2}=\frac{N([a d-b c]-N / 2)^{2}}{(a+b)(c+d)(a+c)(b+d)}
$$

where:

$x^{2}$ is a value calculated to test a hypothesis that the changes in a situation had no affect on the variable mecisured.

$a, b, c, d$ are table values.

$N$ is the number of subjects.

$d f$ is the degrees of freedom.

$p$ is the probability.

Thus, the back-up warning device satisfies the basic criteria of being $95 \%$ effective, and more effective than starting the car (back-up lights, engine noise, etc.) without the device.

\begin{tabular}{|c|c|c|c|}
\hline Test & Subject Noticed & Subject Did Not Notice & Total \\
\hline With Device & 51 & 3 & 54 \\
Without Device & 9 & 11 & 20 \\
\hline Total & 60 & 14 & 74 \\
\hline
\end{tabular}

Note: Entries are frequencies (\# of subjects).

Table 7-6. Overall Effectiveness 
The population that was analyzed was distributed as shown earlier in Table 7-2. It was shown that most of the subjects were 25 years old or older, and that most of the subjects over 45 years old were women. The three subjects who did not notice the car when the device was used were one 25-44 year old and two 45+ year olds, all males, and all in the crosswalk location.

The two independent sets of observations (one from each observer) were matched by subject and a Kendall rank correlation coefficient was computed, where all physical responses were scored as 3, visual response only $=2$, no response $=1.41$ Data from both observers were obtained for 70 test subjects. A correlation of $\tau=0.75$ was found between the two observers. Using the fact that $T$ is approximately normally distributed for $N>10$ (here $N=70$ ), the observed $\tau=0.75$ was found to be very significant $(p<.001)$. Thus, there was a high degree of agreement between the observers.

Although the categories of slow, medium, and fast walking speeds were not defined precisely, the subjects were rated on their speed as they passed the test vehicle. Of the 74 subjects whose responses were known, 10 were classified as walking slowly, 54 were walking medium speed, and 10 were walking relatively fast. Table 7-7 shows the breakdown of walking speeds by the subject's noticing the test vehicle. All three subjects who did not notice the test vehicle when the back-up warning device was used were walking at medium speed. The rate of noticing across speeds is $80 \%, 81 \%$, and $80 \%$ for slow, medium, and fast speeds so walking speed (within this limited sample of data) does not appear to play a significant role.

\begin{tabular}{|c|c|c|c|c|}
\hline \multirow{2}{*}{$\begin{array}{c}\text { Subject } \\
\text { Reaction }\end{array}$} & \multicolumn{3}{|c|}{ Speed } & \multirow{2}{*}{ Total } \\
\cline { 2 - 5 } & Slow & Medium & Fast & \\
\hline Noticed Test Vehicle & $11 \%$ & $60 \%$ & $11 \%$ & $82 \%$ \\
Did Not Notice & $2 \%$ & $14 \%$ & $2 \%$ & $18 \%$ \\
\hline Total & $13 \%$ & $74 \%$ & $13 \%$ & $100 \%$ \\
\hline
\end{tabular}

Table 7-7. Noticing the Test Vehicle Versus Walking Speed 
Table 7-8 presents the test data by location type.

The data show that all three subjects who failed to notice the test vehicle when the back-up device was used were in the crosswalk sitisation.

\begin{tabular}{|l|c|c|c|c|}
\hline \multirow{2}{*}{ Test Location } & \multicolumn{2}{|c|}{ With Device } & \multicolumn{2}{c|}{ Without Device } \\
\cline { 2 - 5 } & Noticed & Didn't Notice & Noticed & Didn't Notice \\
\hline Mid Block & $15 \%$ & 0 & $1 \%$ & $4 \%$ \\
Alley/Driveway & $18 \%$ & 0 & $4 \%$ & 0 \\
Parking Lot & $5.5 \%$ & 0 & $1 \%$ & 0 \\
Crosswalk & $31 \%$ & $4 \%$ & $5.5 \%$ & $11 \%$ \\
\hline \multicolumn{1}{|c|}{ Total } & $69.5 \%$ & $4 \%$ & $11.5 \%$ & $15 \%$ \\
\hline
\end{tabular}

Table 7-8. Test Data Versus Test Location

Of the 40 subjects with exposure to the device who responded to the interview question concerning hearing the device, 36 stated that they did hear it. For the three subjects who did not respond, two said they did not hear the device and no response to the question was obtained from the third. Thus, there were two subjects who responded behaviorally and yet stated that they did not hear the device. This raises the issue that some of the behaviors involved in crassing the street or similar activities may be so well practiced that the subject can respond to stimuli without fully realizing that he has done so.

Finally, 34 of the subjects who were exposed to the device expressed their reactions to the unusual sound. The results of this interview question are tabulated in Table 7-9. Over one quarter of the subjects who responded to the interview question concerning their reaction to the device thought it was a warning of some kind. Several of these thought it was a warning that the test vehicle was backing up. These reactions were with no prior exposure to the device or its intent and purpose. 
The question of exactly where the pedestrian was alerted by the warning signal was critically examined. Based upon the observations during the system evaluation, only a few subjects noticed the signal before they were behind the vehicle. This does not necessarily mean they did not hear the signal before this, only that their visual response was late. A few subjective tests with willing subjects indicated the signal was easily audible at the warning zone limit. The results of the analysis of the system evaluation data was predicated on the thesis that any warning qualified as a positive response.

\begin{tabular}{|l|c|c|}
\hline Reaction & Frequency & \% of Total Reactions \\
\hline Curious & 18 & 53 \\
Startled & 0 & 0 \\
Unaffected & 7 & 21 \\
Thought it was a & 9 & 26 \\
\hline warning & 34 & 100 \\
\hline Total & & \\
\hline
\end{tabular}

Table 7-9. Subject Reactions to Back-up Warning Device

Behavioral Observation Analysis Conclusions

The device was shown to be significantly more effective in getting people to notice a backing vehicle than the combination of normal cues (backing lights, the starting of the motor, etc.). It should be noted that the cue of changing gears (slight movement of the car) was missing in all tests. Also, the device contributed to the test vehicle being noticed in almost $95 \%$ of the tests when the device was used. The subjects stated that their attention was usually drawn to the test vehicle by the device, out of curiousity or because they thought the sound was a warning. 
A large percentage of the subjects were very cooperative, mildly curious, and attempted to be helpful. Many subjects would continue walking if the interviewer walked with them. Some subjects were not cooperative - too busy or in a hurry and would not respond to questions - felt their privacy invaded - objected to the tests one completely ignored the interviewer. These subjects did not comprise more than about $10 \%$ of all the subjects, most were quite helpful.

Identification of the signal as a back-up warning was mixed. Some subjects knew exactly its purpose; others thought it was a sect belt signal, a doctor's paging system, one even thought it was a signal for the driver indicating the presence of a pedestrian behind the car (an interesting alternative).

\subsection{Noise Data Analysis}

Noise data was collected at each test site. The ambient noise level was recorded at the rear of the test vehicle and the noise level of the device was also measured at the same location. Laboratory analysis of these recordings produced ambient descriptors, test vehicle noise levels, and warning signal levels for each successful test sequence.

To illustrate the variations in noise level recorded at the rear of the test vehicle during the evaluation tests, Figure 7-1 shows four typical test sequences. In the time histories, the pulse before the signal is the vehicle engine starting after which the ambient may be controlled by the engine noise. These recordings were made with a microphone above the bumper while the system loudspeaker was mounted below the bumper.

The ambient levels existing during each test sequence are illustrated in Figure 7-2. Actual levels for each individual test are listed with the subject coded data in Appendix B. These levels, in general, represent a reasonable range of levels experienced at the types of sites used.

During the evaluation tests, recordings were made of the ambient levels. Table 7-10 lists the test sites and the computed energy-average of the noise level. These levels were obtained from data recorded between each test sequence. The data at these sites may be compared to the preliminary data obtained at 8 other test sites early in the program, snown in Table 4-3 earlier. 


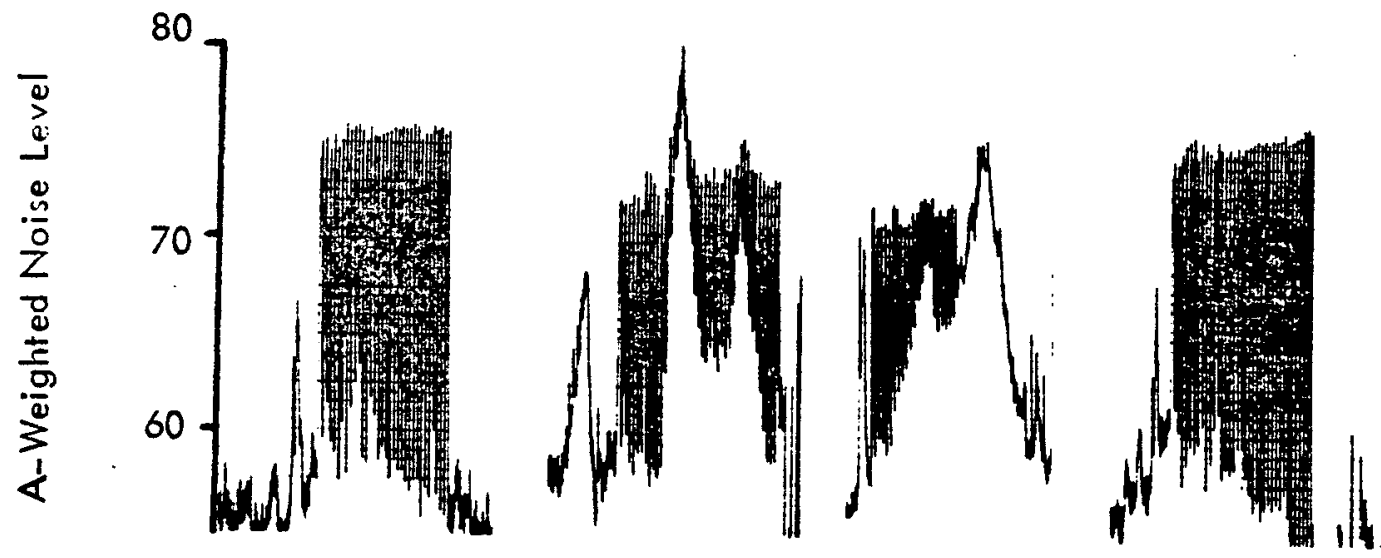

Time Scale -1 division $=5$ seconds

Figure 7-1. Time History Examples of the Warning Signal Test Sequence. Recorded at the test vehicle rear bumper.

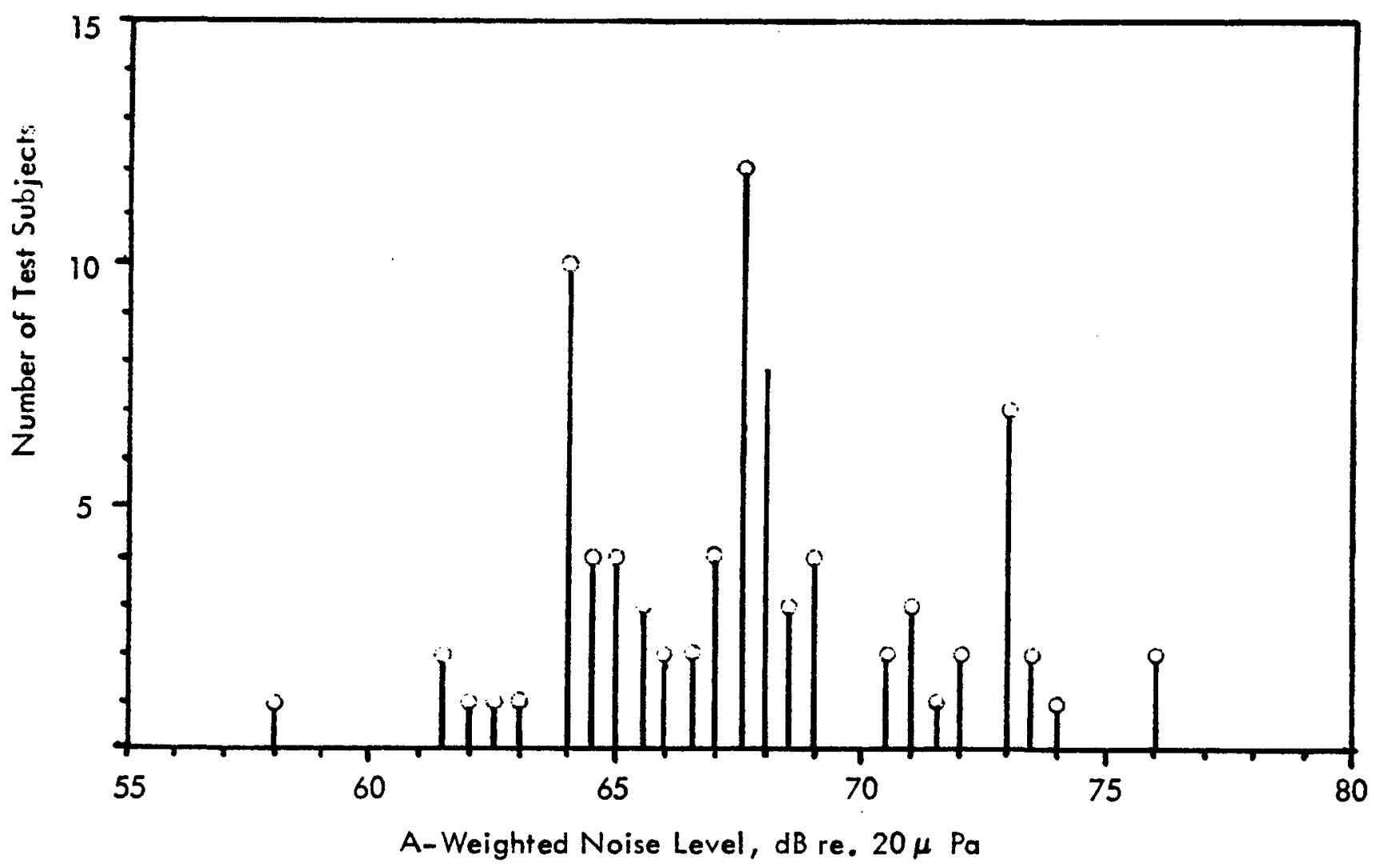

Figure 7-2. Recorded Ambient Level for the Field Evaluation Tests. Noise levels present before the vehicle engine was started. 
Table 7-10

Summary of Ambient Levels Measured at the Evaluation Test Sites

\begin{tabular}{|c|l|l|l|c|}
\hline $\begin{array}{c}\text { Site } \\
\text { Number }\end{array}$ & Site Location & $\begin{array}{c}\text { Type of } \\
\text { Site }\end{array}$ & $\begin{array}{c}\mathrm{L}_{\text {eq }} \\
(1)\end{array}$ & $\begin{array}{c}\text { Approximate } \\
\mathrm{L}_{5}\end{array}$ \\
\hline 1 & Sepulveda (North) & Crosswalk & 72.1 & 80 \\
2 & Sepulveda (South) & Crosswalk & 67.6 & 69 \\
3 & Karls Stationers & Mid-Block & 63.4 & 66 \\
4 & F. W. Woolworth & Mid-Block & 67.4 & 72 \\
5 & Boys Market & Parking Lot & 58.7 & 63 \\
6 & 9th Street Alley & Alley & 73.4 & 76 \\
7 & 6th Street Alley & Alley & 73.5 & 79 \\
8 & Sav-On & Parking Lot & 68.9 & 73 \\
\hline
\end{tabular}

(1) Energy-average noise level during intervals between test periods. 


\section{REFERENCES}

1. Lempert, B.L. and Henderson, T.L., "Occupational Noise and Hearing, 1968 to 1972 - A NIOSH Study." U.S. Department of Health, Education and Welfare, HEW Publication No. (NIOSH) 74-116, 1973.

2. Galloway, W.J., et al, "Population Distribution of the United States as a Function of Outdoor Noise Level." Office of Noise Abatement and Control, EPA Report No. 2592, November 1973.

3. Sutherland, L.C., et al, "A Program for the Measurement of Environmental Noise in the Community and Its Associated Human Response." DOT-T ST -74-5, December 1973.

4. Morgan, C.G., et al, "Human Engineering Guide to Equipment Design." McGraw-Hill Book Co., Inc., New York, 1963.

5. Occupational Safety and Health Administration, "Department of Labor Code of Federal Regulations, Title 29, Chapter XVII, Part 1926, Subpart O, Section 1926.601, Motor Vehicles," 1972.

6. Kryter, K.D., "The Effects of Noise on Man." Academic Press, New York, 1970.

7. Ollerhead, J.B., "Helicopter Aural Detectability." USAAMRDL Technical Report 71-33, Eustis Directorate, U.S. Army Air Mobility Research and Development Laboratory, Fort Eust is, Virginia, July 1971.

8. Abrahamson, A.L., "Correlation of Actual and Estimated Helicopter Aural Detection Criteria." USAAMRDL Technical Report 74-102A, Eustis Directorate, U.S. Army Air Mobility Research and Development Laboratory, Fort Eustis, Virginia, December 1974.

9. Snyder, M.B. and Knoblauch, R.L., "Pedestrian Safety: The Identification of Precipitating Factors and Possible Countermeasures." Vols. I and II - Appendices. DOT-HS-800 404, January 1971.

10. Blomberg, R.D., Hale, A., and Kearney, E.F., "Development of Model Regulations for Pedestrian Safety." DOT-HS-801 287, November 1974.

11. Society of Automotive Engineers, "Criteria for Back-Up Alarm Devices." SAE J 994, 1967.

12. American National Standards Institute, "Specifications for Audiometers." ANSI 53.6-1969. 


\section{REFERENCES (Continued)}

13. Kennedy, J., et al, "Handbook of Human Engineering Data." Tufts University, Medford, Massachusetts, 1952.

14. National Safety Council, "Accident Facts." 1974.

15. U.S. Department of Commerce, National Bureau of Censuls, "Statistical Abstracts of the United States." 1969 and 1974 editions.

16. Wyle Laboratories, "Study of 1960 to 1973 Auto Fleet Mix:." Unpublished data.

17. Bio-Technology, Inc., "Accident Data, 1973 and 1974." Unpublished data.

18. Van Cott, H.P. and Kinkade, R.G. (Editors), "Human Engineering Guide to Equipment Design." (Revised Edition) U.S. Government Printing Office, 1972.

19. Brown, R., "Vehicle Back-Up Accidents - Estimation of the Effectiveness of a Pedestrian Audible Warning Device." Wyle Laboratories Research Report WCR 75-12, 1975.

20. Eldred, K., "Community Noise." Report No. NTID 300.3, prepared by Wyle Laboratories for the U.S. Environmental Protection Agency, December 31, 1971.

21. Szalai, A. (Editor), "The Use of Time." Mouton and Company, The Hague, 1972.

22. Galloway, W.J., Eldred, K., and Simpson, M.A., "Population Distribution of the United States as a Function of Outdoor Noise Level." U.S. Environmental Protection Agency, Report No. 550/9-74-009, June 197.4.

23. Sutherland, L.C. and Sharp, B., "Evaluation of Residential Indoor Noise Environments Due to Outdoor No ise Sources." Proceedings: Inter-Noise 74, Washington, D.C., September 30-October 2, 1974, pp. 633-635.

24. Automotive News, "1975 Almanac."

25. Fletcher, H., "Auditory Pattems." Review of Modern Physics, Vol. 12, January $1940,47-65$.

26. Howkins, J.E. and Stevens, S.S., "The Masking of Pure Tones and of Speech by White Noise." J. Acoust. Soc. Am. 22, January 1950, 6-13. 


\section{REFERENCES (Continued)}

27. Egan, J.P. and Hake, H.W., "On the Masking Pattern of a Simple Auditory Stimulus." J. Acoust. Soc. Am. 22, September 1950, 622-630.

28. Bilger, R.C. and Hirsch, J.J., "Masking of Tones by Bands of Noise." J. Acoust. Soc. 28, July 1956, 623-630.

29. Zwicker, E., Flottorp, G., and Stevens, S.S., "Critical Bandwidth in Loudness Summation." J. Acoust. Soc. Am. 29, Mary 1957, 548-557.

30. Zwislocki, J., "Theory of Temporal Summation." J. Acoust. Soc. Am. 32, August 1960, 1046-1060.

31. Greenwood, D.D., "Auditory Masking and the Critical Band." J. Acoust. Soc. Am. 33, April 1961, 484-502.

32. Scharf, B., "Complex Sounds and Critical Bands." Psychol. Bull. 58 (1961), 705-717.

33. Swets, J.A., Green, D.M., and Tanner, W.P., "On the Width of the Critical Bands." J. Acoust. Soc. Am. 34, January 1962, 108-113.

34. Dubrovskii, N.A. and Tumatrina, L.N., "Investigation of the Human Perception of Amplitude Modulated Noise." Soviet Physics-Acoustics 13:1, July-September $1967,41-47$.

35. Zwicker, E. and Fash, H., "On the Development of the Critical Band." J. Acoust. Soc. Am. 52 (1972), 699-702.

36. Zwicker, E. and Feldtkeller, R., "Das Ohr als Nachrichtenempfanger." Stuttgart, S. Hirzel Verlag, 1967.

37. Galloway, W.J., "Frequency Analyses of Short-Duration Random Noise." Sound 1 (1962), 31-34.

38. Oyer, H.J. and Hardick, E.J., "Response of Population to Optimum Warning Signal." Report No. SHSLR 163, Michigan State University, Department of Speech, September 1963.

39. Furustig, H., "Auditory Perception: A Literature Review." MPI A-Rapport No. 22, Militärpsykologiska Institutet, Stockholm, Sweden, March 1974. 


\section{REFERENCES (Continued)}

40. Siegel, S., "Nonparametric Statistics for the Behavioral Sciences," New York: McGraw-Hill, 1956, 196-202.

41. Hays, W., "Statistics for the Social Sciences," New York: Holt, Rinehart and Winston, 1973, 432-724. 


\section{APPENDIX A \\ SUMMARY OF BACK-UP ACCIDENT DATA}

This appendix contains detailed data derived from a sampling of accident data from three different pedestrian accident studies. Analyses of the data listed is contained in Sections 2.0,3.0, and 4.0 of the report. Code letters used to identify the accident cause, used for the analysis in Section 2.0, refer to the following definitions:

Pedestrians Who Would Not Benefit From an Audible Warning

a. Pedestrian sow vehicle, unable to ovoid

b. Pedestrian saw vehicle, did not avoid

c. Young child (less than 5 years old)

f. Unoccupied vehicle

Pedestrians Who Would Likely Benefit From an Audible Warning

d. Pedestrion was not aware the vehicle was backing

e. Pedestrian saw vehicle too late to avoid 
Table A-1

Summary of Pertinent Data from 34 Cases of Pedestrian Back-up Accidents

(The original data extracted from cases comprising the study of Reference 9)

\begin{tabular}{|c|c|c|c|c|c|c|c|c|c|}
\hline Case & Sex & Age & Localion & Date & lime & $\begin{array}{l}\text { Car } \\
\text { Yeur } \\
\end{array}$ & $\begin{array}{l}\text { Accident } \\
\text { Severity }\end{array}$ & Remarks & $\begin{array}{l}\text { Accident } \\
\text { Cause }\end{array}$ \\
\hline D 2001 & $F$ & 63 & $\begin{array}{l}\text { Commercial } \\
\text { Intersection }\end{array}$ & $12 / 30 / 69$ & 1715 & 1966 & $\begin{array}{l}\text { Slight } \\
\text { Injury }\end{array}$ & $\begin{array}{l}\text { Car parallel-parked, backed into } \\
\text { pedestrian zone; pedestrian did not } \\
\text { see car. }\end{array}$ & $d$ \\
\hline D 2007 & $M$ & 41 & Gas Station Lof & $1 / 12 / 70$ & 1725 & .1964 & No injury & $\begin{array}{l}\text { Car backing in station lot; iterdaint } \\
\text { crossing behind did not sne car move. }\end{array}$ & e \\
\hline D 2055 & $M$ & 5 & $\begin{array}{l}\text { Residential } \\
\text { Intersection }\end{array}$ & $4 / 23 / 70$ & 1545 & - & Serious & $\begin{array}{l}\text { Car backed through intersection, struck } \\
\text { child in roadway near corner. }\end{array}$ & d \\
\hline 02127 & $\mathbf{F}$ & 7 & $\begin{array}{c}\text { Near } \\
\text { Intersection }\end{array}$ & $2 / 16 / 70$ & 1130 & $\begin{array}{c}1959- \\
61\end{array}$ & Serious & $\begin{array}{l}\text { Car backed over curb and struck child } \\
\text { on sidewalk. }\end{array}$ & $d$ \\
\hline D 2086 & $F$ & 4 & $\begin{array}{l}\text { Residential } \\
\text { Oriveway }\end{array}$ & $6 / 9 / 70$ & 1900 & 1966 & Unknown & $\begin{array}{l}\text { Car backing from driveway, child walking } \\
\text { in same direction as car motion. }\end{array}$ & c \\
\hline D 2043 & $F$ & 22 & $\begin{array}{l}\text { Commercial } \\
\text { Intersection }\end{array}$ & $4 / 8 / 70$ & 0135 & - & $\begin{array}{l}\text { Slight } \\
\text { Injury }\end{array}$ & $\begin{array}{l}\text { Car backing near intersection struck } \\
\text { pedestrian in crosswalk. }\end{array}$ & $d$ \\
\hline A 7040 & $M$ & 47 & $\begin{array}{l}\text { Residential } \\
\text { Shopping Area } \\
\text { Street }\end{array}$ & $6 / 27 / 70$ & 1940 & 1966 & $\begin{array}{l}\text { Slight } \\
\text { Injury }\end{array}$ & $\begin{array}{l}\text { Car backing } 10 \text { parallel park; pedestrian } \\
\text { in crosswalk sow car but failed to take } \\
\text { action. }\end{array}$ & b \\
\hline A 3005 & $M$ & 6 & $\begin{array}{l}\text { Residential } \\
\text { Multi-Family }\end{array}$ & $3 / 24 / 70$ & 1150 & 1970 & No injury & $\begin{array}{l}\text { Car backing in mid-block; pedestrian } \\
\text { darted out and did not see. }\end{array}$ & $d$ \\
\hline $02 ! 62$ & $M$ & 76 & $\begin{array}{l}\text { Commercial } \\
\text { Intersection }\end{array}$ & $8 / 11 / 70$ & 1810 & $\begin{array}{c}1968 \\
\text { (iruck) }\end{array}$ & $\begin{array}{l}\text { Slight } \\
\text { lajiui } ;\end{array}$ & $\begin{array}{l}\text { Car backing in street, backed into } \\
\text { podestrion zone. }\end{array}$ & d \\
\hline D 2053 & $\mathbf{F}$ & 39 & $\begin{array}{l}\text { Commercial } \\
\text { Intersection }\end{array}$ & $4 / 17 / 70$ & $\left.123^{\prime}\right\}$ & 1964 & $\begin{array}{l}\text { Slight } \\
\text { Injury }\end{array}$ & $\begin{array}{l}\text { Car backing in street, backed near } \\
\text { pedestrian zone. }\end{array}$ & d \\
\hline 92073 & $M$ & 48 & $\begin{array}{l}\text { Commercial } \\
\text { Mid-block }\end{array}$ & $5 / 22 / 70$ & 153.3 & $\begin{array}{c}1967 \\
\text { (truck) }\end{array}$ & No injury & $\begin{array}{l}\text { Tow-truck backing, hit pedestrian } \\
\text { jarwalking. }\end{array}$ & d \\
\hline D 2153 & $\mathbf{F}$ & 23 & Mid-block & $8 / 5,70$ & 0010 & 1964 & $\begin{array}{l}\text { Slight } \\
\text { Injury }\end{array}$ & Car backed intentionally into pedestrian. & $\mathbf{a}$ \\
\hline D 2124 & $M$ & 25 & $\begin{array}{l}\text { Residential } \\
\text { Intersection }\end{array}$ & $7 / 14 / 70$ & $1801)$ & 1964 & $\begin{array}{l}\text { Slight } \\
\text { Injury }\end{array}$ & $\begin{array}{l}\text { Car backing near intersection; pedestrian } \\
\text { in crosswalk. }\end{array}$ & d \\
\hline 62073 & $M$ & 58 & $\begin{array}{l}\text { Parking Garage } \\
\text { Driveway }\end{array}$ & $8 / 5 / 70$ & 17511 & -- & $\begin{array}{l}\text { Slight } \\
\text { Injury }\end{array}$ & $\begin{array}{l}\text { Car backed from parking garage; } \\
\text { pedestrian on sidewalk. }\end{array}$ & d \\
\hline
\end{tabular}


Table A-1 (continued)

\begin{tabular}{|c|c|c|c|c|c|c|c|c|c|}
\hline Cose & Sex & Age & Location & Date & Tims & $\begin{array}{l}\text { Cor } \\
\text { Year }\end{array}$ & $\begin{array}{c}\text { Accident } \\
\text { Severity }\end{array}$ & Remarks & $\begin{array}{c}\text { Accident } \\
\text { Cause }\end{array}$ \\
\hline 61150 & $M$ & 69 & $\begin{array}{l}\text { Cominercial } \\
\text { Intersection }\end{array}$ & $8 / 12 / 70$ & 1830 & 1960 & $\begin{array}{l}\text { Slight } \\
\text { Injury }\end{array}$ & $\begin{array}{l}\text { Car backing from alley struck pedestrian } \\
\text { crossing alley. }\end{array}$ & d \\
\hline A 5007 & $M$ & 33 & $\begin{array}{l}\text { Commercial } \\
\text { Loading Dock }\end{array}$ & $4 / 10 / 70$ & 1133 & 1969 & $\begin{array}{l}\text { Moderate } \\
\text { Injury }\end{array}$ & Truck backed inlo scaffold injuring 3 men. & a \\
\hline 22170 & $\mathbf{F}$ & 72 & $\begin{array}{l}\text { Residential } \\
\text { Multi-Family } \\
\text { Mid-block }\end{array}$ & $4 / 26 / 70$ & 1335 & 1965 & $\begin{array}{l}\text { Serious } \\
\text { Injury }\end{array}$ & $\begin{array}{l}\text { Vehicle backing in streel; pedestrian slepped } \\
\text { from sidewalk. }\end{array}$ & d \\
\hline B 2010 & $M$ & & $\begin{array}{l}\text { Commercial } \\
\text { Alley }\end{array}$ & $12 / 16 / 69$ & 1101 & $\begin{array}{l}1968 \\
\text { (truck) }\end{array}$ & Fatal & $\begin{array}{l}\text { Vehicle backing in alley; pedestrian visibility } \\
\text { obscured. }\end{array}$ & d \\
\hline B 1058 & $\mathbf{F}$ & 2 & $\begin{array}{l}\text { Residential } \\
\text { Mulli-Family } \\
\text { Mid-block }\end{array}$ & $6 / 4 / 70$ & $1801)$ & 1966 & $\begin{array}{l}\text { Maderate } \\
\text { Injury }\end{array}$ & $\begin{array}{l}\text { Vehicle hacking in driveway; pedestrian } \\
\text { playing. }\end{array}$ & c \\
\hline 11045 & $M$ & 53 & $\begin{array}{l}\text { Residential } \\
\text { Multi-Family } \\
\text { Driveway }\end{array}$ & $3 / 9 / 70$ & $1801)$ & 1966 & No injury & $\begin{array}{l}\text { Vehicle backing near corner; pedestrian saw } \\
\text { but failed to take action. }\end{array}$ & b \\
\hline 11042 & $\mathbf{F}$ & 54 & $\begin{array}{l}\text { Residential } \\
\text { Multi-Family } \\
\text { Mid-block }\end{array}$ & $3 / 28 / 70$ & 1421 & $\begin{array}{l}1959 \\
\text { (truck) }\end{array}$ & $\begin{array}{l}\text { Slight } \\
\text { Injury }\end{array}$ & $\begin{array}{l}\text { Vehicle backing near curb; pedestrian between } \\
\text { parked cars saw too late. }\end{array}$ & e \\
\hline 11031 & $M$ & 58 & $\begin{array}{l}\text { Commercial } \\
\text { Mid-block }\end{array}$ & $2 / 10 / 70$ & 0540 & $\begin{array}{c}1962 \\
\text { (1ruck) }\end{array}$ & $\begin{array}{l}\text { Moderate } \\
\text { Injury }\end{array}$ & $\begin{array}{l}\text { Vehicle backing into porking space; pedestrian } \\
\text { working on vehicle did not see. }\end{array}$ & $d$ \\
\hline 11025 & $F$ & 17 & $\begin{array}{l}\text { Commercial } \\
\text { Mid-block }\end{array}$ & $2 / 2 / 70$ & $194: i$ & 1965 & No injury & $\begin{array}{l}\text { Vehicle backing into parking space; pedestrian } \\
\text { crossing between cars, saw vehicle too late. }\end{array}$ & - \\
\hline 14024 & $F$ & 51 & $\begin{array}{l}\text { Commercial } \\
\text { Mid-block }\end{array}$ & $8 / 18 / 70$ & 15001 & $\begin{array}{l}1968 \\
\text { (van) }\end{array}$ & $\begin{array}{l}\text { Moderate } \\
\text { to none }\end{array}$ & $\begin{array}{l}\text { Vehicle backing into alley; pedestrian } \\
\text { crossing alley. }\end{array}$ & $d$ \\
\hline 61086 & $M$ & 74 & $\begin{array}{l}\text { Residential } \\
\text { Multi-Family } \\
\text { Intersection }\end{array}$ & $4 / 27 / 70$ & 0740 & 1966 & $\begin{array}{l}\text { Slight } \\
\text { Injury }\end{array}$ & $\begin{array}{l}\text { Vehicle backing from parking space; } \\
\text { pedestrian in crosswalk did not see. }\end{array}$ & $d$ \\
\hline B 3053 & $M$ & 29 & $\begin{array}{l}\text { Commercial } \\
\text { Gas Station } \\
\text { Lot }\end{array}$ & $6 / 2 / 70$ & 1330 & & $\begin{array}{l}\text { Moderate } \\
\text { Injury }\end{array}$ & $\begin{array}{l}\text { Vehicle backing in gos stalion; pedestrian } \\
\text { working on car saw vehicle too late. }\end{array}$ & e \\
\hline
\end{tabular}


Table A-1 (continued)

\begin{tabular}{|c|c|c|c|c|c|c|c|c|c|}
\hline Cose & Sex & Age & Location & Date & Time & $\begin{array}{l}\text { Car } \\
\text { Year }\end{array}$ & $\begin{array}{l}\text { Accident } \\
\text { Severity }\end{array}$ & Remarks & $\begin{array}{c}\text { Accident } \\
\text { Couse }\end{array}$ \\
\hline A 8054 & $M$ & $\begin{array}{l}30 \\
35\end{array}$ & $\begin{array}{l}\text { Commercial } \\
\text { Intersection }\end{array}$ & $6 / 22 / 70$ & 2340 & 1970 & $\begin{array}{l}\text { Slight } \\
\text { Injury }\end{array}$ & $\begin{array}{l}\text { Vehicle backing out of intersection; } \\
\text { pedestrians crossing at corner. }\end{array}$ & d \\
\hline A 8050 & $\mathbf{F}$ & 66 & $\begin{array}{l}\text { Commercial } \\
\text { Intersection }\end{array}$ & $6 / 17 / 70$ & 1010 & $\begin{array}{c}1966 \\
\text { (truck) }\end{array}$ & $\begin{array}{l}\text { Moderate } \\
\text { Injury }\end{array}$ & $\begin{array}{l}\text { Vehicle backing; pedestrian crossing } \\
\text { betwcen cars near intersection. }\end{array}$ & $\mathbf{d}$ \\
\hline A 8029 & $M$ & 51 & $\begin{array}{l}\text { Indusirial } \\
\text { Mid-block }\end{array}$ & $5 / 4 / 70$ & 1605 & 1969 & $\begin{array}{l}\text { Moderate } \\
\text { Injury }\end{array}$ & $\begin{array}{l}\text { Vehicle backing from loading dock; } \\
\text { pedestrian on sidewalk. }\end{array}$ & .1 \\
\hline A 8044 & $M$ & 20 & $\begin{array}{l}\text { Commercial } \\
\text { Driveway }\end{array}$ & $5 / 17 / 70$ & 1040 & & No injury & $\begin{array}{l}\text { Vehicle backing into lot; pedestrian } \\
\text { crossing parking lot. }\end{array}$ & $d$ \\
\hline 82036 & $M$ & 50 & $\begin{array}{l}\text { Residential } \\
\text { Single-Family } \\
\text { Inlersection }\end{array}$ & $4 / 9 / 70$ & 1415 & 1969 & $\begin{array}{l}\text { Slight } \\
\text { Injury }\end{array}$ & $\begin{array}{l}\text { Vehicle backing near corner; pedestrion } \\
\text { just exited from vehicle. }\end{array}$ & e \\
\hline B 4023 & $M$ & 25 & $\begin{array}{l}\text { Residential } \\
\text { Single-Family } \\
\text { Intersection }\end{array}$ & $4 / 22 / 70$ & 1010 & $\begin{array}{r}1954 \\
\vdots \quad(\text { van })\end{array}$ & $\begin{array}{l}\text { Slight } \\
\text { Injury }\end{array}$ & $\begin{array}{l}\text { Vehicle backing from parking space; } \\
\text { pedestrian crossing at corner. }\end{array}$ & d \\
\hline 33003 & $M$ & 6 & $\begin{array}{l}\text { Apartments } \\
\text { Mid-block }\end{array}$ & $3 / 8 / 70$ & 1620 & 1961 & $\begin{array}{l}\text { Moderate } \\
\text { Injury }\end{array}$ & $\begin{array}{l}\text { Vehicle backing into street from "driveway", } \\
\text { pedestrian on sidewalk saw vehicle too tate. }\end{array}$ & e \\
\hline A 1019 & F & 54 & $\begin{array}{l}\text { Commercial } \\
\text { Intersection }\end{array}$ & $12 / 29 / 69$ & $0 \$ 25$ & 1969 & Fatal & $\begin{array}{l}\text { Vehicle backing into street; pedestrian } \\
\text { crossing saw vehicle but too shocked to move. }\end{array}$ & a \\
\hline
\end{tabular}


Table A-2

Summary of Pertinent Data from 99 Cases of Pedestrian Back-up Accidents

(original data extracted from Bio-Technology Study - Urban Accidents, Reference 17)

\begin{tabular}{|c|c|c|c|c|c|c|c|c|c|}
\hline Cose & Sex & Age & Localion & Dule & Time & $\begin{array}{l}\text { Car } \\
\text { Year }\end{array}$ & $\begin{array}{l}\text { Accident } \\
\text { Severily }\end{array}$ & Remarks & $\begin{array}{l}\text { Arcident } \\
\text { Cause }\end{array}$ \\
\hline 7049 & $M$ & 19 & Parking Lor & $4 / 30 / 74$ & 1338 & 1958 & No Injury & Car backed out of parking space into pedestrian. & - \\
\hline 5226 & $\mathbf{F}$ & 20 & $\begin{array}{c}\text { Near } \\
\text { Intersection }\end{array}$ & $4 / 14 / 74$ & 1024 & 1986 & $\begin{array}{l}\text { Slight } \\
\text { Injury }\end{array}$ & $\begin{array}{l}\text { Car backed through crosswalk after possing } \\
\text { inlersection. }\end{array}$ & d \\
\hline 10127 & $\mathbf{F}$ & B5 & $\begin{array}{l}\text { Near } \\
\text { Intersection }\end{array}$ & $5 / 25 / 74$ & 2015 & $19 / 3$ & $\begin{array}{l}\text { Slight } \\
\text { Injury }\end{array}$ & $\begin{array}{l}\text { Car stopped in intersection and backed up } \\
\text { through crosswalk. }\end{array}$ & d \\
\hline 14303 & M & 60 & $\begin{array}{l}\text { Residential } \\
\text { Mid-block }\end{array}$ & $9 / 10 / 74$ & 1204 & 1967 & $\begin{array}{l}\text { Slight } \\
\text { Injury }\end{array}$ & $\begin{array}{l}\text { Car parallel-parked, backed into pedestrian } \\
\text { crossing street. }\end{array}$ & d \\
\hline 1625 & $M$ & 28 & $\begin{array}{l}\text { Residential } \\
\text { Open Lot }\end{array}$ & $9 / 27 / 74$ & 1550 & 1972 & $\begin{array}{l}\text { Slight } \\
\text { Injury }\end{array}$ & $\begin{array}{l}\text { Car in open lot backed into pedestrian on } \\
\text { sidewalk. }\end{array}$ & d \\
\hline 1591 & $M$ & 60 & $\begin{array}{c}\text { Gas Station } \\
\text { Lot }\end{array}$ & $9 / 20 / 74$ & 0030 & 1964 & $\begin{array}{l}\text { Slight } \\
\text { Injury }\end{array}$ & Car backing from pump struck pedestrion & d \\
\hline 1599 & $M$ & 3 & $\begin{array}{l}\text { Residential } \\
\text { Driveway }\end{array}$ & $9 / 22 / 74$ & 1700 & 1973 & $\begin{array}{l}\text { Slight } \\
\text { Injury }\end{array}$ & Car backed into child playing in driveway. & c \\
\hline 14365 & $\mathbf{F}$ & 70 & $\begin{array}{l}\text { Residential } \\
\text { Driveway }\end{array}$ & $9 / 11 / 74$ & 1500 & & $\begin{array}{l}\text { Slight } \\
\text { Injury }\end{array}$ & $\begin{array}{l}\text { Car backing out of driveway struck pedestrian } \\
\text { on sidewalk. }\end{array}$ & - \\
\hline 1791 & $M$ & 18 & Intersection & $2 / 3 / 73$ & 1200 & & $\begin{array}{l}\text { Slight } \\
\text { Injury }\end{array}$ & $\begin{array}{l}\text { Car backed through crosswalk from intersection } \\
\text { striking pedestrian in crosswalk. }\end{array}$ & d \\
\hline 3280 & $M$ & 28 & $\begin{array}{l}\text { Residential } \\
\text { Mid-tlock }\end{array}$ & $2 / 28 / 73$ & 1910 & & $\begin{array}{l}\text { Moderate } \\
\text { Injury }\end{array}$ & $\begin{array}{l}\text { Car parallel-parked struck pedestrian while } \\
\text { backing out of space. }\end{array}$ & e \\
\hline 663 & $M$ & 25 & $\begin{array}{l}\text { Gas Station } \\
\text { Lot }\end{array}$ & $4 / 10 / 73$ & 0740 & & $\begin{array}{l}\text { Slight } \\
\text { Injury }\end{array}$ & $\begin{array}{l}\text { Car backing in lot struck pedestrian standing } \\
\text { by another car. }\end{array}$ & d \\
\hline 7074 & $M$ & 36 & $\begin{array}{l}\text { Gas Station } \\
\text { Lot }\end{array}$ & $5 / 5 / 73$ & 1010 & $19 \% 3$ & Moderalo & $\begin{array}{l}\text { Car backed over pedestrian; pedestrian was } \\
\text { working under another car. }\end{array}$ & d \\
\hline 934 & $\mathbf{F}$ & 77 & Parking Lot & $5 / 12 / 73$ & 1025 & $19: 59$ & $\begin{array}{l}\text { Slight } \\
\text { Injury }\end{array}$ & $\begin{array}{l}\text { Cor backing struck pedestrian leaning over } \\
\text { another car. }\end{array}$ & d \\
\hline 8199 & $\mathbf{F}$ & 76 & Driveway & $5 / 25 / 73$ & 1600 & 19619 & $\begin{array}{l}\text { Slight } \\
\text { Injury }\end{array}$ & $\begin{array}{l}\text { Car backing into street struck shopping cart; } \\
\text { pedestrian was walking behind cart. }\end{array}$ & - \\
\hline 1027 & $\mathbf{f}$ & 57 & $\begin{array}{l}\text { School } \\
\text { Parking Lot }\end{array}$ & $5 / 26 / 73$ & 2013 & 1969 & Serious & & $d$ \\
\hline 1149 & $M$ & 52 & $\begin{array}{r}\text { Commercial } \\
\text { Mid-Block }\end{array}$ & $6 / 13 / 73$ & 1630 & 1967 & $\begin{array}{l}\text { Slight } \\
\text { Injury }\end{array}$ & $\begin{array}{l}\text { Car parallel-parked struck pedestrian while } \\
\text { bocking out of space. }\end{array}$ & $d$ \\
\hline 2264 & $M$ & 38 & $\begin{array}{l}\text { Commercial } \\
\text { Parking Lof }\end{array}$ & $11 / 2 / 73$ & 2330 & 196.2 & Moderate & Drunk driver backed into drunk pedestioun. & b \\
\hline
\end{tabular}


Table A-2 (continued)

\begin{tabular}{|c|c|c|c|c|c|c|c|c|c|}
\hline Case & Sex & Age & Location & Date & Tine & $\begin{array}{l}\text { Car } \\
\text { Year }\end{array}$ & $\begin{array}{l}\text { Accident } \\
\text { Severify }\end{array}$ & Remarks & $\begin{array}{l}\text { Accident } \\
\text { Cause }\end{array}$ \\
\hline 16892 & $F$ & 5 & $\begin{array}{l}\text { Residential } \\
\text { Driveway }\end{array}$ & $7 / 3 / 74$ & 1800 & 1964 & Moderato & $\begin{array}{l}\text { Car started in gear, backing into } \\
\text { pedestrian. }\end{array}$ & d \\
\hline 18804 & $F$ & 30 & $\begin{array}{l}\text { Commercial } \\
\text { Intersection }\end{array}$ & $7 / 26 / 74$ & 1700 & $\begin{array}{c}1967 \\
\text { (truck) }\end{array}$ & $\begin{array}{l}\text { Sliglit } \\
\text { Injury }\end{array}$ & $\begin{array}{l}\text { Mail truck parallel-parked; struck } \\
\text { pedestrian while backing out. }\end{array}$ & d \\
\hline 20228 & $\mathbf{F}$ & 79 & $\begin{array}{l}\text { Residential } \\
\text { Alley }\end{array}$ & $8 / 12 / 74$ & 1510 & & Moderate & Unoccupied car rolled into pedestrian. & $f$ \\
\hline 24036 & M & 1 & $\begin{array}{l}\text { Residential } \\
\text { Driveway }\end{array}$ & $9 / 19 / 74$ & 1905 & 1974 & Moderato & $\begin{array}{l}\text { Child in drivewoy; fell under wheel } \\
\text { of backing car. }\end{array}$ & c \\
\hline 597867 & $\mathbf{F}$ & 52 & $\begin{array}{l}\text { Hospital } \\
\text { Parking Lot }\end{array}$ & $11 / 7 / 74$ & 1215 & & $\begin{array}{l}\text { Slight } \\
\text { Injury }\end{array}$ & $\begin{array}{l}\text { Car backing in open crea; struck } \\
\text { pedestrion. }\end{array}$ & d \\
\hline 73948 & $M$ & 29 & $\begin{array}{l}\text { Residential } \\
\text { Mid-block }\end{array}$ & $2 / 11 / 73$ & 0315 & 1972 & Fotal & $\begin{array}{l}\text { Pedestrian unloading van from behind; } \\
\text { driver's foot slipped hilting gos pedal. }\end{array}$ & a \\
\hline $096-038$ & $\mathbf{F}$ & 5 & Residential & $2 / 24 / 73$ & 1225 & & Moder ate & Child sitting on curb; car backed over feet. & a \\
\hline 115301 & $M$ & 83 & $\begin{array}{l}\text { Commercial } \\
\text { Mid-block }\end{array}$ & $3 / 5 / 73$ & 0945 & 1967 & Moderate & $\begin{array}{l}\text { Car backing; pedestrian walked out from } \\
\text { between parked cars. }\end{array}$ & - \\
\hline 150120 & $M$ & 36 & $\begin{array}{l}\text { Residential } \\
\text { Mid-block }\end{array}$ & $3 / 24 / 73$ & 0625 & $\begin{array}{l}1970 \\
\text { (truck) }\end{array}$ & Moderote & Firelruck backing; struck fireman. & d \\
\hline 162740 & $\mathbf{F}$ & 32 & $\begin{array}{l}\text { Commercial } \\
\text { Intersection }\end{array}$ & $3 / 30 / 73$ & 2210 & 1973 & $\begin{array}{l}\text { Slight } \\
\text { lnjury }\end{array}$ & $\begin{array}{l}\text { Car backed through intersection; slruck } \\
\text { pedestrian in crosswalk. }\end{array}$ & d \\
\hline 196516 & $\mathbf{F}$ & 65 & $\begin{array}{l}\text { Commercial } \\
\text { Mid-block }\end{array}$ & $4 / 16 / 73$ & 0900 & 1970 & $\begin{array}{l}\text { Slight } \\
\text { injury }\end{array}$ & $\begin{array}{l}\text { Car backing; pedestrian walked out from } \\
\text { beiweeil puikad cais. }\end{array}$ & e \\
\hline 242089 & M & 70 & $\begin{array}{l}\text { Commercial } \\
\text { Mid-block }\end{array}$ & $5 / 8 / 73$ & 1005 & 1966 & Moderate & $\begin{array}{l}\text { Car backing to parallel park; pedestrian } \\
\text { stepped off curb. }\end{array}$ & d \\
\hline 15 & $\mathbf{F}$ & 31 & $\begin{array}{l}\text { Residential } \\
\text { Mid-block }\end{array}$ & $5 / 1 / 74$ & 1300 & 1974 & $\begin{array}{l}\text { Slight } \\
\text { Injury }\end{array}$ & $\begin{array}{l}\text { Cor backing to park; pedestrion stepped } \\
\text { behind car. }\end{array}$ & d \\
\hline 4 & $\mathbf{F}$ & 53 & $\begin{array}{l}\text { Commercial } \\
\text { Driveway }\end{array}$ & $5 / 4 / 74$ & 1050 & & $\begin{array}{l}\text { Slight } \\
\text { Injury }\end{array}$ & $\begin{array}{l}\text { Car backing from driveway; pedestrian } \\
\text { crossing driveway. }\end{array}$ & d \\
\hline 17 & $F$ & 30 & $\begin{array}{l}\text { Commercial } \\
\text { Bus Stop }\end{array}$ & $5 / 30 / 74$ & 1033 & $\begin{array}{c}1970 \\
\text { (truck) }\end{array}$ & $\begin{array}{l}\text { Slight } \\
\text { Injury }\end{array}$ & $\begin{array}{l}\text { Truck, stopped in bus zone; backed into } \\
\text { pedestrian boarding bus. }\end{array}$ & d \\
\hline 1 & $M$ & 30 & $\begin{array}{l}\text { Residential } \\
\text { Driveway }\end{array}$ & $6 / 4 / 74$ & 0820 & & Serious & $\begin{array}{l}\text { Car backing out of driveway struck } \\
\text { pedestrian on sidewalk. }\end{array}$ & d \\
\hline 00 & $\mathbf{F}$ & 38 & $\begin{array}{l}\text { Commercial } \\
\text { Mid-block }\end{array}$ & $7 / 13 / 74$ & 0100 & & Maderate & $\begin{array}{l}\text { Truck backing; knocked pedestrian down; } \\
\text { truck moved forword, knocking pedestrian } \\
\text { down again with front bumper. }\end{array}$ & d \\
\hline
\end{tabular}


Table A-2 (continued)

\begin{tabular}{|c|c|c|c|c|c|c|c|c|c|}
\hline Cose 1 & Sex & Age & Location & Date & Time & $\begin{array}{l}\text { Car } \\
\text { Yecir }\end{array}$ & $\begin{array}{l}\text { Accident } \\
\text { Severily }\end{array}$ & Remarks & $\begin{array}{l}\text { Accident } \\
\text { Cause }\end{array}$ \\
\hline 0122 & $\mathbf{F}$ & 70 & $\begin{array}{l}\text { Gas Station } \\
\text { Lot }\end{array}$ & $8 / 10 / 74$ & 1200 & & $\begin{array}{l}\text { Slight } \\
\text { Injury }\end{array}$ & $\begin{array}{l}\text { Car backing out of station loo fast; struck } \\
\text { grocery cart and pedestrian. }\end{array}$ & a \\
\hline 24 & $M$ & 27 & $\begin{array}{l}\text { Commercial } \\
\text { Mid-block }\end{array}$ & $11 / 6 / 74$ & 1600 & $\begin{array}{l}1964 \\
\text { (lruck) }\end{array}$ & $\begin{array}{l}\text { Slight } \\
\text { Injury }\end{array}$ & Truck bocking; struck pedestrian jaywalking. & d \\
\hline 91 & $M$ & 13 & $\begin{array}{l}\text { Residential } \\
\text { Mid-block }\end{array}$ & $12 / 9,74$ & 1630 & 1972 & Moderate & $\begin{array}{l}\text { Car parallel-parked; backed into pedestrian } \\
\text { crossing street. Pedestrian was not looking. }\end{array}$ & d \\
\hline 64 & $M$ & 30 & $\begin{array}{l}\text { Commercial } \\
\text { Drivewryy }\end{array}$ & $12 / 5,74$ & 1220 & 1968 & Moderate & $\begin{array}{l}\text { Car backed into police officer. (Officer had } \\
\text { originally stopped traffic to permit this car to } \\
\text { back up.) }\end{array}$ & d \\
\hline 0722 & $M$ & 5 & $\underset{\text { Intersection }}{\text { Near }}$ & $12 / 30 / 74$ & 1200 & 1971 & $\begin{array}{l}\text { Slight } \\
\text { Injury }\end{array}$ & $\begin{array}{l}\text { Car, accidentally in reverse gear, backed } \\
\text { into crosswalk. }\end{array}$ & d \\
\hline 6 & $M$ & 66 & $\begin{array}{l}\text { Commercial } \\
\text { Porking Lot }\end{array}$ & $10 / 12 / 74$ & 0955 & 1966 & $\begin{array}{l}\text { Slight } \\
\text { Injury }\end{array}$ & $\begin{array}{l}\text { Car backed into pedestrian; pedestrian was } \\
\text { standing by cars in the parking lot. }\end{array}$ & d \\
\hline A & $M$ & 5 & $\begin{array}{l}\text { Schoul } \\
\text { Driveway }\end{array}$ & $1 / 19,73$ & 1530 & 1964 & Moderate & $\begin{array}{l}\text { Car backing into street; struck pedestrian on } \\
\text { sidewalk. }\end{array}$ & d \\
\hline 8 & $M$ & 34 & $\begin{array}{l}\text { Residential } \\
\text { Mid-block }\end{array}$ & $6 / 11,73$ & 0830 & $\begin{array}{l}1970 \\
\text { (truck) }\end{array}$ & $\begin{array}{l}\text { Slight } \\
\text { Injury }\end{array}$ & Garbage truck backing; struck garbage man. & a \\
\hline C & $M$ & 1 & $\begin{array}{l}\text { Residential } \\
\text { Driveway }\end{array}$ & $6 / 16,73$ & 1705 & 1964 & Fatal & $\begin{array}{l}\text { Car backing; knocked pedestrian over with } \\
\text { rear bumper and backed over him with front tire. }\end{array}$ & c \\
\hline D & $\mathbf{F}$ & 45 & $\begin{array}{l}\text { Residential } \\
\text { Mid-block }\end{array}$ & $7 / 7 / 73$ & 2215 & 1970 & Severe & $\begin{array}{l}\text { Vehicle backing; struck pedestrian who had } \\
\text { just exited from car. }\end{array}$ & a \\
\hline $\mathbf{E}$ & $M$ & 17 & $\begin{array}{l}\text { Undeveloped } \\
\text { Roodway }\end{array}$ & $7 / 19 / 73$ & 1410 & & Maderate & Tractor backed over pedestrian working on road. & d \\
\hline 02505 & $\mathbf{F}$ & 80 & $\begin{array}{l}\text { Residential } \\
\text { Driveway }\end{array}$ & $2 / 19,74$ & 0804 & 1973 & Moderate & $\begin{array}{l}\text { Car backing out of driveway; struck pedestrian } \\
\text { on sidewalk. }\end{array}$ & e \\
\hline 21 & $\mathbf{F}$ & 58 & $\begin{array}{l}\text { Commercial } \\
\text { Mid-block }\end{array}$ & $1 / 2 / 73$ & 1020 & $\begin{array}{l}1969 \\
\text { (truck) }\end{array}$ & $\begin{array}{l}\text { Slight } \\
\text { Injury }\end{array}$ & $\begin{array}{l}\text { Truck backing at curb; struck pedestrian } \\
\text { crossing street. }\end{array}$ & $d$ \\
\hline 3 & $\mathbf{F}$ & 48 & $\begin{array}{l}\text { Commercial } \\
\text { Parking Lot }\end{array}$ & $6 / 15,73$ & 2105 & 1972 & Serious & $\begin{array}{l}\text { Pedestrian sitting on hood of car behind. Car } \\
\text { in front backed up, hitting pedestrian's leg. }\end{array}$ & a \\
\hline $\mathbf{F}$ & $M$ & 41 & $\begin{array}{l}\text { Residential } \\
\text { Intersection }\end{array}$ & $9 / 21,73$ & 0150 & 1964 & $\begin{array}{l}\text { Slight } \\
\text { Injury }\end{array}$ & $\begin{array}{l}\text { Car backing; struck pedestrian in middle of } \\
\text { intersection. }\end{array}$ & $d$ \\
\hline $2 \dot{3}$ & $M$ & 23 & $\begin{array}{l}\text { Road } \\
\text { Construction } \\
\text { Area }\end{array}$ & $10 / 3,73$ & 1335 & & Serious & $\begin{array}{l}\text { Truck backing; struck flagmon, who wos facing } \\
\text { opposite direction, and run over his leg. }\end{array}$ & d \\
\hline
\end{tabular}


Table A-2 (continued)

\begin{tabular}{|c|c|c|c|c|c|c|c|c|c|}
\hline Case & Sex & Age & Location & D ate & Time & $\begin{array}{l}\text { Cor } \\
\text { Year }\end{array}$ & $\begin{array}{l}\text { Accidenl } \\
\text { Severity }\end{array}$ & Remarks & $\begin{array}{l}\text { Accident } \\
\text { Couse }\end{array}$ \\
\hline 34 & $F$ & 35 & $\begin{array}{l}\text { Commercial } \\
\text { Mid-block }\end{array}$ & $11 / 30 / 73$ & 1849 & & $\begin{array}{l}\text { Slight } \\
\text { Injury }\end{array}$ & $\begin{array}{l}\text { Car backing out of parking lot struck } \\
\text { pedestrian crossing street. }\end{array}$ & d \\
\hline $\mathrm{C} 0875$ & $M$ & 20 & $\begin{array}{l}\text { Residential } \\
\text { Mid-block }\end{array}$ & $1 / 20 / 74$ & 0125 & & $\begin{array}{l}\text { Slight } \\
\text { Injury }\end{array}$ & $\begin{array}{l}\text { Car struck pedestrian while backing up to } \\
\text { flee pursuers. }\end{array}$ & 0 \\
\hline$C 2746$ & $M$ & 25 & $\begin{array}{l}\text { Residential } \\
\text { Mid-block }\end{array}$ & $2 / 28 / 74$ & 2305 & 1965 & Moderate & $\begin{array}{l}\text { Unoccupied vehicle rolled back, pinning } \\
\text { pedestrian against another car. }\end{array}$ & a \\
\hline $\mathrm{C} 2040$ & $F$ & 6 & $\begin{array}{l}\text { Residential } \\
\text { Driveway }\end{array}$ & $2 / 13 / 74$ & 1445 & 1969 & $\begin{array}{l}\text { Slight } \\
\text { Injury }\end{array}$ & $\begin{array}{l}\text { Car backing out of driveway; struck } \\
\text { pedestrian standing in the street. }\end{array}$ & d \\
\hline$C 1739$ & $M$ & 72 & $\begin{array}{l}\text { Commercial } \\
\text { Crosswalk }\end{array}$ & $2 / 7 / 74$ & 1010 & 1972 & Serious & $\begin{array}{l}\text { Car backing from parking space; pedestrian in } \\
\text { crosswalk. }\end{array}$ & $d$ \\
\hline$C 4028$ & M & 5 & $\begin{array}{l}\text { Residential } \\
\text { Driveway }\end{array}$ & $3 / 28 / 74$ & 1555 & 1964 & Serious & Car backing out of driveway struck child. & d \\
\hline C 5382 & M & 7 & $\begin{array}{l}\text { Residential } \\
\text { Driveway }\end{array}$ & $4 / 24 / 74$ & 1710 & 1970 & Moderate & $\begin{array}{l}\text { Car backed out of driveway; pedestrian on } \\
\text { skaleboard darted across. }\end{array}$ & $d$ \\
\hline C5295 & $M$ & 28 & $\begin{array}{l}\text { Commercial } \\
\text { Driveway }\end{array}$ & $4 / 2.3 / 74$ & 1040 & & Moderate & $\begin{array}{l}\text { Van backing out of driveway struck pedestrian } \\
\text { crossing street toward the van. }\end{array}$ & e \\
\hline C675.3 & M & 3 & $\begin{array}{l}\text { Residential } \\
\text { Driveway }\end{array}$ & $5 / 23 / 74$ & 1500 & . & Moderate & $\begin{array}{l}\text { Car backing out of driveway; struck child } \\
\text { behind. }\end{array}$ & c \\
\hline C5851 & $M$ & 29 & $\begin{array}{l}\text { Residential } \\
\text { Mid-block }\end{array}$ & $5 / 4 / 74$ & 0130 & 1966 & $\begin{array}{l}\text { Slight } \\
\text { Injury }\end{array}$ & $\begin{array}{l}\text { Driver of car released hand-brake on slope; } \\
\text { in neutral gear, car backed into pedestrian. }\end{array}$ & a \\
\hline C8579 & $M$ & 83 & $\begin{array}{l}\text { Residential } \\
\text { Driveway }\end{array}$ & $6 / 8 / 74$ & 0655 & 1951 & Serious & $\begin{array}{l}\text { Unoccupied car rolled backward out of } \\
\text { driveway striking owner. }\end{array}$ & 1 \\
\hline$C 7842$ & $F$ & 80 & $\begin{array}{l}\text { Commercial } \\
\text { Driveway }\end{array}$ & $6 / 14 / 74$ & 1645 & 1972 & $\begin{array}{l}\text { Slight } \\
\text { Injury }\end{array}$ & $\begin{array}{l}\text { Car backing out of driveway; struck } \\
\text { pedestrian on sidewalk. }\end{array}$ & $d$ \\
\hline C9064 & $M$ & 53 & $\begin{array}{c}\text { Residential } \\
\text { Dead-End } \\
\text { Street }\end{array}$ & $7 / 8 / 74$ & 1105 & 1969 & Serious & $\begin{array}{l}\text { Car backing; struck pedestrian standing by } \\
\text { second car, went over curb and hit a wall. }\end{array}$ & $d$ \\
\hline C8956 & $F$ & 32 & $\begin{array}{l}\text { Commercial } \\
\text { Bus Stop }\end{array}$ & $7 / 5 / 74$ & 1530 & 1574 & Moderate & $\begin{array}{l}\text { Cor backed up near bus stop; struck pedestrian } \\
\text { on sidewalk. }\end{array}$ & $d$ \\
\hline$C 8886$ & $M$ & 34 & $\begin{array}{l}\text { Recreation } \\
\text { Park Road }\end{array}$ & $7 / 4 / 74$ & 1410 & $\begin{array}{c}1973 \\
(j e n p)\end{array}$ & Sérious & $\begin{array}{l}\text { Jeep, accidentally in reverse gear, backed into } \\
\text { second car crushing pedestrian between. }\end{array}$ & e \\
\hline C11904 & $F$ & 5 & $\begin{array}{l}\text { Residential } \\
\text { Driveway }\end{array}$ & $9 / 1 / 74$ & 1600 & 1971 & Moderate & $\begin{array}{l}\text { Car backing out of driveway; struck child } \\
\text { sitting by driveway. }\end{array}$ & d \\
\hline
\end{tabular}




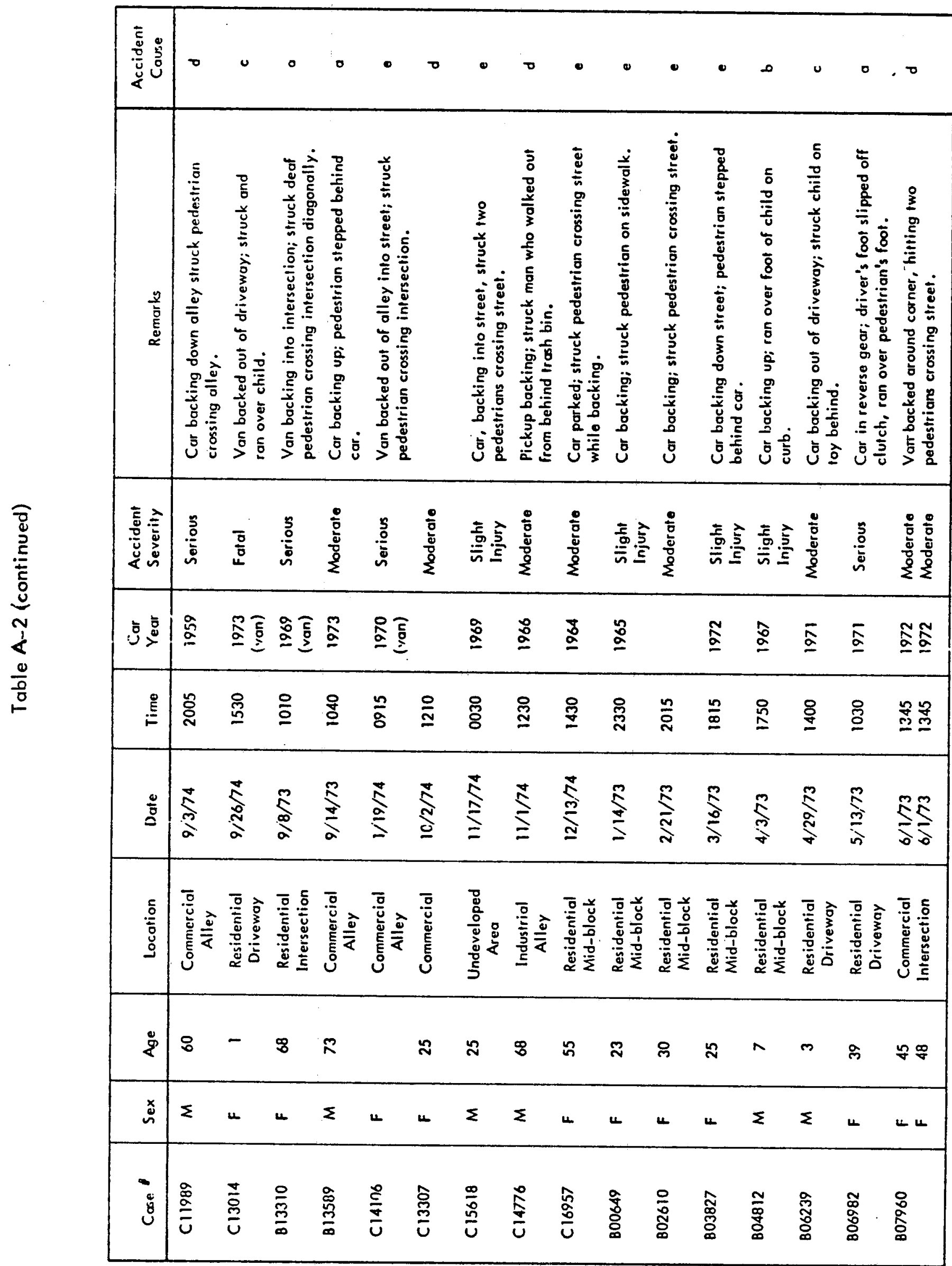


Table A-2 (continued)

\begin{tabular}{|c|c|c|c|c|c|c|c|c|c|}
\hline Cose 1 & Sex & Age & Location & Date & Time & $\begin{array}{l}\text { Car } \\
\text { Year }\end{array}$ & $\begin{array}{l}\text { Accident } \\
\text { Severity }\end{array}$ & Remarks & $\begin{array}{l}\text { Accident } \\
\text { Course }\end{array}$ \\
\hline 808077 & $M$ & 52 & $\begin{array}{l}\text { Undeveloped } \\
\text { Dirt Road }\end{array}$ & $6,3 / 73$ & 0810 & 1972 & Moderalo & $\begin{array}{l}\text { Vehicle bocked into pedestrian, while } \\
\text { pedestrian was giving directions to the driver. }\end{array}$ & e \\
\hline B08168 & $\mathbf{F}$ & 23 & $\begin{array}{l}\text { Residential } \\
\text { Driveway }\end{array}$ & $6 / 5 / 73$ & 0400 & 1965 & $\begin{array}{l}\text { Slight } \\
\text { Injury }\end{array}$ & $\begin{array}{l}\text { Car backing out of driveway struck } \\
\text { pedestrian on sidewalk. }\end{array}$ & - \\
\hline B08293 & $M$ & 15 & $\begin{array}{l}\text { Residential } \\
\text { Mid-block }\end{array}$ & $6,7 / 73$ & 1730 & 1971 & $\begin{array}{l}\text { Slight } \\
\text { Injury }\end{array}$ & Vehicle backing; pedestrian ran behind. & d \\
\hline 808430 & $F$ & 2 & $\begin{array}{l}\text { Residential } \\
\text { Driveway }\end{array}$ & $6 ; 9 / 73$ & 1845 & 1973 & Serious & $\begin{array}{l}\text { Car backing out of driveway; struck child } \\
\text { playing in drivewoy. }\end{array}$ & c \\
\hline 808772 & $M$ & 2 & $\begin{array}{l}\text { Residential } \\
\text { Mid-block }\end{array}$ & $6,15 / 73$ & 1800 & $\begin{aligned} 1972 \\
(\text { ran) }\end{aligned}$ & $\begin{array}{l}\text { Slight } \\
\text { Injury }\end{array}$ & $\begin{array}{l}\text { Van backing up; child drove toy behind } \\
\text { vehicle. }\end{array}$ & c \\
\hline 812109 & $\mathbf{F}$ & $\begin{array}{l}21 \\
20\end{array}$ & $\begin{array}{l}\text { Residential } \\
\text { Residential }\end{array}$ & $\begin{array}{l}8 / 16 / 73 \\
8,16 / 73\end{array}$ & $\begin{array}{l}0600 \\
0600\end{array}$ & $\begin{array}{l}1973 \\
1973\end{array}$ & $\begin{array}{l}\text { Slight } \\
\text { Slight }\end{array}$ & $\begin{array}{l}\text { Car backing with door open; struck iwo } \\
\text { pedestrians. }\end{array}$ & - \\
\hline 14685 & $\mathbf{F}$ & 1 & $\begin{array}{l}\text { Residenlial } \\
\text { Dead End } \\
\text { Sireet }\end{array}$ & $10 / 5 / 73$ & 1510 & 1970 & Moderate. & Child walked behind backing car. & c \\
\hline 815369 & M & 17 & $\begin{array}{l}\text { School } \\
\text { Parking Lot }\end{array}$ & $10 / 18 / 73$ & 0845 & 1965 & $\begin{array}{l}\text { Slight } \\
\text { Injury }\end{array}$ & $\begin{array}{l}\text { Car backing; pedestrian stepped off curb } \\
\text { behind vehicle. }\end{array}$ & - \\
\hline B15502 & $\mathbf{F}$ & 54 & $\begin{array}{l}\text { Commercial } \\
\text { Mid..block }\end{array}$ & $10 / 20 / 73$ & 1250 & 1967 & Moderale & $\begin{array}{l}\text { Truck parallel-parked; struck pedestrian } \\
\text { crossing street while bocking out. }\end{array}$ & d \\
\hline B 16453 & $\mathbf{F}$ & 3 & $\begin{array}{l}\text { Residential } \\
\text { Driveway }\end{array}$ & $11 / 7 / 73$ & 1605 & 1962 & Moderate & $\begin{array}{l}\text { Car backing out of driveway; struck child } \\
\text { walking in gutter. }\end{array}$ & c \\
\hline B 17628 & $M$ & 57 & $\begin{array}{l}\text { Commercial } \\
\text { Intersection }\end{array}$ & $11 / 28 / 73$ & 0955 & 1969 & Moderate & $\begin{array}{l}\text { Car backed over curb; struck pedestrian on } \\
\text { bus bench. }\end{array}$ & - \\
\hline B18010 & $M$ & 81 & $\begin{array}{l}\text { Residential } \\
\text { Driveway }\end{array}$ & $12 / 5 / 73$ & 1600 & 1964 & Serious & $\begin{array}{l}\text { Ca backing out of driveway; struck } \\
\text { pedestrian on sidewalk. }\end{array}$ & - \\
\hline B18006 & $M$ & 4 & $\begin{array}{l}\text { Residential } \\
\text { Driveway }\end{array}$ & $12 / 5 / 73$ & 1510 & 1964 & Serious & Child walked toward backing vehicle. & c \\
\hline B18284 & $M$ & 23 & Mid-block & $12 / 10 / 73$ & 2230 & 1970 & Serious & $\begin{array}{l}\text { Van backed down street; struck pedestrian } \\
\text { crossing street. }\end{array}$ & d \\
\hline $573-5$ & $\mathbf{F}$ & 80 & $\begin{array}{l}\text { Indusirial } \\
\text { Mid-block }\end{array}$ & $1 / 12 / 73$ & 0830 & 1962 & Moderalo & $\begin{array}{l}\text { Pedestrian stepped off curb; backing truck } \\
\text { ran over her foot. }\end{array}$ & d \\
\hline
\end{tabular}


Table A-2 (continued)

\begin{tabular}{|c|c|c|c|c|c|c|c|c|c|}
\hline$C_{\operatorname{cose}}$ & Sex & Age & Location & Date & Time & $\begin{array}{l}\text { Cor } \\
\text { Year }\end{array}$ & $\begin{array}{l}\text { Accident } \\
\text { Severity }\end{array}$ & Remarks & $\begin{array}{c}\text { Accident } \\
\text { Cause }\end{array}$ \\
\hline $673-16$ & $M$ & 55 & $\begin{array}{l}\text { Commercial } \\
\text { Asphalı Yard }\end{array}$ & $1 / 18 / 73$ & 0715 & ... & Fatal & $\begin{array}{l}\text { Truck backed into pedestrion while unloading; } \\
\text { ran over pedestrian's legs. }\end{array}$ & d \\
\hline $673-92$ & $\begin{array}{l}F \\
M\end{array}$ & $\begin{array}{r}33 \\
4\end{array}$ & $\begin{array}{c}\text { Residential } \\
\text { Angle } \\
\text { Parking }\end{array}$ & $\begin{array}{l}4 / 7 / 73 \\
4 / 7 / 73\end{array}$ & $\begin{array}{l}1645 \\
1645\end{array}$ & $\begin{array}{l}1268 \\
1968\end{array}$ & $\begin{array}{l}\text { Moderale } \\
\text { Serlous }\end{array}$ & $\begin{array}{l}\text { Car backed out of parking space; lost control, } \\
\text { struck pedestrians on sidewatk. }\end{array}$ & a \\
\hline
\end{tabular}


Table A-3

Summary of Pertinent Mata from 27 Cases of Pedestrian Back-up Accidenls

(original data extracted from a current study by Bio-Technology - Rural Accidents, Reference 17)

\begin{tabular}{|c|c|c|c|c|c|c|c|c|c|}
\hline Cose & Sex & Age & Location & Dote & Time & $\begin{array}{l}\text { Car } \\
\text { Year }\end{array}$ & $\begin{array}{l}\text { Accident } \\
\text { Severily }\end{array}$ & Remarks & $\begin{array}{l}\text { Accident } \\
\text { Cause }\end{array}$ \\
\hline 070 & $M$ & BO & $\begin{array}{l}\text { Commercial } \\
\text { Parking Lot }\end{array}$ & $8 / 13 / 74$ & 1245 & 1974 & Moderale & $\begin{array}{l}\text { Cor parked diagonally; struck } \\
\text { pedestrian while bocking out. }\end{array}$ & d \\
\hline 095 & $M$ & -- & $\begin{array}{l}\text { Residential } \\
\text { Mid-block }\end{array}$ & $12 / 15 / 74$ & 0035 & 1964 & $\begin{array}{l}\text { Slight } \\
\text { Injury }\end{array}$ & $\begin{array}{l}\text { Car backing struck pedestrion and another } \\
\text { car: driver was attempting to avoid drunk } \\
\text { pedestrions molesting him. }\end{array}$ & a \\
\hline 006 & $F$ & 37 & $\begin{array}{l}\text { Rural Neor } \\
\text { Intersection }\end{array}$ & $7 / 9 / 74$ & 1750 & 1967 & Moderate & $\begin{array}{l}\text { Pickup backing oway from intersection } \\
\text { struck pedestrian crossing road. }\end{array}$ & d \\
\hline 11066 & $M$ & 1 & $\begin{array}{l}\text { Residential } \\
\text { Driveway }\end{array}$ & $6 / 5 / 74$ & 1155 & 1968 & Moderale & $\begin{array}{l}\text { Car backing out of driveway struck } \\
\text { pedestrian crossing driveway. }\end{array}$ & c \\
\hline 050 & $M$ & 64 & $\begin{array}{l}\text { Commercial } \\
\text { Suburban } \\
\text { Mid-block }\end{array}$ & $7 / 1 / 74$ & 0910 & 1967 & Moderate & $\begin{array}{l}\text { Car, accidentally in reverse gear, backed } \\
\text { into officer in CHP inspection lor. }\end{array}$ & $d$ \\
\hline 029 & $M$ & 7 & $\begin{array}{l}\text { Residential } \\
\text { Mid-block }\end{array}$ & $5 / 14 / 74$ & 1515 & 1968 & $\begin{array}{l}\text { Slight } \\
\text { Injury }\end{array}$ & $\begin{array}{l}\text { Car backing out of driveway, struck } \\
\text { pedestrian walking bicycle across street. }\end{array}$ & e \\
\hline 0.42 & $M$ & 24 & Gas Station Lot & $8 / 19 / 74$ & 0250 & 19.57 & $\begin{array}{l}\text { Slight } \\
\text { Injury }\end{array}$ & $\begin{array}{l}\text { Cor backing at gas pump; backed into } \\
\text { car pinning pedestrian in between. }\end{array}$ & a \\
\hline 050 & $M$ & 2 & $\begin{array}{l}\text { Residential } \\
\text { Mid-block }\end{array}$ & $10 / 28 / 74$ & 1405 & 1968 & Serious & Child ran toward backing car. & c \\
\hline 030 & $F$ & $\begin{array}{l}54 \\
52\end{array}$ & $\begin{array}{l}\text { Rural } \\
\text { Shoulder Near } \\
\text { Intersection }\end{array}$ & $\begin{array}{l}6 / 10 / 74 \\
6 / 10 / 74\end{array}$ & $\begin{array}{l}1009 \\
1009\end{array}$ & $\begin{array}{l}1973 \\
1973\end{array}$ & $\begin{array}{l}\text { Serious } \\
\text { Fotal }\end{array}$ & $\begin{array}{l}\text { Vehicle stopped on shoulder. Unaware that } \\
\text { vehicle wos in reverse gear, backed into } \\
\text { two pedestrians. }\end{array}$ & e \\
\hline 061 & $\mathbf{F}$ & 6 & $\begin{array}{l}\text { Residential } \\
\text { Drivewey }\end{array}$ & $1 / 2 / 74$ & 1200 & 1971 & Serious & $\begin{array}{l}\text { Car backing out of driveway; struck child } \\
\text { playing in driveway. }\end{array}$ & d \\
\hline 016 & $M$ & 4 & $\begin{array}{l}\text { Residential } \\
\text { Driveway }\end{array}$ & $4 / 12 / 74$ & 1615 & 1965 & Serious & $\begin{array}{l}\text { Car backing oul of drivenay; backed over } \\
\text { child playing in driveway. }\end{array}$ & $c$ \\
\hline 010 & $F$ & 8 & $\begin{array}{l}\text { Rural Road } \\
\text { Slioulder }\end{array}$ & $4 / 11 / 74$ & 1545 & 1973 & $\therefore$ inderste & $\begin{array}{l}\text { After mosing pedestria:., car stopped then } \\
\text { b.sclied into pedestrion who was focing the } \\
\text { other ditection. }\end{array}$ & d \\
\hline 078 & $M$ & 36 & $\begin{array}{l}\text { Rural } \\
\text { Porking Lot }\end{array}$ & $6 / 9 / 74$ & 1615 & 1965 & $\begin{array}{l}\text { j!ight } \\
\text { Injury }\end{array}$ & Crunk óriver backed into periestrirall. & 4 \\
\hline 068 & $M$ & 3 & $\begin{array}{l}\text { Residential } \\
\text { Driveway }\end{array}$ & $7 / 10 / 74$ & 1630 & 1967 & Serious & $\begin{array}{l}\text { Car backing out of driveway struck child } \\
\text { ploying in driveway. }\end{array}$ & c \\
\hline
\end{tabular}


Table A-3 (continued)

\begin{tabular}{|c|c|c|c|c|c|c|c|c|c|}
\hline Case & Sex & Age & Location & Date & Time & $\begin{array}{l}\text { Cor } \\
\text { Year }\end{array}$ & $\begin{array}{l}\text { Accident } \\
\text { Severity }\end{array}$ & Remarks & $\begin{array}{l}\text { Accident } \\
\text { Cause }\end{array}$ \\
\hline 014 & $\mathbf{F}$ & 3 & $\begin{array}{l}\text { Rural Store } \\
\text { Parking Lot }\end{array}$ & $3 / 22 / 74$ & 1620 & 1965 & Moderale & Car bocking; struck child sitting behind. & c \\
\hline 43008 & $F$ & 52 & $\begin{array}{l}\text { Conmerciol } \\
\text { Porking Lot }\end{array}$ & $3 / 27 / 74$ & 1503 & 1974 & $\begin{array}{l}\text { Slight } \\
\text { Injury }\end{array}$ & $\begin{array}{l}\text { Car, accidentally in reverse gear, backed } \\
\text { into pedestrian. }\end{array}$ & e \\
\hline 70008 & $M$ & 62 & $\begin{array}{l}\text { Rural } \\
\text { Residential } \\
\text { Mid-block }\end{array}$ & $9 / 29 / 74$ & 1130 & 1965 & Serious & $\begin{array}{l}\text { After talking with driver, pedest:ian } \\
\text { walked behind car; car backed into him. }\end{array}$ & - \\
\hline 001 & $M$ & 86 & $\begin{array}{l}\text { Residential } \\
\text { Dead End } \\
\text { Street }\end{array}$ & $10 / 26 / 74$ & 1245 & $1 \cdot 73$ & Moderale & $\begin{array}{l}\text { Pedestrian walked into ambulance backing } \\
\text { up. }\end{array}$ & d \\
\hline 62018 & $M$ & 16 & $\begin{array}{l}\text { Residential } \\
\text { Driveway }\end{array}$ & $2 / 14 / 74$ & 2000 & 1969 & -- & $\begin{array}{l}\text { Car backed out of driveway; struck pedes- } \\
\text { trian on parked motorcycle on opposite } \\
\text { side of road. }\end{array}$ & e \\
\hline 046 & $M$ & 1 & $\begin{array}{l}\text { Residential } \\
\text { Gravel Road } \\
\text { Mid-block }\end{array}$ & $2 / 19 / 74$ & 1810 & 1965 & -- & $\begin{array}{l}\text { Car backing along road; child rar. ov } \\
\text { behind moving vehicle. }\end{array}$ & c \\
\hline 024 & $\mathbf{F}$ & 10 & $\begin{array}{l}\text { Sand } \\
\text { Along Beach }\end{array}$ & $5 / 30 / 74$ & 1310 & 1969 & $\begin{array}{l}\text { Slight } \\
\text { Injury }\end{array}$ & $\begin{array}{l}\text { Vehicle backing out of loose ssid; } \\
\text { pedestrian not watching where she was } \\
\text { going. }\end{array}$ & e \\
\hline 169 & $M$ & 86 & $\begin{array}{c}\text { Residential } \\
\text { Driveway }\end{array}$ & $7 / 15 / 74$ & 1120 & 1951 & $\begin{array}{l}\text { Slight } \\
\text { Injury }\end{array}$ & $\begin{array}{l}\text { Car backed out of driveway; pedestrian } \\
\text { on sidewalk. }\end{array}$ & e \\
\hline 165 & $\mathbf{F}$ & 22 & $\begin{array}{l}\text { Residential } \\
\text { Mid-block }\end{array}$ & $12 / 12 / 74$ & 1225 & 1966 & $\begin{array}{l}\text { Slight } \\
\text { Injury }\end{array}$ & $\begin{array}{l}\text { Car backing with door open; pinned } \\
\text { pedestrian against telephone pole. }\end{array}$ & e \\
\hline 164 & $M$ & B4 & $\begin{array}{l}\text { Residential } \\
\text { Mid-block }\end{array}$ & $12 / 15 / 74$ & 2015 & 1975 & Moderate & $\begin{array}{l}\text { Car backing in street; pedestrian } \\
\text { crossing street walked behind raf. }\end{array}$ & $\mathbf{e}$ \\
\hline 10066 & $M$ & 3 & $\begin{array}{l}\text { Residential } \\
\text { Driveway }\end{array}$ & $7 / 6 / 74$ & 1820 & 1963 & $\begin{array}{l}\text { Slight } \\
\text { Injury }\end{array}$ & $\begin{array}{l}\text { Car backing out of driveway; child riding } \\
\text { tricycle on sidewalk. }\end{array}$ & c \\
\hline 10018 & $\mathbf{F}$ & 11 & $\begin{array}{l}\text { Residential } \\
\text { Mid-block }\end{array}$ & $2 / 7 / 74$ & 2030 & 1965 & $\begin{array}{l}\text { Slight } \\
\text { Injury }\end{array}$ & $\begin{array}{l}\text { Car backing to park along curb; pedes- } \\
\text { trian stepped behind car. }\end{array}$ & d \\
\hline 049 & $M$ & 10 & $\begin{array}{l}\text { Residential } \\
\text { Driveway }\end{array}$ & $6 / 10 / 74$ & 2015 & 1965 & Moderate & $\begin{array}{l}\text { Car backed into driveway; pedestrian } \\
\text { struck while playing in driveway. }\end{array}$ & d \\
\hline
\end{tabular}


APPENDIX B

FIELD EVALUATION - SUBJECT DATA ANALYSIS 
Evaluation Procedure

Observations and interview data was recorded on data acquisition forms. These forms were laid out to correspond to the general objectives of the experiment. Figure B-1 illustrates the form used by the observer who controlled the experiment and logged the subject's reaction. After the test sequence, the interviewer contributed to the site diagram description and, with the observer, generated a pooled subject response rating, incorporating both observations.

Figure $B-2$ is an example of the interviewer's log form to produce observational and interview data. An independent rating for each subject from each observer was recorded along with the subject's distance from the rear of the test car when the behavior was noted. Additional relevant information was also recorded such as the behavior of people, not targeted subjects, who reacted to the device when passing by.

A notable change to the interviewers log was made during the early stages of the evaluation tests. It was originally intended that the interviewer would first identify himself and briefly explain the test. Most subjects appeared confused by the explanation so it was abandoned. After the key questions were answered, if the subject was still curious, the test objective was explained to the subject. At the conclusion, many subjects expressed a favorable judgement toward the test goals.

Analysis Procedure

The most important data results in the evaluation of the back-up warning device were derived from the ratings by the observers. These ratings of the subject's behavior were determined as the subject approached the test vehicle and reacted to the warning cues. The interview occurred after the ratings were generated. Thus, the ratings were not biased by the subject's responses in the interview, or his refusal to be interviewed. Since the two raters generated data independently, a measure of the reliability of their ratings was obtained by generating a contingency coefficient of correlation using the two sets of data. 40 The ratings of the observer and interviewer 
Audible Warning Signal Field Evaluation

Observer's Log

Test No.

Test Site Date Time

Test Sequence: With Device Without

Subject: Male Female

Age: $0-24$ 25-44 $45+$

Subject Response:

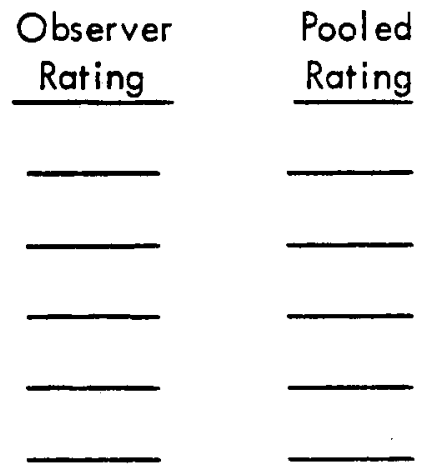

1. No noticeable response

2. Visual response only

3. a. Avoidance response - stopping or retreating

b. Avoidance response - change course (forward)

c. Avoidance response - speeding up

Site Diagram

Indicate North Direction

Indicate Curb or adjacent vehicles

Indicate Subject Path, mark $T$ at test start location and $X$ at subject response location

Subject Speed:

Slow Medium Fast Comments

Figure B-1. Observer's Data Log 
Test No.

Test Site Date Time

Test Sequence: With Device Without

Subject: Male Female

Age: $0-24$ $25-44$ $45+$

Subject Response:

1. No noticeable response

2. Visual response only

3. a. Avoidance response - stopping or retreating

b. Avoidance response - change course (forward)

c. Avoidance response - speeding up

Interview:

"As you walked past that car, did you notice or did you not notice if the engine started up?" Noticed Didn't notice

Interviewer instructions: if device used, ask:

"As you walked past that car, did you or did you not hear an unusual sound?"

Heard

Didn't hear

Interviewer instructions: if they did hear, ask this question:

"Was your reaction to the unusual sound Curious

$$
\begin{aligned}
& \text { Startled } \\
& \text { Unaffected } \\
& \text { (select one) }
\end{aligned}
$$

"Do you have any known hearing problems at this time?"

"Thank you for your help."

Comments

Figure B-2. Interviewer's Data Log 
were compared on-site to generate a pooled score for each subject. If the observers agreed, then the pooled score was the one agreed upon. If they did not agree, they resolved the conflict at the test site and agreed upon a joint rating to be recorded. It was not uncommon for one observer to see some behavior that the other observer could not see. The original independent ratings were used to measure the reliability of the rating scale, while the pooled or joint rating were used to analyze the effectiveness of the device.

All pertinent data derived from the observer and interviewer logs were coded according to the key shown in Figure B-3. These data are listed in Figure B-4. The coding block numbers were then sorted and analyzed using a standard computer analys is program.

Following analysis, all subject scores were categorized in a table similar to the following:

\begin{tabular}{|c|c|c|}
\hline & \multicolumn{2}{|c|}{ Type of Response (Scale Value) } \\
\hline & No Response (1) & Some Response (2 or 3 ) \\
\hline Car With Device & & \\
\hline Car Without Device & & \\
\hline
\end{tabular}

Within the scope of this program it was not feasible to sample a sufficient number of responses to perform a classical statistical analysis. Practical "small sample" analyses were made to assure the overall effectiveness of the device. 4

The observers' descriptions of the responses and the breakdown of responses into scale values 2 and 3 allowed a description of the ways in which people responded to the device. The descriptions of the responses were categorized to indicate which responses were the most prevalent.

The acoustic data, recorded at the rear of the test vehicle, were analyzed to determine:

- The ambient level prior to the test initiation, including the statistical levels and $L_{\text {eq }}$.

- The maximum level of the test vehicle's self noise.

- The warning signal level for each test sequence. 


\begin{tabular}{|l|l|l|l|l|l|l|l|l|l|l|l|l|}
\hline 1 & 2 & 3 & 4 & 5 & 6 & 7 & 8 & 9 & 10 & 11 & 12 & 13 \\
\hline & & & & & & & & & & & & \\
\hline
\end{tabular}

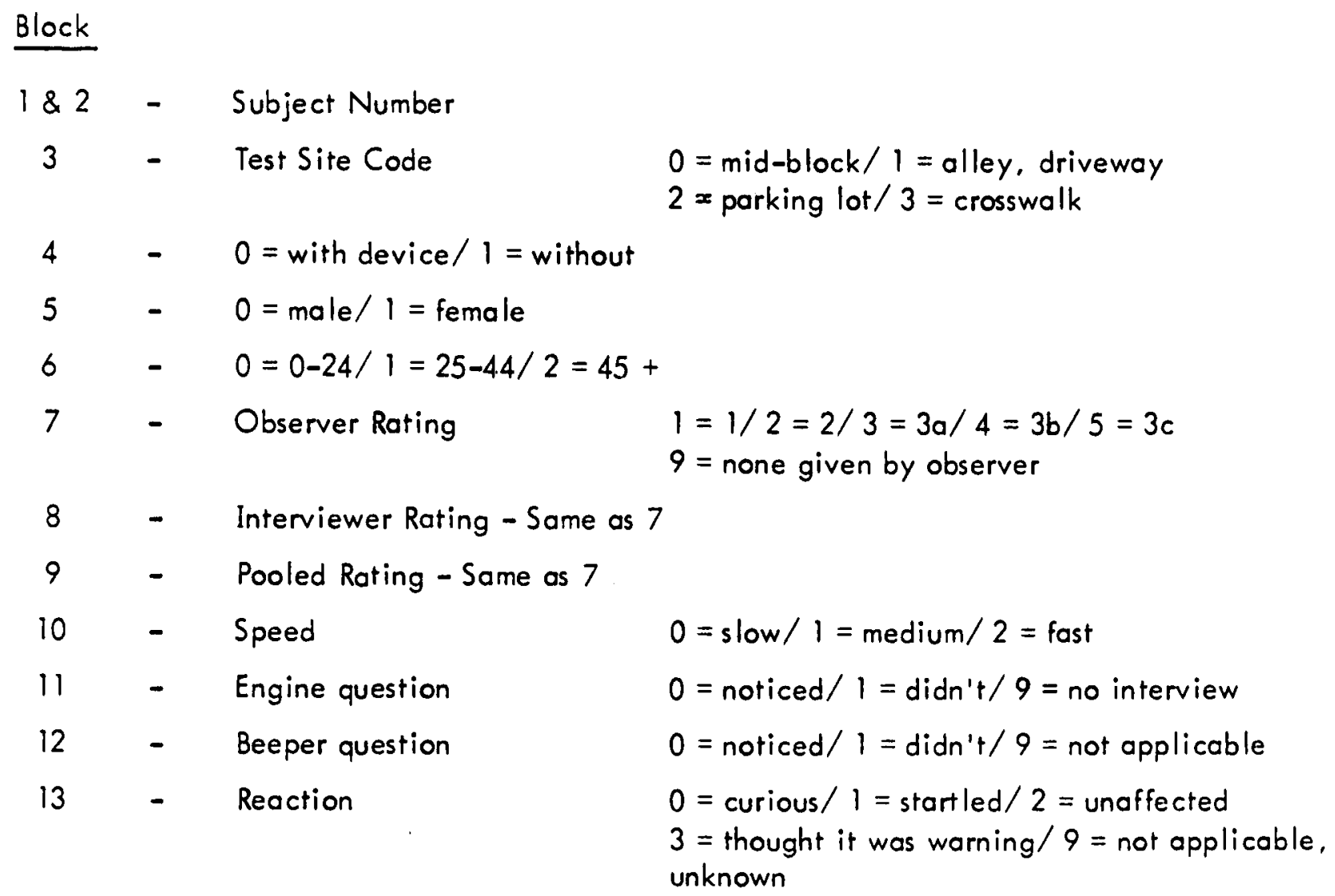

Figure 8-3. Back-Up Warning Device Field Evaluation Subject Coding Key 


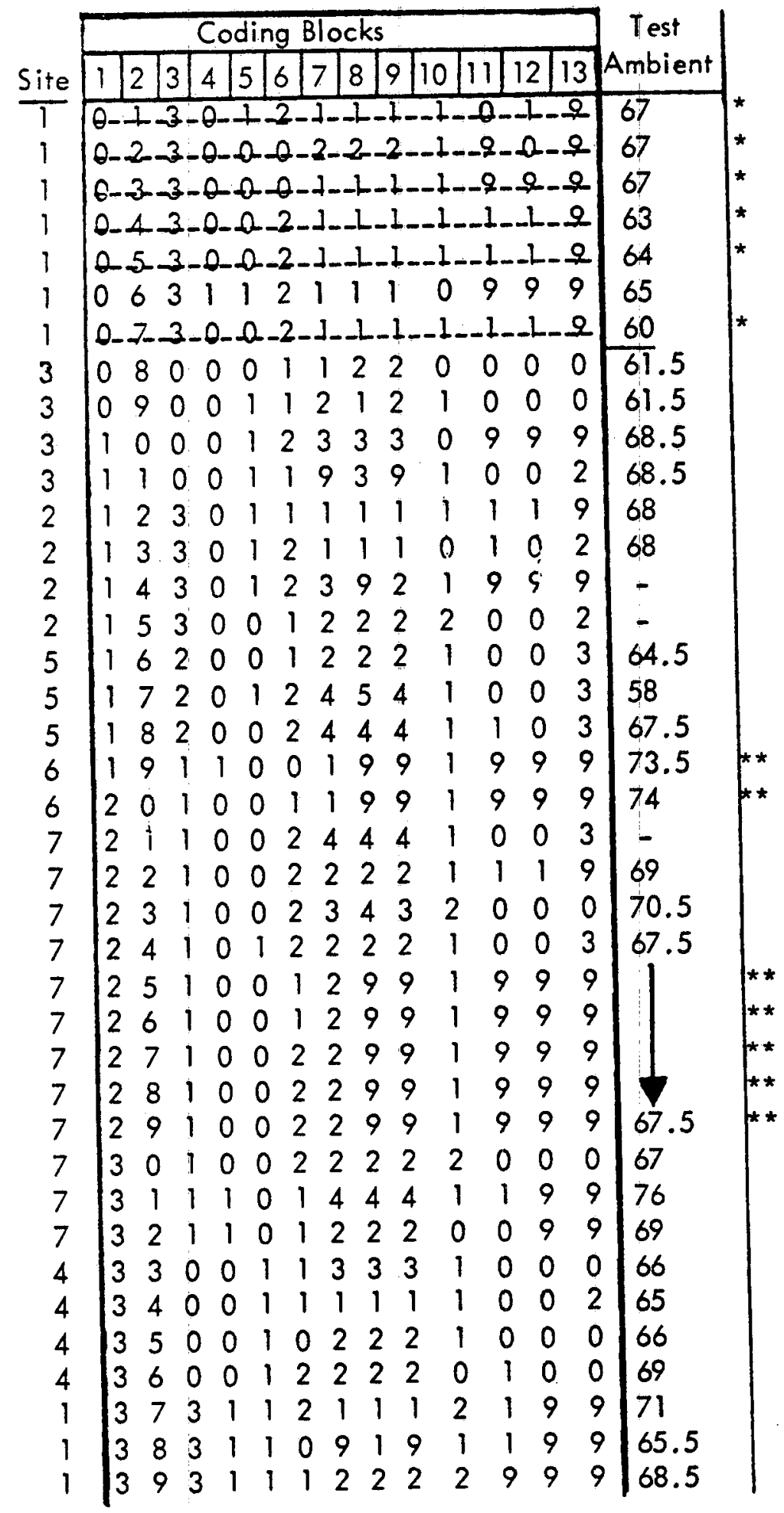

Figure B-4. Coded Subject Data 


\begin{tabular}{|c|c|c|c|c|c|c|c|c|c|c|c|c|c|c|}
\hline \multirow[b]{2}{*}{ Site } & \multicolumn{13}{|c|}{ Coding Blocks } & \multirow{2}{*}{$\begin{array}{c}\text { Test } \\
\text { Ambient } \\
\end{array}$} \\
\hline & 1 & 2 & 3 & 4 & 5 & 6 & 7 & 8 & 9 & 10 & 11 & 12 & 13 & \\
\hline 1 & 4 & 0 & 3 & 1 & 1 & 2 & 1 & 1 & 1 & 1 & 1 & 9 & 9 & 68 \\
\hline 1 & 4 & 1 & 3 & 1 & 0 & 1 & 4 & 1 & 1 & 2 & 1 & 9 & 9 & 68 \\
\hline 1 & 4 & 2 & 3 & 1 & 1 & 2 & 2 & 1 & 2 & 0 & 1 & 9 & 9 & 66.5 \\
\hline 1 & 4 & 3 & 3 & 0 & 0 & 1 & 2 & 2 & 2 & 2 & 1 & 0 & 0 & 71.5 \\
\hline 1 & 4 & 4 & 3 & 0 & 1 & 2 & 2 & 2 & 2 & 1 & 1 & 1 & 9 & 66.5 \\
\hline 1 & 4 & 5 & 3 & 0 & 1 & 2 & 2 & 2 & 2 & 1 & 9 & 9 & 9 & 73 \\
\hline 1 & 4 & 6 & 3 & 0 & 1 & 0 & 2 & 2 & 2 & 1 & 9 & 9 & 9 & \\
\hline 1 & 4 & 7 & 3 & 0 & 1 & 0 & 2 & 2 & 2 & 1 & 9 & 9 & 9 & \\
\hline 1 & 4 & 8 & 3 & 0 & 1 & 1 & 2 & 2 & 2 & 1 & 9 & 9 & 9 & \\
\hline 1 & 4 & 9 & 3 & 0 & 1 & 1 & 2 & 2 & 2 & 1 & 9 & 9 & 9 & \\
\hline 1 & 5 & 0 & 3 & 0 & 0 & 0 & 2 & 2 & 2 & 1 & 9 & 9 & 9 & \\
\hline 1 & 5 & 1 & 3 & 0 & 0 & 0 & 2 & 2 & 2 & 1 & 9 & 9 & 9 & 73 \\
\hline 4 & 5 & 2 & 0 & 1 & 0 & 1 & 1 & 9 & 9 & 1 & 9 & 9 & 9 & 64.5 \\
\hline 4 & 5 & 3 & 0 & 1 & 0 & 2 & 1 & 1 & 1 & 1 & 1 & 9 & 9 & 64 \\
\hline 4 & 5 & 4 & 0 & 1 & 1 & 2 & 1 & 9 & 9 & 1 & 9 & 9 & 9 & \\
\hline 4 & 5 & 5 & 0 & 1 & 1 & 0 & 1 & 9 & 9 & $i$ & 9 & 9 & 9 & \\
\hline 4 & 5 & 6 & 0 & 1 & 1 & 0 & 1 & 9 & 9 & 1 & 9 & 9 & 9 & \\
\hline 4 & 5 & 7 & 0 & 1 & 1 & 0 & 1 & 9 & 9 & 1 & 9 & 9 & 9 & 64 \\
\hline 4 & 5 & 8 & 0 & 1 & 1 & 1 & 1 & 1 & 1 & 1 & 1 & 9 & 9 & - \\
\hline 4 & 5 & 9 & 0 & 1 & 1 & 0 & 1 & 1 & 1 & 1 & 9 & 9 & 9 & - \\
\hline 4 & 6 & 0 & 0 & 0 & 1 & 0 & 9 & 3 & 9 & 1 & 0 & 0 & 3 & 64 \\
\hline 4 & 6 & 1 & 0 & 0 & 1 & 0 & 1 & 2 & 2 & 1 & 0 & 0 & 2 & 64.5 \\
\hline 8 & 6 & 2 & 2 & 1 & 1 & 1 & 1 & 2 & 2 & 1 & 0 & 9 & 9 & 64 \\
\hline 8 & 6 & 3 & 2 & 0 & 0 & 1 & 2 & 2 & 2 & 2 & 1 & 0 & 3 & 76 \\
\hline 7 & 6 & 4 & 1 & 1 & 0 & 1 & 1 & 1 & 1 & 1 & 0 & 9 & 9 & 67 \\
\hline 7 & 6 & 5 & 1 & 0 & 0 & 1 & 2 & 2 & 2 & 1 & 0 & 9 & 9 & 72 \\
\hline 7 & 6 & 6 & 1 & 0 & 1 & 1 & 2 & 2 & 2 & 1 & 0 & 0 & 9 & 72 \\
\hline 7 & 6 & 7 & 1 & 0 & 1 & 2 & 2 & 2 & 2 & 0 & 1 & 9 & 9 & 70.5 \\
\hline 7 & 6 & 8 & 1 & 0 & 0 & 1 & 2 & 2 & 2 & 1 & 9 & 9 & 9 & 71 \\
\hline 7 & 6 & 9 & 1 & 0 & 0 & 2 & 2 & 2 & 2 & 2 & 1 & 0 & 0 & 68 \\
\hline 7 & 7 & 0 & 1 & 0 & 1 & 2 & 2 & 2 & 2 & 1 & 1 & $\dot{0}$ & 0 & 71 \\
\hline 7 & 7 & 1 & 1 & 0 & 0 & 1 & 4 & 2 & 4 & $\mathrm{I}$ & 0 & $c$ & 0 & 67.5 \\
\hline 7 & 7 & 2 & 1 & 0 & 1 & 1 & 4 & 2 & 4 & 1 & 0 & 0 & 0 & 67.5 \\
\hline 2 & 7 & 3 & 3 & 0 & 1 & 0 & 1 & 2 & 2 & 1 & 1 & $c$ & 0 & 65 \\
\hline 2 & 7 & 4 & 3 & 0 & 1 & 0 & 1 & 2 & 2 & 1 & 1 & 0 & 0 & 65 \\
\hline 2 & 7 & 5 & 3 & 0 & 0 & 1 & 2 & 2 & 2 & 1 & 0 & 0 & 2 & 65.5 \\
\hline 2 & 7 & 6 & 3 & 0 & 1 & 1 & 2 & 2 & 2 & 1 & 9 & 9 & 9 & 65.5 \\
\hline 2 & 7 & 7 & 3 & 1 & 0 & 0 & 1 & 1 & 1 & 1 & 1 & 9 & 9 & 64.5 \\
\hline 2 & 7 & 8 & 3 & 0 & 1 & 2 & 2 & 2 & 2 & 1 & 1 & 0 & 0 & 63 \\
\hline 2 & 7 & 9 & 3 & 1 & 1 & 2 & 1 & 2 & 1 & 1 & 0 & 9 & 9 & 68 \\
\hline 2 & 8 & 0 & 3 & 0 & 1 & 2 & 1 & 2 & 1 & 1 & 1 & 1 & 9 & 62 \\
\hline 2 & 8 & 1 & 3 & 0 & 1 & 0 & 2 & 2 & 2 & 2 & 1 & 0 & 9 & 62.5 \\
\hline 1 & 8 & 2 & 3 & 0 & 1 & 2 & 1 & 1 & 1 & 1 & 9 & 9 & 9 & 64 \\
\hline 1 & 8 & 3 & 3 & 1 & 0 & 2 & 1 & 1 & $\mathrm{I}$ & 1 & 1 & 9 & 9 & - \\
\hline
\end{tabular}

Figure B-4. Continued. 


\begin{tabular}{|c|c|c|c|c|c|c|c|c|c|c|c|c|c|c|}
\hline \multirow[b]{2}{*}{ Site } & \multicolumn{13}{|c|}{ Coding Blocks } & \multirow{2}{*}{$\begin{array}{c}\text { Test } \\
\text { Ambient }\end{array}$} \\
\hline & 1 & 2 & 3 & 4 & 5 & 6 & 7 & 8 & 9 & 10 & 11 & 12 & 13 & \\
\hline 1 & 8 & 4 & 3 & 0 & 1 & 2 & 1 & 2 & 2 & 1 & 0 & 0 & 0 & 69 \\
\hline 1 & 8 & 5 & 3 & 0 & 1 & 2 & 2 & 2 & 2 & 1 & 0 & 0 & 3 & 64 \\
\hline 1 & 8 & 6 & 3 & 1 & 1 & 2 & 1 & 2 & 2 & 0 & 0 & 9 & 9 & 67.5 \\
\hline 1 & 8 & 7 & 3 & 0 & 0 & 1 & 1 & 2 & 2 & 1 & 1 & 0 & 0 & 64 \\
\hline 1 & 8 & 8 & 3 & 1 & 0 & 1 & 1 & 2 & 9 & 1 & 9 & 9 & 9 & 67.5 \\
\hline 1 & 8 & 9 & 3 & 1 & 1 & 2 & 1 & 2 & 9 & 1 & 9 & 9 & 9 & 67.5 \\
\hline 1 & 9 & 0 & 3 & 0 & 1 & 2 & 2 & 2 & 2 & 1 & 1 & 0 & 2 & 67 \\
\hline 1 & 9 & 1 & 3 & 1 & 1 & 2 & 2 & 2 & 2 & 1 & 1 & 9 & 9 & 68 \\
\hline 1 & 9 & 2 & 3 & 0 & 1 & 2 & 2 & 2 & 2 & 1 & 1 & 0 & 3 & 73.5 \\
\hline 4 & 9 & 3 & 0 & 0 & 1 & 0 & 2 & 2 & 2 & 1 & 1 & 0 & 0 & 68 \\
\hline 4 & 9 & 4 & 0 & 1 & 1 & 2 & 3 & 1 & 3 & 0 & 0 & 9 & 9 & 67 \\
\hline
\end{tabular}

Figure B-4. Concluded.

Note: The test ambient level was the A-weighted noise level just before the engine was started, recorded at the vehicle rear bumper.

* Data from these subjects was not analyzed due to insufficient signal levels. The signal level was increased following subject 7.

**Data from these subjects were excluded from the analyses because their responses were unknown, or the observations that were made were not adequate due to traffic conditions, obstructions, etc. 
APPENDIX C

EVALUATION TEST SITE DIAGRAM AND DESCRIPTIONS

WYLE LABORATORIES 
SITE 1 - Sepulveda Blvd. (facing north), Westchester (on Sepulveda between Manchester Blvd. and 88th St.)

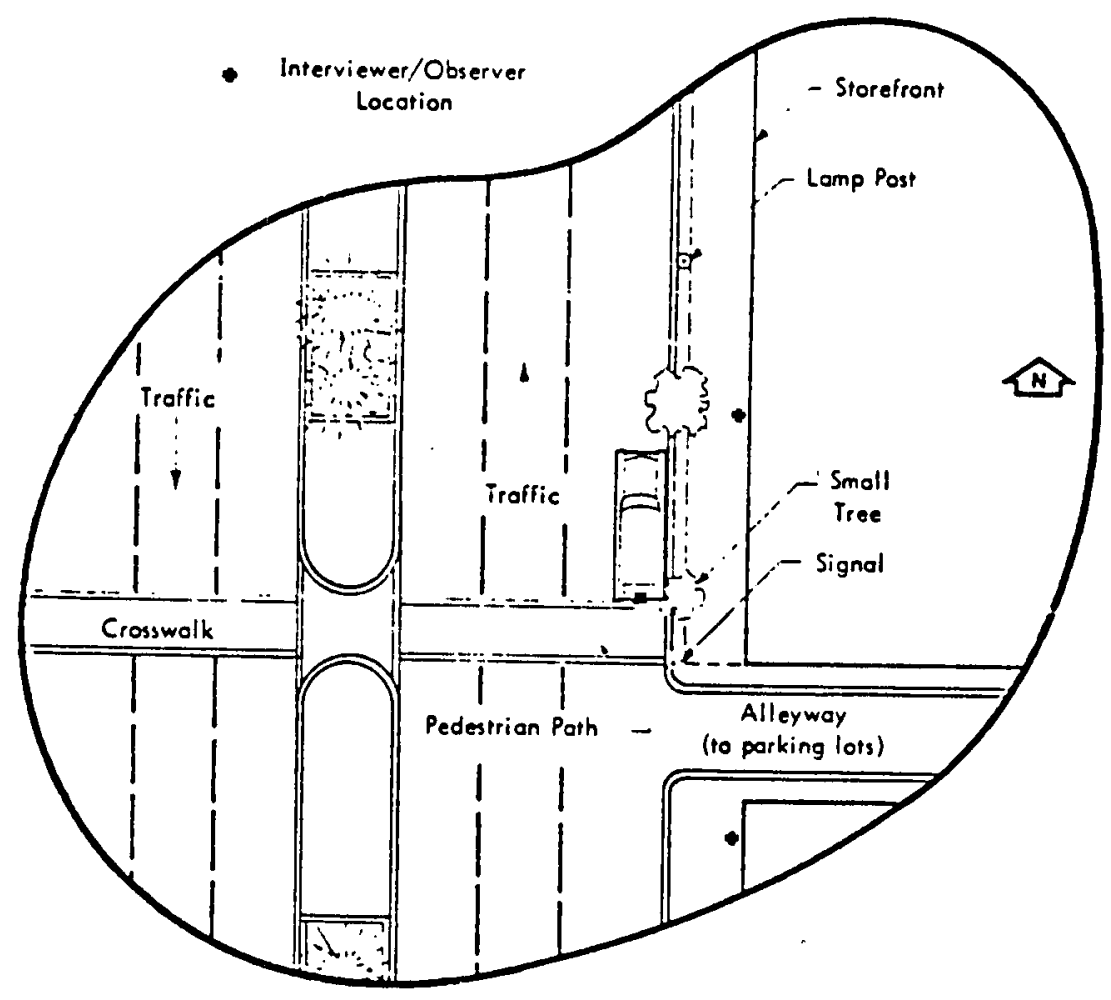

Site Description

A divided highway passing through a downtown shopping district. Very little pedestrian activity before 10:00 a.m. Approximately 20 to 50 pedestrians use the crosswalk during a l-hour period with possibly 20 percent crossing without using a "walk" signal. When the crossing signal button was depressed, a 30 second delay was not uncommon, and a flashing yellow light changed to flashing red, creating a boulevard stop for traffic.

\section{Pedestrian Behavior}

Pedestrians crossing against the light were distracted by approaching traffic, whereas others appeared more secure in the crosswalk. Many pedestrians were at the far boundary of the crosswalk during the test, as they were walking toward the alley way between the shops. Their reaction to the vehicle starting and activating the warning signal was seldom more than a slight turn of the head or a glance in the direction of the vehicle.

Test Sequence

At this location, all subjects approached the vehicle from the street (west to east). Pedestrians going in the other direction (east to west) would wait close to the vehicle; 
consequently, there was insufficient warning time to activate the test sequence. The test sequence began when the pedestrian started to cross the street; the driver, waiting near the front of the vehicle, walked around and entered the vehicle. As the pedestrian left the center divider, the vehicle was started, and as the pedestrian entered the danger zone the warning signal and back-up lights were activated.

Classification

Crosswalk 
SITE 2 - Sepulveda Bivd. (facing south), Westchester

(on Sepulveda Blvd. between Manchester Blvd. and 88th St.)

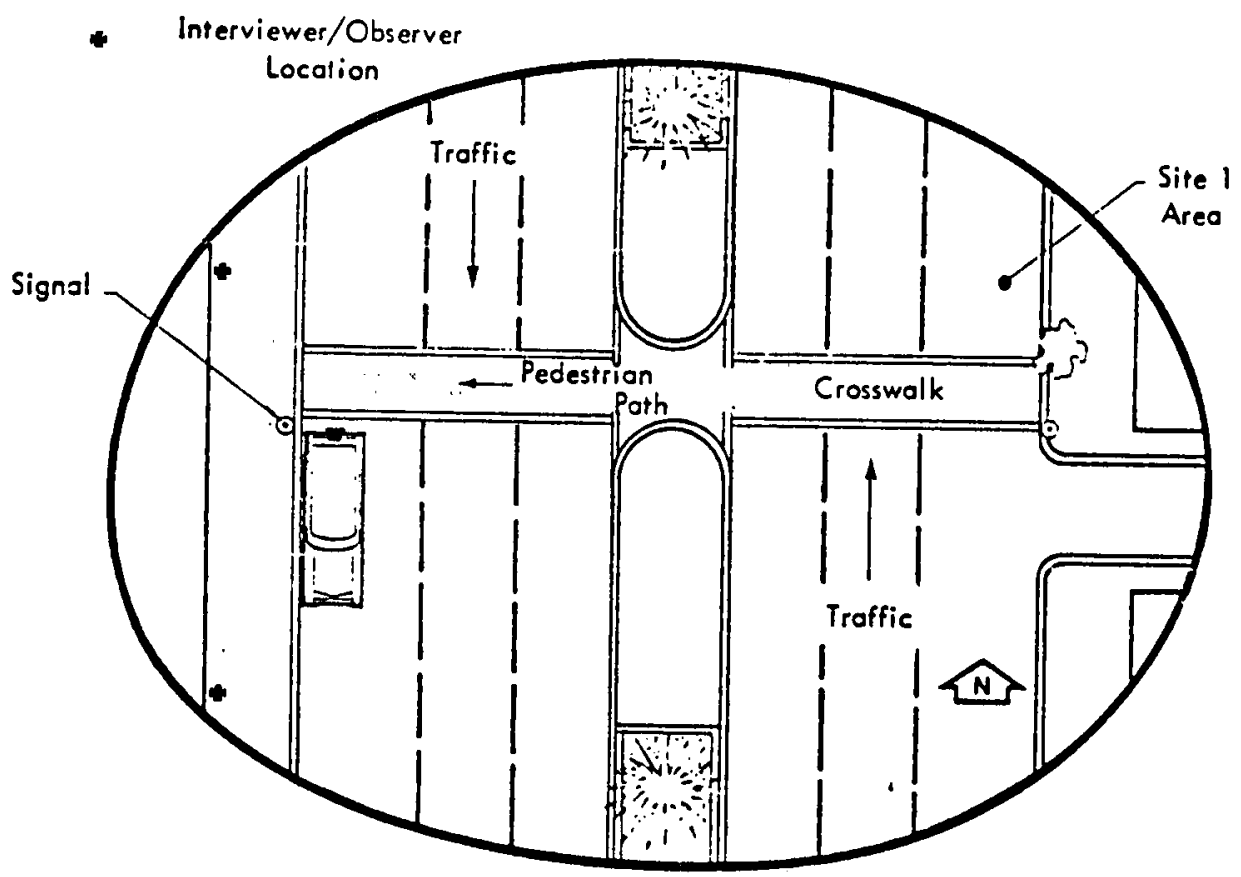

Site Description

Same as Site 1.

Pedestrian Behavior

This area is predominantly occupied by shoppers; the majority waited for the crossing light but at least 20 percent walked across without waiting for the signal. After crossing the street, pedestrians turned north, passing at the far side of the crosswalk or turned south, passing close to the vehicle. Reactions to the vehicle or the warning signal were slight; most people barely turned their heads despite the fact they were usually behind the vehicle.

Test Sequence

Similar to the tests at Site 1. The vehicle was started when the pedestrian left the center divider and the warning signal was activated when the pedestrian was approximately 15 feet from the vehicle, the boundary of the danger zone.

Classification

Crosswalk 
SITE 3 - Karls Stationers, Westchester

(at the intersection of 87 th St. and Sepulveda East Way)

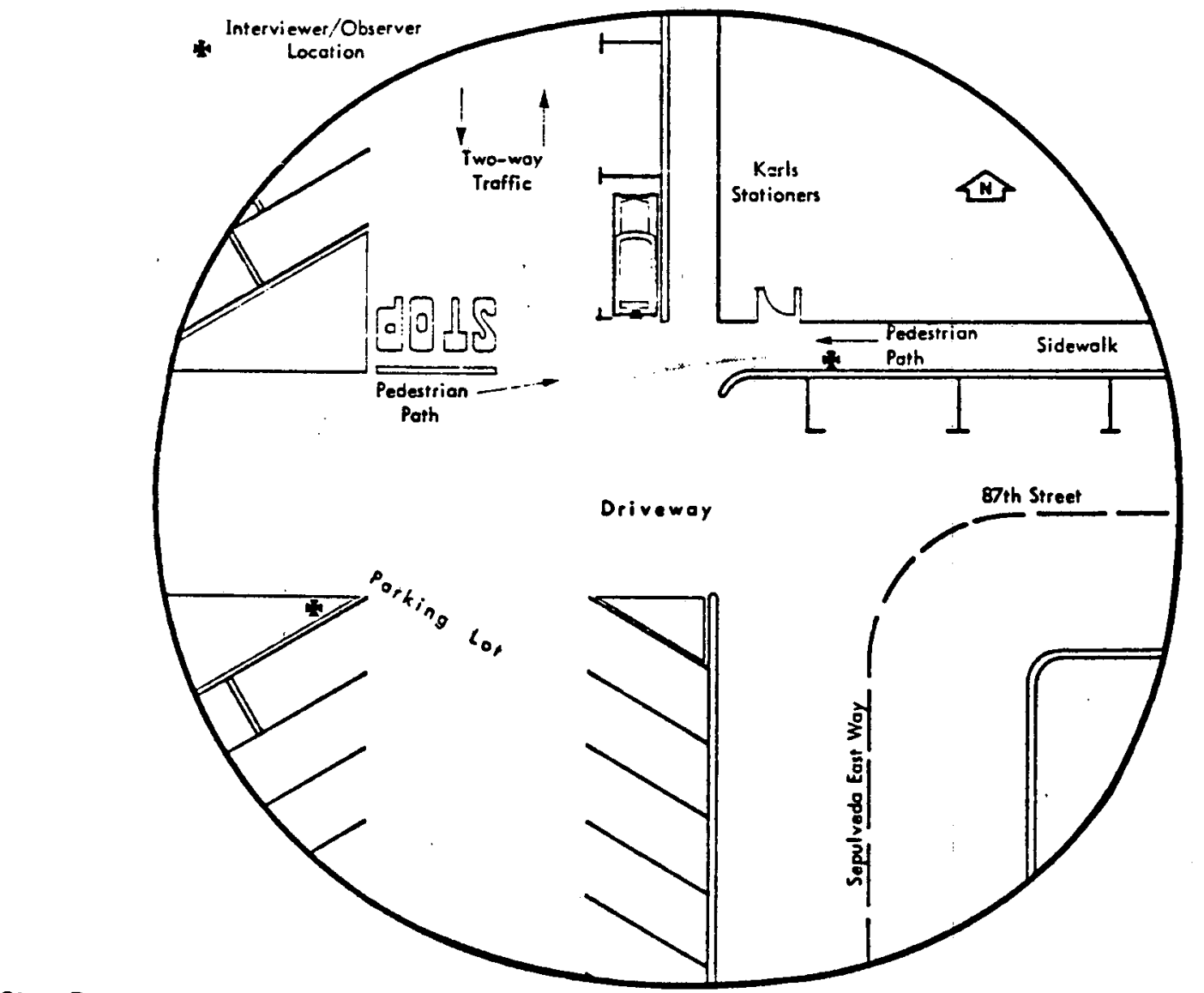

Site Description

A parking lot bounding a right angle street. Sepulveda Blvd. is the next street to the west where Sites 1 and 2 were located. Pedestrian traffic volume was very low with only five to 10 per hour crossing behind the vehicle. Vehicular traffic in this area was also light.

\section{Pedestrian Behavior}

Subjects were selected approaching from both directions. This complex intersection provided many distractions for pedestrians; however, they did not demonstrate any excessive reactions, only looking at the vehicle.

Classification

Mid-Block 
SITE 4-F.W. Woolworth, Westchester (between Sepulveda Blvd. and Sepulveda West Way, south of Manchester Blvd.)

\section{Site Description}

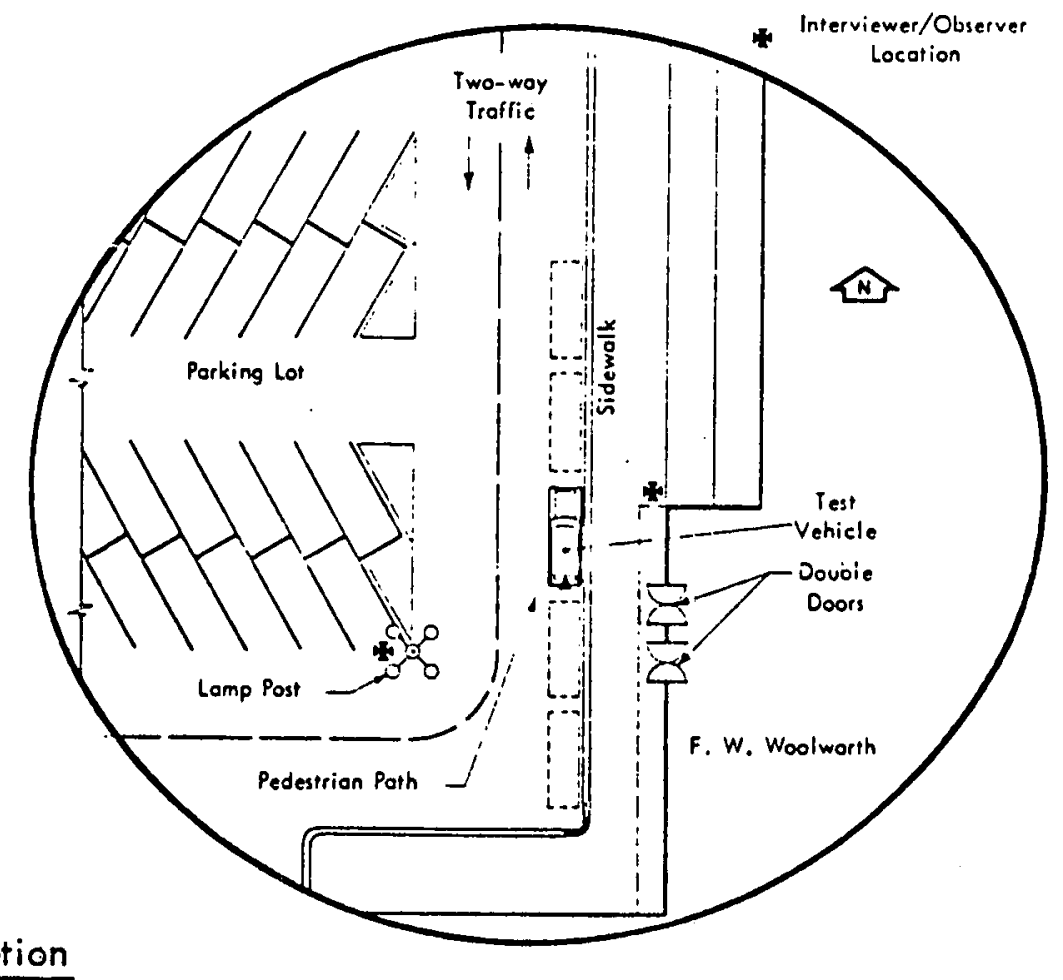

A commercial shopping area where stores face Sepulveda Blvd. on the east with a large parking lot behind the stores. Two-way traffic along the parking lot edge and parallel parking along a sidewalk create an ideal mid-block situation. Pedestrian traffic was light in this area but many customers exiting from Woolworth passed behind the test vehicle to reach the parking lot.

\section{Pedestrian Behavior}

Subjects were observed entering and leaving Woolworth, most of them exiting the store and passing behind the vehicle. Most of the subjects simply glanced at the vehicle but several paused at the curb upon heoring the signal.

\section{Test Sequence}

The vehicle was started when the subjects passed the exit door and the warning signal was activated when they were a few feet from the vehicle.

\section{Classification}

Mid-Block 
SITE 5 - Boys Market, Hawthorne

(at 11873 S. Hawthorne Blvd.)

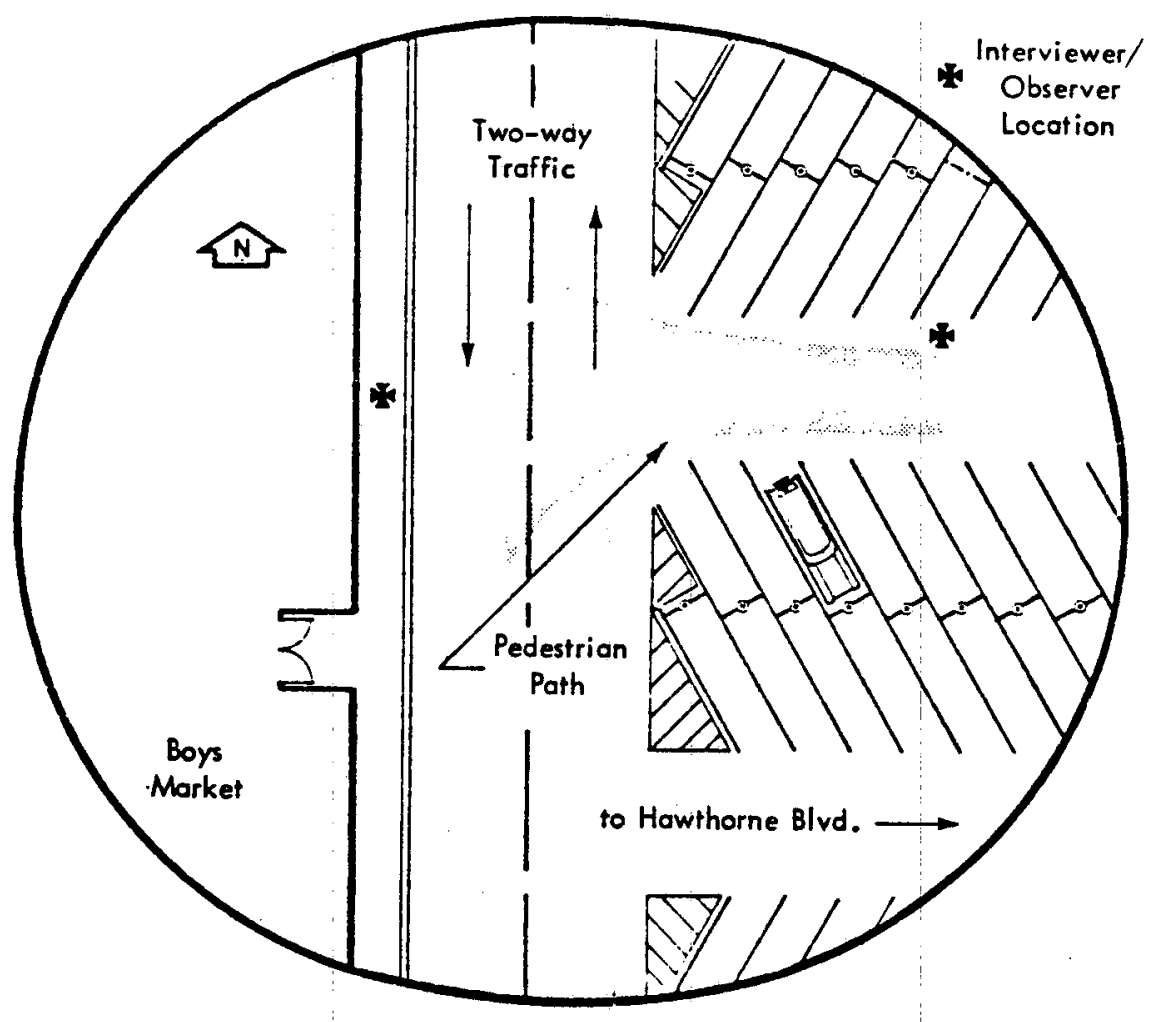

Site Description

A small commercial shopping area. All spaces around the test vehicle were occupied by parked cars during the tests. Subjects were selected from pedestrians coming from the store to the parking lot.

\section{Pedestrian Behavior}

Subjects in parking lots seemed more aware of the test vehicle and usually responded by either slowing or changing course. Mid-block and crosswalk subjects seldom responded in this manner.

\section{Test Sequence}

When the subject was approximately two cars away, the engine was started and when one car away, the warning signal was activated.

\section{Classification}

Parking Lot 
SITE 7 - 6th Street, Los Angeles (alley between Main and Spring Streets crossing 6th St.)

Site Description

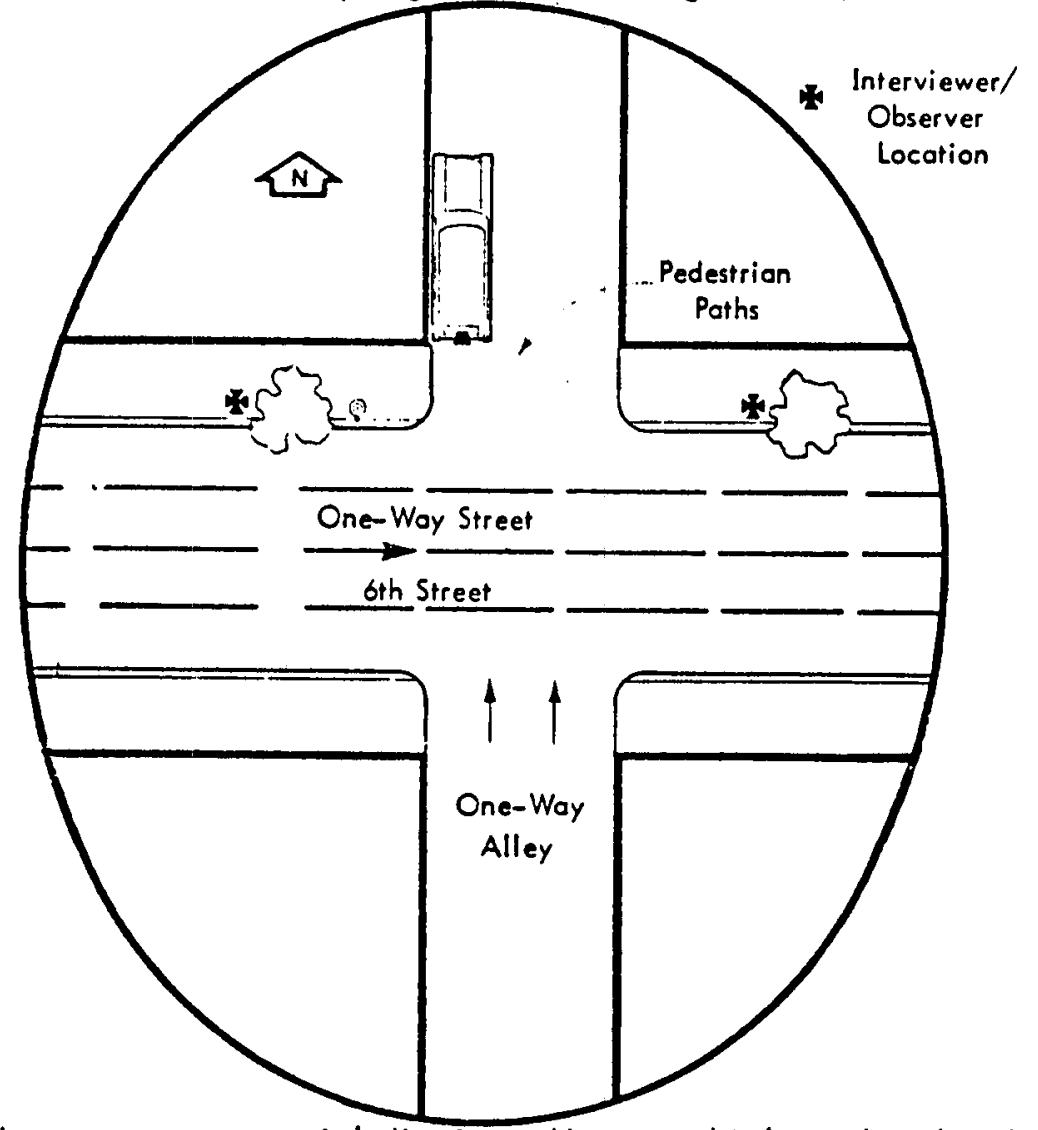

Alley in a busy downtown commercial district. Heavy vehicle and pedestrian traffic. In general, pedestrians were not as cooperative during questioning; most were in a hurry.

Pedestrian Behavior

At this location, pedestrians seemed most threatened by the vehicle; one subject even warned interviewer about backing vehicle. Most subjects responded by looking at the vehicle and some slowed or changed their course.

Test Sequence

Subjects were selected from pedestrians walking from east to west, since they could see the vehicle as they approached. The vehicle was started before they entered the alley and the warning signal activated just before reaching the vehicle.

Classification

Alley or Driveway 
SITE 8 - Sav-On Drug Store

(between Sepulveda Blvd, and Sepulveda West Way south of Manchester Blvd.)

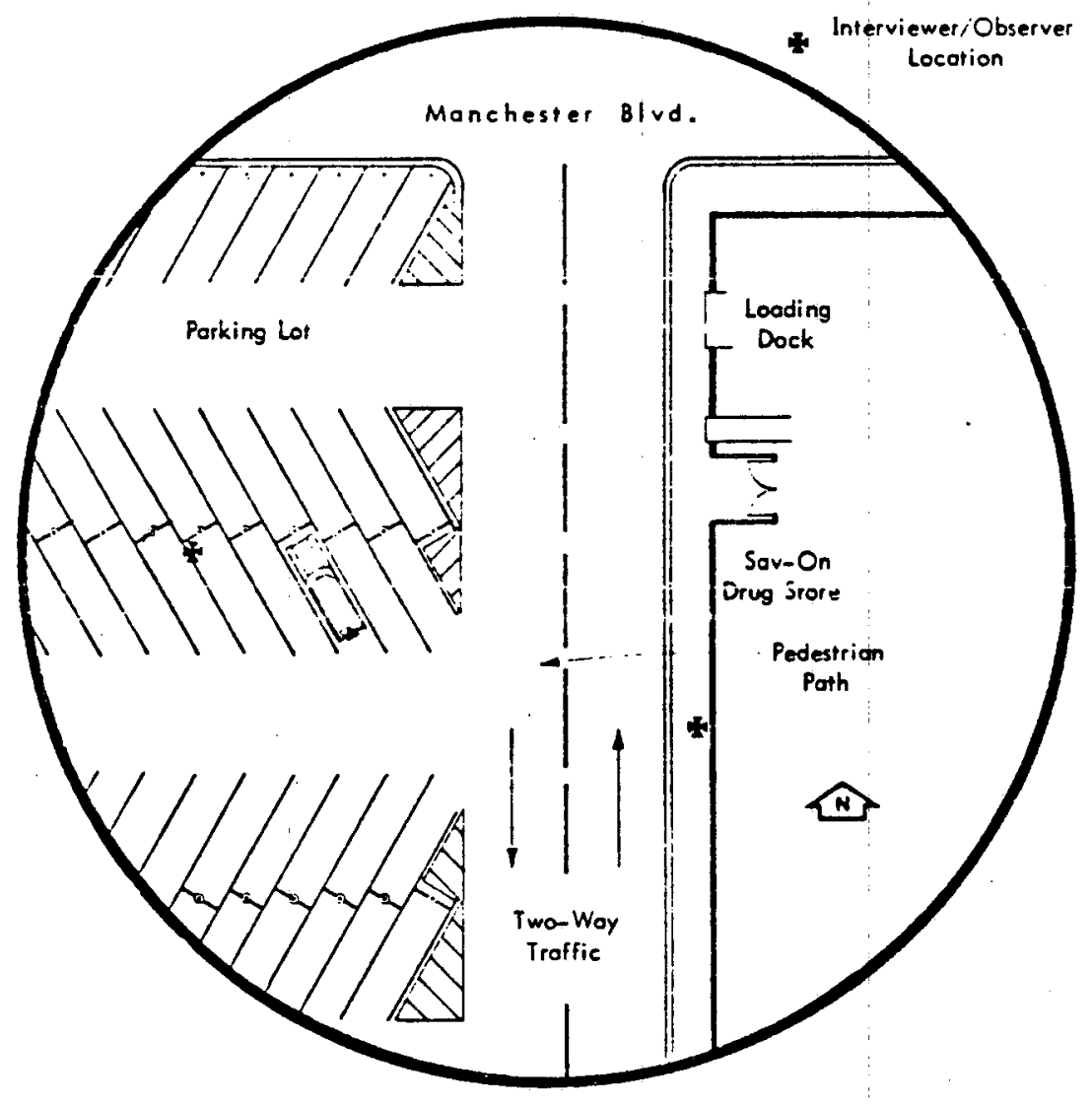

\section{Site Description}

A commercial shopping area adjacent to a large parking lot. Pedestrian traffic volume was light. Subjects were observed exiting from stores and returning to their cars in the parking lot.

\section{Pedestrian Behavior}

Pedestrian traffic was leisurely with most subjects watchful of vehicles in the area. Some subjects slowed or changed their path of travel.

\section{Test Sequence}

The engine was started when the subject was about two cars distant and the warning signal activated when subject was 6 to 8 feet away.

Classification

Parking Lot 